Linköping Studies in Science and Technology

Dissertations, No.1700

\title{
Contextualization of Evolving Patterns in the Internationalization of Small Firms
}

\section{Ya Zhang}

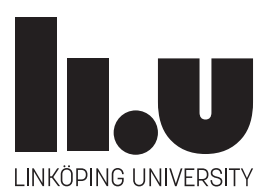

2015

Department of Management and Engineering Linköpings universitet, SE-581 83 Linköping, Sweden 
(C) Ya Zhang, 2015 (Unless otherwise noted)

Cover:

World Map of Exports of Goods and Service (percent of GDP in 2013)

Data source: Balance of Payments Statistics IMF Data Mapper ${ }^{\circledR}$

Back:

Changes of GDP based on PPP in major emerging markets and selected developed markets (1980-2015)

Data source: World Economic Outlook (April 2015) IMF Data Mapper ${ }^{\circledR}$

Contextualization of Evolving Patterns in the Internationalization of Small Firms

Linköping Studies in Science and Technology, Dissertations, No. 1700

ISBN: 978-91-7685-951-3

ISSN: 0345-7524

Printed by: LiU-Tryck, Linköping

Distributed by:

Linköping University

Department of Management and Engineering

SE-581 83 Linköping, Sweden

Tel: +46 13281000 
To my grandparents

R. Ying \& H. Ying

you sketched rainbows in the sky of my childhood 



\begin{abstract}
Growing evidence shows that as small and medium-sized enterprises (SMEs) expand their business operations across national borders, the internationalization of SMEs has been recognized as one of the important paths to growth in SMEs. However, internationalization is also a resource and competence-demanding process. This is especially true for smaller-sized SMEs - the small and micro-sized firms - which have a large resource constraint, making internationalization even more challenging. Although this group of small firms counts for an average of over $98 \%$ of the total population of enterprises in EU countries and has a large potential to contribute to their economies, extant research on the internationalization of this group is still limited. Therefore, the main purpose of this dissertation is to contribute to a better understanding of evolving patterns of internationalization in the smaller-sized SMEs.

This dissertation is written as a monograph. The study uses emerging market entry along the internationalization of small firms as a context to probe the dynamics of perceived risk (uncertainty) and perceived opportunity in different foreign markets which influence the important decisions of small firms during their internationalization. The main study takes a longitudinal approach and uses mixed methods to investigate the features in both the initial period and the continued period of internationalization. It builds on empirical data from 12 Swedish firms, which have/had emerging market entry experience and/or involvement. All the investigated firms started their internationalization process as small or micro firms. This multiple case study illustrates influences from the environmental, organizational and in-
\end{abstract}


dividual levels on evolving patterns of internationalization in the investigated firms.

This dissertation concludes that critical decisions and actions taken in the internationalization process depend on interactions among the influence and resources from the three levels. Such interactions form a conditional preference on perceived risk (uncertainty) and perceived opportunity during the internationalization of small firms. The study further proposes that the dynamics in the internationalization process are caused by a prospect-guided change mechanism.

This dissertation contributes to the literature by: differentiating patterns of internationalization; enriching the study of "born global" in the continued period of internationalization; introducing a new perspective on the interpretation of dynamics in the internationalization; and increasing the understanding on the interactions of resources from three levels on the internationalization of small firms.

Keywords: Internationalization, evolving patterns, small firms, prospect theory, emerging markets 


\section{Kontextualisering av framväxande mönster i samband med små företags internationalisering}

\section{Sammanfattning}

När små och medelstora företag (SMF) expanderar sin verksamhet utanför landets gränser har internationalisering visat sig vara en viktig tillväxtmöjlighet. Internationalisering är dock en resurs- och kompetenskrävande process. Det gäller speciellt mindre SMF - de små och mikrostora företagen - som har stora resursbegränsningar, vilket gör internationalisering än mer utmanande.

Även om denna grupp småföretag i snitt utgör mer än $98 \%$ av den totala företagspopulationen i EU-länderna, och har stor potential att bidra till sina hemländers ekonomi, är befintlig forskning om internationalisering för den här gruppen fortfarande begränsad. Därför är huvudsyftet med den här avhandlingen att bidra till en bättre förståelse av framväxande mönster vid internationalisering för mindre SMF.

Avhandlingen är skriven som en monografi. Denna studie använder småföretags inträde på tillväxtmarknader som kontext för att fånga dynamiken av uppfattad risk (osäkerhet) och uppfattad möjlighet på olika utländska marknader, vilka påverkar viktiga beslut i ett småföretag under dess internationalisering. Studien tar ett longitudinellt grepp och använder blandade metoder för att undersöka karaktäristika vid både den initiala och den fortsatta internationaliseringsperioden. Den bygger på empiriska data från 12 svenska företag som har erfarenhet av inträde på och/eller engagemang i tillväxtmarknader. Samtliga studerade företag startade sin internationaliseringsprocess som små eller mikrostora företag. Denna flerfallstudie illustrerar hur de tre nivåerna miljö, organisation och individ påverkar de framväxande internationaliseringsmönstren hos de undersökta företagen.

Avhandlingen drar slutsatsen att kritiska beslut som tas och aktiviteter som genomförs under internationaliseringsprocessen beror på interak- 
tioner mellan influens av och resurser från de tre nivåerna. Sådana interaktioner skapar förutsättningar, vilka leder till preferenser rörande uppfattad risk (osäkerhet) och uppfattade möjligheter under små företags internationalisering. Studien föreslår vidare att dynamik i internationaliseringsprocessen orsakas av en utsiktsstyrd förändringsmekanism.

Avhandlingens huvudsakliga teoretiska bidrag är en utökning av mönstren vid internationalisering, fördjupning av studierna avseende "born global"företags fortsatta internationalisering, introduktion av ett nytt perspektiv för tolkning av internationaliseringens dynamik, samt ökad förståelse för resursinteraktioner från de tre nivåerna för små företags internationalisering.

Nyckelord: Internationalisering, framväxande mönster, små företag, prospektteori, tillväxtmarknader 


\section{Acknowledgements}

This dissertation is a product of my five years' learning, thinking, reflection and work in the academic world as a $\mathrm{PhD}$ candidate in the Industriell ekonomi division at Linköping University. During this long journey, I have gained knowledge and developed skills and competence. Most importantly, I am lucky to have met many good mentors, friends and colleagues who support me and made this journey rewarding. I would like to express my gratitude to all of them.

I'd like to thank Anna Öhrwall Rönnbäck, my supervisor, for taking me on board and giving me the opportunity to start this journey. Your trust makes me become independent. I appreciate all of your support along the way.

Christina Grundström, my co-supervisor since 2012, thank you for your commitment and engagement in helping me to improve this dissertation. The valuable comments and constructive feedback from you were a great help! I appreciate all our discussions, your encouragement and your support.

Staffan Brege, who was also involved in the supervision, thanks for being there and always being supportive. You gave me many good suggestions in my dissertation seminars and I appreciate your valuable input and advice.

Dear Magnus, Mr. Holmström, my co-supervisor until 2012, you were a great mentor with a positive attitude, who helped me to build a good foundation in methodology. Your input and support during my empirical study in the BENCH project were invaluable. I learned a lot by working with you. A big thanks to you! 
Special thanks to Bengt Högberg, the reader of my dissertation and the opponent in my pre-final seminars. Your knowledge, insights and valuable feedback helped me a great deal. I appreciate all the time and intellectual input you put into my dissertation as the reader.

Thanks for financial support of the BENCH project and the Industriell ekonomi division at IEI.

Thanks my previous project partners from Länsstyrelsen Östergötland, Östsam (merged to Region Östergötland), Cleantech Östergötland and Linköping University for their support in the BENCH project. Special thanks to Caroline, my co-investigator in the project. You were such a good colleague to work with and gave me a lot of support in the field study. Later, we became friends. Thanks for your friendship during these years.

Also thanks to all the entrepreneurs and managers of the small firms who participated in different studies in the research projects. You opened up to me and shared your interesting experiences and knowledge. Thanks for your time and valuable input.

My proofreader Mica, you have done such good job to help me fix my ChinEnglish. Thanks for your efforts and help!

To my colleagues and all the $\mathrm{PhD}$ candidates in Industrial Marketing (now Industriell ekonomi), it has been a pleasure to have colleagues like you. You are very intelligent and nice. I enjoy our discussions during fika and lunchtime, as well as memorable social activities within the $\mathrm{PhD}$ network. Per, it was great to see you become a senior before the summer. Thanks for your friendship during these years. Daniel and Ehsan, I hope we can celebrate very soon. Sarah, Martin, Mohammad, Mojtaba and Mario, thanks for your company during this chilly summer. Emelie, it's great to have more girls as $\mathrm{PhD}$ candidates in our division. In these years, I also enjoyed many small talks with two nice neighbors in our old corridor, Sofi and Tomas. Girls 
in neighbor corridors, it's always nice to have more friends around. Especially to Susan, you are always supportive and I hope I could do the same.

Thanks Karin F. and Lena S. for your administrative support. Gratitude also goes to my old friends and mentors in the SMIO program at FEK. They were always there for me when I needed their advice and support.

To all of my Chinese friends in IEI, you are like my younger sisters and brothers. We could laugh together, share experiences together and help each other. I'm really grateful to have you as friends.

Finally, thanks to my brother and his family for their support. My deepest gratitude goes to my mom. Without your unconditional love, encouragement and support, I would not be where I am today.

Linköping, August, 2015

Ya Zhang

若上
孝水善 


\section{Contents}

Contents $x$

List of Tables $\quad$ xxi

List of Figures $\quad$ xxiii

List of Abbreviations $\quad$ Xxv

1 Introduction 1

1.1 The internationalization of small firms in a change context . . . . 1

1.2 The context of Emerging Markets . . . . . . . . . . 5

1.3 Problem discussion . . . . . . . . . . . . . . . . . . . . . . 6

1.3.1 The applicability of identified patterns . . . . . . . 6

1.3.2 The impact of size . . . . . . . . . . . . . . . 7

1.3.3 The impact of an emerging market context . . . . . . . . 9

1.3.4 The consistency of the pattern over time . . . . . . . . . 9

1.4 Purpose of study and research questions . . . . . . . . . . 10

1.5 Disposition . . . . . . . . . . . . . . . . . . . 12

2 Theoretical Frame $\quad 15$

2.1 Evolving concepts of internationalization . . . . . . . . . . . . . 15

2.1.1 A process view on internationalization . . . . . . . . 16

2.1.2 The internationalization process . . . . . . . . . . . . 17

2.1.3 Behavior pattern and dimensions of motion pattern . . . . 18

2.2 Identified patterns in extant research . . . . . . . . . . . . . 19 
2.2.1 Incremental features . . . . . . . . . . . . . . 20

2.2 .2 Swift feature. . . . . . . . . . . . . . . . 21

2.2.3 Comparison of identified patterns . . . . . . . . . 23

2.3 Perspectives and assumptions . . . . . . . . . . . . . 25

2.3.1 Learning perspective . . . . . . . . . . . . . . . 25

2.3.2 Network perspective . . . . . . . . . . . . . 26

2.3.3 Entrepreneurship perspective . . . . . . . . . . . . . . 28

2.4 Limitations of main theoretical interpretations in emerging markets context . . . . . . . . . . . . . . . . . . 28

2.5 Risk (uncertainty) versus opportunity - a common ground for discussion . . . . . . . . . . . . . . . . . . 32

2.5.1 Influence of risk (uncertainty) in internationalization . . . 33

2.5.2 Influence of opportunity in internationalization . . . . . 35

2.5.3 Synergy of rationalities behind the different behavior patterns 37

2.6 Sources of perceived risk versus perceived opportunity in the EM context . . . . . . . . . . . . . . . . . . . 38

2.6.1 The role of psychic distance in the perceived risk . . . . 39

2.6.2 Role of market size in the perceived opportunity . . . . . 41

2.6.3 Dual serials internationalization mapping . . . . . . . . . 42

2.7 A "fit-based" approach to the internationalization of small firms . 43

2.7.1 Essentials of the "fit-based" approach for an analysis of small firms . . . . . . . . . . . . . . . . . 43

2.7 .2 Organizational settings . . . . . . . . . . . 44

2.8 A multi-level analytic framework . . . . . . . . . . . . . 48

2.8.1 Inputs and influence from the individual level . . . . . . . 48

2.8.2 Input and influence from the organizational level . . . . . 49

2.8.3 Input and influence from the environmental level . . . . . 50

2.8.4 Three-level frame . . . . . . . . . . . . . . . . . 51

2.9 Summary of the theoretical frame . . . . . . . . . . . . . 52

3 Operationalization of Theoretical Constructs $\quad 55$

3.1 Operationalization of perceived risk and opportunity in foreign markets ....................... 55 
3.1 .1 Proxy of perceived risk $\ldots \ldots \ldots \ldots \ldots$

3.1 .2 Proxy of perceived opportunity _ . . . . . . . . . 58

3.2 Operationalization of internationalization patterns . . . . . . 60

3.2 .1 Behavior pattern . . . . . . . . . . . . . 61

3.2 .2 Motion pattern . . . . . . . . . . . . . . . 62

3.3 Internationalization mapping . . . . . . . . . . . . 66

3.3.1 Construct of the mapping . . . . . . . . . . 67

3.3 .2 Implementation of the mapping . . . . . . . . . . . 68

3.4 Process-based analytical model . . . . . . . . . . . . . . . . 69

4 Research Methodology 73

4.1 Epistemology - How the author views reality in social science . . 73

4.2 Research process . . . . . . . . . . . . . . . . . 74

4.2.1 Background of the research _ . . . . . . . . . 75

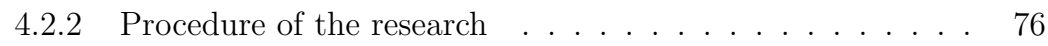

4.3 Strategy of inquiry - a qualitative approach $\ldots \ldots \ldots$. . . . 82

4.3 .1 A qualitative approach . . . . . . . . . . . . . . . . . . 82

4.3.2 Research design . . . . . . . . . . . . . . . . . . . 83

4.3 .3 Role of theory and empirics _ . . . . . . . . . . . 83

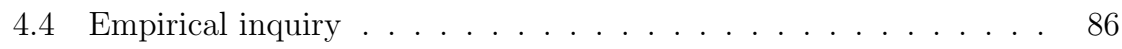

4.4 .1 Pre-study . . . . . . . . . . . . . . . . . . 86

4.4.2 Main inquiry of the multiple case study _ . . . . . . 87

4.5 Data collection methods . . . . . . . . . . . . . . . . 91

4.5 .1 Surveys . . . . . . . . . . . . . . . . . 91 91

4.5 .2 Interviews . . . . . . . . . . . . . . . . . . . 92

4.5 .3 Documents study . . . . . . . . . . . . . . . . . 95

4.5.4 Direct observations . . . . . . . . . . . . . . . 96

4.6 Data analysis . . . . . . . . . . . . . . . . . . . 100

4.6.1 Procedure of empirical data analysis . . . . . . . . . 100

4.6.2 Qualitative data analysis procedure . . . . . . . . . . 101

4.6.3 Quantitative data analysis procedure . . . . . . . . . . 103

4.7 Evaluation criteria of qualitative research _ . . . . . . . 104

4.7.1 Credibility and transferability - analogous to validity . . . 105 
4.7.2 Dependability - analogous to reliability . . . . . . . . 106

4.7.3 Reflection on the role of the research student . . . . . . . . 107

4.8 Ethics of the research . . . . . . . . . . . . . . . 108

4.8.1 Beneficence . . . . . . . . . . . . . . . . . . 108

4.8.2 Anonymity and confidentiality . . . . . . . . . . . . 109

4.8.3 Informed consent . . . . . . . . . . . . . . . . . 109

4.8.4 Intrusiveness . . . . . . . . . . . . . . . . . . 109

5 Within-Case Analysis $\quad 110$

5.1 Overview of the 12 cases . . . . . . . . . . . . . . . 110

5.1 .1 The cases in Kina study stage . . . . . . . . . . . . . . . . 111

5.1.2 The cases in the EM extension study stage . . . . . . . . 111

5.2 Overview of the within-case analysis . . . . . . . . . 113

5.3 Case A (MC1) analysis . . . . . . . . . . . . . . . . 115

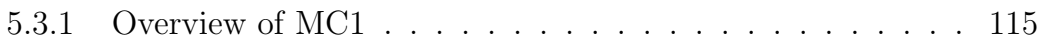

5.3.2 Feature changes in the internationalization process of MC1 116

5.3.3 Findings in changes of motion pattern . . . . . . . . . . . 119

5.3.4 EM (Chinese market) entry process (MC1) . . . . . . . . 120

5.3.5 Influence of the EM (China) context on the internationalization of MC1 . . . . . . . . . . . . . . . . . 124

5.3.6 Behavior patterns of $\mathrm{MC1}$. . . . . . . . . . . . . 124

5.4 Case B (MC2) analysis . . . . . . . . . . . . . . . . 125

5.4 .1 Overview of $\mathrm{MC} 2 \ldots \ldots \ldots . \ldots . \ldots 125$

5.4.2 Feature changes in the internationalization process of MC2 125

5.4.3 Findings in changes of motion pattern . . . . . . . . . . . 128

5.4.4 EM (Chinese market) entry process (MC2) . . . . . . . . . 130

5.4.5 Influence of the EM (China) context on the internationalization of $\mathrm{MC} 2 \ldots \ldots \ldots \ldots$. . . . . . . . . . . . 135

5.4.6 Behavior patterns of $\mathrm{MC} 2 \ldots \ldots \ldots$

5.5 Case $\mathrm{C}(\mathrm{SC} 1)$ analysis . . . . . . . . . . . . . . . . . 137

5.5.1 Overview of $\mathrm{SC} 1 \ldots \ldots . \ldots 137$

5.5.2 Feature changes in the internationalization process of SC1 137

5.5.3 Findings in changes of motion pattern . . . . . . . . . 140 
5.5.4 EM (Chinese market) entry process (SC1) . . . . . . . . 141

5.5.5 Influence of the EM (China) context on the internationalization of SC1 . . . . . . . . . . . . . . 145

5.5.6 Behavior patterns of SC1 . . . . . . . . . . . . 145

5.6 Case $\mathrm{D}(\mathrm{SC} 2)$ analysis . . . . . . . . . . . . . . . . . . 146

5.6 .1 Overview of $\mathrm{SC} 2 \ldots \ldots \ldots \ldots$

5.6.2 Feature changes in the internationalization process of SC2 147

5.6.3 Findings in changes of motion pattern . . . . . . . . . . . 149

5.6.4 EM (Chinese market) entry process (SC2) . . . . . . . . 150

5.6.5 Influence of the EM (China) context on the internationalization of $\mathrm{SC} 2 \ldots \ldots \ldots$. . . . . . . . . . . . . . . 153

5.6.6 Behavior patterns of SC2 . . . . . . . . . . . . . 154

5.7 Case E (MC3) analysis . . . . . . . . . . . . . . . . . . 155

5.7 .1 Overview of MC3 . . . . . . . . . . . . . 155

5.7.2 Motion pattern of MC3's internationalization . . . . . 156

5.7.3 Behavior pattern of MC3's internationalization . . . . . . . 159

5.7 .4 Context of EM entry of MC3 . . . . . . . . . . . . . . 159

5.7.5 Summary of findings in MC3's internationalization . . . . 160

5.8 Case F (MC4) analysis . . . . . . . . . . . . . . . . . . 160

5.8 .1 Overview of MC4 . . . . . . . . . . . . 160

5.8.2 Motion pattern of MC4's internationalization . . . . . . 162

5.8.3 Behavior pattern of MC4's internationalization . . . . . . . 164

5.8.4 Context of EM entry of MC4 . . . . . . . . . . . . 165

5.8.5 Summary of findings in MC4's internationalization . . . . 165

5.9 Case G (MC5) analysis . . . . . . . . . . . . . . . . . . 165

5.9 .1 Overview of MC5 . . . . . . . . . . . . 165

5.9.2 Motion pattern of MC5's internationalization . . . . . . 167

5.9.3 Behavior pattern of MC5's internationalization . . . . . . . 169

5.9.4 Context of emerging market entry of MC5 . . . . . . . . . 170

5.9.5 Summary of findings in MC5's internationalization . . . . 171

5.10 Case H (MC6) analysis . . . . . . . . . . . . . . . . . . . . . 172

5.10 .1 Overview of MC6 . . . . . . . . . . . . . . 172

5.10.2 Motion pattern of MC6's internationalization . . . . . . 172 
5.10.3 Behavior pattern of MC6's internationalization . . . . . . . 175

5.10 .4 Context of emerging market entry of MC6 . . . . . . . . . 176

5.10.5 Summary of findings in MC6's internationalization . . . . 177

5.11 Case I (MC7) analysis . . . . . . . . . . . . . . . . 177

5.11 .1 Overview of $\mathrm{MC7} \ldots \ldots \ldots$. . . . . . . . . . 177

5.11 .2 Motion pattern of MC7's internationalization . . . . . . 179

5.11 .3 Behavior pattern of MC7's internationalization . . . . . . . 179

5.11 .4 Context of emerging market entry of MC7 . . . . . . . . . 181

5.11.5 Summary of findings in MC7's internationalization . . . . 181

5.12 Case J (MC8) analysis . . . . . . . . . . . . . . . . . . 181

5.12 .1 Overview of MC8 . . . . . . . . . . . . . . . . 181

5.12.2 Motion pattern of MC8's internationalization . . . . . . . 183

5.12.3 Behavior pattern of MC8's internationalization . . . . . . . 183

5.12.4 Context of emerging market involvement of MC8 . . . . . 185

5.12.5 Summary of findings in MC8's internationalization . . . . 185

5.13 Case K (MC9) analysis . . . . . . . . . . . . . . . . 185

5.13 .1 Overview of MC9 . . . . . . . . . . . . . . . 185

5.13.2 Motion pattern of MC9's internationalization . . . . . . 187

5.13.3 Behavior pattern of MC9's internationalization . . . . . . . 189

5.13 .4 Context of emerging market entry of MC9 . . . . . . . . . 189

5.13.5 Summary of findings in MC9's internationalization . . . . 189

5.14 Case L (TC) analysis . . . . . . . . . . . . . . . . . . . . 190

5.14 .1 Overview of TC . . . . . . . . . . . . . . . 190

5.14 .2 Motion pattern of TC's internationalization . . . . . . . . 191

5.14.3 Behavior pattern of TC's internationalization . . . . . . . 193

5.14.4 Context of emerging market entry of TC . . . . . . . . . . 194

5.14.5 Summary of findings in TC's internationalization . . . . . 194

6 Cross-case Analysis and Findings 195

6.1 Cross-case comparison of the motion patterns . . . . . . . 195

6.1 Data preparation . . . . . . . . . . . . 196

6.1 .2 Data analysis method . . . . . . . . . . . . . . 197

6.1.3 Results. . . . . . . . . . . . . . . . . . . 198 
6.1.4 Findings from clusters of motion pattern . . . . . . . . . 202

6.1.5 Interpretation of results . . . . . . . . . . . . . . 204

6.2 Variance in the features of internationalization patterns . . . . . . 211

6.2.1 Initial context of small firms' internationalization . . . . . 211

6.2.2 Difference between the industrial sectors . . . . . . . . . . 215

6.2.3 Difference in status quo prospects . . . . . . . . . . . 216

6.2.4 Difference between initial period and continuous period . . 217

6.3 Influence of EM context on the changes in the patterns of internationalization . . . . . . . . . . . . . . . . . 224

6.3.1 Timing of EM entry . . . . . . . . . . . . . . . . . . 224

6.3 .2 Ex-ante of the EM entry . . . . . . . . . . . . . 228

6.3.3 Influence from perceived risk versus perceived opportunity from EMs . . . . . . . . . . . . . . . . 230

6.4 Summary of findings from the cross-cases analysis . . . . . . . . . 233

6.4.1 Dynamic changes in forming motion patterns of internationalization . . . . . . . . . . . . . 233

6.4.2 Disproportional change among the three dimensions of motion pattern during internationalization . . . . . . . . 235

6.4.3 Conditional preference on the perceived risk (uncertainty) and opportunity . . . . . . . . . . . . . . . . 236

7 Concluding discussions and implications $\quad 239$

7.1 Summary of the study . . . . . . . . . . . . . . . . . . . 239

7.2 Discussion and interpretation of the findings . . . . . . . . . . . 241

7.2.1 Dynamic and mixed features of the internationalization patterns (Answer to RQ1) . . . . . . . . . . . . . . 241

7.2.2 A balanced approach in pattern investigation (Answer to RQ2) . . . . . . . . . . . . . . . . 244

7.2.3 Multiple influences on the context of internationalization (Answer to RQ3) . . . . . . . . . . . . . . . 244

7.2.4 Influence from the status quo prospect (Answer to RQ4) . 253

7.3 Conclusions . . . . . . . . . . . . . . . . . 261

7.3.1 A holistic framework on the patterns of internationalization 261 
7.3.2 Conditional preference on the perceived risk and perceived opportunity . . . . . . . . . . . . . . 263

7.3.3 Prospect-guided change mechanism in the internationalization process . . . . . . . . . . . . . 264

7.4 Theoretical contributions . . . . . . . . . . . . . . 265

7.5 Managerial implications . . . . . . . . . . . . . . . . 267

7.6 Limitations and further work . . . . . . . . . . . . . 270

$\begin{array}{lr}\text { References } & 272\end{array}$

$\begin{array}{ll}\text { Appendix A. Pre-study } & \text { A1 }\end{array}$

A-1 Pre-study of the gap in China business involvement among $\begin{array}{ll}\text { Swedish SMEs in Östergötland } & \text { A2 }\end{array}$

.1 Introduction . . . . . . . . . . . . . . . A A

.2 Conceptual model and operationalization . . . . . . . . A 5

.3 Method . . . . . . . . . . . . . . . A 6

.3.1 Sample . . . . . . . . . . . . . . . . A 6

.3.2 Survey . . . . . . . . . . . . . . . . . A A7

.3 .3 Analytic strategy . . . . . . . . . . . . A A

.3.4 Basic model . . . . . . . . . . . . . . A9

.4 Results . . . . . . . . . . . . . . . . . . . . A 11

.4.1 Sample descriptive . . . . . . . . . . . . . . A11

.4.2 Model comparisons . . . . . . . . . . . . . . A13

.4 .3 Interpretation of results . . . . . . . . . . . . A15

.5 Discussions and conclusions . . . . . . . . . . . . . . . . . . A16

$\begin{array}{ll}\text { A-2 Survey questionnaire } & \text { A20 }\end{array}$

$\begin{array}{ll}\text { Appendix B. Illustration of cases } & \text { B1 }\end{array}$

.1 Structure of case illustration . . . . . . . . . . . . . . B B1

.2 Case A description - The emerging China entry of MC1 . . . . . B B

.2.1 The founders and CEO of MC1 . . . . . . . . . . B2

.2.2 The evolving technology and offerings of $\mathrm{MC1} \ldots$. . . . . B3

.2.3 The evolving market and marketing of $\mathrm{MC1} \ldots$. . . . . . B4 
.2.4 The operational environment of MC1 . . . . . . . . . B B

.2.5 The internationalization process of MC1 (2004-2011) . . . B5

.2.6 The China market entry of MC1 . . . . . . . . . . . B7

.3 Case B description - MC2's fast entry into the Chinese market . B10

.3 .1 History of $\mathrm{MC} 2 \ldots \ldots \ldots$. . . . . . . . . . . . . B11

.3.2 The founder and CEOs of $\mathrm{MC} 2 \ldots \ldots$. . . . . . . B11

.3.3 The evolving technology and offerings of MC2 . . . . . . B12

.3.4 The evolving market and marketing of $\mathrm{MC2}$. . . . . . . . B12

.3.5 The operational environment of $\mathrm{MC} 2 \ldots \ldots$. . . . . . . B13

.3.6 The internationalization process of $\mathrm{MC} 2 \ldots \ldots$. . . . . . B15

.3.7 The China market entry of MC2 . . . . . . . . . . . B17

.4 Case C description - The fresh trials of SC1's Chinese market entryB22

4.1 History of $\mathrm{SC} 1 \ldots \ldots \ldots \ldots$. . . . . . . . . . . . . . . . . . . . . . . . . . . . .

.4.2 The founders and CEO of SC1 . . . . . . . . . . . . B22

.4.3 The evolving services and offerings of SC1 . . . . . . . . B23

.4.4 The evolving market and marketing of SC1 . . . . . . . . B23

.4 .5 The operational environment of SC1 . . . . . . . . . . B24

.4.6 China market entry of SC1 . . . . . . . . . . B25

.5 Case D description - SC2's alternative approach to the Chinese

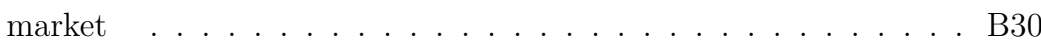

$.5 .1 \quad$ History and background of $\mathrm{SC} 2 \ldots \ldots$. . . . . . . B30

.5 .2 The founder and $\mathrm{CEO}$ of $\mathrm{SC} 2 \ldots \ldots$. . . . . . . . . B30

.5 .3 The evolving service and offerings of SC2 . . . . . . . B31

.5.4 The evolving market and marketing of SC2 . . . . . . . . . B31

.5.5 The operational environment of $\mathrm{SC} 2 \ldots \ldots$. . . . . . . . B32

.5.6 The internationalization process of $\mathrm{SC} 2 \ldots \ldots$. . . . . . . B32

.5.7 SC2's "China project" . . . . . . . . . . . . . B33

.6 Case E description - OEM-focused internationalization . . . . . . B37

.6 .1 A brief history of MC3 . . . . . . . . . . . . B38

.6.2 Context of MC3's internationalization . . . . . . . . B38

.6 .3 Internationalization process of MC3 . . . . . . . . . . B44

.6.4 Emerging market entry of MC3 . . . . . . . . . . B46

.6.5 Future plans related to internationalization . . . . . . . B47 
.7 Case F description - Internationalization by entrepreneurship . . B48

.7.1 A brief history of MC4 . . . . . . . . . . . . B48

.7.2 Context of MC4's internationalization . . . . . . . . . . B49

.7.3 The internationalization process of MC4 . . . . . . . . B57

.7.4 MC4's involvement in emerging markets . . . . . . . . . . B59

.7.5 Future plans related to internationalization . . . . . . . . B59

.8 Case G description - New markets-directed internationalization . B60

.8.1 A brief history of MC5 . . . . . . . . . . . . B60

.8.2 Context of MC5's internationalization . . . . . . . . . B61

.8.3 Internationalization process of MC5 . . . . . . . . . . . B62

.8.4 Changes in the approach of internationalization by MC5 . B62

.8.5 MC5's involvement in emerging markets . . . . . . . . . . B63

.9 Case $\mathrm{H}$ description - Internationalization of a small high-technology

firm . . . . . . . . . . . . . . . . . . . B64

.9.1 A brief history of MC6 . . . . . . . . . . . . B64

.9.2 Context of MC6's internationalization . . . . . . . . . B64

.9.3 Internationalization process of MC6 . . . . . . . . . B66

.9.4 Emerging market entry of MC6 . . . . . . . . . . . B67

.9.5 Changes in internationalization . . . . . . . . . . B67

.10 Case I description - Internationalization of a small manufacturer . B68

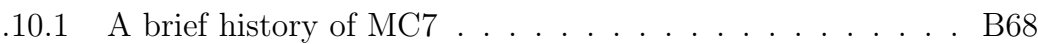

.10.2 Context of MC7's internationalization . . . . . . . . . . B69

.10 .3 Internationalization process of MC7 . . . . . . . . . . . B70

.10.4 MC7's involvement in emerging markets . . . . . . . . . . B71

.10.5 Changes in internationalization . . . . . . . . . . . B71

.11 Case $\mathrm{J}$ description - Internationalization of a small firm with a long history . . . . . . . . . . . . . . . . . . . . B72

.11 .1 A brief history of MC8 . . . . . . . . . . . . B72

.11.2 Context of MC8's internationalization . . . . . . . . . . B73

.11 .3 Internationalization process of MC8 . . . . . . . . . . . B75

.11.4 Changes in internationalization . . . . . . . . . . B75

.11.5 MC8's involvement in emerging markets . . . . . . . . . B76

.12 Case K description - Internationalization of a small family business B77 


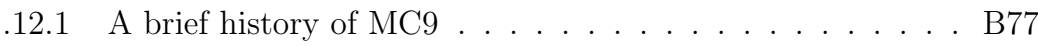

.12 .2 Context of MC9's internationalization . . . . . . . . . B79

.12 .3 Segments and channels of marketing and sales . . . . . . B79

.12 .4 The internationalization process of MC9 . . . . . . B B80

.12 .5 Changes in internationalization . . . . . . . . . B82

.12 .6 MC9's involvement in emerging markets . . . . . . . . . B83

.13 Case L description - Internationalization of a small independent distributor . . . . . . . . . . . . . . . . B B 84

.13 .1 A brief history of TC . . . . . . . . . B B84

.13 .2 Context of TC's internationalization . . . . . . . . B85

.13 .3 Internationalization process of $\mathrm{TC} \ldots \ldots \ldots \ldots$. . . . . B86

.13 .4 TC's involvement in emerging markets . . . . . . . . . B87

.13 .5 Changes in internationalization . . . . . . . . B88

$\begin{array}{ll}\text { Appendix C. Interview guidelines } & \text { B89 }\end{array}$ 


\section{List of Tables}

2.1 Comparison of the identified three representative motion patterns 25

2.2 Interpretations of internationalization from three perspectives . . 29

2.3 Differences among the three behavior patterns . . . . . . . . . 38

3.1 Arbitrary score of psychic distance . . . . . . . . . . . . . . 58

3.2 Construct of MPI $2014 \quad \ldots \ldots \ldots 9$

3.3 Arbitrary score of market potential . . . . . . . . . . . . . 60

3.4 Arbitrary score of foreign market turnover . . . . . . . . . . . . . 64

3.5 Arbitrary score of entry modes . . . . . . . . . . . . . 65

4.1 Brief profile of case firms in the Kina study stage . . . . . . . . . 90

4.2 Brief profile of case firms in the EM extension study stage . . . . 91

4.3 Overview of data collection in the 1st stage (Kina study stage) . . 97

4.4 Overview of data collection in the 2nd stage (EM extension study stage) . . . . . . . . . . . . . . . . . . . . . . . . . . 98

5.1 Overview of the in-depth case companies . . . . . . . . . . . 112

5.2 Overview of the additional case companies . . . . . . . . . . 114

5.3 Three-layer effect analysis on the Chinese market entry of MC1 . 121

5.4 Three-layer effect analysis on the Chinese market entry of MC2 . 131

5.5 Three layer effect analysis on the Chinese market entry of SC1 . . 142

5.6 Three layer effect analysis on the Chinese market entry of SC2 . . 151

5.7 Profile of MC3 . . . . . . . . . . . . . . . . . . . 156

5.8 Profile of $\mathrm{MC} 4 \ldots \ldots \ldots 161$

5.9 Profile of MC5 . . . . . . . . . . . . . . . . . . . 166 
5.10 Profile of MC6 . . . . . . . . . . . . . . . . . . . 173

5.11 Profile of $\mathrm{MC7} \ldots \ldots \ldots \ldots$. . . . . . . . . . . . . 178

5.12 Profile of MC8 . . . . . . . . . . . . . . . . . . . . . 182

5.13 Profile of MC9 . . . . . . . . . . . . . . . . . . . 186

5.14 Profile of TC . . . . . . . . . . . . . . . . . . . . 191

6.1 Summary of cluster variables . . . . . . . . . . . . . . . . 197

6.2 Comparison of cluster analysis . . . . . . . . . . . . . . . . . 200

6.3 Overview of the internationalization motion pattern of 12 case companies . . . . . . . . . . . . . . . . . . . . . 205

6.4 Contextualization of motion patterns in initial internationalization 212

6.5 Contextualization of behavior patterns in initial internationalization . . . . . . . . . . . . . . . . . 221

6.6 Summary statistics of internationalization speed in two epochs (unit: years) . . . . . . . . . . . . . . . . 2 225

6.7 Contextualization of EM entry during internationalization . . . . 227

1 Thresholds of SMEs . . . . . . . . . . . . . . . . A 8

2 Sample Description of Four numerical Predictors . . . . . . . . . . A11

3 Description of the Response Variable related to the Categorical predictors . . . . . . . . . . . . . . . . A12

4 Level of China business involvement by 3 prediction models . . . A14 


\section{List of Figures}

2.1 Organizational framework . . . . . . . . . . . . . . . . 45

2.2 The inner layer of small firms' means pool . . . . . . . . . . . . . 49

2.3 The middle layer of small firms' means pool . . . . . . . . . . 50

2.4 The outer layer of small firms' means pool . . . . . . . . . . . 52

2.5 Overview of the theoretical framework . . . . . . . . . . 54

3.1 Foreign operational modes of main business activities (entry modes) 65

3.2 Internationalization trail map . . . . . . . . . . . . 67

3.3 Processual analytic model for the internationalization pattern of small firms . . . . . . . . . . . . . . . . . . . . 72

4.1 Overview of the research process . . . . . . . . . . . 78

4.2 Overview of the empirical inquiry . . . . . . . . . . . . 86

4.3 Overview of the data analysis procedure . . . . . . . . . 101

5.1 Structure of the within-case analysis . . . . . . . . . . . . 113

5.2 Turnover and operating profit change of MC1 . . . . . . . . 115

5.3 The internationalization trail map of $\mathrm{MC1}$. . . . . . . . . . 117

5.4 The internationalization motion pattern of MC1 . . . . . . . . 119

5.5 Turnover and operating profit change of MC2 vs. trade change in its industry . . . . . . . . . . . . . . . . . . . . 126

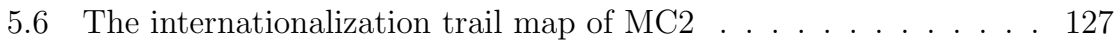

5.7 The internationalization motion pattern of $\mathrm{MC} 2 \ldots$. . . . . . 129

5.8 Turnover and operating profit change of SC1 . . . . . . . . . . 138

5.9 The internationalization trail map of SC1 . . . . . . . . . . . 139 
5.10 The internationalization motion pattern of SC1 . . . . . . . . . 140

5.11 Turnover and operating profit change of SC2 . . . . . . . . . . . . 147

5.12 The internationalization trail map of SC2 . . . . . . . . . . . . . 148

5.13 The internationalization motion pattern of SC2 . . . . . . . . . . 149

5.14 Financial performance of MC3 . . . . . . . . . . . . . . . . . 155

5.15 The internationalization map of MC3 . . . . . . . . . . . . 157

5.16 Financial performance of MC4 . . . . . . . . . . . . . . . . . 161

5.17 The internationalization map of MC4 . . . . . . . . . . . 163

5.18 Financial performance of MC5 . . . . . . . . . . . . . . . 166

5.19 The internationalization map of MC5 . . . . . . . . . . . . . 168

5.20 Financial performance of MC6 . . . . . . . . . . . . . . . . . 172

5.21 The internationalization map of MC6 . . . . . . . . . . . . . . . . 174

5.22 Financial performance of MC7 . . . . . . . . . . . . . . . . . 178

5.23 The internationalization map of MC7 . . . . . . . . . . . . . . . 180

5.24 Financial performance of MC8 . . . . . . . . . . . . . . . . . . 182

5.25 The internationalization map of MC8 . . . . . . . . . . . . . . . . 184

5.26 Financial performance of MC9 . . . . . . . . . . . . . . . . . 186

5.27 The internationalization map of MC9 . . . . . . . . . . . . . 188

5.28 Financial performance of TC . . . . . . . . . . . . . . . . . 190

5.29 The internationalization map of TC . . . . . . . . . . . . . 192

6.1 Changes in the motion dimensions . . . . . . . . . . . . . . . 199

6.2 Key characteristics of the four clusters . . . . . . . . . . . . . 201

6.3 Comparison of internationalization speed (industrial sector-based) in two epochs . . . . . . . . . . . . . . . . . . . 226

6.4 Changes in risk versus opportunity perception for EM entry . . . 232

7.1 Prospect-based internationalization process model . . . . . . . . . 259

2 Conceptual framework of a primary decision of emerging market

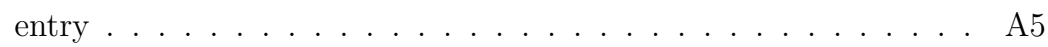

3 Gaps of China Business Involvement . . . . . . . . . . . . A12

4 Structure of the case illustration . . . . . . . . . . . . B B 


\title{
List of Abbreviations
}

\author{
BaG Born-again Global \\ BENCH Beneficial Business Relations between the Central Baltic Region and China \\ BG Born Global \\ BP Behavior Pattern \\ BRICS Brazil, Russia, India, China and South Africa \\ DOI Degree of Internationalization \\ EM Emerging Market \\ EO Entrepreneurial Orientation \\ FDI Foreign Direct Investment \\ GDP Gross Domestic Product \\ IB International Business \\ ICT Information and Communication Technology \\ IE International Entrepreneurship \\ INV International New Venture \\ Intl. Internationalization \\ M \& A Mergers and Acquisitions \\ MNE Multi-national Enterprise \\ MP Motion Pattern \\ OECD Organization for Economic Co-operation and Development \\ OEM Original Equipment Manufacturer \\ PD Psychic Distance \\ SCB Statistics Sweden (Statistiska centralbyrå) \\ SME Small and Medium-sized Enterprise \\ TMT Top Management Team
}





\section{Chapter 1}

\section{Introduction}

"A good theory is one that holds together long enough to get you to a better theory."

- Donald O. Hebb

This chapter serves as an introduction to the research topic. The main objective of the introductory first part is to problematize the ongoing debate on patterns of small firms' internationalization. The problematization starts with examining the current internationalization situation of small and medium-sized enterprises (SMEs) from a small and open economy in the EU (Sweden focus) under an increasing influence from large emerging markets. It continues with probing whether the existing literature offers an insightful explanation of the topic. The focus then turns to potential problem areas and the current debate. Furthermore, it specifies a purpose and research questions for this dissertation. The last part presents a disposition for chapters to follow.

\subsection{The internationalization of small firms in a change context}

The internationalization of firms is an evolving concept (Welch and Luostarinen, 1988; Chetty and Blankenburg Holm, 2000). It has commonly been referred to 
as the expansion process of firm operations across national borders (Welch and Luostarinen, 1988). Research on the internationalization of small firms has attracted increasing attention in the past 20 years, since small firms have been noticed to play an active role in international business arenas. The traits of the internationalization of small firms seem to deviate from big multi-national enterprises (MNEs) (Bell et al., 2003), which was a main focus group of internationalization studies from the beginning (Johanson and Wiedersheim-Paul, 1975; Dunning, 2001).

In most economies, SMEs account for a majority of the total population of firms. Within the EU-28, for example, according to the EU definition (European Commission, 2005) more than 99\% of the firms are SMEs with fewer than 250 employees and less than EUR 50m in turnover. Since SMEs account for about $67 \%$ of the employment and $58 \%$ of the value added (European Commission, 2014), they have great potential to contribute to export, employment and the national economy. Internationalization has been recognized by policy makers as one of the important indicators of SME development (European Commission, 2014). This is of special interest for SMEs' home countries with a rather limited domestic markets, for example Sweden and New Zealand (Andersson and Evangelista, 2006).

Research on internationalization has found that SMEs from developed economies have increased in importance for both their home and host country economies since the early 1990s (Rialp and Rialp, 2001), when various external barriers for international trade were decreasing. The decreasing price of transportation, the fast diffusion of innovations in information and communication technology (ICT) (Aspelund and Moen, 2003; Loane, 2005) and the lowering of trade barriers (Naldi, 2008; Sandberg, 2012) attributed to this change. In addition, the global operation of big multi-national enterprises (MNEs) also shortened the perceived distance by SMEs between the home country of MNEs and their multiple host countries (Chetty and Blankenburg Holm, 2000; Johanson and Vahlne, 2009). Those big contextual changes have made SMEs face and operate in a more internationally connected business world, while they have also offered SMEs new 
possibilities to develop internationally. In academia, discussion of the internationalization of SMEs has largely increased, corresponding to a change in the empirical context. In the early 1990s, scholars began to focus more on the phenomenon of rapid internationalization of SMEs (Knight and Cavusgil, 1996; Madsen and Servais, 1997; McAuley, 1999). After 20 years of studying this phenomenon, there are various explanations and interpretations from different perspectives, helping scholars to understand what factors might stimulate and enable some SMEs to become internationalized earlier and faster than others (Rialp et al., 2005; Keupp and Gassmann, 2009). Yet, results from studies focusing on a short period cannot provide sufficient insights on whether there are changes during the unfolding internationalization process of firms and whether the internationalization process is sustained. Therefore, several scholars, such as Jones et al. (2011) and Kuivalainen et al. (2012), argue that future research should expand from a limited focus on the earlier period of rapid internationalization to cover the evolving pattern afterwards. It is reasonable suggestion, because potential changes in an overall internationalization process can barely be captured and understood by a "snapshot" view of the early period of internationalization.

Within the research field of internationalization, a major goal for the process studies of firm internationalization in general is to understand the pattern and pace of firm internationalization over time (Johanson and Vahlne, 1977; McAuley, 2010). Earlier research in the 1970s identified a few patterns based on samples from MNEs, where internationalization was interpreted as an incremental process with a feature of step-wise patterns (Johanson and Wiedersheim-Paul, 1975; Bilkey and Tesar, 1977; Johanson and Vahlne, 1977). In fact, up until the 1990s, research on firms' internationalization process with a longer period of focus had been dominated by the incremental feature in step-wise patterns, such as the Uppsala model (U-model), the Innovation-related model (I-model) and the Finnish model (Andersen, 1993; Vissak, 2003). During the last two decades of studying the internationalization of SMEs, due to context changes, a few new patterns have been identified and labeled, such as "International New Venture" (INV) (McDougall et al., 1994; Zahra, 2005), "Born Global" (BG) (Rennie, 1993; Moen, 
2002; Moen and Servais, 2002) and "Born-again Global" (BaG) (Bell et al., 2001). As mentioned earlier, because of a short period-focus in the rapid internationalization study of SMEs, there is still limited knowledge on how the identified patterns change over time (Kuivalainen et al., 2012). Furthermore, there are very few longitudinal studies capturing the changes that occur during the internationalization of a firm (Welch and Paavilainen-Mäntymäki, 2014).

Looking at an empirical situation of SMEs' internationalization, it is easier to understand why an internationalization study focused over a longer period is needed for guiding the practice of small firms and supportive agents from policy makers. Empirical data reflect that despite of an external context change, internationalization is still a challenging task for the majority of small firms, particularly for those involved in outward internationalization activities such as export. Internationalization is a time and resource-demanding process, especially for smallersized SMEs with larger human and financial resource constraints (fewer than 50 employees and no more than EUR 10m turnover based on the EU definition). These firms account for nearly $99 \%^{1}$ of the total population of firms in Europe, and their interest for internationalization is still rather low. Empirical data based on survey responses from 16,000 Swedish SMEs show that less than $10 \%$ of the smaller-sized firms had their primary market abroad (Tillväxtverket, 2014). Commonly perceived barriers for less internationalized firms include insufficient information and knowledge about potential foreign markets, a lack of qualified personnel for export, a lack of the right technology or suitable offerings for foreign markets and perceived political-economic impediments in foreign markets, etc. (Leonidou, 2004; Pinho and Martins, 2010). Because of those difficulties, policy makers in many countries as well as at the EU level have launched different programs to stimulate and support export by SMEs (Acedo and Galán, 2011). However, scholars such as Crick (2004) and Acedo and Galán (2011) point out that these supportive programs seem to be less effectively or ineffectively designed, because there is a lack of understanding of why and how a majority of

\footnotetext{
${ }^{1}$ The proportions of medium-sized SMEs in Sweden is $0.8 \%$, which is similar to $1 \%$ in EU-28, based on the 2014 SBA fact sheet from European Commission.
} 
SMEs do or could fail to respond to the external stimulation to internationalize their business over time.

\subsection{The context of Emerging Markets}

The surge in large emerging markets (EMs) is providing the empirical context for studying the internationalization process of smaller SMEs under different circumstances. Emerging markets often refer to countries and economies that have experienced a rapid pace of economic growth and where government policies are leaning toward a free-market system (Khanna et al., 2005). Big emerging markets, such as BRICS ${ }^{2}$, have offered attractive growth opportunities to various foreign companies, which mature economies might no longer offer (Sakarya et al., 2007). Yet, these growth potentials are often accompanied by various challenges for foreign companies to enter those markets, especially for small and micro firms with large constraints on human and financial resources.

Emerging markets are commonly viewed as in transition to a more mature level of economic development. Compared to developed markets or more mature economies, such as the majority of the developed OECD ${ }^{3}$ countries, some of the important institutional infrastructure is still more or less underdeveloped in EMs (Li and Hoyer-Ellefsen, 2008; Khanna and Palepu, 2010). Khanna and Palepu (2010) argue that the main obstacles for western companies to enter and operate in EMs are caused by so-called "institutional voids". According to these authors, the term refers to a lack of qualified intermediaries such as market research and credit checking systems to connect buyers and sellers in an efficient way in emerging markets. In addition, embedded inefficiency in institutional settings such as bureaucracy as well as corruption make doing business with EMs more challenging and costly compared to most of the developed markets (Luo, 2011; Hilmersson and Jansson, 2012). A more dissimilar institutional setting in those markets also

\footnotetext{
${ }^{2}$ BRICS is the acronym for five major emerging national economies: Brazil, Russia, India, China and South Africa.

${ }^{3}$ OECD is the acronym of Organisation for Economic Cooperation and Development.
} 
creates higher perceived risks (uncertainty).

In academia, despite the increasingly important role of EMs in the global economy as well as increasing trade and cooperation between emerging and developed markets, research on the internationalization of SMEs related to the context of EMs is still limited (Hessels and Kemna, 2008; Sandberg, 2012). EMs offer an interesting context and opportunity to gain a deeper understanding of the internationalization process of SMEs under different political and economic circumstances over time. Since EMs often involve two recognizable traits at the same time perceived higher opportunities and perceived higher risks (uncertainty) it is interesting to know if those two elements influence the internationalization pattern of smaller SMEs with high resource scarcity.

\subsection{Problem discussion}

Since early 1990, the study of the internationalization process of small firms has diverged from incremental pattern recognition to a more rapid type of internationalization. However, unlike previous studies, which often focused on a longer period, the new rapid patterns of internationalization such as INV and BG only focus on the initial period of firm internationalization (Melén and Nordman, 2009) to show their fast speed in initial internationalization. In the context of EMs, it is hard to gauge the applicability of both theories - the incremental and the rapid pattern of internationalization - due to a different scope in sampling and focus.

\subsubsection{The applicability of identified patterns}

The incremental pattern was identified from and reflected MNEs in the manufacturing sector; therefore, its application to service companies is questionable. In addition, the theory represented by the U-model is very internally focused and largely neglects the influence from the external networks of a firm (Johanson and 
Vahlne, 2009). Furthermore, the theory was developed in the 1970s, when the cost of information searching and transport fares, trade barriers and the impact of globalization were very different from the last decade. Therefore, the incremental pattern has been questioned by researchers who identified the rapid pattern, regarding the applicability of the incremental pattern, in a new context (Moen and Servais, 2002; Rialp et al., 2005; Crick, 2009).

The rapid pattern, on the other hand, was identified from and reflected small high-technology companies and trading companies (McDougall et al., 1994; Madsen and Servais, 1997; Jones, 1999). It has a particular focus on the early phase of the internationalization process. It could be questionable whether it is a local phenomenon in some types of firms or ventures, or a more general phenomenon. Since this theory focuses on the early phases of internationalization, it is also questionable how stable or consistent it is for the whole process. In addition, it focuses more on the profile of firms rather than any potential changes during the internationalization process in different international markets' contexts. Therefore, it offers insufficient guidance for the EM's context.

\subsubsection{The impact of size}

Since the 1990s, the focus on the internationalization of SMEs has generally increased. In the resulting studies, with regard to size, scholars often treat SMEs as a homogeneous group. European studies often use the EU standard and sample SMEs with up to 250 employees. American studies sample SMEs with up to 500, or even 1000 employees in some industries. Asian studies are often a mixture of the two, but in general they tend to follow the American standard. Whether different-sized firms should be treated as one group is a problematic issue. Shuman and Seeger (1986) point out that smaller firms cannot be treated as smaller versions of big businesses. Because of the smallness of such firms, they have their own way of interacting with the environment. Buckley (1989) noticed that due to smallness, SMEs have difficulties in managing time commitment in different markets when they are involved in international business. However, some 
researchers also point to how size is just a snapshot view at a specific point in time during the internationalization process of a firm (Buckley and Ghauri, 1999).

The author of this thesis agrees that size of an SME will change along with the internationalization process of the firm. However, small firms cannot ignore sizerelated constraints in the internationalization process. Especially in the initial phase of internationalization, many SMEs either are reactively led to the internationalization process (Sallis and Deo Sharma, 2009) or they have to find an alternative solution in order to overcome size-related constraints. Based on data in 2013 from Statistics Sweden (SCB), about 74\% of the total number of firms do not have any employees and $18 \%$ of the total number of firms have fewer than 5 employees. Management in those firms is to a large degree different from firms with more than 50 employees. Resources which might not be available within such small firms need to be identified and mobilized via external channels (Coviello and McAuley, 1999). Current studies on the rapid internationalization of SMEs also point to the critical influence of entrepreneurs in the smaller firms (Blomstermo et al., 2004; Harris and Wheeler, 2005; Komulainen et al., 2006). Treating SMEs as a homogeneous group might neglect the important influence of larger resource constraints on the decisions and behavior in the internationalization of the smaller firms.

Empirical data from Sweden and the EU also show that there is a large difference in internationalization between medium and smaller-sized companies with less than 50 employees. For example, based on the study by Tillväxtverket ${ }^{4}$ from 2013 to 2014, less than $10 \%$ of the smaller-sized companies had export markets as their primary market, compared to about $25 \%$ of the medium-sized companies (Tillväxtverket, 2014). Considering that the earlier studies on the internationalization of SMEs is very seldom focused on the smaller-sized firms, this study intends to add more knowledge to the understanding of the behavior of this group with regard to internationalization.

\footnotetext{
${ }^{4}$ Swedish Agency for Economic and Regional Growth (Tillväxtverket) www.tillvaxtverket.se
} 


\subsubsection{The impact of an emerging market context}

Earlier studies in international business and internationalization often associate the EMs' context with characteristics such as instability, uncertainty and risk (Khanna and Palepu, 2010; Hilmersson and Jansson, 2012). Although there are a few studies focusing on the EM context (e.g., Freeman and Sandwell (2008), Jansson (2009) and Balkow (2012)), very few focus specifically on small-sized firms in this context. In Sweden, there are two recent Ph.D. dissertations which study internationalization in the EM context relating to China. Balkow's (2012) study focuses on the role of the intermediary in sourcing from China, while Sandberg's (2012) research covers Chinese SMEs entering the European market. This study uses EMs in a general context, with BRICS as examples, to highlight two striking traits of EMs: high perceived opportunities and higher perceived risks (uncertainty). The former refers to both the huge economic potential based on market size and a rapid development process, while the latter refers to higher perceived risks and uncertainty based on a larger difference in cultural, institutional, geographic and economic aspects (Ghemawat, 2001). Both potential opportunities and perceived risk would influence the change in strategy and actions of smaller firms when approaching EMs. This study intends to add more empirical and theoretical understanding of how small firms treat perceived opportunities and risks when they enter EMs.

\subsubsection{The consistency of the pattern over time}

Internationalization can also be considered as multifaceted development processes which involve changes in firm strategy, structure, resource commitment, operation and relations with other organizations during the process (Calof and Beamish, 1995; Johanson and Vahlne, 2009). When a study focuses on the pattern of the internationalization process, it should cover changes in its major and basic dimensions such as extent, scope and speed (De Clercq et al., 2005; Casillas and Acedo, 2013; Welch and Paavilainen-Mäntymäki, 2014). From a purely logical reasoning point of view, the author of this thesis would argue that combinations of the above 
mentioned dimensions could form various patterns rather than merely the three major patterns identified in the extant literature: stage models (Johanson and Vahlne, 2009), "born global" and "born-again global" (Coviello and McAuley, 1999). A challenge in understanding the dynamic nature of the internationalization pattern of small firms lies in how to capture changes in the evolution of patterns during critical time periods of the internationalization process. Kuivalainen et al. (2012) point out the importance in understanding the longitudinal development of internationalization, and argue that there is a lack of studies on the time dimension of internationalization. For example, mentioned earlier was that due to the short period-focus of BG studies, there are insufficient studies on how changes with time affect continued internationalization. Therefore, this study intends to add knowledge on possible changes in the internationalization pattern over time.

\subsection{Purpose of study and research questions}

Aware of the identified limitations in the extant research, the purpose of this study is to identify the evolving patterns in the internationalization of small firms. By doing so, the study intends to facilitate a better understanding of change mechanisms which may influence the sequence, scope, scale, timing and pace of small firms' internationalization. Considering the previously discussed gaps in existing research on the internationalization processes of small firms toward those perceived high potential opportunity and high-risk (uncertainty) markets, this study has two objectives at different levels. The primary objective is related to internationalization pattern identification, while the second objective is to go further in order to understand why the pattern has evolved in a certain way.

The primary objective of this study is to describe and illustrate the pattern of small firm internationalization in order to explore how the internationalization pattern features evolved under different context. By using internationalization toward these large institutionally different EMs as a research context, the study 
aims to gain a better understanding on small firm internationalization via a proper contextualization of this phenomenon.

The features of the internationalization pattern of firms have been more explicitly discussed in internationalization literature in recent years (Bell et al., 2001; Moen and Servais, 2002; Madsen, 2013). It is very common that researchers just put a partial focus on one of dimensions during firm internationalization, such as speed, in order to differentiate their studies from the earlier incremental models (e.g., the U-model). However, as internationalization is a multi-dimensional concept, it should at least cover the spatial and temporal dimensions (Jones et al., 2011) at the same time to obtain a common ground for discussion and comparison. Therefore, the first research question aligned with the primary objective is:

1. What are the major features in the pattern of small firm internationalization? In order to achieve the first objective, this study needs to address another theoretically and methodologically relevant question as well: how to capture the evolving features of the pattern during the internationalization of small firms.

In existing research on the subject, internationalization has been operationalized under the term "degree of internationalization" (DOI) (Pangarkar, 2008; Papadopoulos and Martín Martín, 2010). There are various ways to interpret this. For example, compared to the studies on incremental patterns in internationalization, very few studies on the rapid patterns of internationalization cover the scope dimension of internationalization as the early models (e.g., the U-model) did. Indeed, there are many fragmented and differently evaluated observable indicators of internationalization in the literature. However, there are very few integrated analytical tools which could incorporate the critical contextual variables aiming to capture the changes in the patterns of internationalization. Therefore, the second research question derived from the primary objective is:

2. How can evolving patterns of the internationalization of small firms be described and captured? 
The second objective of this study is to create a better understanding of why the features of the internationalization pattern have evolved in a certain way along the development process of the small firm. Due to multifaceted development processes of internationalization (Calof and Beamish, 1995), the pattern of internationalization can be influenced by different contextual factors at different levels. Considering the potential influence from the different contextual factors on the internationalization, the third research question, derived from the second objective, is:

\section{How do contextual factors influence evolving patterns of internationalization?}

Finally, because internationalization process studies are mainly based on empirical phenomena, earlier identified patterns in the literature can still be found in more recent empirical study. To get a better understanding on the patterns of internationalization, the single perspective and the short periods-focus used in most of the existing research (Kuivalainen et al., 2012) could hardly achieve the second objective in this study alone. Some scholars suggest that in the internationalization study, researchers need to go further to refine the boundary and condition of their theory or propositions (Andersen, 1993) in order to get more insight and be less biased about causal explanations. Nevertheless, it is also worth to be aware of the importance of parsimony in theory development. Taking overt characteristics of EMs into consideration and aligning with the second objective, the final research question of this study is:

4. How does the perceived high market potential, with a high perception of risk (uncertainty) in the context of emerging markets, influence the changes in the internationalization patterns of small firms?

\subsection{Disposition}

In addition to the introduction (Chapter 1), this thesis consists of six chapters. The logic between these chapters is as follows.

Chapter 2 contains the theoretical framework. It establishes a tentative ana- 
lytic framework through a synergy of important knowledge blocks from previous research and inputs from the pre-study. Important concepts related to the patterns of internationalization are clarified in this chapter. Extant theoretical perspectives associated with several major patterns were critically reviewed in the chapter. After reading this chapter, readers will be able to see the perspective and key concepts used in this study as well as the reasons they were selected.

Chapter 3 contains an overview of the theoretical constructs operationalization and implementation. This chapter intends to refresh and clarify the links among the theoretical constructs, the operationalization and the analysis methods. It offers detailed information for readers regarding how these key relevant concepts and constructs were operationalized to construct a process-based analytical tool. In addition, it also offers information regarding the implementation of the construct in the study.

Chapter 4 contains the methodology. This chapter explains and justifies the choice of selected research approach and methods, the interdependence between theory and empirical study, and the overall research process of this research. After reading this chapter, readers will be able to know why and how mixed research methods were used in this study for data collection and analysis, who were the important stakeholders involved in different phases of this study, and what were their roles and possible influences on the study. Furthermore, it also offers information regarding the quality and ethics assurance of this study.

Chapter 5 contains four in-depth within-case analyses and summaries of eight within-case analysis. Each in-depth case is analyzed using a visualization tool and a processual analysis framework developed in Chapter 2 and Chapter 3.

Chapter $\boldsymbol{6}$ contains the cross-case analyses of the 12 cases. Based on the quantification of findings and results from 12 within-case analyses, a cluster analysis was performed to identify the motion pattern of internationalization. In addition, it presents a qualitative analysis on the changes in the features of both motion and behavior patterns during internationalization. Based on the findings, this chapter offers basic evidence for the answers to the four research questions. 
Chapter 7 contains concluding discussions, final conclusions, implications of the study and further work. The main findings of the study are discussed and interpreted in this chapter. Based on interpretation of the findings, propositions are proposed and a new concept model is constructed for theoretical development. This chapter presents answers to the four research questions, theoretical contributions and managerial implications of this study. In addition, it suggests a direction for further research.

Appendices contains the pre-study and 12 within-case descriptions, along with other additional materials. 


\section{Chapter 2}

\section{Theoretical Frame}

This chapter presents the theoretical foundation of this study. It begins with a clarification of the main concepts related to the internationalization process and pattern of the study. The chapter continues with a probe of common latent assumptions under three major perspectives on the internationalization process and pattern research. Based on a critical discussion of the adoptability of the latent assumptions in those perspectives under the EM context, two key concepts, namely "risk" (uncertainty) and "opportunity", are derived from the research. Furthermore, by operationalizing and incorporating the "risk" (uncertainty) and the "opportunity" into a tentative analytic frame, the chapter intends to achieve a theoretical synthesis and justify a chosen perspective in the study. Lastly, an "organizational frame" is adopted to construct a basic tentative analytic frame for the latter analysis.

\subsection{Evolving concepts of internationalization}

The definition of internationalization has evolved over time. In the late 1980s, Welch and Luostarinen (1988) insightfully discussed a multi-dimensional concept regarding the meaning of internationalization. They suggested using a broader concept as a starting point in order to reveal a whole internationalization process of a company taking off. According to these authors, internationalization can be defined as "the process of increasing involvement in international operations" (Welch and Luostarinen, 1988, p. 36). 
This definition modified an earlier common push-oriented concept in the international business field, implying that internationalization is more related to the outward activities of a company. Outward activities include various modes to penetrate foreign markets. For example, the Uppsala model in the 1970s (Johanson and WiedersheimPaul, 1975), which revealed sequences of a company's foreign market expansion, and Dunning's eclectic paradigm framework in the early 1980s (Dunning, 2001), which explored choices in taking production overseas, interpret choices and decisions made for outward international business activities. Welch and Luostarinen (1988)'s definition does not exclude inward international business actives, which are related to, for examples, international sourcing, franchising and so on. Although the word increasing in the Welch and Luostarinen (1988)'s definition still implies unidirectionality, they also point out that there would be cases in which de-internationalization occurs, especially during the early phase of a firm's internationalization. To adjust the second part of the problem regarding the direction of change, Calof and Beamish (1995) define internationalization as "the process of adapting firms' operations (strategy, structure, resources, etc.) to international environments" (p. 116).

\subsubsection{A process view on internationalization}

In existing research, the concept of internationalization has been more commonly accepted as a process. For example, three generations of the Uppsala model (U-model) regard a firm's internationalization as a learning process, either in foreign markets or in a firm's network (Johanson and Wiedersheim-Paul, 1975; Johanson and Mattsson, 1987; Johanson and Vahlne, 2009). Melin (1992) regards internationalization as a strategic process, while Oviatt and McDougall (2005) and Schweizer et al. (2010) treat internationalization as an international entrepreneurial process. Calof and Beamish (1995) regard internationalization as a firm's adaptation process in international environments. Since the interaction between small firms and their embedded and enacted environments have a strong influence on internationalization, this study tends to focus on such interactions. Thus, the study mainly adopts the broad definition from Calof and Beamish (1995). In addition, reflecting on possible drawbacks of using a broad concept, it might be argued that in today's increasingly internationally connected world, firms in an open economy rarely are entirely isolated from their "international environments", as referred to by Calof and Beamish (1995, p. 116). Therefore, the study would 
also add a partial restriction to define internationalization as the process of adapting firms' operations to international environments via their conscious engagement in business activities in offering products and services across national borders. This restriction would differentiate a firm's purposeful involvement in international business activities (e.g., export, franchising, outsourcing and foreign direct investment (FDI)) from those merely indirectly related. Therefore, the study would focus on firms' deliberate behaviors in internationalization. Even though the concept of the internationalization process in this study covers both outward and inward international business activities, this study has its main focus on the outward internationalization process.

The internationalization process of small firms has attracted a large amount of attention in the last 20 years. Yet, ideas on how to capture the features of small firms' actions during the internationalization process vary in different studies. More commonly used descriptive terms include: pathways, patterns, trajectories, dynamic international profile, and so on (Bell et al., 2003; Jones and Coviello, 2005; Jones et al., 2011; Kuivalainen et al., 2012). In recent years, scholars such as Kuivalainen et al. (2012) have suggested distinguishing the terms and definitions because they might lead to methodological problems as well. This study regards the terms used in the internationalization study as important for the analysis. Thus, these terms need to be further clarified in order to arrive at proper terminology to describe and capture the features of internationalization. In a systematic review of the last two decades of internationalization studies related to the International Entrepreneurship research field, Jones et al. (2011) categorize these studies into two major related themes - pattern and process. Pattern refers to features of the international development progress, while Process refers to the progress of internationalization itself.

\subsubsection{The internationalization process}

The Merriam-Webster dictionary defines process as a series of actions or operations conducted to an end. Pettigrew (1997) defines a process as "a sequence of individual and collective events, actions, and activities unfolding over time in context" (p. 338). Based on these linguistic meanings and extant studies in internationalization, this study regards the internationalization as a process, in which small firms consciously engage in offering products and services across national borders and adapt their operations to 
the international business environment. The internationalization process might consist of a sequence of related actions in the international businesses' development during certain time spans. The end of the process in this context refers to a temporary state of the international business involvement at a given time period along a small firm's development history. The beginning of the process refers to the point when the firm's international involvements take off or (re)occur. The features of the overall internationalization process unfolding could be investigated via certain periods suggested by Kuivalainen et al. (2012). These authors propose to discern an initial period of internationalization from a more stable period of internationalization. From a development angle, their suggestion is relevant and reasonable, because a priority of a firm's international involvement and the level of international knowledge and network of a firm most likely are different during the internationalization process. Thus, taking a development view, this study has a focus on investigating changes and evolving features of the internationalization process in different important periods.

\subsubsection{Behavior pattern and dimensions of motion pattern}

In existing research, the internationalization pattern often refers to features of firms' international expansion or international business involvement (Jones et al., 2011). For identifying and analyzing patterns of internationalization, this study will go further and treat the pattern from two different aspects. One refers to the behavior pattern, which could relate to small firms and their top management team (TMT) taking recurrent responses in certain situations (Jones and Coviello, 2005; Kuivalainen et al., 2012). The other refers to the motion pattern, for capturing how the general course of the internationalization is formed over time. For facilitating an adequate analysis on internationalization, this study differentiates the behavior pattern from the motion pattern, since the behavior pattern is based on actions taken under different rationality rather than firms' motion features during internationalization.

\section{The spatial dimension of motion pattern}

The motion pattern in this study is consistent with existing internationalization studies. The motion pattern relates to general patterns of the firms' international market expansion or contraction. An incremental pattern in the Uppsala model or an instant pattern 
in the born global study are examples of motion patterns. In the existing studies, the major difference among identified (motion) patterns mainly comes from two different dimensions - spatial and temporal (Jones et al., 2011). Some quantitative studies often focus more on the spatial dimension of internationalization. The spatial dimension is commonly measured by the degree of internationalization (DOI) (Papadopoulos and Martín Martín, 2010; Matanda and Ndubisi, 2011). There are two sub-dimensions scope and scale - which often appear in the spatial dimension of internationalization (Jones et al., 2011). In extant research, the scope commonly refers to how diversified or dispersed the international markets a firm entered are. The scale refers to what extent or intensity a firm is involved in the internationalization (Zahra, 2005). Since these two sub-dimensions are highly relevant components to the spatial dimension of the motion pattern, this study also adopts the terms scope and scale from extant research.

\section{The temporal dimension of motion pattern}

Since the instant type of internationalization was identified in the 1990s, for example, "global start-ups", "international new ventures" (INV) and "born global" (BG), the time dimension has received a great deal of attention (Jones et al., 2011; Casillas and Acedo, 2013). The time or temporal dimension has a focus on the speed of internationalization (Oviatt and McDougall, 2005; Acedo and Jones, 2007). For example, BG and INV have emphasis on how fast a firm can achieve a certain percentage of turnover from foreign markets. However, the research with a focus on speed seldom gives fair attention to the scope dimension at the same time. Taking these existing limitations into consideration, this study investigates both the temporal dimension and the two sub-dimensions of the spatial dimension.

\subsection{Identified patterns in extant research}

Since the 1970s, three major patterns have been identified in internationalization studies: the incremental pattern (e.g., U-model), the instant pattern (e.g., BG and INVs) and the big leap pattern (e.g., $B a G$ ), based on the features of their corresponding motion patterns. The major difference in these patterns emphasized in the existing studies is along the temporal or time dimension. Compared to the rapid motion patterns (e.g., 
BG and INVs) identified in the late 1990s and 2000s, the incremental pattern was dominant in internationalization process studies through the 1970s to the 1990s (Andersen, 1993; Coviello and McAuley, 1999; Moen and Servais, 2002; Acedo and Casillas, 2007). These earlier dominant models from the 1970s and 1980s, such as the previously mentioned U-model presented by Johanson and Wiedersheim-Paul (1975) and several different versions of innovation-related models (I-models) presented by Cavusgil (1984) and Reid (1983), are well known for their incremental features to explain firms' motions during internationalization. Since the U-model is the most influential model with the incremental features, this study mainly uses the U-model as a representative for such features.

\subsubsection{Incremental features}

The U-model shows a step-wise motion pattern in the firms' outward international expansion (Andersen, 1993). It regards firms' international expansion as an experiential learning process (Johanson and Wiedersheim-Paul, 1975; Johanson and Vahlne, 2009). In this model, there are two types of step-wise change patterns (Andersen, 1993). One relates to the scope dimension of the internationalization. According to the U-model, firms will establish themselves in their domestic market first. Then, they would enter markets with low psychic distance, which are close to firms' domestic market in a cultural, institutional and economic context. For example, many Swedish firms tend to enter the German market or that of a Nordic neighbor before entering other foreign markets. Gradually, firms might expand their operations to those markets with a higher psychic distance, such a Swedish firm entering the French or US markets. Psychic distance was an important concept in the U-model. It refers to "factors preventing or disturbing the flow of information between potential or actual suppliers and customers" (Johanson and Wiedersheim-Paul, 1975, p. 308). Those factors include differences in language, culture, political system and levels of industrial development. High psychic distance often implies a higher unfamiliarity between two countries. Unfamiliarity causes a higher perceived risk (uncertainty). Thus, firms would prefer to enter low psychic distance markets in order to avoid potential extra cost brought on by those uncertainties and risks. The second type of incremental change reflects on firms' resource commitment change in a specific market. The U-model conceptualizes commitment in a foreign market as different types of establishment modes in the foreign market. A large 
resource commitment implies more direct involvement in foreign markets' operation for increased control over assets involved in overseas operations and activities, while bearing a higher financial risk. Therefore, there are step-wise features in the U-model. Such features reflect decisions and actions in incremental commitment in a foreign market as a gradually established chain, supported by increasing experiential knowledge in the specific market (Johanson and Wiedersheim-Paul, 1975). The U-model explains and projects motion change based on uncertainty avoidance (Figueira-de Lemos et al., 2011) along the spatial dimension. According to the U-model, firms would work step-by-step to accumulate experience and knowledge in domestic and low psychic distance markets before they move to high psychic distance markets. In addition, in each market, firms would start from a low commitment type of operation and gradually change their commitment based on increasing local market knowledge.

Despite its influential role in the internationalization research field, contextual changes, such as increasing MNEs' international operations and a massive ICT diffusion in the 1990s, meant that the U-model faced more challenges after the late 1990s. One of commonly referred to drawback was the deterministic nature of the incremental model (Moen and Servais, 2002; Freeman et al., 2010; Sandulli et al., 2012). In addition, it was more relevant to large, early internationalized manufacturing companies. There have been a few MNEs which have internationalized since the beginning of the 20th century. Johanson and Mattsson (1988) identified them as the early starters in internationalization. Furthermore, the model has neglected external elements, such as embedded networks, and other internal elements, such as entrepreneurial opportunity seeking, which might moderate firms' uncertainty avoidance tendency during internationalization.

\subsubsection{Swift feature}

In the beginning of the 1990s, scholars began to identify another type of internationalization pattern - an instant or rapid pattern of internationalization. This type of pattern is associated with studies of a new venture type, termed the International New Venture (INV) by McDougall et al. (1994), and a rapid type of internationalization named "born global" (BG) by McKinsey \& Co. INV refers to a firm that "from inception, seeks to derive significant competitive advantage from the use of resources and 


\section{THEORETICAL FRAME}

the sale of outputs in multiple countries" (McDougall et al., 1994, p. 470). Based on the scale of international operation involvement and the number of foreign markets involved, McDougall et al. (1994) further differentiate INV into four subgroups:

1. Export or import start-up (International market markers sub-group)

2. Multinational trader (International market markers sub-group)

3. Geographically-focused start-ups (small scope focus)

4. Global start-ups

Trading companies have relatively few coordination tasks in value chain activities. Therefore, only the global start-up firms can differentiate themselves from the incremental motion pattern in the three dimensions of speed, scope and scale.

The term born global has various definitions. BG was first named by McKinsey \& Co. based on survey studies of samples from Australian exporters (Rasmussen and Madsen, 2002). A more formal identification of BG came from scholars such as Knight and Cavusgil (1996), who defined technology-oriented firms, which have been involved in international business and operated in international markets from the earliest days of their establishment. Although there is no agreed-upon or consistent criteria on how fast (e.g., two, three or five years) a firm could achieve a certain percentage of overseas turnover (e.g., more than $25 \%$ or $75 \%$ ) to be categorized as BG (Rasmussen and Madsen, 2002; Cesinger et al., 2012), instant or rapid speed is a clear feature of both INV and BG (Madsen, 2013). Some scholars further regard BG as one of the special groups within INV (Zahra, 2005).

Although there are also some differences between INV and BG regarding whether firms have an intention to enter international markets earlier (Jones et al., 2011), a common feature in INV and BG is that they do not follow the step-wise type of motion from the U-model. Different from the earlier identified incremental pattern, INV and BG might enter international markets directly or concurrently with the domestic market. From the temporal dimension, they are commonly recognized as faster patterns compared to the U-model. 
The big leap pattern is the third pattern identified in the research. Bell et al. (2001) labeled this pattern, which reflects some firms' sudden commitment to internationalization after operating in their domestic markets for an extended period of time. A sudden commitment is often triggered by some critical incidents and events such as ownership change, client followership or mergers and acquisitions (M \& A) (Bell et al., 2001, 2003). The big leap pattern mixes features of incremental and instant patterns. Before the "leap" triggered by a few critical events, firms follow the incremental pattern; after that, firms follow the instant pattern.

\subsubsection{Comparison of identified patterns}

Comparing the features of the three patterns described above based on their motion pattern, the major difference is on the temporal dimension. The motion pattern with incremental features was identified during the 1970s and 1980s. At that time, information search cost was still high and e-business did not yet exist. The incremental pattern, especially in the U-model, was identified based on the development progress of four big manufacturing MNEs (Johanson and Vahlne, 1977), which have been engaged in different types of international operations over the years. Because the U-model focused on the international development of these firms rather than the bigger context in which the firms were operating, the speed-related temporal dimension was not a primary focus of the model. Although there is no clear evidence showing the length of time lag between the stages, a slow pace movement was implicitly reflected from step-wise changes in the both scope and scale dimensions of firms' internationalization. Furthermore, the U-model also implied a unidirectional motion in the outward expansion of internationalization.

INV and BG, on the other hand, show a swift feature. Both INV and GB have more focus on the beginning phase of a small firm's internationalization. During this phase, firms get involved in international business rather quickly (no more than five years). Therefore, INV and GB have more emphasis on the temporal dimension. From the scope dimension, one of the key concepts in the U-model's psychic distance was not on the focus. The role of psychic distance, which was highlighted in the U-model as an origin of perceived risk (uncertainty), has been downplayed in INV and BG studies. This change might attribute to a comparable short period of focus in the instant pat- 


\section{THEORETICAL FRAME}

tern. Thus, the instant pattern has not differentiated a micro-sequence of market entry and ongoing changes in different foreign markets after immediate entry. An alternative argument is that the psychic distance has become less influential in today's world than in the past, such as in the 1970s. Context changes, for example the massive diffusion of ICT, the Internet, e-business (Loane, 2005) and an increase in firms' internationally connected networks (Johanson and Mattsson, 1988; Johanson and Vahlne, 2009), has made psychic distance shorter than ever before. Most instant pattern studies have a primary focus on factors, which enabled and triggered firms' instant internationalization in their early life. Relevant contexts, in which small firms start-up, are heavily addressed. However, a noticeable drawback in many INV and BG studies is that the research only focuses in an initial period of firms' internationalization, rather than capturing a longer continuous period of overall motion features during the internationalization process.

The big leap pattern has mixed features of both the incremental and the instant motion patterns. It also focuses on a relatively short period. A comparison of the three motion patterns in the spatial and temporal dimensions is shown in Table 2.1. From the comparison of the three major motion patterns identified from previous studies (see Table 2.1), it shows that since the 1990s, the temporal features in the motion pattern have gained focus. Studies with a temporal focus often paid attention to special periods or influences of critical incidents during internationalization. The internationalization process began to speed up during those special episodes and short critical period. The incremental pattern in the studies of the 1970s and 1980s did not pay attention to the temporal dimension under special contextual conditions in such periods. Compared to the earlier incremental patterns, the intensity of commitment and the scale of involvement also began to diverge in the instant and big leap patterns (see Table 2.1). Overall, all patterns identified after the 1990s are more temporal in focus and contextually relevant, while only covering a short period of focus.

From the 1990s to the 2000s, other motion patterns have also been identified, such as de-internationalization and re-internationalization (Pauwels and Matthyssens, 1999; Vissak, 2003; Welch and Welch, 2009). However, the three major motion patterns reviewed in this chapter are among the most representative. 
Table 2.1: Comparison of the identified three representative motion patterns

\begin{tabular}{|c|c|c|c|}
\hline Motion patterns & $\begin{array}{l}\text { Incremental } \\
\text { (e.g. U-model) }\end{array}$ & $\begin{array}{l}\text { Instant } \\
\text { (e.g. INV and BG) }\end{array}$ & $\begin{array}{l}\text { Big leap } \\
\text { (e.g. Born-again global) }\end{array}$ \\
\hline $\begin{array}{l}\text { Time of } \\
\text { identification }\end{array}$ & $1970 \mathrm{~s}$ & $1990 \mathrm{~s}$ & Late $1990 \mathrm{~s}$ \\
\hline Tempo scope focus & $\begin{array}{l}\text { Relatively long term } \\
\text { along biographic history }\end{array}$ & $\begin{array}{l}\text { Short term in the early } \\
\text { period of firms' life }\end{array}$ & $\begin{array}{l}\text { Relative short term in } \\
\text { critical events and episodes }\end{array}$ \\
\hline Tempo traits & $\begin{array}{l}\text { Incremental outward } \\
\text { expansion } \\
\text { No clear criteria in time }\end{array}$ & $\begin{array}{l}\text { Accelerate from beginning } \\
\text { Including inward and } \\
\text { outward involvement }\end{array}$ & $\begin{array}{l}\text { Accelerate after critical } \\
\text { events or episodes }\end{array}$ \\
\hline \multicolumn{4}{|l|}{ Spatial dimensions } \\
\hline $\begin{array}{l}\text { 1. Scope } \\
\text { (Diversity of entered } \\
\text { markets) }\end{array}$ & $\begin{array}{l}\text { From close to far in } \\
\text { "psychic distance" }\end{array}$ & $\begin{array}{l}\text { Scope depending on } \\
\text { previous and new } \\
\text { established networks and } \\
\text { traits of product or service }\end{array}$ & $\begin{array}{l}\text { Scope depending on } \\
\text { emergent networks }\end{array}$ \\
\hline $\begin{array}{l}\text { 2. Scale } \\
\text { (Intensity of recourse } \\
\text { commitment and } \\
\text { operational } \\
\text { involvement) }\end{array}$ & $\begin{array}{l}\text { Incremental increased } \\
\text { commitment and } \\
\text { involvement }\end{array}$ & $\begin{array}{l}\text { Relatively large scale in } \\
\text { terms of overseas turnover } \\
(>25 \%) \text {, while no common } \\
\text { pattern in operational } \\
\text { involvement }\end{array}$ & - \\
\hline
\end{tabular}

\subsection{Perspectives and assumptions}

Pattern recognition in internationalization studies reflects a few different perspectives. Although there are four to five major perspectives or approaches in internationalization studies (Ruzzier et al., 2006; McAuley, 2010), three of them are explicitly linked with explanations of the internationalization process. They are the behavioral learning perspective (Johanson and Wiedersheim-Paul, 1975), the network perspective (Johanson and Mattsson, 1987, 1988; Johanson and Vahlne, 2009) and the international entrepreneurship perspective (Fletcher, 2004; Jones and Coviello, 2005; Andersson, 2011).

\subsubsection{Learning perspective}

The incremental pattern of internationalization was explained by the behavioral learning perspective based on an earlier organizational study from Cyert and March (1963). Johanson and Wiedersheim-Paul (1975) were mainly inspired by the uncertainty avoidance and organizational learning concepts. The theory regards learning as a continuous adaptive behavior over time based on firms' accumulated past experience (Cyert and 
March, 1963). Stage-type models (e.g., the U-model), or so-called incremental types of internationalization, focus on how firms cope with the different types of risks (uncertainty) associated with doing business in foreign markets, especially in high psychic distance markets. The basic assumption of the incremental type of model takes a managerial approach. It assumes that doing business outside a home country is costly and has a higher risk (uncertainty) (Eriksson et al., 1997). Because of difference in culture, institutional settings and geographic distance, a firm will incur additional social and economic cost termed as "liability of foreignness" (Eden and Miller, 2004, p. 196). In U-model, risk is regarded as a consequence of an uncertainty set (Figueira-de Lemos et al., 2011). The risk formula in the $\mathrm{U}$-model is $\mathrm{R} i=\mathrm{C} i^{*} \mathrm{U} i$. The formula reflects the existing market risk situation as determined by the product function of the existing market commitment $(\mathrm{C} i)$, and the existing market uncertainty $(\mathrm{U} i)$. ( $i$ ) refers to a certain international market (Figueira-de Lemos et al., 2011). From the learning perspective, such risks could only be effectively handled and managed by accumulating experiential knowledge via operating in host countries (Johanson and Vahlne, 1977). Acquiring experiential knowledge takes time. Therefore, from the behavioral learning perspective, the incremental pattern of resource commitment in a foreign market, and low to high psychic distance foreign markets reflects firms' attitude on uncertainty avoidance, which, in turn, mirrors firms' managerial rationality.

\subsubsection{Network perspective}

To complement the previous stage-type model (e.g., U-model), which is very much focused on firms' internal resources and experience in internationalization, Johanson and Mattsson $(1987,1988)$ take a network approach to explain firms' internationalization process. The network approach was developed from a branch of research in industrial marketing and international business, the so-called Industrial Marketing and Purchasing (IMP) group (Johanson and Mattsson, 1987; Ford, 2001). This approach was inspired by earlier studies in organization theory, such as the resource dependence (Pfeffer and Salancik, 2003) and the social exchange (Levine and White, 1961). Those theories are mainly take external perspectives to study inter-organizational relationships. They reason that resource dependence and social exchange actions lead to interdependence among inter-organizations. The essential idea behind the interdependence is that organizational activities and outcomes are influenced by firms' or organizations' embedded 
context and environment (Pfeffer and Salancik, 2003, p. 39). It assumes that, in most situations, firms rely on complementary resources and competence controlled by other firms or organizations to fulfill their tasks and goals effectively. From the network perspective, the interdependence regards firms which are involved in different yet related value chain activities as an interdependent industrial system (Håkansson, 1982). This system consists of networks of relationships among firms (Johanson and Mattsson, 1987). From the network perspective, the interaction of relationships among firms forms the main market activities. Therefore, firms' internationalization was treated as one of outcomes of an accumulative international business relationship development process.

Different from the behavioral learning perspective, the embeddedness and the exchange angles have a focus on "inter-" rather than "intra-" organizational relations and behavior. The network approach treats the relationship networks as the market, and highlights the impact of firms' external relations on internationalization. According to this approach, some firms which are in a highly internationalized network (referring to the market) will become internationalized faster than others due to their improving position within such a network and their knowledge about the network. The indirectly or directly internationally connected firms labeled as the late starters and the international among others are two types of cases, which might speed up internationalization, due to firms' positions in such internationally linked networks (Johanson and Mattsson, 1988). Johanson and Vahlne (2009) updated the U-model by using the same model framework with the new network theory content, and formed the network dynamic model (U-network model). The old model framework keeps the importance of knowledge and experience in behavioral learning theory, while the new network content emphasizes the "relationship-specific knowledge" (Johanson and Mattsson, 1988, p. 1146) within firms' business networks. In the updated U-network model, knowledge was interpreted as important knowledge about partners and relationships with partners in the international business-related network. Such knowledge helps the firms to change their positions in the network.

Uncertainty avoidance is still an important implicit assumption in the U-network model. However, a root of uncertainty has shifted from the specific psychic distance of markets to an outsidership of internationally connected networks. It argues that trust is a key 
mechanism to counter risk (uncertainty) from opportunism. Therefore, trust-building is vital, while taking time to improve knowledge and a firm's position in the network. Internationalization from the network perspective is regarded as a specific relationship development process (Johanson and Vahlne, 2009). In addition to learning, trustbuilding for so-called insidership in a relevant network is highlighted.

\subsubsection{Entrepreneurship perspective}

The third major perspective on the internationalization pattern is mainly from the entrepreneurship field, with a connection to the resource-based review. The instant pattern is associated with this perspective, and has more of a focus on the firms' startup period. This perspective regards firms' international expansion as an entrepreneurial opportunity identification process by internationally-oriented entrepreneurs (Jones and Coviello, 2005; Acedo and Casillas, 2007). Since the late 1980s and early 1990s, when scholars such as McDougall et al. (1994) and Oviatt and McDougall (1994) started to have a focus on INVs, the entrepreneurial perspective has been largely adopted. Scholars found that some young, high-tech-based start-up companies intentionally built their advantage by sales to different countries right after their establishment (Coviello et al., 2011). This phenomenon could not be explained by previous traditional theories such as the U-model. The INV theory emphasizes an entrepreneurial component in the internationalization process. Characteristics, personal network and networking ability, past experience, visions and strategic choice of small firms' founders and TMT are often highlighted as important components for opportunity identification (Ardichvili et al., 2003; Ellis, 2011). Based on a few key themes suggested by Chetty and CampbellHunt (2004), Table 2.2 illustrates an overview of three major perspectives with their underpinning motion mechanisms, which influence firms' motion patterns.

\subsection{Limitations of main theoretical interpreta- tions in emerging markets context}

Based on the above discussions, one can get an overview of the three major perspectives in existing internationalization studies in Section 2.3. The overview further shows that 
Table 2.2: Interpretations of internationalization from three perspectives

\begin{tabular}{|c|c|c|c|}
\hline Perspectives & Behavior learning & Network & Entrepreneurial \\
\hline Focus & Internal focus & $\begin{array}{l}\text { External focus on change } \\
\text { in business relationship }\end{array}$ & Internal focus \\
\hline Unit of analysis & Firm level & $\begin{array}{l}\text { Firm level } \\
\text { Network level }\end{array}$ & $\begin{array}{c}\text { Individual level (TMT); } \\
\text { firm level }\end{array}$ \\
\hline Motion patterns & $\begin{array}{l}\text { Incremental } \\
\text { (e.g. U-model) }\end{array}$ & $\begin{array}{c}\text { Leap } \\
\text { (e.g. Client followship) }\end{array}$ & $\begin{array}{c}\text { Instant } \\
\text { (e.g. INV and BG) }\end{array}$ \\
\hline $\begin{array}{l}\text { Timing } \\
\text { (from early life) }\end{array}$ & $\begin{array}{l}\text { No } \\
\text { Need to build up } \\
\text { resources and experience } \\
\text { in domestic market }\end{array}$ & $\begin{array}{c}\text { Depends } \\
\text { Timing of establishment } \\
\text { of firms' relevant } \\
\text { networks } \\
\text { (e.g. Client followship) }\end{array}$ & $\begin{array}{c}\text { Yes } \\
\text { Based on traits of } \\
\text { productsand service, } \\
\text { TMT's strategic choice, } \\
\text { previous experience and } \\
\text { resources }\end{array}$ \\
\hline $\begin{array}{l}\text { Sequence of entry or } \\
\text { control mode }\end{array}$ & $\begin{array}{l}\text { From low to high level } \\
\text { control mode }\end{array}$ & $\begin{array}{l}\text { Depends on partners in } \\
\text { firm's networks }\end{array}$ & Various \\
\hline Sustainability & $\begin{array}{c}\text { From low to high } \\
\text { Depends on feedback } \\
\text { from learning. Basically } \\
\text { in unilinear }\end{array}$ & $\begin{array}{c}\text { Depend on change of } \\
\text { knowledge and relations } \\
\text { with actors in relevant } \\
\text { networks }\end{array}$ & $\begin{array}{c}\text { Relatively high in early } \\
\text { period } \\
\text { N/A on long-term } \\
\text { sustainability }\end{array}$ \\
\hline $\begin{array}{l}\text { Influence of domestic } \\
\text { environment context }\end{array}$ & $\begin{array}{c}\text { Starting place for learning, } \\
\text { resource and knowledge } \\
\text { accumulation }\end{array}$ & $\begin{array}{c}\text { Firms' domestic networks } \\
\text { are internationalized }\end{array}$ & $\begin{array}{c}\text { Indifference to foreign } \\
\text { markets (e.g. INV) }\end{array}$ \\
\hline & & Yes & Yes \\
\hline $\begin{array}{l}\text { Leverage of external } \\
\text { resources }\end{array}$ & N/A & Form relevant networks & $\begin{array}{l}\text { Access knowledge and } \\
\text { resources from existing and } \\
\text { newly established networks }\end{array}$ \\
\hline
\end{tabular}




\section{THEORETICAL FRAME}

the difference among the three major internationalization theories lies in their different foci and angles of investigation. All of them have been supported by their observed empirical evidence under different investigation contexts. They are also theoretically grounded from organizational theory and the entrepreneurship literature. The U-model is theorized on the basis of an intra-organizational focus. It is largely influenced by the behavioral learning theory from Cyert and March (1963), and the model has a dynamic feature. The network approach extends the stimulus of internationalization from an intra-organizational focus to a multilateral influence. The entrepreneurial approach sheds light on the importance of firms' entrepreneurial actions and the conscious choices of firms' TMT. However, although these three major theories have contributed to a general understanding of the internationalization process of a firm, each of them could hardly stand alone to offer a plausible explanation regarding possible changes in the motion pattern and the behavior pattern during the internationalization process toward emerging markets.

The behavioral learning perspective has more focus on the firm's own foreign market learning process. From this perspective, the internationalization was treated as a process of overcoming liability of foreignness via accumulating the important experiential knowledge in specific markets. Acquiring such experiential knowledge in foreign market takes time. Therefore, the internationalization appears somewhat as an incremental motion pattern for avoiding potential risk in hasty resource commitment (Figueira-de Lemos et al., 2011). Following this logic, small Swedish firms would hardly appear to the EMs outside of Europe before they could establish themselves in more familiar markets. In addition, even if they finally make their way to those big EMs, it is more likely for firms to use a low commitment mode from the beginning. One could argue that despite the importance of the learning and the experiential knowledge in firms' foreign market exploration, its entire internal focus makes the U-model questionable. The behavioral learning perspective in the U-model largely neglects possible influence from firms' external relationships, which might moderate the accumulation process of experiential knowledge.

The network approach, on the other hand, still incorporates the learning concept. However, it has switched focus entirely to external relationships and firms' positions within their relevant business networks. It puts one of the environmental influences, business 
networks, in a dominant position and considers that what happens in a relationship (Johanson and Vahlne, 2009). Knowledge about network actors and trust-building among actors play an important role in overcoming liability of outsidership. The internationalization of firms was treated as a by-product of firms' improved position in their relevant network(s) (Schweizer et al., 2010). From this perspective, the firms will enter the EMs once other actors in the firms' network appear in those markets. Since the market in this approach refers to the relationship of the network, there is no concrete market or country boundary for firms to enter. Thus, changes in the sequence of entry and the entry mode mean the loss of a sound grounds for discussion. In sum, it shows how the network perspective has a strong external relationship focus. The network perspective offers partial explanations for some small firms, which are well connected in MNEs' value chain; examples include sub-contractors or sub-suppliers of MNEs. However, one should be cautious that the network approach emphasizes the influence from firms' embedded business and industrial networks so much as to neglect the possible role of firms as an autonomous unit acting on a real market. Therefore, the network perspective could only be held up to a point that the network relations offer an important external resource for small firms and have an important influence on the internationalization of small firms.

The entrepreneurship perspective is also based an internal focus. It has an emphasis on firms and their TMT's past international experience, knowledge, networking capability and strategic choice in discovering and exploiting opportunities across borders (McAuley, 2010; Rialp et al., 2005; Moen, 2002). Resource, knowledge and capability at both an individual level (e.g. entrepreneurs) and an organizational level (e.g. the small firms) are highlighted. Network in this perspective is treated as a dyadic relationship of ties and personal ties to TMT. Network is regarded as part of firms' potential external resources or even social capital (Melén, 2009) for the private good. Common criticisms of this perspective include its narrow focus and the ambiguity of the international entrepreneurship concept (Vissak, 2003). It overlooks, for example, the changes after initial export or the international business commitment (Rialp et al., 2005; Hashai, 2011). Keupp and Gassmann (2009) reviewed 179 articles about international entrepreneurship studies published in 16 journals from 1994 to 2007. They found that many International Entrepreneurship (IE) studies (nearly $50 \%$ of the selected studies) do not clearly relate to any theoretical foundation. These IE studies, which have been 
grounded in theory, have an imbalanced focus on IB theory. Hence, there is a lack of theory integration between the traditional international business theory (IB) and the entrepreneurship theory. In addition, scholars also point out that the industrial sector settings, such as industrial traits, are often associated with early internationalization. Knowledge-intensive sectors, such as IT and bio-tech, often appear in early IE studies (Rialp et al., 2005). Therefore, whether the earlier and instant internationalization pattern should be attributed to some specific characteristics of industries or attributed to firms and their TMT's entrepreneurship across different industries is debatable. As Keupp and Gassmann (2009) commented, IE needs a better balanced knowledge base, one which covers both IB and Entrepreneurship. Otherwise, it is difficult to differentiate IE from either general IB or entrepreneurship. To this point, it is clear that all three of the reviewed perspectives above have their own inherited biases, i.e. either a strong internal or external focus.

\subsection{Risk (uncertainty) versus opportunity - a common ground for discussion}

With an awareness of both merits and limitations from each of the three major perspectives in Section 2.4, this study intends to take the important elements from those different perspectives in order to gauge and map various internationalization motion patterns. Davis (1971) and Alvesson and Karreman (2012) wisely suggested that in the social science studies, a better way to critically discuss existing research and make a further contribution to theory is to probe the underpinning assumptions of existing theories. It could reason that such underpinning assumptions set the constraints of a theory. Thus, examining the assumptions could help researchers to spot these constraints and try to avoid them in further theory development. Based on a review of the current literature, this study further discovers that despite a difference in endogenic versus exogenic focus, the essentials, which explain the different patterns of the internationalization process from the three different perspectives, lay on how firms treat or react to two fundamental elements related to conducting business activities in the international markets - risk (uncertainty) versus opportunity.

Risk (uncertainty) was in a center position in the incremental pattern from the behav- 
ioral learning perspective, however have switched to a marginal position in explaining the instant pattern. In the early phase of IE study, McDougall and Oviatt (2000) had put risk-seeking behavior as one of key features for international entrepreneurship. Five years later, they shifted their emphasis from Entrepreneurship Orientation (EO), which consists of innovative, proactive, and risk-seeking behavior, to the opportunity exploration (Oviatt and McDougall, 2005). In the instant pattern, firms' attitudes regarding risk seem quite different from the incremental pattern, because firms' fast-paced motion in the internationalization could partially reflect their risk-tolerant attitudes. Nevertheless, it might also be the case that a cognitive bias of small firms' TMT causes firm's risk-tolerant attitudes and actions. The cognitive bias refers to people's overconfidence or having an illusion of control (Liesch et al., 2011). Therefore, current IE researchers tend to have more focus on the opportunities concept rather than the risk attitude. In sum, the discussion of relevant literature shows that the internationalization of a firm incorporates both risk (uncertainty) and opportunity in pursuing economic benefits in different foreign markets. In fact, the reason to take and bear such risk (uncertainty) is to find more opportunities for better paybacks (George et al., 2006). For this reason, it is hard to discuss potential gains exclusively without dealing with their associated potential costs. Thus, one should regard the perceived risk (uncertainty) and the perceived opportunity during internationalization as an intertwined pair of concepts.

\subsubsection{Influence of risk (uncertainty) in internationaliza- tion}

Liesch et al. (2011) made a critical review of the role of risk and uncertainty in both classic internationalization studies and recent international entrepreneurship studies. They found that different from classic economics, in which risk and certainty are differentiated based on whether the probability distributions of consequence on actions are calculable, risk and uncertainty in both internationalization and IE studies are often treated interchangeably, as if they were one term. In the classic internationalization studies, perceived high risk and uncertainty in unfamiliar foreign markets are associated with extra cost, which might restrict or suppress firms' internationalization processes in two ways. It intimidates small firms' resource commitment in either unfamiliar foreign markets (Figueira-de Lemos et al., 2011) or in international business-related relationship development (Johanson and Vahlne, 2009; Schweizer et al., 2010). The U-model, 


\section{THEORETICAL FRAME}

for example, points to the higher perceived risk and uncertainty in large psychic distant markets. The high perceived risk leads to the need to exercise greater caution in using high resource demanding types of entry modes and even in choosing such markets. Risk perception and coping with the tacit risk and uncertainty of a firm are commonly investigated at the firm level in the classic internationalization studies.

Extant IE studies, on the other hand, are more from the individual level of entrepreneurs' perception and actions and discuss a general attitude toward uncertainty and risk in internationalization. Uncertainty from this perspective is often interpreted as entrepreneurs' confidence in their judgment or expectation, while risk refers to the possible consequences or loss of the actions (Liesch et al., 2011). There has been a recent change in IE studies. In the earlier IE studies, risk-seeking was one of the characteristics or latent confirmatory variables of firms' entrepreneurial orientation (EO) (Covin and Wales, 2012). In more recent IE studies, there has been a shift from actively risk seeking to inactively risk bearing, or just tolerating risk no matter what, when firms start to internationalize. As a result, more recent studies have reduced their focus on the impact of entrepreneurs' attitudes on the perceived risk and uncertainty in firms' internationalization (McDougall and Oviatt, 2000; Oviatt and McDougall, 2005). Accordingly, current IE studies have more focus on the potential gain in terms of opportunity rather than the loss in terms of risk and uncertainty in the internationalization.

The context of this study is in the internationalization of small businesses. In this context, small businesses are more likely to face a lower internal uncertainty and a higher external uncertainty (Storey and Greene, 2010), compared with large MNEs. The internal uncertainty can be understood as preventable internal risks within small firms as categorized by Kaplan and Mikes (2012). According to Kaplan and Mikes (2012), there are three categories of risks in operating an organization and a firm preventable risks, strategy risks and external risks. The preventable risk is from internal organization and is controllable. Due to its small size, the preventable internal risks of a small firm are relatively low. Thus, this study mainly considers the other two types of risks associated with the internationalization process. Consistent with the terms defined by Kaplan and Mikes (2012), strategy risks in this study refer to potential costs in pursuing a higher expected return from operations in foreign markets. Strategy risks are not intrinsically undesirable, because they can be regarded as a potential learning 
cost, which is necessary for the further development of a small firm. External risks refer to risks triggered by unexpected external events and are beyond the control of any firm (Kaplan and Mikes, 2012). This type of risk includes, for example, political risk or an economic crisis. Since it is hard to estimate, such types of external risk can be regarded as external uncertainty (Storey and Greene, 2010). In sum, risks (uncertainty) in the internationalization of a small business context have mixed features from both risk and uncertainty in classical economics terms. There is no clear cut between risk and uncertainty in extant internationalization studies. Hence, risk and uncertainty are used interchangeably in this study as well.

\subsubsection{Influence of opportunity in internationalization}

The role of the opportunity in internationalization has not been explicitly discussed in the behavioral learning and the network approach. The international entrepreneurship perspective, on the other hand, has an increasing focus on the opportunity side (Chandra et al., 2012). Opportunity is one of the key concepts in the entrepreneurship literature (Kirzner, 1999; Ardichvili et al., 2003). Based on a review of different meanings and definitions of opportunity in the literature, Ardichvili et al. (2003) interpret opportunity for a firm. According to them, opportunity should be a positive value related to favorable chance. This study regards value as potential economic benefits or rewards conveyed by firms' capabilities in supporting or facilitating activities for their potential customers' own value creation process.

Two major schools of views in the entrepreneurship literature have paid attention to sources of the opportunity. Both of them are rooted in economics theory. One is from Schumpeterian while the other is from authors like Kirznerian and Misesian from the Austrian School of Economics (Chandra et al., 2009). Although both Schumpeterian's and Kirznerian's view regard an opportunity as appearing from market disequilibrium, their views are very different in terms of sequence. Schumpeterian's view regards opportunities generated by breaking the status quo market equilibrium through firms' and entrepreneurs' innovations, so-called creative destruction, until imitators catch up and bring back market equilibrium (Kirzner, 1999). In the Schumpeterian view, such opportunity is created by actively engaging in different types of innovation such as introducing new products or service, new technology, a new method of production, or 


\section{THEORETICAL FRAME}

creating a new market. Therefore, the opportunities in the Schumpeterian theory come from market disequilibrium generation. Kirznerian's view, on the other hand, is that the opportunities are from firms' and entrepreneurs' different capabilities in spotting or recognizing status quo market disequilibrium (Kirzner, 1999). Those differences are caused by, for example, information asymmetry and differences in the knowledge structure of firms. Therefore, some firms or entrepreneurs could alert and identify that status quo market disequilibrium faster than others, and thus could seize those opportunities for profit. Opportunities in Kirznerian's view begin from a recognition of current disequilibrium in market (Kirzner, 1999).

Furthermore, when assuming that opportunity exists by exogenous changes in the market, such as changes in technology, industry and the preference of customers or changes in politics and institutions, there are two diverging ideas - search versus discovery (Chandra et al., 2009) - regarding whether the opportunity is found or realized. A difference between those two ideas starts from the premise of whether firms or entrepreneurs know what they are searching for. If firms and their TMTs know what they are looking for (in terms of ends and means) and are aware of what do know and do not know, then opportunities could be identified by a more rational and purposeful searching process (Sarasvathy, 2008; Chandra et al., 2009). This is similar to a strategic planning process. Quite often, however, firms and entrepreneurs are not aware of problems or opportunities until they encounter them by chance or during other searching processes for other solutions. Therefore, opportunities are mainly discovered. The discovery process is different from pure luck, because the discovery requires certain skills and knowledge. Those skills and knowledge are associated with firms' and entrepreneurs' prior experience and learning abilities which makes them alert (in Kiznerian terms) (Kirzner, 1999) potential opportunities from the markets or in their immediate networks (Ardichvili et al., 2003). The fast pace of the internationalization pattern theorized and interpreted by IE mainly follows this vein of reasoning. IE regards the internationalization process as "the discovery, enactment, evaluation and exploitation of opportunities across national borders to create future goods and services" (Oviatt and McDougall, 2005, p. 540). 


\subsubsection{Synergy of rationalities behind the different behav- ior patterns}

Different attitudes towards risk aversion and uncertainty avoidance versus opportunity seeking reflect different rationalities underpinning behaviors and actions. Kirzner (1978) differentiates the managerial and entrepreneurial decisions in actualizing a perceived opportunity via means and ends metaphors. According to Kirzner (1978), the managerial decision has an emphasis on the efficient utilization of means to achieve ends, while the entrepreneurial decision has an emphasis on the successful identification of relevant ends and means.

Sarasvathy (2008) makes a further differentiation by demonstrating that there is different emphasis on perceived means and ends among the managerial, strategic and entrepreneurial ways of thinking. For example, from a managerial perspective, the ends, interpreted as goals, are predetermined, while alternative means are also defined. Therefore, firms could use the causal rationality, which allows firms' managers to identify the optimal options among different means to achieve pre-defined goals, such as the most cost efficiency or the fastest response. Through these optimization efforts, firms could reduce a projected risk in an operation. The entrepreneurial perspective is at the other end of the spectrum. From the entrepreneurial perspective, there are imprecise or fuzzy ends, which make a goal negotiable. Sarasvathy (2001) coined the term effectual reasoning to describe a decision process, which starts from a set of given means and allows ends to emerge over time. The strategic perspective falls somewhere in between. Firms start from pre-defined goals but they allow new means to emerge. This type of behavior could correspond to the planned and the emerging strategies in Mintzberg's theory (Mintzberg and Waters, 1982). Sarasvathy (2008) regards the strategic planning process as creative causal reasoning for achieving pre-determined goals. Different from having a goal as a starting point, Sarasvathy's effectual reasoning starts from three categorized means:

1. Who and what kind of firms they are - traits, preferences and abilities

2. What they know - knowledge, expertise, and experience

3. Whom they know - their social, professional and business networks 
Based on those means in the status quo stage, a firm or an entrepreneur starts an opportunity discovery or seeking process, which leads to various ends. Typologies used in Kirzner (1978) and Sarasvathy (2008) are suitable for this study, because they are helpful in the differentiation of firms' behaviors based on the rationality of their actions. Therefore, this study adopts categories from Sarasvathy (2008) to differentiate firms' behavior patterns in the EMs' context, which has a perceived high risk (uncertainty). The differentiation is based on how firms interact with means and ends during the internationalization, as shown in Table 2.3. A summary of firms' projected preferences and attitudes regarding risk and opportunity under each behavior pattern is found in the last row of Table 2.3 .

Table 2.3: Differences among the three behavior patterns Adapted from Sarasvathy $(2001,2008)$

\begin{tabular}{|llll|}
\hline & Managerial & Strategic & Entrepreneurial \\
\hline $\begin{array}{l}\text { Means } \\
\text { (resources and methods) }\end{array}$ & Planned & Planned and generated & $\begin{array}{l}\text { *Starting point } \\
\text { (identified in current stage) }\end{array}$ \\
\hline Ends (goals) & $\begin{array}{l}\text { *Starting point } \\
\text { (predefined) }\end{array}$ & $\begin{array}{l}\text { *Starting point } \\
\text { (basically predefined) }\end{array}$ & Negotiable \& emerged \\
\hline $\begin{array}{l}\text { Rationalization } \\
\text { process }\end{array}$ & Causal reasoning & Creative causal reasoning & Effectual reasoning \\
\hline $\begin{array}{l}\text { Preference under } \\
\text { uncertainty }\end{array}$ & Risk aversion & Risk aversion & Opportunity seeking \\
\hline
\end{tabular}

\subsection{Sources of perceived risk versus perceived opportunity in the EM context}

As discussed in Section 1.2, the EM context implies two distinguishing features at the same time - perceived high risk versus perceived high opportunity. The potential sources and proxies of these two features have been discussed in the internationalization field for many years. Distance is one of the key concepts, which is frequently associated with perceived risk (uncertainty) in international business (Zaheer et al., 2012). 


\subsubsection{The role of psychic distance in the perceived risk}

In international business studies, distance is a commonly used metaphorical term used to depict differences and dissimilarities between host and home markets (Håkanson and Ambos, 2010). Compared to local companies, differences between host and home countries of foreign companies often create extra cost in firms' overseas operations, especially for small firms. Thus, one of essential issues in international management is to manage different perceived distances (Zaheer et al., 2012). There are a few wellknown distance concepts in international business studies, such as Cultural Distance, Administrative Distance, Geographic Distance and Economic Distance in the CAGE framework (Ghemawat, 2001); Institutional Distance (Phillips et al., 2009); and the most well-known concept - Psychic Distance (PD) - from the U-model Johanson and Wiedersheim-Paul (1975).

$\mathrm{PD}$ is one of the earliest and the most important distance concepts associated with perceived additional cost in handling risks (uncertainty) in foreign operations. The PD concept originated from Beckerman in 1956 on the study of trade patterns among countries (Johanson and Wiedersheim-Paul, 1975; Håkanson and Ambos, 2010). Beckerman found that economic distance associated with costs (e.g. transportation and tariffs) alone could not explain the trade preferences of countries. The trade preference reveals that countries tend to focus more on trade with their nearby countries than with distant markets. As mentioned earlier, Johanson and Wiedersheim-Paul (1975) developed the psychic distance concept even further and defined it as a set of "factors preventing or disturbing flows of information between firm and market" (Johanson and Wiedersheim-Paul, 1975, p. 308). Higher PD implies a higher cost of acquiring information from and operating in foreign markets. Therefore, there is a higher risk and possible higher cost associated with the liability of foreignness (Eden and Miller, 2004) in high PD markets than in low PD foreign markets.

As the root of perceived risk (uncertainty) in foreign markets, PD is the core concept in the U-model. It has taken a central role since the mid-1950s (Håkanson and Ambos, 2010). However, this concept has diminished in importance in the network approach and International Entrepreneurship (IE) theory. IE researchers in particular believe that PD in its current context is losing ground. Since PD could not explain empiric 


\section{THEORETICAL FRAME}

evidence from INV and BG, it is very rarely mentioned in IE studies. The U-network model, on the other hand, changes focus entirely from the liability of foreignness in the U-model to the liability of outsidership in industrial networks (Johanson and Vahlne, 2009). The U-network model associates firms' perceived additional operating costs in foreign markets with its outsidership of foreign markets related to industrial networks.

Whether PD is still a relevant, or even a useful predictor in its current context, is still debatable. Some scholars argue that despite the increasing international connections in today's world, the PD concept is still relevant (Schweizer et al., 2010; Figueira-de Lemos et al., 2011). Nebus and Chai (2014) emphasize the importance of understanding the influence from the psychic - the social cognitive dimension - of PD. They argue that individual awareness, perception and understanding determine perceived distance, because the basis of PD lays in the heuristic-based process of decision-makers' minds (Evans and Mavondo, 2002). This argument is reasonable, because the subjective aspect of $\mathrm{PD}$ has a large influence on decision-makers. It could even be argued that PD is a particularly relevant indicator in studying the influence of an emerging markets' (EMs) context on small firms' motion and behavior patterns in their internationalization. In the EM entry context, a subjective view of the distance between big emerging markets and more mature markets might be larger than objective indicators. Since PD is a helpful concept in showing small firms and their TMT's preferences in sequences of firms' foreign market entry and resource commitment, it could be an useful indicator to illustrate firms' possible changes in a entry preference guided by risk (uncertainty) reduction or one driven by opportunity.

Furthermore, compared with larger companies, small companies face relatively severe resource constraints (Buckley, 1989) and have less bargaining power (Storey and Greene, 2010). Researchers on the internationalization of small firms point out that liability of smallness adds more difficulty for small companies than dealing with liability of foreignness (Child et al., 2009). In the emerging market context, of all the dimensions of $\mathrm{PD}$, the perceived risk (uncertainty) associated with the institutional difference could be a very important component of PD. In a broader sense, institution refers to the rules of a game, which provide regulative, normative, and cognitive guidance for stability and the meaning of social behavior (Scott, 2002). The institutional distance refers to the "difference or similarity between the regulatory, cognitive and normative 
institutions of two countries" (Eden and Miller, 2004, p. 200). Eden and Miller (2004) argue that the institutional distance increases the risk and extra cost associated with the liability of foreignness. Peng et al. (2008) further emphasize that in the emerging market context, where the formal institution, for example the regulative dimension, is under development, the informal institutional substitute becomes an important support for companies operating in such contexts. For example, the role of the "Guanxi" network - a type of interpersonal network - is highlighted in Chinese daily and business activities for its substitute role of an incomplete formal institution frame (Davies et al., 1995; Xin and Pearce, 1996). Foreign companies, which might lack such informal institutional resources and support, may face a higher cost and risk. It could reason that due to the complexity of the emerging market context, different dimensions of the perceived and objective PD might largely disturb and impede information flows between distant emerging markets and small firms from Sweden. Therefore, PD could create higher perceived obstacles and uncertainty for small firms which want to enter the emerging markets.

\subsubsection{Role of market size in the perceived opportunity}

Contrary to $\mathrm{PD}$, the large market size seems a natural pulling factor, one which motivates firms to enter the EMs. When dealing with outward internationalization, the target market size in foreign countries had a long time be recognized as a counteracted factor of PD (Johanson and Wiedersheim-Paul, 1975). Dow (2000) found that contrary to PD, market size is positively correlated with firms' market selection. Rothaermel (2006) found that international market size weakens the negative effect caused by uncertainty avoidance in foreign market entry. Ellis (2008) even puts the market size as a main driving force, one which influences firms' international expansion, because of its correlation with entrepreneurial opportunity. Among these studies, which examine market size, scholars often use macro economy indicators such as GDP and GDP per capita as a major dimension for evaluation. A study from Sheng and Mullen (2011) shows that the industrial-specific model offers more accurate prediction of the export opportunity in foreign markets than macroeconomic data. Empirical evidence from the software industry also indicates that foreign market size in the specific industry is a strong indicator for the entry decisions of small firms (Ojala and Tyrväinen, 2008; Sinha et al., 2015). In the EM context, extent research shows that the dynamism of emerging 
markets and the future growth potential need to be considered during market evaluation (Sakarya et al., 2007). Thus, this study will first prioritize the industrial level indicator as one of the proxies for perceived opportunity. Second, the study will prioritize a multi-dimensional index, which takes the growth potential and market dynamics into consideration, when the industrial level index is not available.

\subsubsection{Dual serials internationalization mapping}

Inspired by one of the important findings from behavioral economics, this study regards the perceived risk (uncertainty) versus the perceived opportunities as two dynamic variables, which drive or suppress firms' internationalization processes intermittently. The existing research on the internationalization process often treats influence from these two variables separately, as if the internationalization process were consistently driven by either uncertainty avoidance or opportunity seeking. However, behavioral economics studies such as the prospect theory (Kahneman and Tversky, 1979; Tversky and Kahneman, 1992) indicate that decision makers' responses and behavior patterns under uncertainty might change to similar events (George et al., 2006). It subjects to decision makers' reference point of status quo value at a certain time. This study intends to probe the pattern of the internationalization process of the small firms under the EM entry context. The EMs often have a higher perceived risk and opportunity at the same time. The reasoning logic from several theories, such as the prospect theory, fits the investigated theme well. In addition, the empirical pre-study also points to an inverse relation between recent profitability of the firms and their positive attitude toward EMs (see Section .5 of Appendix A-1). Following the reasoning from the prospect theory, firms' decision-makers might be risk tolerant or even risk-seeking in the internationalization, when the decision-makers perceive their firms were under potential loss at status quo. One possible explanation is that when a firm has a negative prospect at the moment, it might give less weight to the possible additional loss, and more weight to the alternative possible opportunity (George et al., 2006; Liesch et al., 2011). When a firm has a positive prospect, it might act in the opposite way and exhibit uncertainty avoidance or risk-aversion. There are also other propositions suggested by the threat-rigidity hypothesis showing contradictory conditions from the prospect theory. However, the key takeaway points from those theories are the dynamics of firms' decision-makers' attitude on a potential loss and gain regarding the 
perceived high risk (uncertainty) of international markets. Therefore, this study uses the risk and the opportunity, two variables side-by-side, to illustrate possible changes in firms' motion patterns and behavior patterns in the internationalization toward the perceived high risk with high opportunity EMs. The study intends to construct and use a dual serials mapping to show the motion features of a firm during its internationalization. Mapping could also directly help to answer the second research question How can evolving patterns of the internationalization of small firms be described and captured?

\subsection{A "fit-based" approach to the internation- alization of small firms}

As discussed in Section 2.4, extant studies often take a dichotomic approach in the internationalization of a firm. Earlier studies had either entirely an internal focus or an external one. However, in small firms' context, it is hardly the case that firms could act either totally autonomously or totally subject to other firms. Thus, to avoid potential bias and to have a balanced view, this study tends to focus on influence from the interaction between the small firm and its contextual environment. With this in mind, the study takes important learning points from the three major perspectives in extant studies and uses a fit-based approach to probe for changes in the internationalization process of small firms.

\subsubsection{Essentials of the "fit-based" approach for an analysis of small firms}

The basic assumptions and rationality to take the fit-based approach come from contingency theory (Drazin and Van de Ven, 1985). This study assumes that the context matters and has a considerable influence on the pattern of small firms' internationalization processes. Compared to the domestic environment of a small firm in the western world, less similar international markets, especially EMs, imply higher risk and cost for small firms to operate in (Ivarsson and Alvstam, 2013). Furthermore, one could reason that small firms' attitudes and perception of risk and opportunities in foreign markets 
might not be static along small firms' development processes. Rather, it is subject to an interaction between a firm and its environment. Therefore, the reference points for decision-making and actions taken under uncertainty might shift, as the prospect theory (Tversky and Kahneman, 1992) or the threat-rigidity hypothesis (George et al., 2006) suggested.

The contingency theory regards a firm as an open system (Scott, 2002) and emphasizes a fit between a firm's strategy and its operational context (Morgan, 2006; Banalieva and Sarathy, 2011). The concept of fit plays a central role in contingency theory. Venkatraman (1989) did a systemic analysis and identified six different perspectives of fit. This study uses the fit as Gestalts perspective from Miller (1981), which takes a multivariate perspective to identify patterns defined as "the degree of internal coherence among a set of theoretical attributes" (Venkatraman, 1989, p. 432). This perspective could incorporate many criterion-free variables, which mitigate the degree of the precise level in each variable (Venkatraman, 1989). Thus, the fit as Gestalts perspective leaves more space for the exploratory purposes of this study.

The environment addresses how no firm coan be self-sufficient and how all firms have to exchange with environment, which offers "stocks of resources" and "sources of information" (Scott, 2002, p. 133). The firm's environment is evolving over time. It is hard to map a small-sized firm's position in evolving multilateral inter-organization networks along its growth path, if one cannot find a reference point from the time when the firm began internationalization. Therefore, this study mainly uses the concept of task environment from Dill (1958) and adopts a dyadic model of the environment. The network approach will be used for a complementary purpose to demonstrate the relationship rather than for mapping motion in a changing network structure.

\subsubsection{Organizational settings}

To gain a better understanding of influences from traits being small in firms' internationalization, this study adapts the basic framework of Leavitt's Diamond Model for Analyzing Management Change (Figure 2.1) from Scott (2002) as a departure point for constructing a primary tentative analytic frame to illustrate different sources of influ- 
ences on small firms' behavior and motion patterns in the internationalization process.

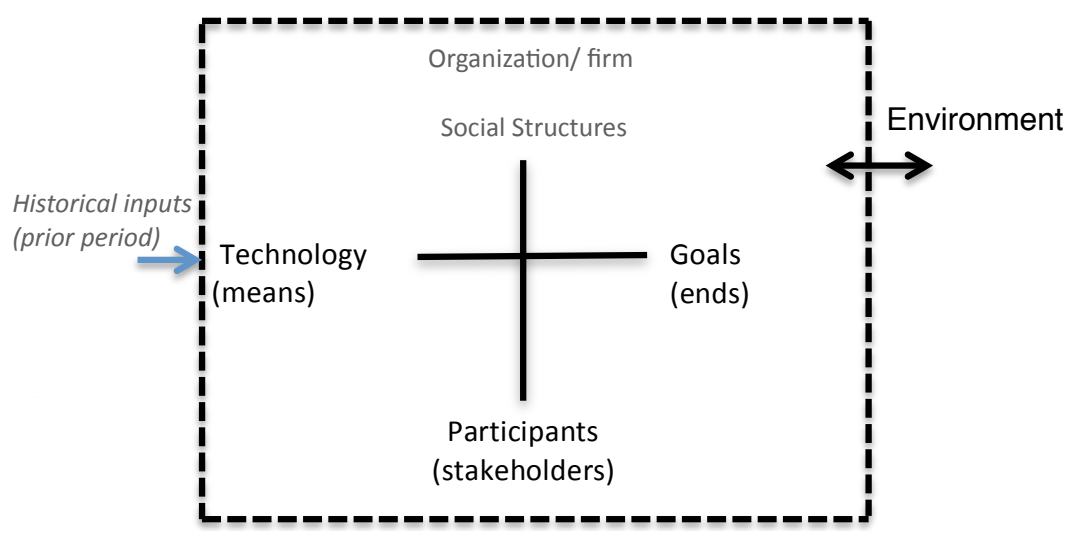

Figure 2.1: Organizational framework Adapted from Scott (2002)

The purpose of adapting the organizational model as a part of the analysis framework is to show the interrelationship between a small firm and its environment for identifying important elements, which influence the internationalization process of small firms. The original model includes four major internal elements within an organization and its external environment. As seen in Figure 2.1, this study adds an additional element as an historical input, which is part of the means creating before as small firm's establishment.

An organization or a firm can be roughly regarded as group of people, who coordinate their behaviors and actions in order to achieve shared goals and to deliver products or services by performing certain tasks (McFarland, 2012). From a resource-based view, in Penrose's theory, for instance, a firm is regarded as a collection of productive resources directed by administrative coordination and authoritative communication (Penrose, 1995). As a profit-based organization, a small firm can be analyzed via organizational elements in Leavitt's Diamond Model for Analyzing Management Change. In Scott's (2002) interpretation of an organization, there are four basic elements (Scott, 2002; Scott and Davis, 2006). Along the vertical axis, participants refers to employees, TMTs and other social actors and stakeholders such as suppliers, main clients, and 


\section{THEORETICAL FRAME}

external consultants who contribute to and derive benefits from the firm (Scott, 2002; McFarland, 2012). Social structure refers to lasting or regularized relations among participants in a firm (Scott, 2002, p. 18). Since the main focus of this study is on the influence between small firms adapting to the international business environment rather than the internal and external social structure of a firm per se, the social structure is not in the focus of this study.

Along the horizontal axis, technology represents tangible and intangible means which can be used to carry out certain tasks or work. Tangible means can be various material inputs, while intangible means can be skills, knowledge and know-how (Scott, 2002; Scott and Davis, 2006). Intangible means are similar to the managerial resource (Penrose, 1995) in the Theory of the Growth of the Firm. The goal in this model refers to the preferred end(s), which firm's stakeholders want to achieve by carrying out certain tasks (Scott, 2002; McFarland, 2012). The goal could be understood as vision and mission in strategic management. However, it can vary, depending on the individual firms. In Penrose's theory, the firm's specific managerial resource delivers when the firm implements plans or tasks certain actions (Penrose, 1995) to reach the goal. During this process, the firm can gain and accumulate experience and knowledge as additional intangible means. Therefore, it can reason that the technology enables the firm to perform certain tasks. Performing certain tasks, in turn, will add more value to the technology.

An organization or a firm is placed and embedded in a wider environment, rather than existing in a vacuum space and being isolated from its environment. Especially for small-sized firms, the influence from the environment can be a very important input for their decision-making. The environment in Scott's (2002) model refers to the industrial, technological, institutional, cultural and social context in which a small firm is embedded (Scott, 2002; Scott and Davis, 2006). In organizational studies there are three different major perspectives on relationships between organizations (e.g., a firm) and their environment: the closed or rational system perspective; the natural system perspective; and the open systems perspective (Davis and Powell, 1995; Scott, 2002; Scott and Davis, 2006), depending on whether they focus more on the organization itself or focus more on the organization's embedded contexts. These perspectives also had a profound influence on later internationalization studies. This study takes the 
open system perspective, because the study focuses more on the adaptive interaction between a firm and its environment during the internationalization of the firm.

From an open systems perspective, each of the four elements within a firm are more or less related to and influenced by its environment. Organizational theories have various views and typologies regarding the environment (Scott, 2002; Scott and Davis, 2006). From an objective view, it can be regarded as the technical environment, which reflects the industrial traits (Scott, 2002) and influences the competitive situation and firms' strategy. From an interdependence or relationship perspective, it can be regarded as either a dyadic model of the environment or an "environment" formulated by the network type of inter-organizational relationship. According to Dill (1958), in the dyadic model the task environment consists of both internal and external task agents. The internal task agent is the employees, while the four external task agents are as follows (Davis and Powell, 1995, p. 318):

1. Customers and clients

2. Suppliers of materials, labor, capital, equipment etc.

3. Competitors for markets and resources

4. Regulatory groups such as government agencies, unions and inter-firm associations

With research progress in the field, one should be aware that important stakeholder groups, such as the external task agents in the task environment of the firm, are likely to be more than the four groups mentioned above. For example, the derivative stakeholders in the stakeholder theory cover a broad group, which might influence the organization and its primary normative stakeholders (Phillips et al., 2003). The task environment addresses the external impact on the extent of firms' autonomy (Dill, 1958). As Scott (2002, p. 133) points out, no firm can be "self-sufficient" and firms have to change with the environment. The interaction and interdependence relationship between a firm and its environment is highlighted in the open systems approach. Influence from the environment is particularly strong for young firms. Thus, this study mainly adopts the dyadic type of relationship to construct a tentative analytic framework for showing the relationship between small firms and their task environment. 


\subsection{A multi-level analytic framework}

Based on the Leavitt's Diamond of Organization, this section constructs a basic tentative analytic framework to show the sources of important resources (means) and influences on the internationalization process of small firms.

\subsubsection{Inputs and influence from the individual level}

The role of small firms' founders and TMTs became very important elements in the internationalization of small firms. In many studies on small firms, the firms' behavior is often attributed to their entrepreneur(s) and TMT(s) (Andersson and Florén, 2011). Small firms' TMTs usually take broader responsibility in both the firms' market and business development. As individuals, they play a significant role in important decisionmaking regarding the internationalization of their firms (Nielsen, 2010; Hutzschenreuter and Horstkotte, 2013). In addition, the entrepreneur and TMT are important human resources. Their knowledge, vision, skills and connections are valuable inputs for their firms' internationalization. Based on a review of SMEs' internationalization studies, Ruzzier et al. (2006) argue that entrepreneurs' human capital and social capital are the important inputs and antecedents in their firms' internationalization. Consistent with this argument, the role of TMT's influence is often highlighted as key attributes in the instant internationalization pattern and international new venture (INV) (Andersson and Evangelista, 2006; Freeman et al., 2006). For instance, Rialp et al. (2005) argue that the small firm's founder(s) and the founding team's characteristics, international vision, prior international experience, managerial commitment and networking capability are important factors, which enable an instant type of internationalization. Kyvik et al. (2013) find that the global mindset, cognitive flexibility and networking capability of the CEO and key decision-makers in the small business determine the level of instant internationalization of their small firms compared with other small firms from the same industry. Note that the entrepreneur and TMT are both important participants and technology (means) in the firms (see Figure 2.1) to carry out important tasks during internationalization. This study regards resources and competence owned by entrepreneurs and their TMTs as inputs from an individual level. The individual level inputs are put as the primary layer of the means pool (see the inner layer of Figure 2.2 ) in the analysis framework. International vision and attitude (Kyvik et al., 2013; 
Ruzzier et al., 2006), human capital with international knowledge and skills (Felício et al., 2012; Evers and O'Gorman, 2011), and TMT's social capital (Zhou et al., 2007; Ellis, 2011), are the three important elements identified in earlier literature at this level.

\section{Environmental level \\ Organizational level \\ Individual level (Entrepreneur and TMT) International vision \&
attitude $\quad \begin{gathered}\text { Human capital } \\ \text { (International } \\ \text { knowledge \& skills) }\end{gathered}$}

Figure 2.2: The inner layer of small firms' means pool

\subsubsection{Input and influence from the organizational level}

At an organizational level, influences from technology enabling are often highlighted in the instant pattern of internationalization (Efrat and Shoham, 2011). Empirical studies also show that product innovation and technological knowledge increase the likelihood of firms' decisions on export (Cassiman and Golovko, 2011; Freeman et al., 2010). Thus, the technical core, which consists of organizational tasks and technology (Scott, 2002; Peng et al., 2008), is considered to be a main input from the organizational level. As a firm's value creation resource, the technical core forms a foundation to enable the internationalization process. In addition, extant research also suggests that small firms' market focus, for example the so-called deep niche focus and other strategic focus, will influence the internationalization of firms (Knight and Kim, 2009; Kalinic and Forza, 2012). Furthermore, recent studies also show a strong influence from the management intentionality of a firm on its decision in the internationalization process (Dasí et al., 2015). Extant studies often point to how different orientations of a firm, such as the entrepreneurial orientation, international market orientation or 
growth orientation, impact its internationalization (Javalgi and Todd, 2011; Ruokonen, 2007; Knight and Kim, 2009). These different orientations directly affect knowledge acquisition and information interpretation within an organization (Dasí et al., 2015). It can reason that such orientations reflect the managerial attention and intentionality of small firms. As a result, they influence important decisions on resource allocation for and commitment to internationalization. Thus, this study adds the three elements of market knowledge and focus, technology representing technical core, and managerial attention to the middle layer of the means pool framework in Figure 2.3.

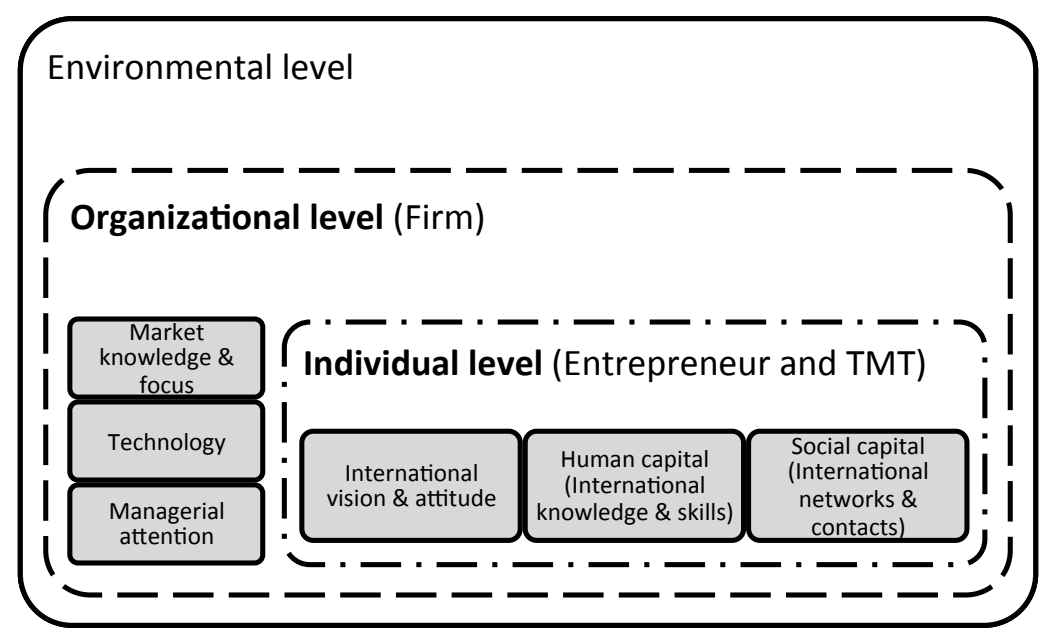

Figure 2.3: The middle layer of small firms' means pool

\subsubsection{Input and influence from the environmental level}

Smaller-sized firms are also subject to the relationships of their important participants and stakeholders from their task environment. The influential external stakeholders are closely related to small firms' various embedded networks. Based on their business networks study, Johanson and Mattsson (1988) use the network approach to go beyond the dyadic network of firms to show how the important influence of firms' relevant business and industrial network structure leads them to foreign markets. In the late 2000s, Johanson and Vahlne (2009) further developed the network model and used the previous U-model framework to capture dynamic change in knowledge and position in 
a network. They interpreted internationalization as a multilateral network development process. Studies from other scholars, such as Agndal and Chetty (2007), Agndal et al. (2008), and Slotte-Kock and Coviello (2010), show the importance of dyadic relationships. Extant studies indicate that entrepreneurial, social, and business ties and networks largely influence and affect important decisions during the internationalization of small firms, such as entry mode and strategy change. Via interaction with their task environment agents, small firms could further develop and expand their different networks, which offer complementary knowledge and connect small firms to other external resources to develop foreign business. Considering the important influence from small firms' important stakeholder networks in the task environment, this study puts firms' networks from various external task environment agents as the third layer of the means pool in the analytic framework. At this level, embedded networks are formed with firms' stakeholder agents from their task environment. The embedded networks include connections and ties from business contacts, professional contacts, institutional contacts, etc.

Besides the task environment, extant studies also identify that characteristics of the industry in which small firms operate as having important influence on the internationalization of small firms. For example, industry's degree of internationalization, knowledge intensity and competitive situation are those important environmental elements influencing firms' internationalization (Oviatt and McDougall, 1997). In addition, the structure and size of firms' targeted industrial segments also play a large role in internationalization (Ellis, 2008; Ojala, 2008). Therefore, this study includes this set of environmental elements as components of the outer layer of means pool in Figure 2.4.

\subsubsection{Three-level frame}

To sum up, based on characteristics of the small firms, this study constructs a multilevel model to show inputs from internal and external influences of small firms on their internationalization process. This study regards a set of these inputs as a means pool (see Figure 2.4). It consists of inputs (means) from three layers:

1. Means from the individual level (entrepreneurs and TMT) (Ruzzier et al., 2006; Rialp et al., 2005; Andersson and Wictor, 2003) covering: 


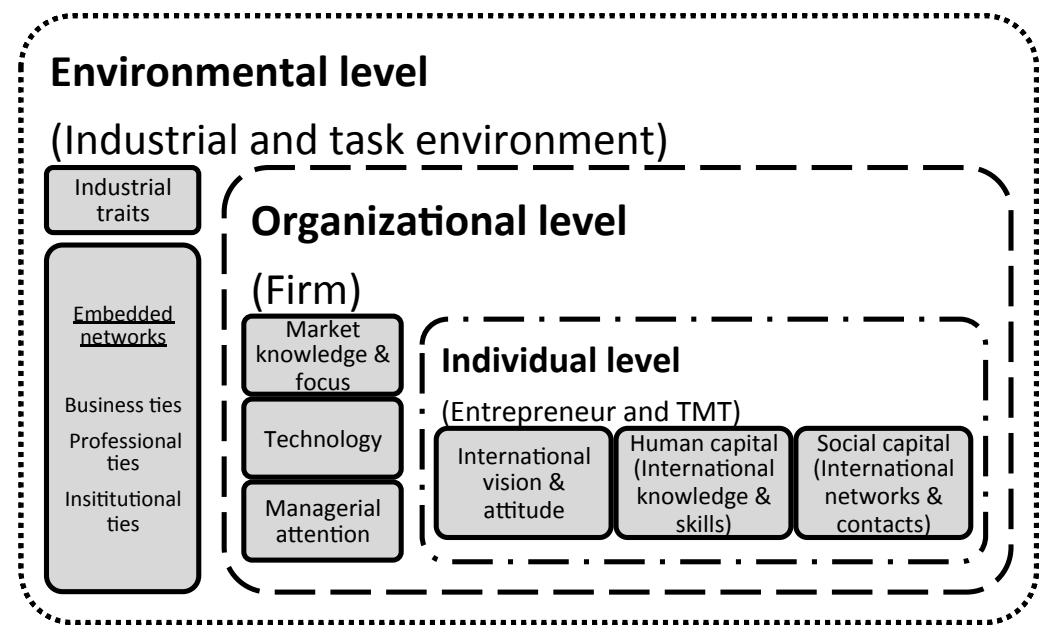

Figure 2.4: The outer layer of small firms' means pool

(a) International vision and attitude of TMT (e.g., global mindset (Kyvik et al., 2013; Ruzzier et al., 2006))

(b) Human capital of TMT (e.g., international business knowledge and skills (Felício et al., 2012; Evers and O'Gorman, 2011))

(c) Social capital of TMT (e.g., international related networks and contacts (Zhou et al., 2007; Ellis, 2011))

2. Means from the organizational level (e.g. market knowledge and focus; technology (technical core) and managerial attention)(Ocasio, 1997; Autio et al., 2000; Bell et al., 2004; Chetty and Campbell-Hunt, 2004)

3. Means from the environmental level (e.g., industrial traits and firms' various inter-organizational networks) (Chetty and Blankenburg Holm, 2000; Agndal and Chetty, 2007; Johanson and Vahlne, 2009)

\subsection{Summary of the theoretical frame}

The purpose of the theoretical frame developed in this chapter is to help answer research questions developed in Section 1.4, and to fulfill the main purpose of the study: 
contributing to a better understanding of evolving patterns in the internationalization process of small firms. The theoretical framework is summarized in Figure 2.5. Through a critical view of relevant literature, the theoretical frame builds up a basic foundation to construct an analytic model for further analysis. By differentiating and clarifying the various terminology in extant internationalization process research, it extracts three different dimensions from the spatial and temporal, and two primary dimensions to depict the motion patterns of internationalization. The clarified dimensions offer essential terms to answer the first research question regarding the features of the internationalization pattern. In addition, through incorporating entrepreneurship theory and internationalization theory, the theoretical framework further differentiates patterns by their natures. It distinguishes motion patterns and behavior patterns in the internationalization process. This differentiation contributes key conceptual terms to answer the second research question - How can evolving patterns of the internationalization of small firms be described and captured? Furthermore, through reflecting on pros and cons of the extant literature in patterns of internationalization process research, the theoretical frame creates synergy using three major theoretical perspectives on the internationalization study - behavioral learning, network theory and entrepreneurship. Based on a critical discussion of the underpinning assumptions of these three theories, this study develops a common basis for the perceived risk (uncertainty) and perceived opportunity concepts for capturing patterns in the EM entry context. A multi-level analytic framework with a focus on interactions among the small firm, its TMT and its operation environment are further developed to help answer the second research question and to offer instruments for solving the third and fourth research question in Section 1.4 . 


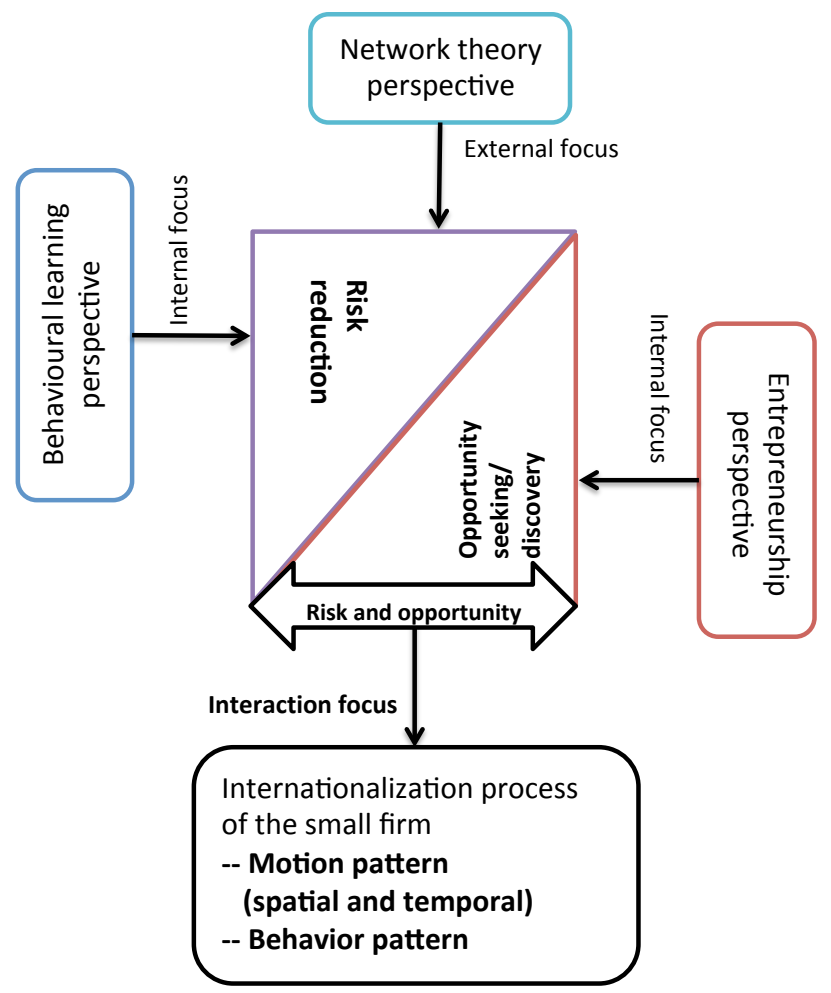

Figure 2.5: Overview of the theoretical framework 


\section{Chapter 3}

\section{Operationalization of Theoretical Constructs}

This chapter summarizes the key theoretical concepts and constructs formulated in Chapter 2. Further, it decomposes and operationalizes those constructs. In addition, the key concepts and constructs are combined with analytic strategy explained in the Research Methodology chapter to build up the analytic model. The objective of this chapter is to give a review of key concepts in the study and its analytic frame, and to clarify how these concepts will be used in the empirical analysis.

\subsection{Operationalization of perceived risk and op- portunity in foreign markets}

As discussed in Chapter 2, in the extant literature, internationalization researchers either have more focus on uncertainty and risk aversion (e.g. in the U-model) (Figueira-de Lemos et al., 2011; Liesch et al., 2011), or have more focus on opportunity-seeking behavior (e.g. in INV and BG). This study tends to have a balanced view of the influence from both the perceived risk and the perceived opportunity on the internationalization process. Risk and uncertainty are treated as interchangeable terms in this study. 


\subsubsection{Proxy of perceived risk}

Distance matters in international business (Ghemawat, 2001; Eden and Miller, 2004; Brock et al., 2011). Distance-associated dissimilarities between home and host countries often require firms to put more effort into assuring proper information flow in decision-making during internationalization. The required extra effort and cost create the liability of foreignness (Eden and Miller, 2004), which is a main source of perceived risk (uncertainty) in foreign markets. In internationalization studies, researchers have shown that managing different types of distance is one of the key issues in this field (Håkanson and Ambos, 2010; Freeman et al., 2012; Eden and Miller, 2004; Ghemawat, 2001). As it was discussed in Section 2.6, the psychic distance is a classical and wellaccepted concept in the field. Thus, the $P D$ is used to represent distance. It is also used as a proxy for the perceived risk in different foreign markets, and for measurement of the scope dimension of internationalization in this study.

Operationalization of PD Despite its importance at the concept level, operationalization of the PD concept varies largely in the existing literature. Its prediction power also varies and depends on different operationalization methods. In Johanson and Wiedersheim-Paul's (1975) original paper, the researchers gave a few examples of influential factors, which might be attributed to PD itself, rather than to the specific dimensions and indicators for the operationalization of PD. There have been a few further attempts to operationalize PD as well. Researchers such as Kogut and Singh (1988), Dow and Karunaratna (2006), Brewer (2007), and Håkanson and Ambos (2010) operationalized PD into a measurable index in their studies. Their study results show that the method of PD operationalization largely influences its prediction power on firms' initial foreign market entry preference. For example, when studies use Hofstede's national culture construct as a proxy of PD, it results in poor prediction power (Dow and Karunaratna, 2006; Håkanson and Ambos, 2010). A broader stimuli of a multi-dimensional construct has a much stronger association in firms' entry preference (Brewer, 2007; Håkanson and Ambos, 2010). When PD is operationalized as a degree of differences or connections in e.g. geographic, language, religious, political and industrial development, it turns robust. Moreover, influences of those major dimensions of PD are also unequally weighted (Brewer, 2007; Håkanson and Ambos, 2010). Thus, this study adopts a multi-dimensional PD as a proxy of the 
perceived risk in foreign markets. PD is defined by a sum of factors, including cultural, political, economic development differences and geographical distance, which influence information flow and interpretation of information between home and a foreign country (Ambos and Håkanson, 2014; Johanson and WiedersheimPaul, 1975).

Measurement of the proxy This study mainly uses the psychic distance index developed by Håkanson and Ambos (2010) with a range from 0 to 100. Sweden is the domestic country, which is the reference country $(\mathrm{PD}=0)$ in this study. This index covers 8 dimensions (e.g. cultural, geographical, economic, common language, political etc.) ${ }^{5}$ of difference among 25 major economies. In addition, this study also uses a rank developed by Nordström (1991) as a complementary list to cover a few small countries which are close to Sweden but are not included in the 25 markets in Håkanson and Ambos (2010)'s study. Both of the studies constructed a multi-dimensional PD and had cognitive elements of the individual perception of PD. Furthermore, both indexes incorporate a Swedish perspective. The index from Nordström (1991) was based on Swedish data entirely, while the PD index of Sweden in the index matrix from Håkanson and Ambos (2010) was also from a specific country perspective (e.g., a Swedish perspective for the PD index of Sweden). Therefore, they are the suitable indexes for this study, based on the author's best knowledge from the literature review. Countries which are not covered by both lists are ranked based on their geographic distance from Sweden and their common EU connections.

Implementation of the proxy As a proxy of perceived risk (uncertainty), the PD index will be used as the primary $y_{1}$ axis to map the internationalization process of a firm from a spatial aspect. The study assigns five arbitrary scores (1-5), from a low degree of PD (score=1) to a high degree of PD (score=5), as seen in Table 3.1. The PD index range of 25 major markets (Håkanson and Ambos, 2010) is in the first row of Table 3.1, while the index range of other foreign markets excluding the 25 markets is in the second row of Table 3.1. The $y_{1}$ axis will use the five arbitrary scores to differentiate the levels of PD associated with degrees of perceived risk.

\footnotetext{
${ }^{5}$ For more detailed information, please see (Håkanson and Ambos, 2010).
} 
Table 3.1: Arbitrary score of psychic distance

\begin{tabular}{|l|l|l|l|l|l|}
\hline PD index (the 25 markets) & $0-20$ & $21-40$ & $41-60$ & $61-80$ & $>80$ \\
Foreign markets (out the 25) & Nordic & EU & Europe (non-EU) & Asian & Others \\
Degree of PD & Low & Low-medium & Medium-high & High & Very high \\
Score of PD & 1 & 2 & 3 & 4 & 5 \\
\hline
\end{tabular}

\subsubsection{Proxy of perceived opportunity}

Operationalization of perceived opportunity The perceived opportunity in a foreign market is very relevant to a few objective indicators, such as market size (Ellis, 2008) and the growth potential of the market. Market size has been found to be one of the primary drivers for the internationalization of a firm (Rothaermel, 2006; Johanson and Wiedersheim-Paul, 1975). Thus, this study uses the market size as a proxy of the perceived opportunity in foreign markets.

Measurement of the proxy At a macro level, market size is often measured by a country's gross domestic product (GDP) (Ellis, 2008). Purchasing power parity (PPP)-based GDP can adjust for influence from the currency exchange rate. Therefore, it is a proper indicator for a cross-country comparison. Sakarya et al. (2007) pointed it out that in an emerging markets context, growth rate and the potential of a market should be included in a formula. Some scholars, for example Sheng and Mullen (2011), criticize the macro level approach and show that the market size at an industry level is more valid in export market opportunity analysis (Ojala, 2008). However, compared with macro-level data, industry-level data are not always easy to obtain. Taking the above arguments into consideration, this study will prioritize industry-level indicators (e.g., market size and growth potential of an industry; exports or imports from an industry (Sheng and Mullen, 2011)), when such data are available. When the industry-level data are not available, a multiple dimensions market ranking approach will be adopted to evaluate market potential at a macro level.

Taking the emerging market context into account, this study adopts the Market Potential Index (MPI) 2014 (globalEDGE, 2015) developed by GlobalEdge at Michigan State University as a major measurement of market potential at a macro level. The index was developed based on studies by Cavusgil (1997) and 
Cavusgil et al. (2004). Since $2014^{6}$, MPI has measured the market potential of 87 countries and economies, excluding the U. S. ${ }^{7}$ The MPI uses an additive function of a set of 8 dimensions as weighted indicators to rank the market potential of a country on a scale of 1 to 100 . Table 3.2 shows the 8 dimensions and their weight in the MPI 2014 construct.

Table 3.2: Construct of MPI 2014

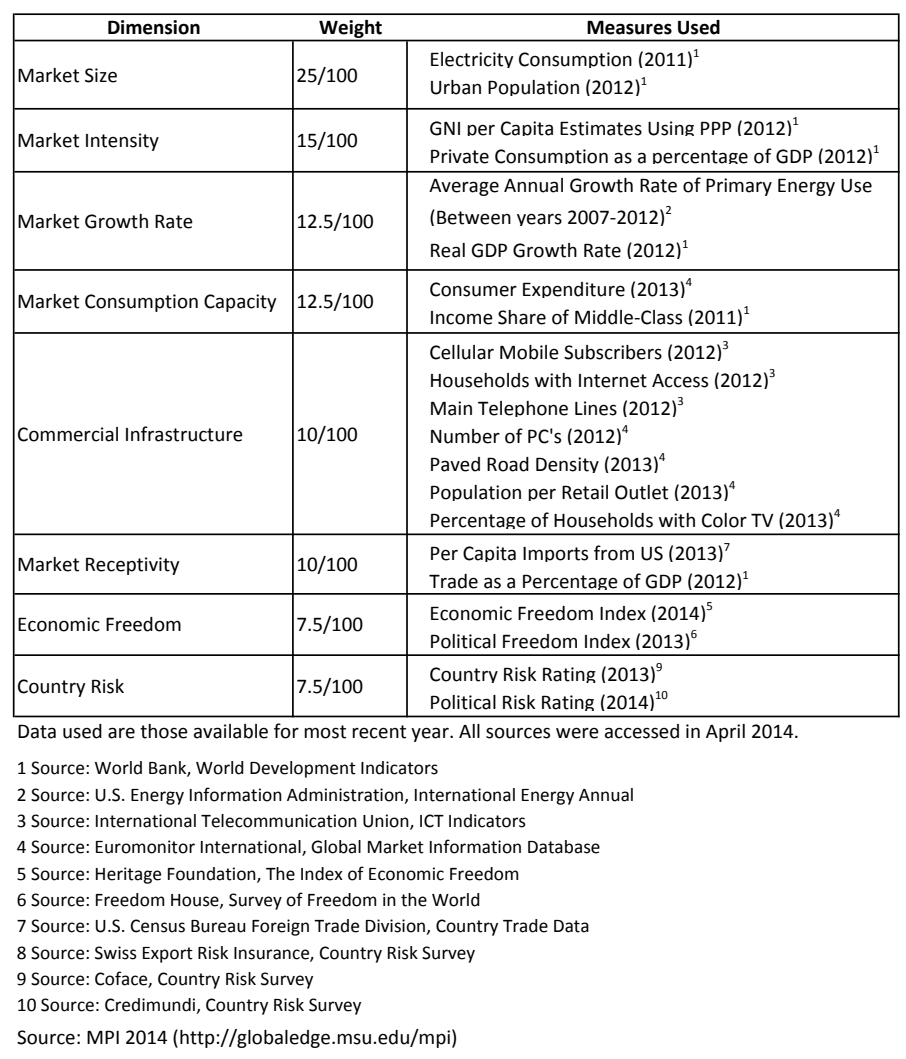

${ }^{6}$ From 1996 to 2013, MPI provided the index of 26 "Emerging markets" identified by The Economist magazine.

${ }^{7}$ The MPI was developed using the U. S. as the home country to evaluate foreign markets' potential. Therefore, the U. S. is excluded in the MPI. 
Table 3.3: Arbitrary score of market potential

\begin{tabular}{|l|l|l|l|l|l|}
\hline MPI index range & $1-20$ & $21-40$ & $41-60$ & $61-80$ & $81-100$ \\
Degree of market potential & Low & Low-medium & Medium-high & High & Very high \\
Score of market potential & 1 & 2 & 3 & 4 & 5 \\
\hline
\end{tabular}

Based on same approach, GlobalEdge at Michigan State University also developed an Industry Market Potential Index ${ }^{8}$ (IMPI) with 6 dimensions as weighted indicators ${ }^{9}$. This study will prioritize the industrial-level indicators, when they are available.

Implementation of the proxy As a proxy of perceived opportunity, the MPI 2014 index or the industry-level index will be used as the secondary $y_{2}$ axis to map the internationalization process of a firm from a spatial aspect. Corresponding to the proxy of perceived uncertainty (PD index), this study assigns 5 arbitrary scores (1-5) to differentiate a level of market potential associated with perceived opportunity (see Table 3.3). This study is aware the market potential index has also changed over time. Some European economies, such as Greece and Portugal, are still in a difficult situation following the 2008 recession. Therefore, as a reference, the secondary $y_{2}$ axis (e.g. MPI 2014) reflects market opportunities in more recent years rather than in the earlier period.

\subsection{Operationalization of internationalization pat- terns}

As described in Section 2.1.3, for a further pattern identification of internationalization, this study differentiates internationalization patterns based on two different aspects. Thus, internationalization patterns in this study will be analyzed based on two concepts - behavior pattern and motion pattern.

\footnotetext{
${ }^{8}$ GlobalEdge 2015, Industry MPI. Access from: < http ://globaledge.msu.edu/industrympi/index $>$. [8 March 2015]

${ }^{9}$ The indicators cover size $(.3)$, growth rate $(.15)$, capacity $(.1)$, openness of the market $(.15)$ and existing logistics infrastructure (.15) and risk (.15) of the country to gauge a few industries.
} 


\subsubsection{Behavior pattern}

Operationalization of behavior pattern The behavior pattern in this study refers to the traits of important decision-making during the internationalization of small firms. As explained in Section 2.5.3, this study adopts a means-ends based differentiation approach (Sarasvathy, 2008) to classify three types of behavior: managerial, strategic and entrepreneurial behavior. Based on studies by Sarasvathy (2008), Ardichvili et al. (2003) and Mintzberg and Waters (1985), this study uses a combined classification criteria to differentiate the three behavior patterns as follows:

- Managerial behavior:

Ends (goal) The "ends" is a pre-defined goal in the managerial behavior pattern and it is a starting point of managerial decision.

Means (e.g., resources, knowledge and networks) The "means" are the resources, competence and network, etc. which can facilitate firms to achieve the "ends". In the managerial behavior pattern, firms take a deliberately planned process in seeking optimal options and in deploying "means" to achieve the "end".

Risk versus opportunity preference The managerial behavior pattern has a risk aversion tendency under uncertainty.

- Strategic behavior:

Ends (goal) The "ends" is a generally defined goal in the strategic behavior pattern and it is a starting point of strategic decision.

Means (e.g., resources, knowledge and networks) In the strategic behavior pattern, firms take both planned and emergent processes in deploying "means" to achieve the "end".

Risk versus opportunity preference Risk perception in the strategic behavior pattern aligns with the general strategic goal. Compared to the managerial behavior, there is less of a risk aversion tendency under uncertainty in the strategic behavior pattern.

- Entrepreneurial behavior: 
Ends (goal) The "ends" is negotiable and emergent in the entrepreneurial behavior pattern.

Means (e.g., resources, knowledge and networks) The entrepreneurial behavior often starts from the "means", which is identified at the status quo stage of decision-making.

Risk versus opportunity preference The entrepreneurial behavior pattern has an opportunity seeking tendency under uncertainty.

Implementation of behavior pattern In this study, a means-ends-based analysis will be used in the within-case and cross-case analyses to differentiate three types of behavior patterns. It aims to distinguish traits of important decisions during the internationalization of a firm.

\subsubsection{Motion pattern}

Operationalization of motion pattern The motion pattern in this study refers to features of international business involvement of a firm in its internationalization process. As explained in Section 2.1.3, the study considers three important dimensions from both spatial and temporal aspects identified in extant internationalization literature. They are scope, scale and speed of internationalization (Jones et al., 2011; Zahra, 2005; Johanson and Wiedersheim-Paul, 1975).

\section{Scope}

Operationalization and measurement of scope of internationalization This study defines scope as the width of covered distant markets. It gauges the wideness of a distance range in international markets covered by a firm.

Scope $=\sum_{n=0}^{i} n_{i} *$ Distance $_{\text {score }}$.

The formula reflects the scope of extant international markets determined by the number of international markets $n_{i}$ and the score of the distance of those markets. Thus, this study defines scope by two factors:

1. The number of international markets $(n)$ 
2. The distance between the corresponding international market and the home market

Operationalization of distance As it is operationalized in Section 3.1.1, distance in the formula refers the psychic distance (PD). The measurement and score of PD is the same as in Section 3.1.1

Implementation of scope of internationalization As one of three dimensions of motion pattern, the scope of internationalization will be used for comparison purposes in the within-case analysis, cross-case analysis and final discussion. As a sub-dimension of the scope, PD (e.g., index, degree and its score) will be used in three parts:

- PD as a proxy of perceived risk (uncertainty) in different international markets

- PD for visualization purposes in internationalization mapping in within-case analysis

- PD for comparison purposes in the cross-case analysis and final discussion

\section{Scale}

Operationalization and measurement of scale of internationalization Scale is the second dimension from the spatial aspect. It refers to the extent of a firm's international business involvement in this study. In the extant literature, the scale dimension is often measured by a percentage of firms' overseas turnover in BG and INV studies (Zahra, 2005; Crick, 2009). Classical internationalization studies, on the other hand, use the entry mode to evaluate the level of resource commitment and control for different types of foreign operations (Johanson and Wiedersheim-Paul, 1975). This study considers the above two aspects, when those data are available.

Scale $=F_{\% \text { turnover }} *$ Mode score $_{\text {sction }}$

The scale of internationalization in this study is determined by:

1. Percentage of foreign market turnover $\left(F_{\% \text { turnover }}\right)$. An arbitrary score is assigned to four different levels of percentage of foreign market turnover from 1 to 4 , which corresponds to a low to high degree of foreign turnover (see Table 3.4). 
Table 3.4: Arbitrary score of foreign market turnover

\begin{tabular}{|l|l|l|l|l|}
\hline Foreign market turnover (\%) & $1-25$ & $25-50$ & $51-75$ & $76-100$ \\
Degree of foreign turnover & Low & Low-medium & Medium-high & High \\
Score of foreign turnover & 1 & 2 & 3 & 4 \\
\hline
\end{tabular}

2. To simplify the comparison, an arbitrary score is also assigned to different types

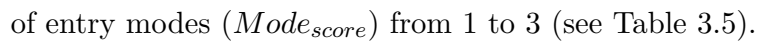

Operationalization of entry mode Entry mode refers to firms' operational choices regarding production or service, marketing and export activities in the foreign host countries (Sharma and Erramilli, 2004; Johanson and Wiedersheim-Paul, 1975). Different entry modes require different resource commitment and reflect different levels of operational control. For example, compared with export via agents and distributors, having sales subsidiaries in a foreign market requires more resource commitment, while having better control over operations. Compared with having only sales and marketing activities in the host country, production operations in a foreign country requires more resource commitment, etc. The entry mode decision is subject to multiple influences and can be analyzed by, for example, the "OLI" paradigm from Dunning (2001), which takes a structural view of the entry decision. This study only uses the entry mode as one of the sub-dimensions in gauging the scale of internationalization. Figure 3.1 classifies common entry modes based on Sharma and Erramilli (2004)'s study.

Measurement of entry mode The measurement of entry mode is based on firms' control level and type of foreign operation (Sharma and Erramilli, 2004). Based on the seven classified common entry modes (see Figure 3.1), this study assigns the foreign operational modes into three arbitrary levels of score (see Table 3.5). The study assigns the lowest score (EntryMode $=1$ ) to entry modes with a low level of control (indirect exporting and exporting via intermediaries in host markets) and a low level of operating activities involvement (e.g., activities related to sales and marketing only). The highest score (EntryMode $=3$ ) is assigned to entry modes with a high level of control (e.g., wholly-owned subsidiary). Other types of combinations are assigned as score $=2$.

Implementation of scale of internationalization The scale of internationalization 


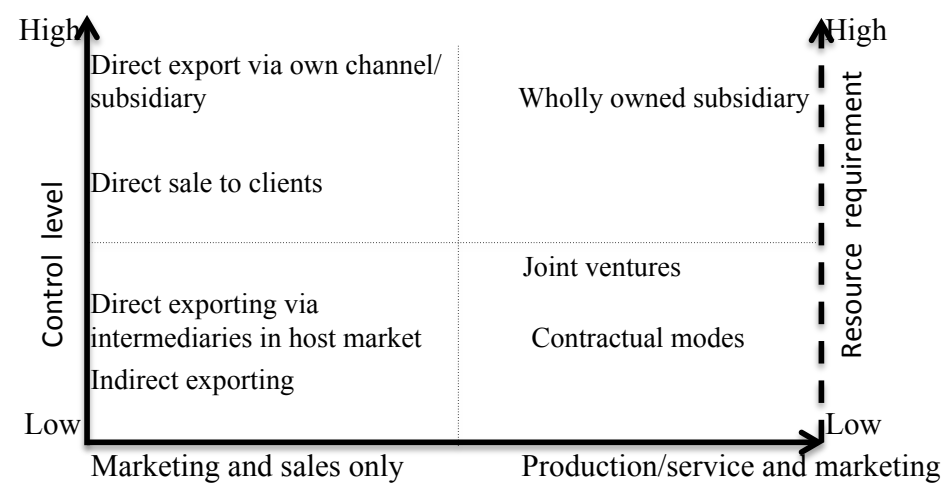

Figure 3.1: Foreign operational modes of main business activities (entry modes) Adapted from (Sharma and Erramilli, 2004)

Table 3.5: Arbitrary score of entry modes

\begin{tabular}{|l|l|l|l|}
\hline Operating activities & Only sales \& Marketing & Production \& sales & \\
\hline \multirow{3}{*}{ Score of mode } & 2 & 3 & High \\
& 1 & 2 & Low \\
& & & Control level \\
\hline
\end{tabular}


and its two sub-dimensions will be used in the within-case analysis to show changes during firms' internationalization. It will also be used to compare investigated firms in the cross-case analysis and final discussion. The entry mode will serve as a proxy, representing the resource commitment level in different foreign markets. It also serves as symbol coding in mapping internationalization along the horizontal $x$-axis.

\section{Speed}

Operationalization and measurement of speed of internationalization Speed refers to how fast the internationalization process evolves. Unlike scope and scale dimensions, which have a focus on the spatial aspect, speed has a focus on a tempo aspect of internationalization (Kalinic and Forza, 2012; Jones et al., 2011; Oviatt and McDougall, 2005). Consistent with the extant literature, this study uses a time span between the establishment year $\left(T_{0}\right)$ of a firm and its first international business involvement (e.g., initial business prospects or leads from a foreign market) $\left(T_{\text {Intl }}\right)$ as the speed of internationalization.

Speed $=T_{\text {Intl }}-T_{0}$

Implementation of speed of internationalization The speed of internationalization will be used in the within-case analysis, the cross-case analysis and the final discussion to compare the investigated firms. It will also be used for visualization purposes in mapping the internationalization process along the timeline.

\subsection{Internationalization mapping}

In order to capture the dynamics in the process of a combined impact from risk (uncertainty) versus opportunity during the internationalization of small firms over time, this study uses proxies from the operationalization of two elements discussed in Section: 3.1 and Section 2.6.3 as a dual $y$ serial to construct an analytic tool. 


\subsubsection{Construct of the mapping}

Figure 3.2 shows the construction of a process-oriented analytical tool with dual $y$ serials.

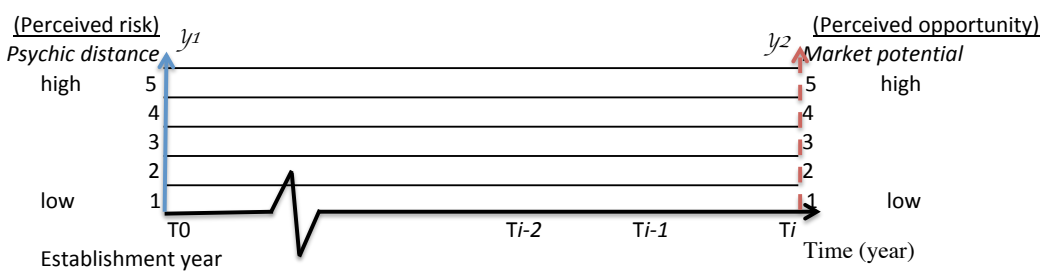

\begin{tabular}{|c|c|c|c|c|c|c|c|c|}
\hline & \multicolumn{7}{|c|}{ Change in market commitment } & \multirow[b]{3}{*}{ Control level } \\
\hline x & (i) & $\square$ & $\checkmark$ & 0 & $v$ & $\odot$ & $\star$ & \\
\hline Withdraw & Checking & Trials & iAgent's network & Exclusive agent & Agents & Sister co. & Sub-org & \\
\hline
\end{tabular}

Figure 3.2: Internationalization trail map

$y_{1}$ axis The primary $y_{1}$ axis (in blue color) represents the perceived risk (uncertainty) level of foreign markets. This study uses PD as a proxy for the perceived uncertainty and risk in foreign markets. The $y_{1}$ axis is from $0-100$ in the PD index based on studies from Håkanson and Ambos (2010) and Nordström (1991). The lowest value of 0 represents the domestic market - Sweden in this case. In addition, to be concise in the visualization, this study assigns 5 arbitrary scores to present PD from a low level (1) to a high level (5) (see Table 3.1), as discussed in the earlier operationalization Section 3.1.1.

$y_{2}$ axis The secondary $y_{2}$ axis (marked as a red dash) represents the opportunity level of foreign markets. This study uses the market size as a proxy to represent perceived potential opportunities in foreign markets. As explained in Section 3.1.2, based on Sheng and Mullen's (2011) research, this study prioritizes the market size at the industry level. Based on the operationalization discussion in Section 3.1.2, this study mainly uses the MPI and IMPI indexes (Cavusgil, 1997; Cavusgil et al., 2004) developed by Global Edge to evaluate foreign market potential.

The scale of the $y_{2}$ axis is from 1-100 in both IMPI and MPI. Taking a similar approach as it is used in the $y_{1}$ axis, this study assigns another 5 arbitrary scores 


\section{OPERATIONALIZATION OF THEORETICAL CONSTRUCTS}

to present market potential from a low level (1) to a high level (5) (see Table 3.3). The ordinal scale ranks 5 at the top, representing a high level of perceived market potential, and 1 at the bottom, representing a low level of market potential.

$T$ axis The horizontal time-axis (units: year) represents a calendar timeline along firms' biographic history for capturing the temporal dimension of firms' internationalization. $T_{0}$ is the establishment year of a firm. $T_{i}$ is the investigation year of the study.

Additional $x$ coding Along the time axis, a symbol coding system will be used to show the level of resource commitment and control in different foreign markets. The different codes correspond to different types of entry modes in Table 3.5.

\subsubsection{Implementation of the mapping}

The internationalization trail map (Figure 3.2) developed for this research aims to capture the motion pattern of a firm's internationalization over time. Mapping the spatial and the temporal dimensions of motion in the internationalization of a firm can reveal the main features of the internationalization process. Therefore, it helps in answering the first research question - What are the major features in the pattern of small firm internationalization? It also directly helps to answer the second research question How can evolving patterns of the internationalization of small firms be described and captured?

The dual $y$ serial, representing the perceived risk (uncertainty) and the perceived opportunity side-by-side, can map the potential changes in the motion pattern along the scope dimension of the internationalization along the timeline. The dual references in the spatial dimension of internationalization also help offer evidence for interpreting potential changes of behavior patterns during internationalization. In addition, the mapping tool can also partially reveal potential change in the scale dimension of internationalization by showing the changes in the entry modes. Further, the time axis can show potential changes in the speed dimension of internationalization. The mapping will be used as one of three main building blocks in the process-based analytical model in the following section. The mapping tool will also be used in the within-case analysis. 


\subsection{Process-based analytical model}

In order to explore evolving patterns and potential changes in the risk versus opportunity preference during internationalization, this study takes a process-based longitudinal approach to investigate the internationalization process. Melin (1992) studied typologies within internationalization studies and identified four types of longitudinal approaches - time serials of events, short period of episode, longer period of epoch and biographic history. The longer period epochs and biographic history types of approaches are valuable in real longitudinal studies. According to Melin (1992), one epoch could be 2-20 years, while one episode might range from a few weeks to a few years.

Based on reviews of extant studies, this study regards internationalization as a dynamic process, one which is subject to multiple levels of influence. For capturing the dynamics during the internationalization of small firms, this study combines a process model suggested by Melin (1992) and the "means pool" model for small firms developed in the Section 2.8. Thus, the process-based analytical model is a combination of three major elements. The first element is the internationalization mapping (see Figure 3.2) presented above. The second element is the "means pool" framework shown in Section 2.8 (see Figure 2.4). The third element is to use the process-based approach to analyze the change state of internationalization.

The mapping element basically follows the internationalization mapping (Figure 3.2). A detailed explanation of the construct is given in Section 3.3.

- The y-axis represents the state of internationalization, which covers two dimensions of the motion pattern:

1. $y_{1}$ partially representing the scope of internationalization by using the $\mathrm{PD}$ index as a proxy. The PD index also reflects a perceived risk (uncertainty).

2. $y_{2}$ axis is an additional reference indicator representing a perceived opportunity in foreign markets by using the MPI index as a main proxy.

3. $x$ partially representing the scale of internationalization by using the entry mode as a proxy. 


\section{OPERATIONALIZATION OF THEORETICAL CONSTRUCTS}

- The time axis represents the biographic timeline in the internationalization of a firm. It covers the speed dimension of internationalization.

The means pool frame element is constructed based on the literature review in Section 2.8. It differentiates the sources of influence on the internationalization pattern and process from three levels.

- At the individual level, as discussed in Section 2.8.1, the entrepreneur's and TMT's international vision and attitude, international knowledge and skills, and international networks and contacts are primary sources of influence.

- At the organizational level, as discussed in Section 2.8.2, market knowledge and focus, traits of technology and managerial attention are primary sources of influence.

- At the environmental level, as discussed in Section 2.8.3, a firm's embedded external task environment (e.g., business networks and ties) and traits of its focused industrial segments are primary sources of influence.

Connection element is a process analysis approach, which consists of three main steps in this study:

1. Identifying critical events, episodes or epochs suggested by Melin (1992) during internationalization. The identification is based on an examination of changes in the internationalization mapping. For example, the initial period and changes in internationalization and the EM entry would be regarded as critical in this study.

2. Analyzing triggers, actions and outcomes in the identified critical events or episodes in order to discern the sources of influence.

3. Examining the ex-ante and ex-post period motion patterns to reveal how the identified key events or episodes impact the internationalization process of the firm.

The connection element links the mapping element and the multilevel framework together by analyzing the identified critical events or episodes during internationalization in approaching EMs.

The blue line in parallel with the timeline in the mapping element represents a longer time period epoch in internationalization (Intl.), while the red line 
represents a short time period episode related to the EM entry (e.g., the Chinese market)

The "means pools" framework, as argued in Section 2.8, offers resources or sets constraints for the ex-ante situation of the internationalization epoch or episode at the state of internationalization at time $n$ ("state of intl. $n$ " in Figure 3.3). The means pools will change until the ex-post situation of the internationalization epoch period at the state of internationalization at time $n+1$ ("state of intl. $n+1$ " in Figure 3.3). Based on the features of change, this could identify the behavior pattern of a firm during epochs and episodes.

Figure 3.3 shows a processual analytic model for the internationalization of small firms.

Based on the internationalization mapping tool (see Section 3.3), the process-based analytic model can further reveal a few critical epochs, episodes or events for the firm's entry to the EM (e.g., the Chinese market) during its internationalization process. After using the mapping to show feature changes in the three dimensions of the motion pattern around important events or episodes, the "means pool" model of small firms aims to reveal details of the changes brought on by those key incidents. A processual analysis helps catch changes in those critical moments related to conditions, interaction and results etc (Langley, 1999). Thus, the combined model intends to show where the triggers come from and how these events influence the key elements of the means pool during the internationalization of the firm. Together with the dual serial "internationalization mapping" developed in Section 3.3, the process-based analytic model was developed to offer a tool for answering the second research question RQ2 - How can evolving patterns of the internationalization of small firms be described and captured? 


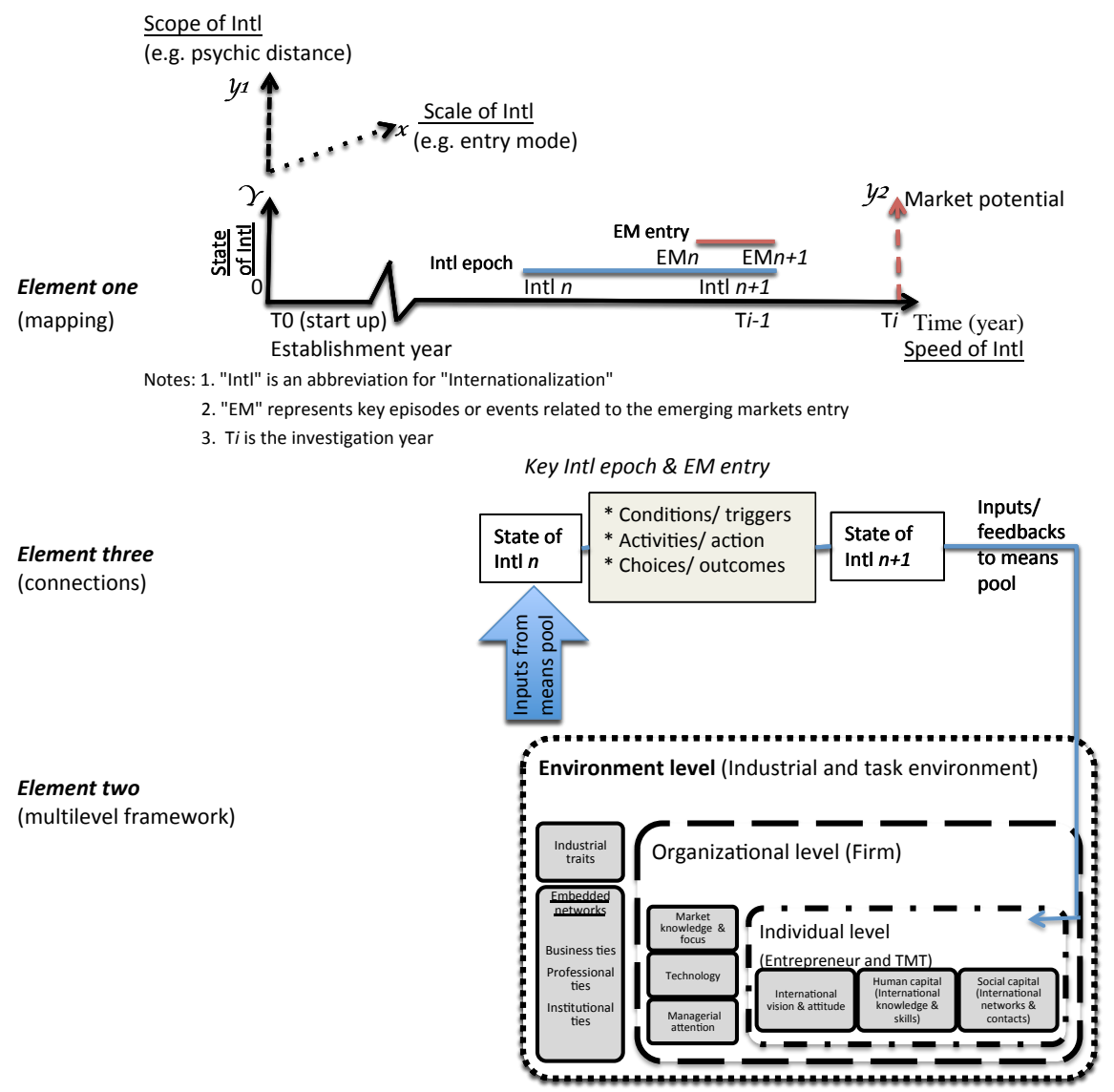

Figure 3.3: Processual analytic model for the internationalization pattern of small firms 


\section{Chapter 4}

\section{Research Methodology}

This chapter describes the research approach and the design of the study. It presents an overview of the study design and different methods for data collection and analysis. It further clarifies the reasons for adopting these methods in the different phases of the research process for fulfilling the research purpose and answering the four research questions presented in Section 1.4. The chapter describes how the study achieves some important alignments among the probed research questions, the overall research strategy and design, and the different study methods adapted in the theoretical and empirical studies. In addition, the chapter provides some guidelines used in the study for selfmonitoring the study's quality control.

\subsection{Epistemology - How the author views real- ity in social science}

Generally speaking, this study closely relates to three domains of research - international business, organizations, and entrepreneurship. Each of these domains belongs to branches within social science. In social science, the epistemological view of a realworld phenomenon has a profound impact on the methodology and research design. It is, in a sense, about to what extent people believe there is a concrete reality or true fact out there. There is a long, ongoing debate on the qualitative versus quantitative approach in social science related to epistemology view. Morgan and Smircich (1980) 
criticize a common dichotomy between the discussion of subjective versus objective in social science. They draw a subjective-objective continuum to illustrate a variation between two extreme endpoints, e.g. the (post)-positivism and the phenomenological approaches. Creswell (2008) also argues that there could be a mixed approach based on a pluralistic view.

As demonstrated by both Morgan and Smircich (1980) and Creswell (2008), the dichotomous approach oversimplifies a variance of assumptions under different views of knowledge within social science. Compared with natural science, social science hardly could be pure positivism or post-positivism, which regards reality as a concrete and objective construct (Morgan and Smircich, 1980; Creswell, 2008), as in natural science. These arguments are plausible, because in social science, reality often comes with a different hue. For instance, even for those perceived objective quantitative approaches, such as observational survey studies, the construct, the measurement scales and the study results all depend on one's subjective interpretation in order to make sense out of the study. Therefore, the objectivity of reality in social science is a comparable and relative term to the author of this study. Yet, in light of some macro data, the author of this study is also aware that in some situations, indicators such as macro economy data or firms' financial performance could help people to better understand the topic. Therefore, this study takes a pluralistic view and regards the reality as a "contextual field of information" (Morgan and Smircich, 1980, p. 945). This epistemology regards the social or business world as a field in ever-changing form (Morgan and Smircich, 1980). It also emphasizes the importance of understanding the context in a holistic manner. Since the context is evolving in the social world, the relationship is also seen as relative rather than fixed (Morgan and Smircich, 1980).

\subsection{Research process}

The purpose of this study is to facilitate a better understanding of possible change mechanisms, which may influence the formation of patterns in the internationalization process of small firms. It requires additional theoretical insights beyond existing theories. Therefore, this research is primarily guided by the theory-building process suggested by Eisenhardt (1989). However, the actual process is also close to the ab- 
ductive approach described by Dubois and Gadde (2002). In addition, the study is also inspired from a tactic suggested by Van de Ven (2007). The study adopts an attached insider perspective perspective recommended by Van de Ven (2007) to get multi-stakeholders involved in the research as much as possible, in order to bridge the knowledge gap between academia and practice.

\subsubsection{Background of the research}

This study consists of a pre-study and two stages of a main study. The pre-study and the first stage were previously under the framework of an EU-funded project called BENCH (June 2010 - May 2013) ${ }^{10}$, which aimed to support SMEs from the Central Baltic regions to enter the Chinese market. Therefore, the study in the first stage had a unique opportunity to get different stakeholders from SMEs, academia, governmental organizations and cluster associations, as well as individual industrial practitioners, involved in the co-creation of knowledge.

The author of this thesis joined the BENCH project as a Ph.D. student and a member of the academic team from Sweden in June 2010. The research conducted in this study has intertwined with the BENCH project studies with which the author was involved. The study was triggered by the practical needs and interests for obtaining a better understanding of the internationalization of small firms in order to offer better support for small firms approaching emerging markets like China.

The second stage of the main study was an extension of the first-stage study. It was mainly based on the academic interests of the author. The author of this thesis intended to gather more evidence on small firms' EM involvement during internationalization. In this stage, EMs included not only China, but also other large EMs from BRICS and smaller EMs. Unlike the first-stage study, which had focus on only one EM and had many stakeholders involved, the field study at the second stage was conducted by the author as a single investigator. At the second stage, the study had focus on the patterns in the internationalization process of SMEs with an international growth

\footnotetext{
${ }^{10}$ Beneficial Business Relations between the Central Baltic Region and China - an EU-funded project (June 2010 - May 2013) in the Central Baltic Interreg IV A Programme 2007-2013
} 
aspiration. For a clarification, in the following sections the first stage of the main study is referred to as the "Kina study" 11 and the second stage of the main study is referred as the "EM extension study".

\subsubsection{Procedure of the research}

The author of this thesis began with a literature study in order to see whether there were existing answers to be found. In the first round of the literature study, a major focus was on the main themes and current debates in the existing research from the early 1970s up until today. The author investigated, for example, whether there were common or contradictory conclusions in existing studies regarding possible changes in the features of the patterns during the internationalization of the firm.

After getting an overview of the existing research in the internationalization study, the author began a tentative problematization from existing debates. Meanwhile, in the project, and supported by project partners, the author also began to use a webbased qualitative questionnaire to identify a target group and its basic experience and attitude toward Swedish SMEs in Östergötland regarding internationalization toward China. Through combining the results from both parts during the beginning of this research, the author found that the three major patterns identified in the literature could not fully capture and explain the dynamic feature during the internationalization of small firms. This finding motivated the formulation of research questions in the study.

Reflecting on the observed variations, the author went back to the literature again to identify their sources. As McAuley's review (2010) pointed out, the methodological limitation for most of the empirical studies in internationalization is cross-sectional in nature. Due to the difficulty in gathering longitudinal data and conducting the process-based analysis, few studies, even those with longitudinal data, still did factorbased analysis (Welch and Paavilainen-Mäntymäki, 2014). Those limitations prevented an understanding of any changes during the internationalization process under influence from external and internal factors of the firm over time (McAuley, 2010). Furthermore, those lessons were taken as a part of the inputs into the research design of this study.

\footnotetext{
${ }^{11}$ Kina is China in Swedish
} 
Meanwhile, motivated by new empirical findings within the project studies, the author referred back to the literature from time to time to compare and identify interesting issues and enrich the protocols for the case study. Figure 4.1 presents an overview of the research process in this study, from the middle of 2010 to the spring of 2015. It shows an iterative route between theory (in green) and empirics (in blue) for theory development.

1. Pre-study stage (first six months) - formulation of research questions and initial design of the study:

Tentative research questions were formulated based on the results from the primary literature review and an interpretation of results from the initial qualitative survey during the pre-study stage. This resulted in a basic study design for the main study, including a preliminary choice of methods for an in-depth study, to answer the research questions (see Chapter 1, Section 1.4).

The main purpose and objectives of the pre-study were to increase the focus of the research topic, identify interesting firms to study and create a general study blueprint for further steps.

2. The Kina study (first stage of the main study) included two phases of data collection. The first phase of data collection was from the field study in the Kina study (about one year):

(a) Following the basic study design determined in the pre-study stage, the author decided on strategies to select cases and collect basic data. Supported by senior researchers in the project, the author also constructed a few instruments and protocols for gathering primary and secondary data.

(b) Identify and contact the first two case companies to collect primary data.

(c) Get consent from the case companies regarding the methods and possible timeframes for follow-up investigation throughout the study period.

(d) Select a few additional potentially interesting candidate firms to follow and observe to contribute to a better understanding in the case study. 


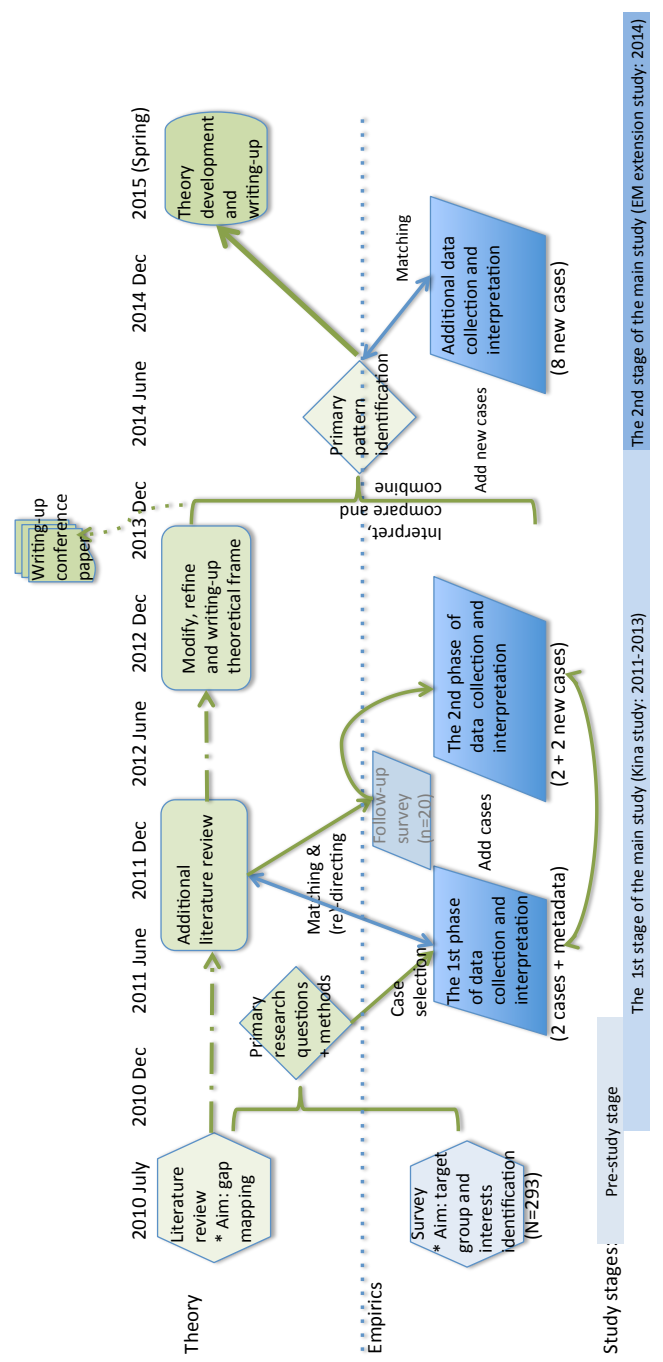

Figure 4.1: Overview of the research process 
The main purpose and objectives of the first phase field study in the Kina study stage was to get a few potential cases of particular interest based on purposeful sampling suggested by Patton (2002). This was done to develop and use similar instruments during the data collection process to reduce variance across the cases, while assuring that some basic theoreticallyrelevant themes were covered.

3. Iterate the "abductive" process between the literature and field study (about two years $^{12}$ )

(a) An initial interpretation of the data from the 1st phase of the field study in the Kina study stage study was done.

(b) Some main points and emerging new themes from the interpretation of data were compared with theory. Additional underlying theories and methodological literature were added to support additional data collection and analysis.

(c) A follow-up mini survey ${ }^{13}$ was carried out for preparation of the secondphase data collection in the Kina study stage. Two extra cases were selected from additional candidate firms based on their responses in the follow-up survey.

(d) Data collection was conducted using multiple methods in four case firms, at more than three different points in time during two years, to capture changes during the entry of the firms on the EM (China).

(e) Literature was revisited from time to time to compare the empirical findings with existing theories up to the beginning of 2013.

Collecting data at several points in time helped to capture the dynamics and changes over a period of time during the internationalization of the firms. This iterative process, in an "abductive" way, provided an opportunity for timely comparisons and a combination between empirical and theory studies to generate new themes. The process enabled the author to make good use of existing knowledge, while not losing out on taking a fresh perspective.

\footnotetext{
${ }^{12}$ There was some overlap in the timeframe with the first phase of the field study and the analysis.

${ }^{13}$ Detailed information from the mini survey is excluded from this dissertation.
} 
4. Analyze and write up the four in-depth case studies in the Kina study stage with theoretical frame (about six months).

(a) The key themes and the tentative analytic frame developed in Section 2.8, and the processual-based analytical instruments developed in Section 3.3.1, served as the basis for writing up the cases for within-case analysis.

(b) The cross-case analysis was based on common pattern identification.

Analyzing and writing up the four in-depth cases helped to generate primary findings and identify new emerging themes in the EM entry during internationalization of small firms. It also enriched the theme codes for an extended study in the EM extension study stage (the second stage of the main study).

5. The field study in the EM extension study stage (about three months)

(a) Based on primarily findings from the cross-case analysis from the field study in the Kina study stage to prepare the criteria for case selection in the EM extension study stage. Developed an interview protocol based on experience accumulated from the field study in the Kina study stage.

(b) Primary identification of case candidates from firms in "Östergötlands Framtidsföretag" project, based on case selection criteria. Firms participating in this project were in the sample frame of the previous survey in the pre-study stage.

(c) Pre-investigating three researchers who participated the "Östergötlands Framtidsföretag" project to adjust the candidate pool and create a candidate list.

(d) Contacting founders, owners and top managers of the 12 selected case candidates and communicating research interests and purpose.

(e) Recruiting 8 selected cases, which are positive to the study for a further investigation.

(f) Investigating selected cases based on secondary data sources from public databases and information from web pages.

(g) Collecting primary data from the selected case companies. 
The main purpose and objectives of the field study in the EM extension study stage was to get a few more potential cases, which related to internationalization and EM entry in general, to verify the patterns identified in the field study of the Kina study stage. This part of the study used additional cases in general EMs entry context to compare the initial findings from the four in-depth studies in the Kina study stage. Unlike the the Kina study stage, where it was possible to do a real-time investigation of the EM entry, the investigation in the EM extension study stage was mainly retrospective. However, the study kept similar instruments during the data collection process in the EM extension study, as those were used in the four in-depth studies at the Kina study stage, to reduce variance across the cases, while covering common theoretically-relevant themes (Creswell, 2012).

6. Analyze and write up the eight additional case studies in the EM extension study stage and the whole study (about four months)

(a) Use the key themes identified from the four in-depth cases in the Kina study stage to code the new data gathered for the eight additional cases.

(b) Use the tentative analytic frame developed in Section 2.8 and processualbased analytical instruments developed in Section 3.3.1 as the common ground to write the 8 additional cases descriptions and within-case analysis.

(c) The cross-case analysis was based on common patterns identification among 12 cases from both the Kina study stage and the EM extension study stage.

(d) The formulated propositions were derived from discussions of the theory and by cross-case findings.

(e) The research questions were answered and conclusions were drawn.

The purpose of the analysis and writing up the whole dissertation was to wrap up and communicate the results in a more logical and reader-friendly way to potential interesting groups in both academia and other stakeholders in industry and society. 


\subsection{Strategy of inquiry - a qualitative approach}

Strategy of inquiry concerns how to conduct the research in order to fulfill the purpose of the study and answer the research questions. In line with the purpose of this study, a qualitative approach was taken.

\subsubsection{A qualitative approach}

The purpose of this study was to characterize patterns of internationalization in order to understand the mechanism underpinning the potential changes during the internationalization process of small firms. Hence, the study needs to incorporate contextual factors into the internationalization to probe how changes take place during internationalization and understand why certain patterns might appear. Earlier studies in this field have seldom focused on the changes stimulated by the interactions between small firms and their environment during internationalization. It requires not only longitudinal investigation, but also the interpretation by key participators during a firms' internationalization process. In this case, a qualitative approach is a proper way to create a deeper understanding of the evolution of the patterns during internationalization process. The qualitative approach is suitable for understanding the business phenomena in a natural setting, which implies contextual richness and multiple participators' interpretation (Patton, 2002; Flick, 2009). Therefore, it fits for pattern identification in this study and could untangle how patterns emerge along the internationalization. Yet, a general qualitative approach in this study does not necessarily exclude the use of quantitative types of data and quantitative methods in data collection and analysis used in the study. In fact, the pre-study uses a quantitative method and modeling for its designed purpose. In cross-case analysis, a quantitative cluster analysis method is also applied to help explore common motion patterns of internationalization among investigated firms. A primary purpose of using quantitative data and methods in the study is to add complementary inputs to the main study and to facilitate pattern identifications. 


\subsubsection{Research design}

Research design should align with the research purpose and research questions (Creswell, 2008). In line with the research purpose of this study, a qualitative process-based study design is more appropriate when investigating changes over time (Pettigrew, 1997; Langley, 1999). Despite being time and organizationally demanding, a longitudinal study has a methodological advantage in process studies with regard to consistency (Flick, 2009). In internationalization process studies, a longitudinal case study is the most appreciated and recommended to investigate any changes in the internationalization (Melin, 1992; McAuley, 2010; Welch and Paavilainen-Mäntymäki, 2014). A case study is suitable for in-depth investigation (Yin, 2009) and fits the complex features of internationalization. According to Eisenhardt and Graebner (2007), a multi-case study could be a better choice to offer more empirical support for potential theory building. Therefore, this study mainly uses a multi-case longitudinal study approach.

More specifically, to capture the dynamics of change, this study uses real-time longitudinal design, which follows the entry of a few small firms into the Chinese market over approximately a two-year period in the field studies in the Kina study stage. This part of the study uses multiple methods to collect both qualitative and quantitative data during different points in time in order to capture any changes during the entry process, and to avoid post-rationalization of informants in interpreting the process.

The field study in the EM extension study stage still follows a longitudinal approach to investigate the internationalization process. However, due to resource limitations, real-time investigation for EM entry is not feasible. Thus, the extended case studies are based on the key informants' knowledge and experience from the internationalization of their firms.

\subsubsection{Role of theory and empirics}

As explained in Section 4.2, Figure 4.1 could also illustrate the general role of theory and empirics in this study along the research process. The theoretical part of the study involves several rounds of literature reviews. The main part of literature reviews 
include the research topics' related substantive literature (Flick, 2009) regarding the three major perspectives on internationalization in Section 2.3) and the methodological literature in this chapter.

\section{The role of literature}

The selection of substantive literature involving internationalization covers important books, relevant $\mathrm{Ph} . \mathrm{D}$. dissertations and over 200 articles from high-impact academic papers based on average yearly citation of the paper in peer-reviewed journals. Journal selection was based on the relevance of the field and certain impact factors. The basic search strategy used in this study was to search on a few topic-related keywords from the Web of Science and Scopus databases. The substantive theoretical and empirical literature included published influential studies from the 1970s and onwards related to the process and pattern of the internationalization. Since this study has a focus on the process view of internationalization, the structural view of internationalization theories, such as the well-cited "Eclectic Paradigm" study from Dunning (2001), was not in the focus of this paper. The role of this part of the theoretical review was to gain insight into the evolution of critical concepts and assumptions in this field in order to open up the discussion and problematization from the beginning. It also served as a guide for the theoretical sampling and analytical framework.

The second field of literature studies included a few relevant organizational theories which were linked to internationalization study. The selection of this part of the literature was mainly based on the relevance of the topic. Relevant literature was chosen from a few well-cited books and classical literature recommended by a Ph.D. course ${ }^{14}$ and an online course ${ }^{15}$ the author took. This part of the literature was useful in understanding the theoretical foundation and basic assumptions in the reviewed essential theories of substantive literature on which it relies. Reviews of this part of the literature were helpful in forming a common ground for discussion from various internationalization theories.

\footnotetext{
${ }^{14}$ Teorier avseende interorganisatoriska relationer - tillbaka till rötterna given by Prof. Bengt Högberg at Linköping University in 2011

${ }^{15}$ Organizational analysis given by Assoc. Prof. Daniel A. McFarland from Stanford University in 2012
} 
The third part of the literature study included a small number of sources from the entrepreneurship literature (e.g., Sarasvathy's effectuation logic, entrepreneur(-ial) views of Schumpeter versus Kirzner and Mises, etc.) and behavioral economics (e.g., prospect theory). Selection of entrepreneurship literature was primarily based on commonlyrefereed classical works in the substantive literature study. In addition, the selected behavioral economics literature was motivated by findings from the pre-study in connection with the research topic and the author's own area of interest in behavioral economics. As a combination of the three relevant theoretical fields, theory plays a significant role in this study in the problematization, analytical process and theoretical discussion to enable new insights.

Methodological literature was an invaluable guide throughout the study. It was particularly helpful in the research design, the selection of methods, the instrument development and in the data collection and analysis. The selection of methodological literature was mainly based on widely-cited books and articles on the qualitative research approach, case study methods and interview tactics, etc. The selected literature was often recommended by fellow researchers from $\mathrm{Ph}$.D. courses and research seminars the author took.

\section{The role of empirics}

Regarding the role of empirics in a case study, there are several differing opinions. For instance, Yin (2009) regards empirics as important material to build a chain of evidence for justifying theory. Eisenhardt (1989), on the other hand, uses empirics as a foundation for the formulation of new constructs, while Alvesson and Karreman (2012) use empirics as a source of stimulation for creating innovative and interesting research. Eisenhardt's way (1989) of using empirics has been doubted for its overweight on construct, while compromising on the contextual story (Dyer and Wilkins, 1991). Pentland (1999) suggests using empirics to build process theory so researchers can obtain a better story and constructs at the same time. Empirics in this study were not isolated from theory; they served different roles in different stages. In the pre-study stage and the first phase of the Kina study stage, empirics were used as a simulator for theory discussion and seeking new theoretical explanations. In the second phase of the Kina study stage and the EM extension study stage, they served as a foundation for 
building possible process-based theory.

\subsection{Empirical inquiry}

The empirical inquiry consists of a pre-study and the main study. The pre-study primarily uses a quantitative method in its data collection and data analysis, while the main study uses a qualitative multiple case study design. A part of the crosscase analysis uses a quantitative method, which is embedded in the overall qualitative analysis of the cases. Figure 4.2 shows an overview of the empirical inquiry.

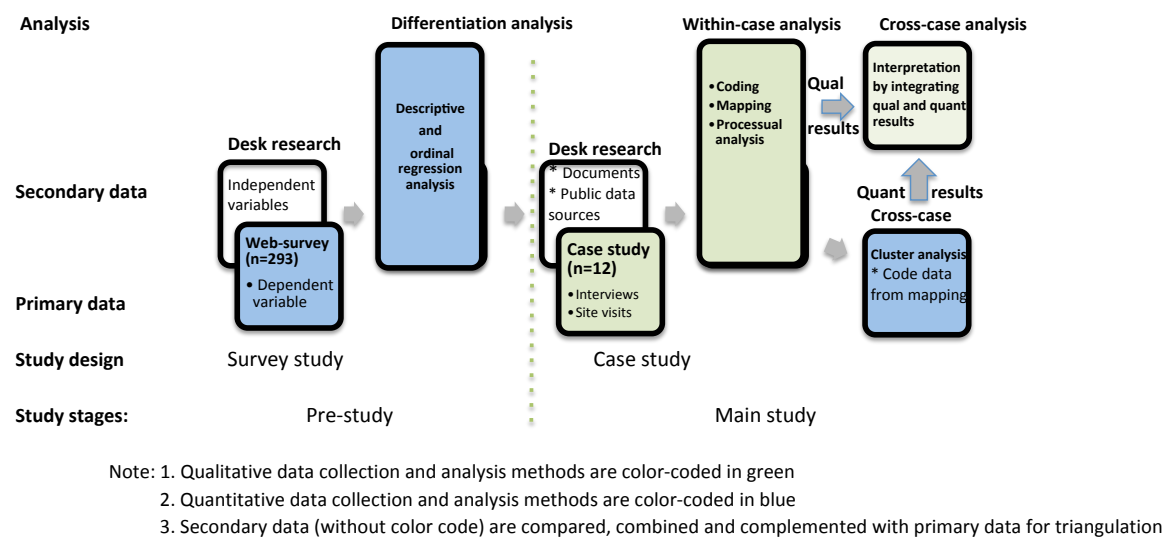

Figure 4.2: Overview of the empirical inquiry

\subsubsection{Pre-study}

The empirical investigation of this research began with a quantitative study of the EM (China market), of interest to Swedish SMEs from the southeastern part of Sweden. This part of the study became the pre-study of this research. The primary aim of the pre-study was to identify potentially interesting groups for the main study. Aligned with its aim, the pre-study used the survey method to investigate the attitudes of local Swedish SMEs toward business involvement in an EM (China). The data collection of the pre-study was conducted in the beginning of the research, under the BENCH project 
in the autumn of 2010. The population of the survey was SMEs in the Östergötland their choices. The information gathered from responses in the open fields of the survey helped in the case selection for the multiple case study. The two levels of dichotomous responses on the EM involvement were further coded as ordinal data and used as the response variable in the statistic analysis of the pre-study. The statistic analysis used the response variable from the survey and predictor variables from the public database of all registered local firms. The identified statistical significant predictors - industry and the recent managerial performance of the firm - were taken into consideration in the case selection and case analysis in the main study. The findings from pre-study were also a motivation to expand the literature review to other relevant theories beyond the substantive literature in the internationalization of small firms. Detailed information regarding the survey design, analysis, conclusions and their inputs to the main study can be found in the pre-study section (see Appendix A-1). The pre-study is illustrated on the left side of Figure 4.2.

\subsubsection{Main inquiry of the multiple case study}

The second part of the empirical investigation in this study used a multiple case design to capture changes during internationalization in different contexts. As discussed in the introduction chapter, this research mainly used micro and small companies from Sweden. These companies were facing a limited domestic market, while having high constraints in human and financial resources, when they intended to enter a high psychic distance big emerging market like China. In the Kina study stage, the case referred to the EM (China market) entry process of the investigated firms. The EM entry process was studied under the general context of firms' overall international business involvement. The study used a purposeful sampling (Patton, 2002; Flick, 2009) to cover a variety of cases and gain insights from rich information. In the EM extension study stage, the case referred to the internationalization process in general with a connection to the EMs' business involvement. Case selection also used purposeful sampling to gain more focused attention on the industrial sectors, which are identified as more positive in the EM business involvement from the initial survey in the pre-study stage. 


\section{Criteria of case selection}

In the Kina study stage, the cases were selected from small and micro companies with different industrial backgrounds and in different phases of the Chinese market entry process. The basic case selection criteria included that the companies:

1. were micro or small in size and independent based on the EU definition

2. had made efforts in China-related business

3. were from different industries

At the EM extension study stage, the cases were selected from SMEs from 2-3 industries, which are identified as more positive in EM involvement from the survey in the prestudy stage. The basic case selection criteria included that the companies:

1. were micro or small in size when they began internationalization

2. had business experience related to EMs as their markets

3. were from industries, which were identified as positive toward the EM in the pre-study

\section{Case selection procedure}

\section{Case selection in the Kina study stage}

The case companies for the study were selected in two phases (see Figure 4.1) in the Kina study stage. The first two cases were selected during the identification of the population at the end of 2010. Case selection in this step was based on maximum variation (Flick, 2009), and along key dimensions identified in the earlier literature review such as international experience and types of offerings. In the end of 2010, one case was selected from the pre-study survey respondents and another was selected from participants in the first project seminar.

Parallel with the first two case studies, the author also followed a few additional potential candidate firms from the survey respondents to observe actions they had taken 
in approaching the EM (China). Although the parallel observation of additional firms was not as much in depth as the first two case firms, it added additional understanding to the case study.

The second phase of case selection followed the idea of "theoretical sampling" (Flick, 2009). The case selection framework was based on information gathered during a follow-up survey study on 20 small and micro firms ${ }^{16}$, which responded to the initial survey and/or joined project seminars in the pre-study stage. The observed candidate firms were all in the case selection framework and participated in the second survey. From the case selection frame, two additional case firms were selected at the end of 2011.

Gradual case selection enabled this study to use information gathered in two surveys and additional information gathered during general project seminars and company visits. The primary comparison was made between the two first cases and the literature study. The additional two firms were contacted and confirmed via initial interviews during the second phone survey involving 20 micro and small firms.

In sum, in the Kina study stage, two small firms were selected: one micro firm and one micro firm becoming a small firm ${ }^{17}$ were selected. Two of these firms were in the manufacturing sector, while two of them were professional service firms. All four firms were in different phases of entering the Chinese market. Table 4.1 shows profiles of the four in-depth case study firms selected in the Kina study stage of the main study.

\section{Case selection in the EM extension study stage}

Case selection in the second stage of the main study, the EM extension study stage, started in the summer of 2014. The case candidate pool was from local SMEs, which participated another EU-supported regional development project ${ }^{18}$. Since these SMEs were also in the sample framework of the pre-study, some local small firms participated

\footnotetext{
${ }^{16}$ The follow-up survey study was reported as attachment No.4 in The BENCH Final Report. Since the follow-up survey only facilitated case selection, it is excluded from this thesis.

${ }^{17}$ Based on the EU definition for both headcount and turnover in 2010.

${ }^{18}$ The Östergötlands Framtidsföretag project. The project targeted SMEs with a growth intention.
} 
Table 4.1: Brief profile of case firms in the Kina study stage

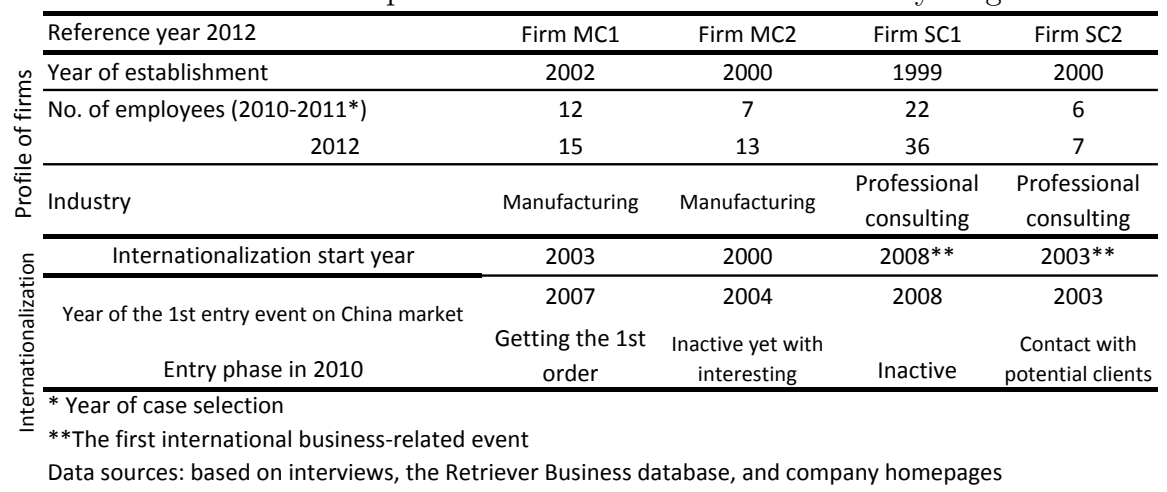

in activities in both the BENCH project and this EU-supported project. Firms with EM connections were selected into a candidate pool. A pre-investigation of these firms was conducted by interviewing three researchers, who were in the project and familiar with candidate firms. Combining results from pre-investigation and case selection criteria, 12 candidates from three industries - Wholesales and retail, manufacturing, and information and communications technology (ICT), were conducted by interviewing three researchers who were in the project and familiar with the candidate firms. Combining results from pre-investigation and case selection criteria, 12 candidates from three industries Wholesale and retail, manufacturing, and information and communications technology (ICT) - were contacted in the autumn of 2014. Eight companies were positive to joining the research at the EM extension study stage. Seven of them were manufacturers and one of them was a distributor. Except for one middle-sized company, the other seven were small-sized companies. All of the selected SMEs were micro or small independent companies when they started the internationalization process. Table 4.2 shows profiles of the eight case study firms selected at the EM extension study stage. Five of the selected companies also participated in a few activities in the BENCH project in the Kina study stage. Four of them were respondents to the initial survey in the pre-study stage. 
Table 4.2: Brief profile of case firms in the EM extension study stage

\begin{tabular}{|c|c|c|c|c|c|c|}
\hline Case firms & $\begin{array}{c}\text { Year of } \\
\text { establishment }\end{array}$ & $\begin{array}{c}\text { Employees } \\
\text { (2014) }\end{array}$ & $\begin{array}{c}\text { Start year of } \\
\text { internationalization }\end{array}$ & $\begin{array}{l}\text { Firm size at initial } \\
\text { internationalization }\end{array}$ & Industry & $\begin{array}{c}\text { Emerging markets } \\
\text { (examples) }\end{array}$ \\
\hline Firm MC3 & 1985 & 28 & 1960s* & Small & Manufacturing & China \\
\hline Firm MC4 & 1991 & $90\left(174^{* *}\right)$ & 1992 & Micro & Manufacturing & South Africa \\
\hline Firm MC5 & 1997 & 27 & 1998 & Micro & Manufacturing & Malaysia; Brazil \\
\hline Firm MC6 & 2003 & 23 & 2005 & Micro & Manufacturing & China \\
\hline Firm MC7 & 1993 & 21 & $1990 \mathrm{~s}$ & Micro & Manufacturing & Russia \\
\hline Firm MC8 & 1993 & 36 & 1940s* & Small & Manufacturing & China \\
\hline Firm MC9 & 1966 & 29 & $1960 \mathrm{~s}$ & Micro & Manufacturing & India \\
\hline Firm TC & 1995 & 17 & 1996 & Micro & $\begin{array}{l}\text { Trading and } \\
\text { distributor }\end{array}$ & India; China \\
\hline
\end{tabular}

\subsection{Data collection methods}

This study used multiple methods suggested by Creswell (2008) to collect both qualitative and quantitative data, in order to get different yet complementary information relevant for answering the research questions. The qualitative data played a major role in this research for gaining a deeper understanding of the phenomena and for theory development. Quantitative data, on the other hand, had a minor complementary role for triangulation and providing contextual information.

\subsubsection{Surveys}

There were two surveys conducted during this research in the fall of 2010 and in the winter of 2011. The surveys used in this study were designed for the BENCH project through a joint effort by the BENCH project team. The author was a main implementer and one of designers of the surveys in Sweden. Since this study had intertwined with the BENCH project study, the author had access to results from the surveys. As mentioned earlier, the main purpose of the initial survey in the BENCH project (during the fall of 2010) was to investigate the target group - SMEs from BENCH project regions (e.g. Östergötland in Sweden) - concerning their experience in the Chinese market, and their attitude and needs in getting public support to approach the Chinese market. Therefore, the initial survey used a few dichotomous questions with open fields for collecting qualitative data. A web-based survey link with an invitation 
letter was sent out to the contact email addresses of about 2,000 individual companies in Östergötland; 293 companies responded to the survey. The survey results from a descriptive analysis were communicated at the first BENCH project seminar ${ }^{19}$, where the very first case company had been invited by a senior researcher ${ }^{20}$ to join the case study. As mentioned earlier, the pre-study uses a part of the initial survey data as the response variable, while other secondary data were collected from the public database as predictor variables for further differentiation analysis. The detailed information about the initial survey and its statistical analysis can be found in the pre-study section of the appendices. The left part of Figure 4.2, marked as Pre-study, shows data collection from and analysis of the initial survey study.

As explained in the empirical inquiry section, the follow-up survey was a small-scale survey conducted in the winter of 2011 with 20 companies, which had shown interest in approaching the Chinese market in the initial survey or in the 1st seminar, to get their updated information regarding business development related to the Chinese market. This survey combined telephone interviews with an email questionnaire developed by the BENCH project team. Survey participation of the selected case study firms is shown on the lower parts of Table 4.3, and in Table 4.4 in the rows labeled as Survey participation.

\subsubsection{Interviews}

The interview is one of most important data collection methods in a case study. It helps the investigator obtain information which directly focuses on the investigated topic, and can lead to insightful explanations from key informants (Yin, 2009). Thus, the major qualitative data collection method used in this study was semi-structured face-to-face interviews. The criteria for selecting key informants were that:

1. Candidates had good knowledge about the firm's development history related to

\footnotetext{
${ }^{19}$ Held in November 2010, the first project seminar was a part of the activities in the event "Vecka45" - a main theme week with innovation and entrepreneurship focus held in the 45th week of each year in the East Sweden business region since 2010, http://vecka45.se/aboutvecka45/

${ }^{20}$ Öhrwall Rönnbäck A., Professor at Luleȧ University of Technology since Aug. 2014. (Associate Professor at Linköping University during BENCH project period 2010-2013)
} 
the internationalization of the firm.

2. Candidates had actively participated in the firm's entry process on the Chinese market (in the first stage of the study) or had experience with his or her firm's involvement in major emerging markets (at the second stage of the study)

3. Candidates should be accessible and willing to give their frank interpretation of and reflection on the investigated topic.

Based on these criteria, as the main investigator the author of the study contacted and selected key informants among CEOs, founder-owners and key people in small firms' TMTs. In addition, in the Kina study stage, two extra interviews from key firms' stakeholders were also conducted. External informants were the leaders from local governmental organizations and cluster leaders. They were also insiders of business-related provincial cooperation between Sweden and China. At the EM extension study stage, the author conducted three extra interviews from researchers who were familiar with the identified candidate firms.

\section{Interviews in the Kina study stage}

Interview data in the Kina study stage were collected from 2011 to 2012. The primary data were based on interviews with two key informants from each small firm and one key informant from each micro firm. Key informants had been interviewed at least two times for each firm at different periods during the firms' entry process into the Chinese market. In total, nine key informants participated thirteen times for one to two hours of semi-structured interviews in the study. In twelve out of thirteen interviews, permission was given to record. Coordinated by the author and supported by two senior researchers ${ }^{21}$, several interviewers contributed to data collection. The main interviewers were the author (eleven interviews) along with an industrial expert (seven interviews) and a senior researcher (one interview). Two groups of masters students (two per group) also contributed data collection from three interviews under guidance ${ }^{22}$. Table 4.3 shows detailed information from interviews in the first stage study in the rows

\footnotetext{
${ }^{21}$ The supervisors of the author were Holmström M. (2010-2012) and Öhrwall Rönnbäck A. at Linköping University. The author and her two supervisors were in the BENCH project team representing Linköping University.

${ }^{22}$ The author was the co-supervisor of the first group and was the supervisor of the second group for their master's thesis based on the master's thesis project related to BENCH.
} 
marked as Interviews.

Initial and follow-up interview protocols in the Kina study stage were developed and modified for an improvement based on suggestions from internal reviews by the author's supervisor ${ }^{23}$ before the interviews. In initial interviews for the firms, the author and the co-investigator ${ }^{24}$ used a primary interview protocol, which had a few major questions covering main critical events and epochs during internationalization of the firms in their development history. The interviewers also prepared a back-up question protocol for additional follow-up questions. However, the back-up question protocol was seldom used during actual interviews.

All of the interviews the author joined were semi-structured face-to-face interviews, and held in the head office of each small firm. The interviews were taken in a formal setting environment. The author and co-investigator(s) communicated the aim of each interview and the neutral role and academic interests of the main interviewers, in order to get a frank interpretation and attitude from the informants. In-depth interviews were used to collect data (Yin, 2009). During the interviews, not only were the facts related to internationalization information gathered; informants' opinions and reflections on their experience with the internationalization of the firm were also collected. In the initial interviews, the interviewers let informants from the firm describe the development journey of the firm and interpret the experience and process of the internationalization of their respective firm in order to understand the context of the internationalization. The initial interviews also covered critical events or episodes related to the entry process for the Chinese market. The follow-up interviews concerned the entry process to the Chinese market at different points in time. Informants in the follow-up interviews were encouraged to reflect on the progress and changes compared to the initial period. During the interviews, informants had the freedom to elaborate on their experiences and organizational issues during the entry process for the Chinese market.

\section{Interviews in the EM extension study stage}

\footnotetext{
${ }^{23}$ Protocols were developed and modified with help from Holmström M., the research leader in the BENCH project and the author's supervisor (2010-2012).

${ }^{24}$ Davidsson C., Project Manager of BENCH in Cleantech Östergötland, the main coinvestigator in the interviews.
} 
From the end of June to beginning of October 2014 the author, as a single investigator, collected primary data from face-to-face interviews with 14 internal informants from 8 case companies and 3 external informants ${ }^{25}$, all who were familiar with the selected case companies. Key internal informants were owners and members of TMT in the selected SMEs.

Interview protocols at the EM extension study stage were further developed based on previous protocols used in the Kina study stage. The protocol was revised based on $n$ internal review by a senior researcher ${ }^{26}$. Informants got a basic protocol before the interview started. The author used a complete protocol with follow-up question leads. The author explained the purpose of the study and how the study would handle the information from the interview. Each of the interviewees gave their permission to be recorded. All of the interviews at the EM extension study stage were semi-structured interviews, and informants were free to describe and reflect on their experiences related to the internationalization of their firm. Interviews were conducted in a formal setting and lasted from one hour to around three hours with key informants. Table 4.4 shows detailed information from interviews in the EM extension study stage in the rows marked as Interviews.

\subsubsection{Documents study}

Documents were used in this study as the secondary data for different purposes. The documents included reports and statistical data based on: the official BRICS Summit prepared by the National Statistics Offices of the BRICS Group; the EU SMEs profile and trade data from the European Commission; the metadata of major EMs' profiles from the World Bank Group, WTO and UN, Swedish trade data and SMEs data from SCB and Tillväxtverket; specific reports related to business with China from the Embassy of Sweden in China, the Swedish Chamber of Commerce in China, the Swedish Trade Council in China ${ }^{27}$, and the Association of Swedish Engineering Indus-

\footnotetext{
${ }^{25}$ The external informants were senior researchers at Linköping University involved in The Östergötlands Framtidsföretag project.

${ }^{26}$ The protocol was modified in the introduction text and language with help from Assistant Professor of Industrial Marketing Grundstöm C. at Linköping University, the co-supervisor of the author (2012-2015).

${ }^{27}$ This name was changed to Business Sweden in January, 2013.
} 
tries (Teknikföretagen); reports from the Chinese national statistics bureau, etc. The main criteria for documents selection were relevance, representativeness and authenticity (Flick, 2009) to ensure the credibility and authenticity of the documents.

To obtain reliable proxies for the operationalization of a main concept used in the study - Perceived opportunity - the study used reports and data at a national level (e.g., Market Potential Index published by globalEDGE; ) and industrial reports at an international level (e.g., steel industry development data and reports 2000-2012 from the World Steel Association). For triangulation purposes (Creswell, 2008), the author studied over 10 years of annual financial reports from 12 case firms, news related to the firms from public web media sources in both Sweden and $\mathrm{China}^{28}$, and historical information published on the firms' homepages. The secondary data row in the lower section of Table 4.3 and Table 4.4 provide a summary of documents studied for the case study firms.

\subsubsection{Direct observations}

In addition to formal interviews and secondary data collection, in the Kina study stage, the author also used direct observation and took field notes on different occasions, which included site visits, project seminars with small firms, a one-week "China trip" ${ }^{29}$ and the Swedish part of "Nordic week" 30 .

In the BENCH project seminars in Sweden, the author was one of the organizers. The CEO and TMT of the four case firms joined several of the seminars ${ }^{31}$. The key informants from the four selected case firms were also invited to give presentations and share their experiences at different project seminars and workshops from the end of 2010 to

\footnotetext{
${ }^{28}$ For the in-depth China market entry case in the Kina study stage

${ }^{29}$ This was the BENCH delegation trip mainly organized by the County Administration Board of Östergötland and headed by the Governor of Östergötland, Sweden to Jiangsu, China from 2012-03-17 to 2012-03-24. All of the four case firms received the information. The CEOs of $\mathrm{SC} 1$ and $\mathrm{SC} 2$ joined the delegation trip.

${ }^{30}$ This refers to the investment study trip organized by the BENCH project for incoming Chinese investors to Sweden, Finland and Estonia, 2012-09-16 to 2012-09-22.

${ }^{31}$ From November 2010 to March 2013, the BENCH project organized six China businessrelated supportive seminars and the final project conference for SMEs in Östergötland, Sweden.
} 
Table 4.3: Overview of data collection in the 1st stage (Kina study stage)

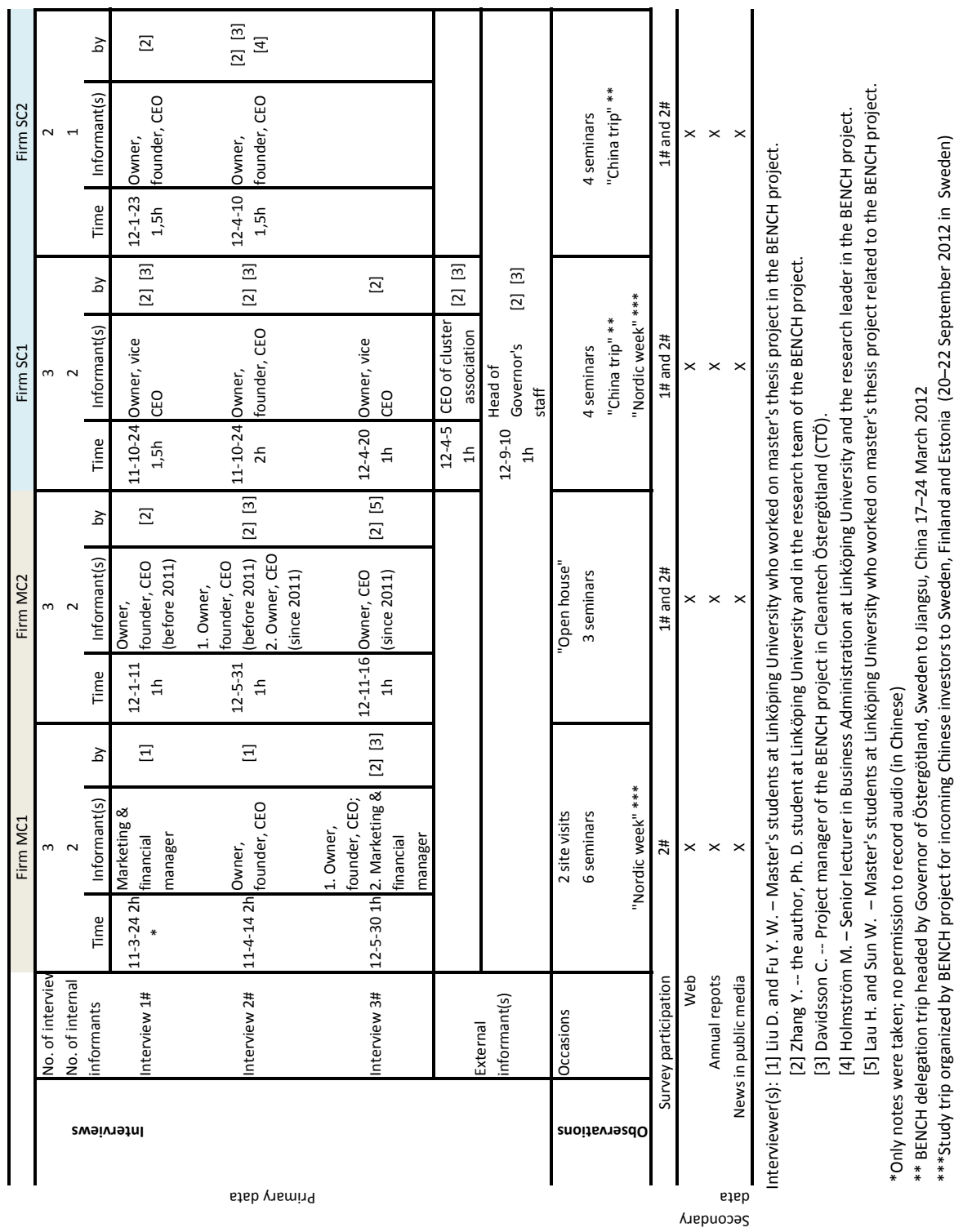


Table 4.4: Overview of data collection in the 2nd stage (EM extension study stage)

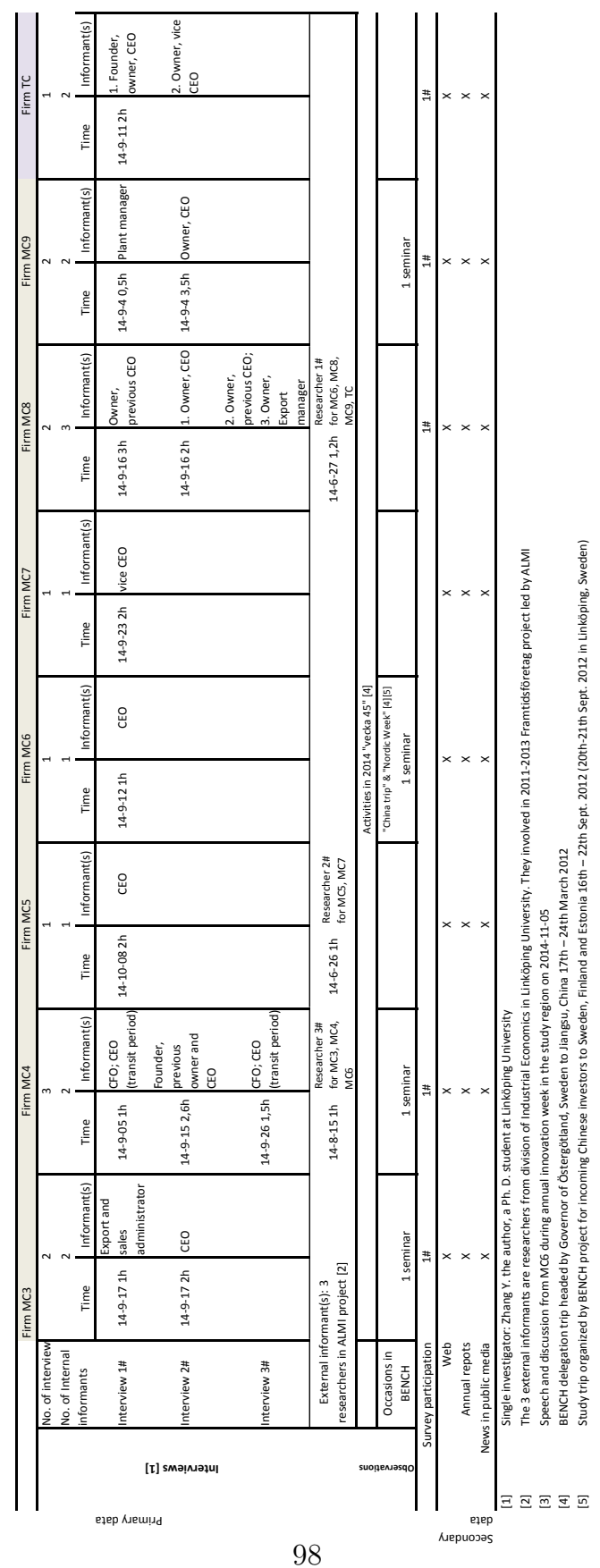


the beginning of 2013. During the seminars, the author participated as an observer (Flick, 2009). The author did not play an active role in the seminars, and just focused on observing the interactions and discussions among small firms' participating CEOs and supportive agents such as representatives from Business Sweden.

During the "China trip", the author was one of the Swedish delegation members and participated in different official meetings and "match-making" activities between Chinese companies and small firms' representatives from Sweden, Finland and Estonia in the "Nordic room". The author had selective observation of the CEOs from the two case companies, and focused on how they presented their firms to Chinese officials and Chinese industrial representatives and the interactions among them. The author also conducted a few brief, informal interviews during the trip. The CEOs of the case firms and the cluster leader were interviewed regarding their expectations, experiences and progress in different activities during the trip. These interviews were not recorded, although notes were taken.

During "Nordic week", the author participated in all of the meetings and social activities as an interpreter for the Swedish representatives. The author observed the meetings between the CEO of MC1 and SC1 and Chinese investors on 21 September 2012 in Linköping, Sweden. These meetings were confidential. Being part of these meetings gave the author some insights and helped the author understand the two cases better.

Observation of the TMTs' interaction with other small firms and supportive agents in China business-related activities under different contexts helped the author to gain a better understanding of their attitudes, strengths, and concerns when approaching the EM. It also gave the author some new inputs for the following-up interviews in the observed case study firms. The observation row in Table 4.3 provides a summary of direct observation occasions for the case study firms in the Kina study stage. 


\subsection{Data analysis}

As Hurmerinta-Peltomäki and Nummela (2006) argue, in international business study, a mixed method in data collection and analysis can add more value in different phases of the research process for serving its designed purpose. A good example of using a mixed method in the analysis is from some of the most cited Uppsala research (Johanson and Wiedersheim-Paul, 1975) in this field. With a pluralistic view of the reality, this study also does not exclude quantitative methods in data collection and data analysis. Therefore, the study also applies a mixed method in data analysis as well.

\subsubsection{Procedure of empirical data analysis}

As explained in Section 4.2, this study consists of the pre-study and the main study. In addition to gathering information about the targeted study group, the pre-study also aimed to get a pre-understanding of the topic. Thus, a survey method combined with desk research were used to collect the data for the dependent variable (by survey) and the independent variables (by desk research). As described in Section 4.4, two levels of dichotomous responses gathered from the initial survey were recorded and used as the dependent variable. Other predictors gathered from the secondary data were used as the independent variables. The pre-study used a multivariate analysis for a differentiation purpose in the analysis. The results from the pre-study were used as additional inputs to the main study. In the main study, data gathered from semi-structured interviews were validated and combined with other primary and secondary data. Qualitative analysis methods were applied in visualizing, describing and interpreting cases in the within-case analysis. In the cross-case analysis, both quantitative and qualitative analysis methods were applied for different purposes. The quantitative cluster analysis technique was used to help motion pattern identification. Qualitative analysis was used for further exploring potential reasons, which cause changes in identified motion patterns. Based on the identified clusters, the cross-case analysis further combined and integrated the qualitative results from the within-case analysis to interpret the final findings. Figure 4.3 provides an overview of the different methods of data collection and analysis used in this study. 


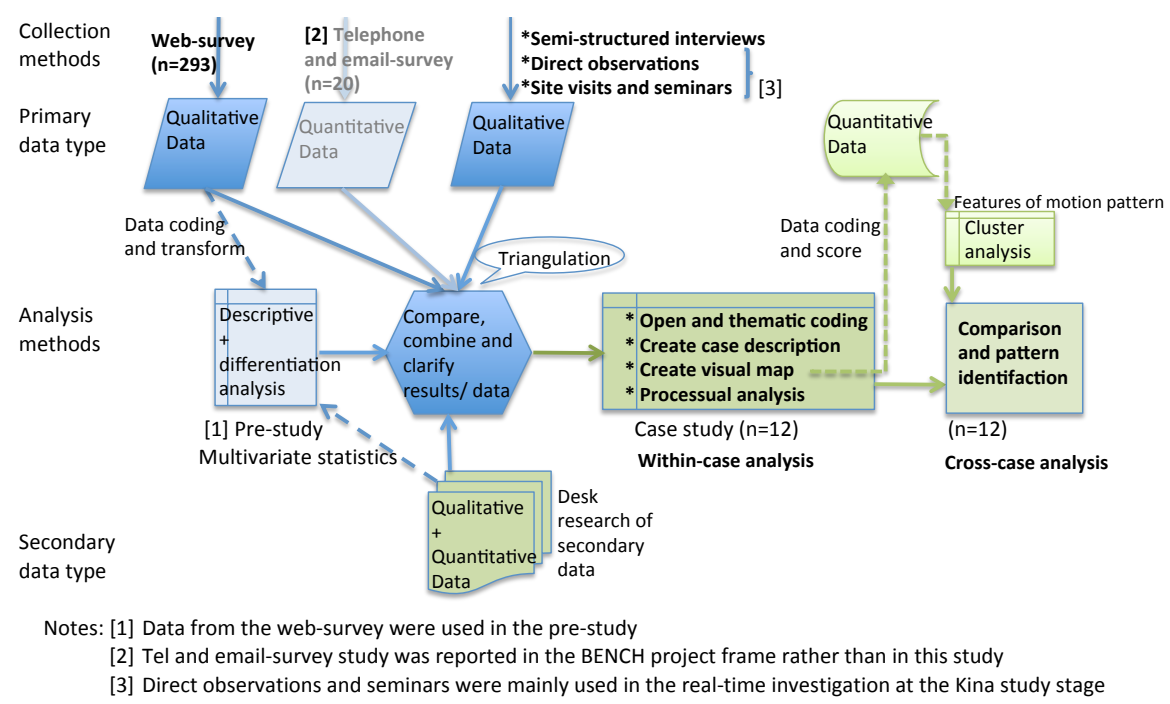

Figure 4.3: Overview of the data analysis procedure

\subsubsection{Qualitative data analysis procedure}

The analysis of the qualitative data in this study followed the steps suggested by Miles and Huberman (1994) for reducing data, displaying data and drawing conclusions.

Data verification In the Kina study stage, the analysis procedure started with organizing the interview transcripts and the field notes from the observations. These qualitative data were triangulated with the responses from the initial and the mini follow-up survey studies and other secondary data sources. Data verification in the EM extension study stage followed a similar procedure as in the Kina study stage. Interview data were triangulated with other secondary data.

Coding In the Kina study stage, the analysis started from the open coding of one single case. Open coding marked familiar and emerging new concepts and themes corresponding to the theories reviewed. Then, a process-based selective coding was used on the changes in conditions, interaction among the actors, strategies or actions and consequences thereof (Flick, 2009) to develop a thematic structure for the three other cases. The analysis replicated the coding from the first single 
case to the other cases.

In the EM extension study stage, a code book was developed based on thematic codes generated from the four in-depth cases in the Kina study stage. The procedure of coding was similar to that used in the Kina study stage. Expanded codes were generated and new themes emerged from eight additional cases. In the EM extension study stage, the text management program MAXQDA, Version 11, was used for coding to help make structuring and visualizing thematic codes clearer and easier in the within-case and cross-case analyses.

Ordering Since the sequence of time is important in processual analysis, the author used the method suggested by Pettigrew (1997) to organize the coded data in chronological order to identify any potential causal links among the epochs, episodes and events.

Interpretation and/or Storytelling Based on the preparation, the author wrote a single case story for each of the firms. In the Kina study stage, cases drafts were cross-checked with both the internal co-investigator ${ }^{32}$ and the key informants in the small firms. In the EM extension study stage, the author as a single investigator interpreted each case. Written case drafts were sent to key informants from the case study firms for verification and confirmation.

Additional complementing analytical devices or instruments Based on an operationalization of selected key concepts from the theoretical frame, a visualization tool was developed. It combines important time periods during internationalization and during the entry process in the EM, to complement the basic analytical framework designed in Section 2.8. This was done to show the changes and the interaction among the factors from the three levels identified in the literature studies on the internationalization process over a period of time.

Combined processual analysis The analytical model (Figure 3.3) and the historical performance of the firms were used in each case and cross-case analysis to show new patterns and influencing elements during the internationalization. The implementations of the analytic model are slightly different between the Kina study and EM extension study.

\footnotetext{
${ }^{32}$ This was Davidsson C., Project Manager of BENCH at Cleantech Östergötland (CTÖ).
} 
Implementation at the Kina study stage As explained earlier, the investigation used a real-time longitudinal design in the Kina study stage. Processual analysis of epochs and episodes were combined along with biographic history. Depending on the case, the analysis of the entry to the EM (e.g., the Chinese market) was either based on an analysis of critical events or on episodes, as shown by the red "EM entry" line in Element one of Figure 3.3. The mapping of the overall internationalization process of the firm mainly used the epoch type of analysis, as shown by the blue internationalization epoch line in Element one of Figure 3.3. Thus, the analysis at the first stage first focus on the mapping, and then on the Chinese market entry process.

Implementation at the EM extension study stage At the EM extension study stage, a real-time investigation was not feasible due to resource limitations and timing. Nevertheless, a longitudinal biographic history-based approach is still valuable for keeping a similar standard and common analysis procedure used in the Kina study stage. Important events related to internationalization of the firms are recalled and reflected by key informants, who have good knowledge about these events. Therefore, within-case analysis in the EM extension study stage is not at the same level of detail as in the in-depth cases, which used a real-time investigation.

\subsubsection{Quantitative data analysis procedure}

Inspired by studies from for example Kuivalainen et al. (2012), part of the results from the within-case analysis (e.g. mapping internationalization) was further transformed into quantitative data. This quantitative analysis is embedded in the overall qualitative study (Creswell, 2012) and final analysis. The analysis starts with assigning scores to quantify the degree of internationalization. It depicts the motion pattern of internationalization from three dimensions (e.g. scope, scale and speed) in two epochs for each case company. The quantitative analysis was performed to facilitate a common pattern identification among 12 cases. The study used BM SPSS version 22 to conduct a cluster analysis on the quantified data. The cluster analysis helped the author to explore and visualize identified motion patterns across the cases. More detailed information on the theoretical basis and operationalization of measurement is explained in Sections 2.1.3 and Section 3.2.2. The general procedure was as follows: 
Data transformation was based on the visualization results (e.g., mapping internationalization) and case interpretation from the within-case analysis. Quantifiable information related to the motion pattern of internationalization was extracted from each case.

Database preparation was based on extracting and scoring the three dimensions of the motion pattern for each case from two important epochs. The database consists of categorical variables and qualified scores on the scope, scale and speed of internationalization from 12 firms in their initial internationalization period and recent period (after the 2008 global crisis) for further analysis.

Data analysis used a statistical package, IBM SPSS Version 22, to perform the two steps in the cluster analysis. The analysis also used the JMP package from SAS to construct a 3D image to illustrate changes in the three dimensions of motion patterns across 12 cases. The graphic plot also offers a decision for an initial cluster number based on heuristics.

Results interpretation was based on the patterns identified from the cluster analysis and the visualization.

The quantitative analysis helped in the identification of the motion pattern changes across the cases. It benchmarked the motion pattern and offered a common ground for further qualitative analysis and interpretation of the findings. After interpreting the combined results from both qualitative and quantitative results, conclusions were drawn to answer the research questions.

\subsection{Evaluation criteria of qualitative research}

In the qualitative methodology literature, the question of how to evaluate the quality of qualitative studies is an on-going discussion. Different from quantitative studies, which tend to be context-independent or to quantify context variables, qualitative studies emphasize richness in context and multiple interpretations (Patton, 2002; Flick, 2009). Using validity and reliability to evaluate construct, measurements and replication, which is normal for quantitative studies, is therefore a bit ambiguous to use directly for qualitative studies (Flick, 2009). In general terms, validity refers to how good the designed 
instrument is at measuring the target concepts, while reliability refers to how consistent it is 33 .

For the case study method, Yin (2009) and Eisenhardt (1989) are among those with the most cited works. Yin (2009) uses Kidder and Judd's summary of validity and reliability as criteria for case studies. He emphasizes four quality criteria in case study evaluation: construct validity, internal validity (only relevant for explanatory or causal studies p.40), external validity and reliability. Eisenhardt (1989), on the other hand, uses Pfeffer's (1982) suggestion and emphasizes more the evaluation of the strength of the final theory developed from a case study. Despite some merits for both ways of evaluation, the terms, which Yin adopted directly from quantitative study (e.g. construct validity), could be questioned in a qualitative study context. Mishler (1990) reformulated the concept of validity to "validation as social construction of knowledge" (p. 417) in qualitative study. He suggested to achieve validation of study via the establishment of trustworthiness. Sinkovics et al. (2009) also advocate the importance of building trustworthiness in international business studies. In this study, the author followed this vein of arguments and used Lincoln and Guba's analogy (1986) to illustrate how the trustworthiness in this study was built up.

\subsubsection{Credibility and transferability - analogous to valid- ity}

Credibility is a core part of trustworthiness (Flick, 2009). Lincoln and Guba (1986) use the terms credibility as an analogy to internal validity - true value in quantitative terms. Credibility can be achieved by prolonged engagement, persistent observation, and triangulation (Flick, 2009). In the Kina study stage (the first stage of the main study), a real-time investigation was conducted to follow the entry process of small firms for one to two years on an EM (Chinese market). Interviews at different points in time from key internal informants and external stakeholders, and direct observations on different occasions (e.g., site visits, seminars, and "Nordic week") offered sufficient time for the author to get to know the case companies from statements made by many

\footnotetext{
${ }^{33}$ From a discussion with Professor P. N. Ghauri during the EDEN seminar on Doctoral Dissertation Writing in Vilnius on 29 June 2011.
} 
participants and actions observed on different occasions. Real-time longitudinal investigation and using multiple sources for the purpose of triangulation helped the author to acquire more credible information for the study. In the EM extension study stage (the second stage of the main study), a real-time investigation was not feasible. However, a longitudinal approach and a triangulation of primary data based on multiple sources still contributed to enhanced credibility. Those efforts were helpful in building up the credibility of the study.

Lincoln and Guba (1986) use the terms transferability as an analogy to external validity. It refers to whether propositions and/or hypotheses built up in the qualitative study are transferable to another time or a similar context (Davis, 1992). It requires the researcher to offer a detailed description of data (Guba and Lincoln, 1982; Davis, $1992)$ in order to offer other readers or researchers enough information about the situation of the research context. Then, other researchers can make their own judgments regarding its similarity and applicability to their studies (Davis, 1992). In this study, transferability was facilitated by presenting, with the most detail possible, the case description and the context in which this research was done. In addition, the study offers a special chapter (see Chapter 3 ) to give readers detailed information regarding the operationalization, measurement and implementation of important concepts in this study for the quantitative data analysis and its embedded qualitative analysis. All the chosen proxies of the concepts are based on the critical review of extant literature. These efforts can facilitate the transferability of this study.

\subsubsection{Dependability - analogous to reliability}

Reliability commonly refers to how consistent or replicable the results from the research process are (Davis, 1992). Several researchers have questioned whether reliability is a relevant term in qualitative studies (Golafshani, 2003; Flick, 2009). In qualitative studies, it is awkward to discuss reliability separately without the validity component (Davis, 1992; Flick, 2009). Reliability in qualitative studies has been interpreted as a consequence of validity (Davis, 1992; Patton, 2002). Lincoln and Guba (1986) use the term dependability as analogous to reliability. They do not explicitly define the term dependability but do give a suggestion on how to achieve it - through the use of an audit. Yin (2009) suggests using interview protocols in data collection in order to 
achieve reliability. Reflecting on these discussions, the author regards dependability in qualitative studies as a way to assure consistency in the data collection procedure and methods. Thus, the study used protocols for the data collection. As mentioned earlier in Section 4.5.2 on the interviews, in the Kina study stage, a co-investigator helped double-check the cases to ensure the quality. In the EM extension study stage, to enhance consistency in the investigation and analysis by the sole investigator, further improved protocols based on previous protocols at the first stage were used in the interviews. Furthermore, in this stage, the text management program MAXQDA 11 was used in coding and managing interview data to improve consistency in the analysis.

\subsubsection{Reflection on the role of the research student}

In qualitative studies, the researcher is a part of the tool for conducting research (Patton, 2002; Flick, 2009). To be aware of and reflective on the researcher's influence on the research is important (Flick, 2009; Alvesson and Karreman, 2012). During the Kina study stage in particular, the author had the opportunity to directly observe, and even be a part of, the investigated events. As a Chinese research student with previous industrial experience, living and studying in Sweden, the author had cultural awareness from both countries. For enhancing fairness (Lincoln and Guba, 1986) at the first stage of this study, the author teamed up with a native industrial practitioner in most data collection via interviews (for interviewers' information, see the column marked by in the Interviews part of Table 4.3). The combination of culture and industrial knowledge from both countries proved valuable and effective during the interviews. It offered a more balanced view and helped the author to make better sense of the context and data.

In addition, to shorten the distance between theory and practice, the author followed the suggestion by Van de Ven - "don't go it alone" 34 , June 27th, 2011) - which means to do research together with practitioners and stakeholders who are knowledgeable in the research area. In the Kina study stage, being part of the BENCH project gave the author a unique opportunity to engage different stakeholders from industry, academia and governmental organizations. The collection of empirics for this part of the study had consistent support and engagement from the project partners. Two

\footnotetext{
${ }^{34}$ From discussion with Professor A. Van de Ven during EDEN seminar on Doctoral Dissertation Writing in Vilnius, 2011-06-27.
} 
senior researchers (the author's supervisors ${ }^{35}$ ) were the main moderators at different seminars. In addition to the small firms who participated in this study, interviews and observations, this study received practical support from BENCH project partners in Sweden ${ }^{36}$. The author, as implementer of, observer in and conductor of this study, aimed to bring the knowledge and perspectives of these different stakeholders into this study.

\subsection{Ethics of the research}

When conducting qualitative research with multiple stakeholders involved, ethics and ethical behavior have to be considered. In this study, the author followed a few general principles and considerations suggested by Miles and Huberman (1994) and Lichtman (2012).

\subsubsection{Beneficence}

The aim of this qualitative research was to improve the understanding of the internationalization process of small firms. It required more interaction and different methods to gain a relevant understanding of the context from the small firms and their TMTs. The bottom line for protecting the participants in this study was to avoid unnecessary harm for them (Miles and Huberman, 1994). Lichtman (2012) suggests to be sensitive to the adverse reactions of the participants. In this study, the general business practices and operations in the small firms were investigated. All of the participants, such as founders and TMTs in small firms, were well-informed. The participants in the case studies were positive and cooperative during the study. The author tried to prevent potential harm via consent, anonymity, respect and fairness. For instance, in the initial survey study, three receivers expressed their unwillingness to join the study. As result, the author removed their names from the email list of the survey.

\footnotetext{
${ }^{35}$ Öhrwall Rönnbäck, A. Associate Professor in Industrial Marketing at Linköping University; Holmström, M. Senior Lecturer in Business Administration at Linköping University

${ }^{36}$ Cleantech Östergötland, Östsam and County Administration Board of Östergötland
} 


\subsubsection{Anonymity and confidentiality}

To protect privacy and sensitive information, as suggested by Miles and Huberman (1994) and Lichtman (2012), the author did not reveal the names of the companies and informants without their permission. All the data collected in this study were guarded based on confidentiality consent with the studied firms. In the survey study, all the identities of participants were treated as confidential. Their responses were not reported as individuals. In addition, when the author used financial data from the case companies, it showed the trend of change in the financial performance of the firms without explicit numerical data.

\subsubsection{Informed consent}

Based on the recommended considerations by Miles and Huberman (1994) and Lichtman (2012), a clear and honest communication with all participants about the aim and forms of the investigation in the interviews was maintained. All participants had full freedom in relation to whether they wanted to join different parts of the study and whether they allowed the interviews be recorded and so on. Interview transcripts in the Kina study stage and case descriptions in the extended study were reviewed by companies for clarification and consent.

\subsubsection{Intrusiveness}

In qualitative studies, there are some trade-offs in intrusiveness and degree of engagement (Flick, 2009; Lichtman, 2012). On the one hand, as researchers, the author and co-investigator(s) wanted to prolong the engaged time at the case sites to get more trustworthy data. On the other hand, there was a concern that it might take too long and intrude on the space of the informants, whose time is a scarce resource for their respective small company. During the Kina study stage, two groups of master's students also used two case companies as part of their empirics in their thesis writing. The author and the student groups tried to compile protocols and combine interviews to avoid redundancy and repeated intrusiveness. 


\section{Chapter 5}

\section{Within-Case Analysis}

This chapter is the first part of the analysis of the empirical data. Based on a common analytic frame and instruments developed from a literature study (see Section 2.8 and Chapter 3), the chapter presents a detailed analysis of four in-depth cases in the Kina study stage as well as a briefer analysis of eight cases in the EM extension study.

\subsection{Overview of the 12 cases}

As explained in the methodology chapter, the 12 case studies were conducted in two study stages. This section presents a brief overview of the four in-depth cases in the Kina study stage and the basic profile study of the 8 cases in the EM extension study stage. Detailed case illustrations can be found in Appendix B. Cases material is based on data collection from interviews, news reports from public channels, and economic information from the Retriever Business database for each case.

\section{Common EM-related (e.g. China) context of the cases}

All of cases companies were small or micro-sized firms at initial internationalization 37 from Östergötland county, Sweden. The case companies were operating under a

\footnotetext{
${ }^{37}$ Based on the EU definition, "small-sized" refers to firms with fewer than 50 employees and no more than EUR 10m turnover, while "micro-sized" refers to firms with fewer than 10
} 
common local, social, economic and institutional context, in which interaction and cooperation among universities (academia), industry and government - the so-called "triple helix" model - are highly valued and encouraged. Östergötland county government has had established official connections with Jiangsu, China since $1995^{38}$. Jiangsu is one of the richest provinces in China and one of the largest FDI receiver provinces from the Nordic countries (Zhang, 2012). In 1996, the Östergötland county government began to use these official relations for facilitating and generating business cooperation between the two regions. Local government-organized "China trips" with representatives from both the government and local businesses were conducted. These activities were supported by other governmental organizations such as the Consulate General of Sweden, the trade councils, the trade of commerce, etc. By March 2012, there were 12 official trips from Sweden to China. There were also incoming Chinese delegations from Jiangsu to Östergötland. All the case companies were aware of these activities, but two of them were more actively engaged than the other selected companies.

\subsubsection{The cases in Kina study stage}

The four cases companies in the Kina study stage were in different industry sectors. Two of them were high-tech equipment producers, while the other two were professional service companies. All of the firms were established or transformed into limited companies around early 2000. The selected companies worked in the B2B and B2G markets. Table 5.1 shows a brief overview of the four in-depth case firms (2012 data).

\subsubsection{The cases in the EM extension study stage}

The eight case companies in the EM extension study stage were from two different industrial sectors. Seven companies were manufacturers, while one firm was a distributor. All the companies had been involved in both inward and outward internationalization. For the purpose of this study, the focus was on the outward internationalization. All of the selected cases were small or micro-sized companies when they started internationalization. Up to the time of the investigation, only one firm had become a middle-sized company, while the other seven were small-sized companies based on the EU definition

employees and no more than EUR 2m turnover (European Commission, 2005).

${ }^{38}$ Olsson, S. Interviewed by: Zhang, Y. and Davidsson, C. (10th Sept. 2012) 
Table 5.1: Overview of the in-depth case companies

\begin{tabular}{|c|c|c|c|c|c|}
\hline \multicolumn{2}{|c|}{ Reference year 2012} & Firm MC1 & Firm MC2 & Firm SC1 & Firm SC2 \\
\hline \multicolumn{2}{|c|}{ Year of establishment } & 2002 & 2000 & 1999 & 2000 \\
\hline \multicolumn{2}{|c|}{$\begin{array}{l}\text { Prior experience as an } \\
\text { organization/firm }\end{array}$} & No & $\begin{array}{l}\text { Division of a } \\
\text { small firm }\end{array}$ & $\begin{array}{c}\text { Economic } \\
\text { association fr. } \\
1992\end{array}$ & $\begin{array}{c}\text { Economic } \\
\text { association } \mathrm{fr} . \\
1993\end{array}$ \\
\hline \multicolumn{2}{|c|}{ No. of employees } & 15 & 13 & 36 & 7 \\
\hline \multicolumn{2}{|l|}{ Industry } & Manufacturing & Manufacturing & $\begin{array}{l}\text { Professional } \\
\text { consulting }\end{array}$ & $\begin{array}{l}\text { Professional } \\
\text { consulting }\end{array}$ \\
\hline \multicolumn{2}{|c|}{ Type of market } & B2B & B2B & $\mathrm{B} 2 \mathrm{G}$ and $\mathrm{B} 2 \mathrm{~B}$ & $\mathrm{~B} 2 \mathrm{~B}$ \\
\hline \multirow{2}{*}{\multicolumn{2}{|c|}{ Type of clients (e.g.) }} & $\begin{array}{l}\text { Organizations } \\
\text { and institutions } \\
\text { in underwater } \\
\text { investigation }\end{array}$ & $\begin{array}{c}\text { Global leading } \\
\text { steel producers } \\
\text { (MNE) }\end{array}$ & $\begin{array}{c}\text { Organizations or } \\
\text { contractors in } \\
\text { nature } \\
\text { exploitation }\end{array}$ & Nordic MNEs \\
\hline & & $2-3$ years & $2-3$ years & 2-3 months & 1 year \\
\hline \multirow{3}{*}{$\begin{array}{l}\text { International } \\
\text { markets } \\
\text { engagement }\end{array}$} & Intl. start year & 2003 & 2000 & \multirow{3}{*}{$\begin{array}{l}2008^{*} \\
\text { Sporadic in one } \\
\text { foreign market }\end{array}$} & $2003^{*}$ \\
\hline & $\begin{array}{l}\text { Scope (No. of } \\
\text { markets) }\end{array}$ & Active $>10$ & Active $>20$ & & $\begin{array}{l}\text { Worldwide via } \\
\text { Nordic MNEs }\end{array}$ \\
\hline & $\begin{array}{l}\text { Extent } \\
\text { (operation } \\
\text { forms) }\end{array}$ & $\begin{array}{c}\text { Sales agents' } \\
\text { networks }\end{array}$ & $\begin{array}{l}\text { Sales agents' } \\
\text { networks }\end{array}$ & & $\begin{array}{l}\text { One shared } \\
\text { sales office }\end{array}$ \\
\hline
\end{tabular}

*The first international business-related event

Data sources: based on interviews, the Retriever Business database, and company homepages 
of number of employees. All of the case companies were in the B2B market. Table 5.2 provides a brief overview of the eight case firms (2014 data).

\subsection{Overview of the within-case analysis}

Based on the individual case illustration in the Appendix B, each within-case analysis consists of two parts. The first part consists of a longitudinal analysis on the potential changes in the motion pattern of the internationalization process in each case. This part uses the mapping instrument developed in Section 3.3 to answer the first research question: What are the major features in the pattern of small firm internationalization? The second part of the analysis has a focus on the context of the EM entry of each case. In the analysis of in-depth cases, the analysis of EM (e.g. China) entry is based on the three layers model developed in section 2.8 for answering the fourth research question: How does the perceived high market potential, with a high perception of risk (uncertainty) in the context of emerging markets, influence the changes in the internationalization patterns of small firms? The linkage between the primary analysis in the case illustration and the within-case analysis is shown in Figure 5.1.

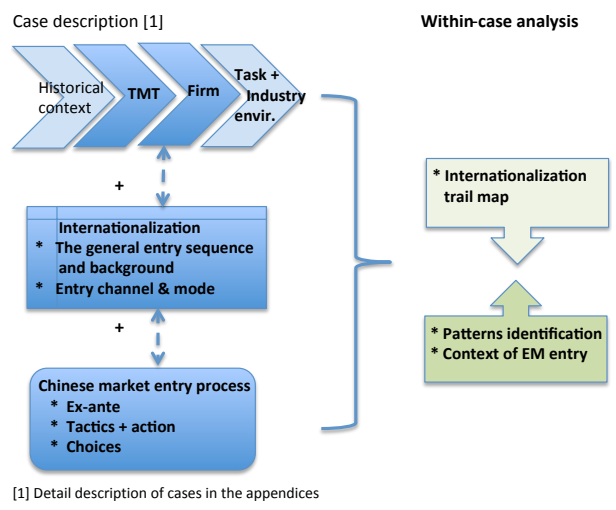

Figure 5.1: Structure of the within-case analysis 
Table 5.2: Overview of the additional case companies

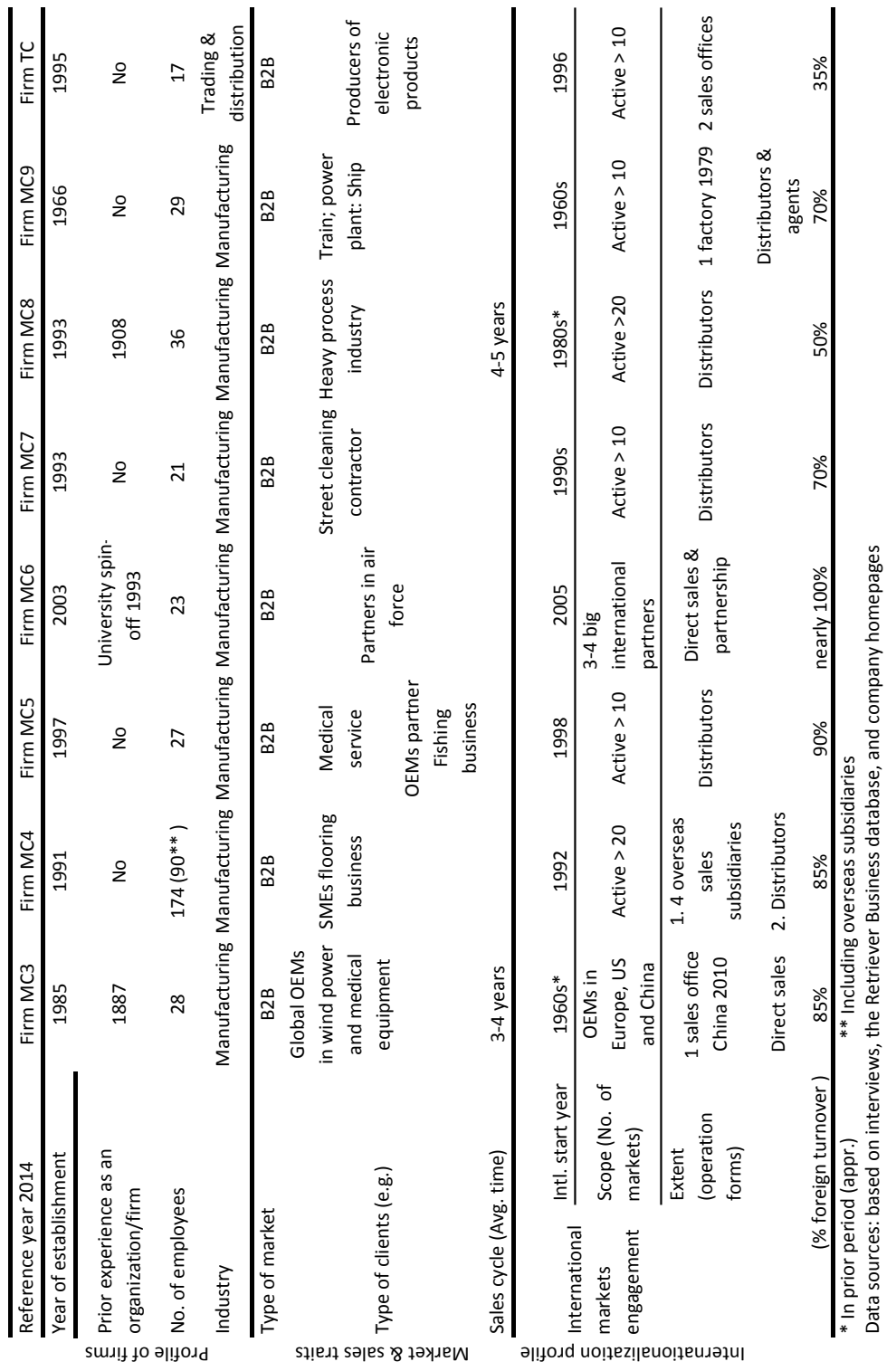




\subsection{Case A (MC1) analysis}

\subsubsection{Overview of MC1}

MC1 is a small Swedish high-tech equipment producer with 15 employees. In 2002, MC1 was established as a sub-system provider for end users and other big equipment producers. The firm became an equipment producer in 2007.

The products of $\mathrm{MC} 1$ are high value-added and few in units. The firm has a very small niche yet a worldwide market. $\mathrm{MC} 1$ works in the $\mathrm{B} 2 \mathrm{~B}$ market and its normal sales cycle is two to three years. MC1 has offered its products through direct sales and sales through foreign agents in fourteen different countries since 2007. The Chinese market entry of MC1 was motivated by mainly personal interests in 2007. Figure 5.2 shows a change in the turnover and the operating profit of MC1 over time.

MC1

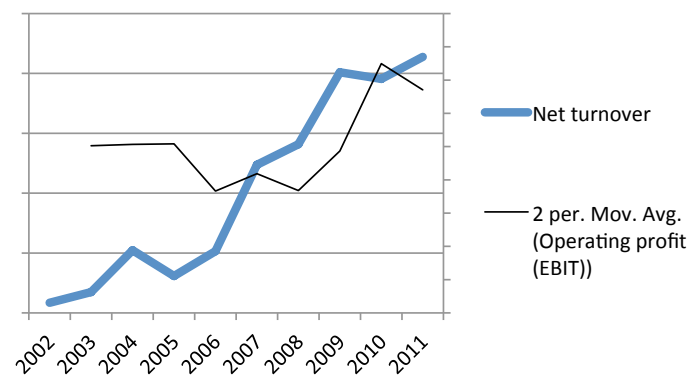

Data source: Retriever

Figure 5.2: Turnover and operating profit change of MC1 


\subsubsection{Feature changes in the internationalization process of $\mathrm{MC1}$}

To demonstrate the motion pattern of the internationalization of $\mathrm{MC} 1$, the internationalization trail map (Figure 3.2) - the tool developed in Section 3.3 - is used to visualize the overall internationalization pattern of the firm (Figure 5.3) in dual serials of "perceived risk (uncertainty)" (blue line with black symbol code for the scope and scale of market commitment) versus "perceived risk (opportunity)" (red line with red symbol code for the scale of market commitment).

When combining the internationalization motion pattern of MC1 in Figure 5.3 and its financial performance in Figure 5.2, these two figures show that the overall development of the firm follows its internationalization. The map reveals the firm's trials in different foreign markets over a number years. Figure 5.3 shows substantial motion along the spatial dimension toward perceived high uncertainty markets in different time periods. There are three peaks in the internationalization trail map.

\section{The initial epoch}

MC1 targeted international markets in its early days (Figure 5.3). The first peak in its initial epoch of internationalization was around 2004 (Year 2-3). At that time, MC1 was only a subsystem provider. The firm went to a handful of countries to explore international markets. Three were its Nordic neighbors in low-PD markets (less than 20 in PD index rank and within range of the first reference line PD score=1). Two markets were in higher PD markets (higher than 50 and within the third reference line). When compared with a motion track (the red line) along the "market potential index" (MPI) as a moderate element to counteract perceived high PD, there was only one foreign market, Australia, which was high in both proxies of index rank - PD indicator and MPI indicator. This market was also the only country where MC1 used a high control mode with a high commitment entry mode via establishing a sister company to operate in a foreign market. The field study of the MC1 case (see Section .2 of Appendix B) revealed that one of MC1's founders had previous business connections and work experience from Australia. At that time, business ties and market knowledge from the owners' earlier career facilitated distant market entry in the firm's early days. 


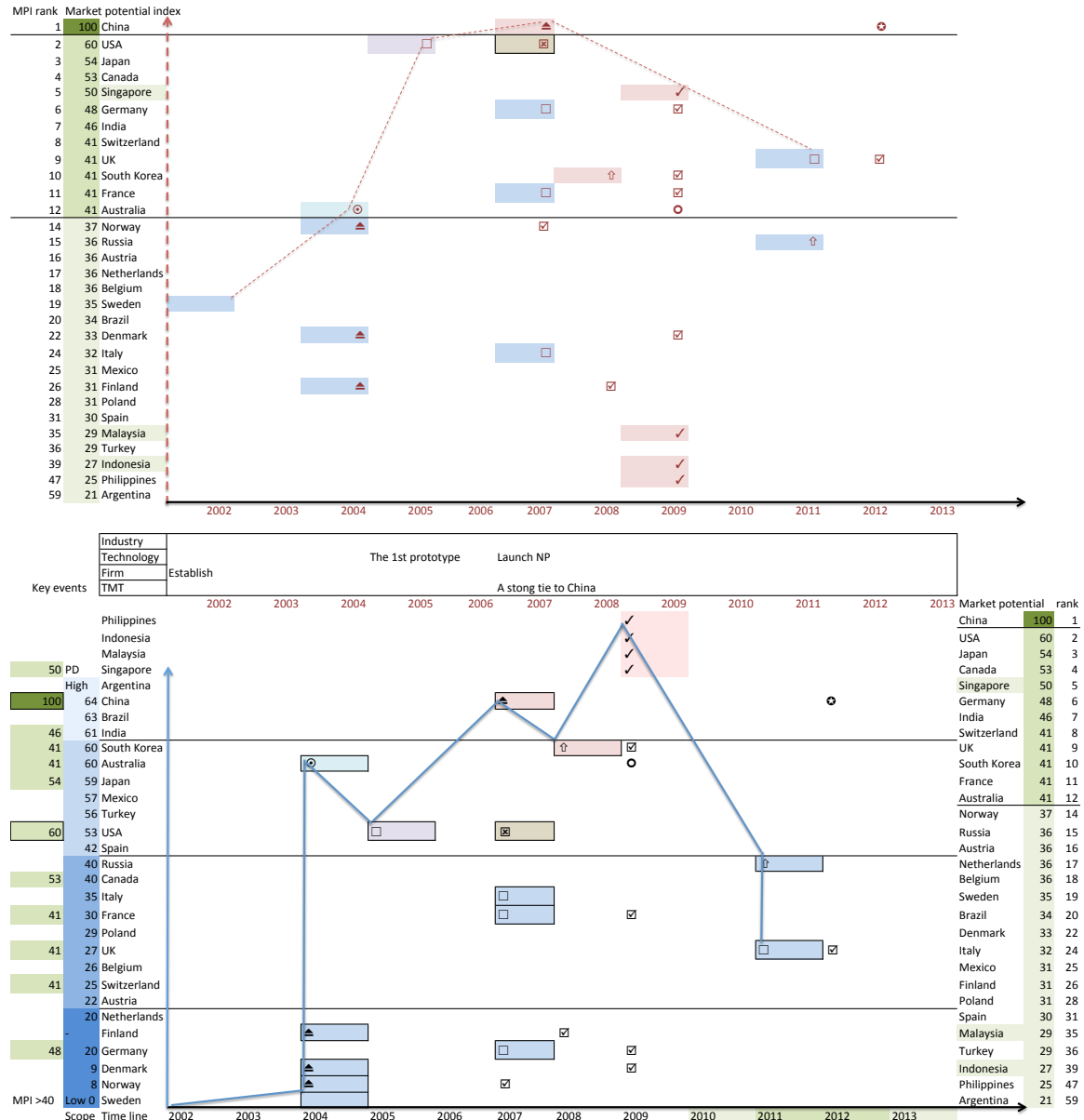

\begin{tabular}{|l|l|l|}
\hline EuropeN. Amercia & Aus + NZ & Color code of international markets \\
\hline Asia & S. Amercia & Middle East \\
\hline
\end{tabular}

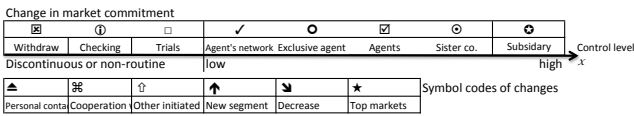

Data sources: interviews, information from public media, public database from Retriever and homepages of MC1

Notes: 1. The proxy of perceived uncertainty (in Plue line) represented by the psychic distance (PD) index, which is based on the studies from Häkanson and Ambos (2010) and Nordström (1991) 2. PD index (0-100) is color coded with blue into 4 levels: Lowl<21) Score=1 Low-medium (21-40) Score=2 Medium-high(41-60) Score=3 High (61-80) Score=4

3. The proxy of perceived opportunity (in red line) represented by a market potential index at country level, which is based on the studies from Cavusgil (1997) and Cavusgil et al., (2004) 4. MPI (1-100) is color coded with green into 4 levels: Low-medium (21-40) Score=2 Medium-high (41-60) Score=3 High(61-80) Score=4 Highest(>80) Score $=5$

Figure 5.3: The internationalization trail map of MC1 
Along with its international market expansion, the firm's turnover started to grow (see Figure 5.2) in 2004.

\section{The second epoch}

The second peak point was around 2007 (Year 5-6). The firm withdrew from one of its far distant foreign markets (PD score $=3$ ) and expanded to three other low-PD markets ( $\mathrm{PD}$ score $=1$ ) within Europe and one high-PD market in Asia (PD score=3). Compared to a motion track (the red line) along the "market potential index", the majority of the new expanded markets were relatively high (MPI score=3). The only high-PD (PD score=4) market entry was in the EM (China). It was triggered by a newly emerged family tie at that time, rather than a planned event. MC1 used low commitment with a low control mode in almost all of its foreign market. This epoch of international market expansion was facilitated by the new product launched in 2007, and MC1's financial performance boomed as a result (see Figure 5.2).

\section{The third epoch}

The third peak point was around 2009 (Year 7-11). MC1's international markets extended to four even higher PD markets (outside of the PD index). However, a large scope of international market coverage was achieved by having a very low extent of market commitment and control (score of entry mode=1). The firm gave exclusive agent rights in its first distant PD market from its early on, and used this agent's subsidiaries to cover other far distant markets in Southeastern Asia. In this epoch, the firm intended to enlarge its markets in major European countries. In its distant markets in Asia, China was the only market in which the firm actively engaged in. Other new markets, such as South Korea, were initiated by external inquiries rather than sought by $\mathrm{MC} 1$ as an intended target. The firm received continuous positive financial performance during this period (see Figure 5.2). 


\subsubsection{Findings in changes of motion pattern}

Combined with the mapping of internationalization (see Figure 5.3), Figure 5.4 shows changes in MC1's motion pattern in the three epochs during internationalization of the firm across the three dimensions.

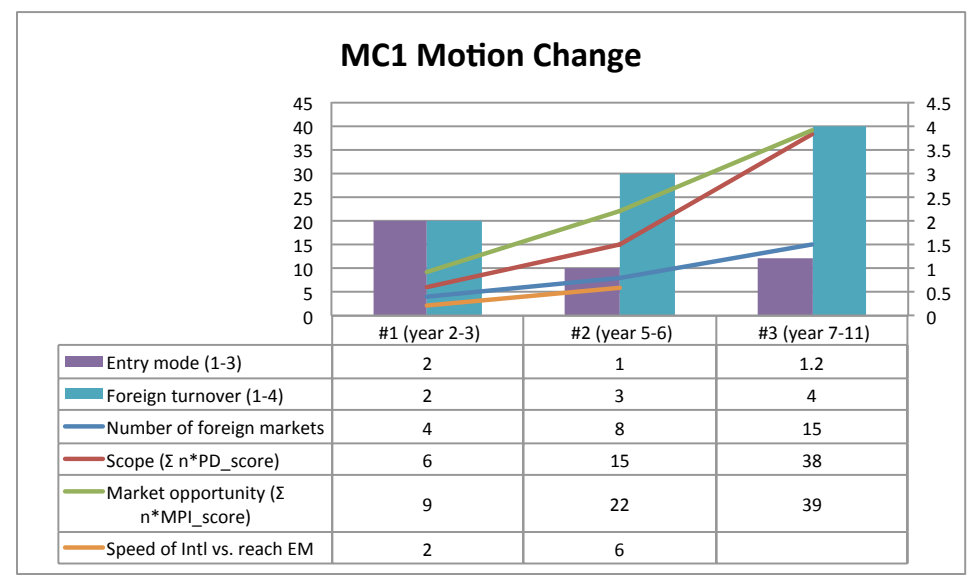

Figure 5.4: The internationalization motion pattern of MC1

Changes in the scope dimension As explained in Section 3.2.2, the scope of internationalization is expressed as Scope $=\sum_{n=0}^{i} n_{i} *$ Distance $_{\text {score }}$ in this study. In Figure 5.4, the changes of scope (the red line) and the number of foreign markets (the blue line) show that MC1 extended to high-PD markets gradually. MC1 started with a narrow scope in the first epoch with three neighbor country markets and one distant market. Despite being geographically stretched, all of the foreign markets MC1 entered during this period were based on previous business connections and the experience of MC1's owners. The scope of internationalization enlarged during the second and third epochs in terms of number of markets (see Figure 5.4).

Changes in the scale dimension The columns in Figure 5.4 show changes in two subdimensions of the scale of internationalization. The share of foreign turnover (the purple column) gradually increased in the second and third epochs. However, the score of entry mode (the blue column) decreased in the later epochs. MC1 
has used a low market commitment with a low level of control entry mode in most of its international markets. It often started with trials by direct sales. The firm then continued using local agents. However, there were changes and variance in these high- "psychic distance" markets. As shown in Figure 5.3, MC1 either increased (i.e. China) or decreased (i.e. Australia) its control mode.

Changes in the speed/tempo dimension The speed dimension is shown by the orange line. MC1 entered international markets very early (around Year 2-3, the first epoch). The tempo of international market expansion became fast with the new product launch (in Year 5, the second epoch). Later, the tempo began to slow down during the third epoch (around Year 10).

Changes in the financial performance related to internationalization The corresponding financial performance of $\mathrm{MC1}$ (see Figure 5.2) shows that the new product launch and its international market expansion in Year 5 (the second epoch) resulted in quick growth in terms of net turnover. It also resulted in a positive prospect and feedback from the international markets. Further internationalization contributed to an improvement in both net turnover and operational profit.

\subsubsection{EM (Chinese market) entry process (MC1)}

MC1's first trial in the EM (Chinese market) was in Year 6. The timing of MC1's Chinese market entry corresponded with its international market expansion in the second epoch period (see Figure 5.3). The fast tempo of international market expansion was fueled by a new product launch in 2007 (Year 5). Managerial focus at that time was to explore new markets in order to secure revenue from multiple international markets for compensating the investment in product development. Table 5.3 uses symbol codes to show the sequence of condition changes in the three-level "means pool" developed in Section 2.8 during China market entry (see Section .2 of Appendix B). This also illustrates changes in the process through time. 
Table 5.3: Three-layer effect analysis on the Chinese market entry of MC1

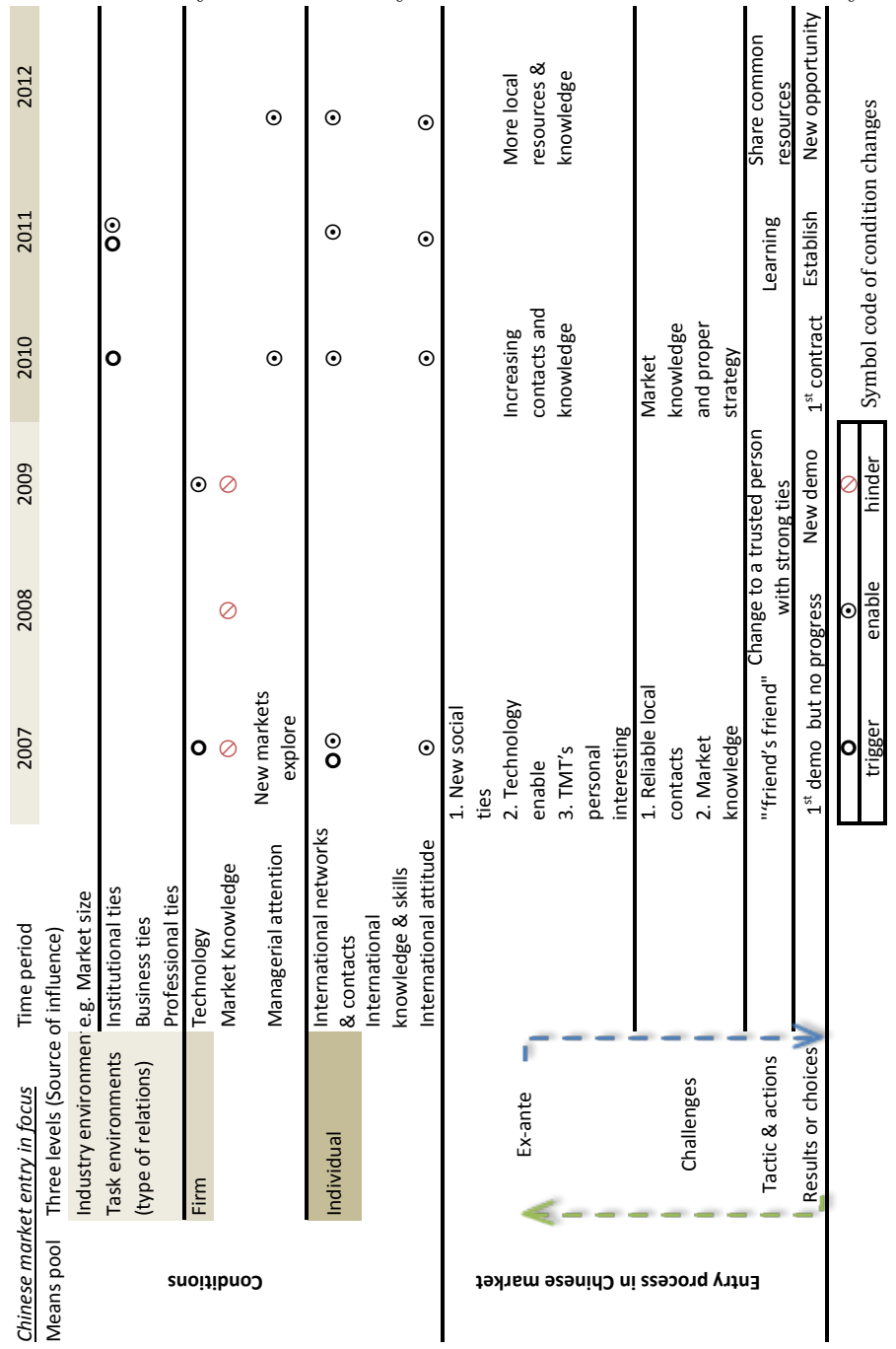




\section{Ex-ante of the Chinese market entry ("means")}

In Case A, the major triggers of MC1 to approach a big EM (the Chinese market) were from internal sources of the firm.

At the beginning of the second epoch:

"Means" at the individual level The trigger of the Chinese market entry was mainly from the TMT's strong social ties at an individual level. The strong personal interests led MC1 toward China. It also became a natural choice for $\mathrm{MC} 1$ to use direct export channels. In this case, emergent means from connections and networks at an individual level decreased the earlier perceived high-PD emerging market - the Chinese market. The TMT's personal interest oriented MC1 toward the Chinese market in the second epoch.

"Means" at the firm level The secondary trigger was from the firm level. Newly launched products triggered and enabled MC1's market expansion in general.

"Means" at the firm's environmental level There were no trigger from the external environment level.

In the third epoch:

"Means" at the firm's environmental level Triggers at the external level appeared in the third epoch. Institutional ties within MC1's Swedish regional networks encouraged and facilitated knowledge sharing and experience exchange between MC1 and other small firms.

\section{Challenges during the entry process}

There were two major challenges at the beginning of the Chinese market entry in the second epoch.

Local contacts Trust between the firm and local contacts regarding the reliability of the Chinese local contact person was a major issue in the Chinese market entry. In its distant and unfamiliar markets, MC1 tended to set stricter rules than in 
its nearby markets for its potential agents in order to reduce risk. During the second epoch period, both the potential agent and the TMT of MC1 felt insecure in investing resources without getting a final deal.

Knowledge of the local market MC1's previous international experience and market knowledge could not be directly used in the Chinese local market. The product was not adjusted for Chinese local conditions and the firm had to totally rely on its local contact person's knowledge and networks in the early period of entry process.

\section{Tactics and actions}

MC1 changed its tactics for coping with the challenges met in the Chinese market during the second epoch

Using strong personal ties The firm started to favor the use of a trusted and capable person with strong family ties in China after over two years with no progress in the Chinese market (over an average sales period of $\mathrm{MC} 1$ ).

In the third epoch:

Sharing resource After gaining more knowledge and contacts in the Chinese market, MC1 started to use both as a new common resource (means) to generate new business opportunities.

\section{Changes in results ("ends")}

There were changes in the results and choices during the second and third epochs.

In the second epoch, $\mathrm{MC} 1$ got a prospect and the first demon opportunity to the end customers in the Chinese market, but the firm could not get a deal.

In the third epoch, after changing to a local agent, the firm started to get contracts. In this epoch, by using knowledge and contacts accumulated during Chinese market entry, MC1 started to establish local offices in China and use its local contacts to generate more business opportunities for MC1's CEO. 


\subsubsection{Influence of the EM (China) context on the inter- nationalization of MC1}

In the $\mathrm{MC} 1$ case, despite having prior international experience and knowledge, the CEO had no intention to approach any of its current EMs (i.e. China and Russia) until either personal ties (e.g. in Chinese market) or external initiatives (i.e. in Russian market) appeared.

\section{Perceived high risk (uncertainty)}

"Psychic distance", which represented high perceived risk (uncertainty) (Dow, 2000; Nebus and Chai, 2014) still shows a strong influence in the MC1 intended market entry sequence. However, a strong personal tie which emerged in the second epoch moderated this perceived $\mathrm{PD}$ and made $\mathrm{MC1}$ initiate its first action in the EM (China). The perceived high uncertainty had even reinforced when the firm met challenges in the Chinese market. Until the firm found coping tactics, the impact from PD remained.

\section{Perceived high opportunity}

In Case A, a large growth potential in the EM (China) had not attracted MC1's attention in the beginning. However, once the firm started to enter the Chinese market and to accumulate local market knowledge and networks, other additional business opportunities began to emerge.

\subsubsection{Behavior patterns of MC1}

From the timing of its EM (China) market entry in a sequence of the firm's overall international market entry (see Figures 5.3 and 5.4 and Table 5.3), the firm intended to either enter those nearby markets or the markets in which the TMT of MC1 had prior knowledge and contacts. This reflects the "risk aversion" and "uncertainty reduction' (Figueira-de Lemos et al., 2011) logic discussed in Section 2.5. 
In the EM (China) entry process, MC1 was implementing stricter rules in agent selection in order to reduce the risk of unfamiliar new contexts. Meanwhile, MC1 also fully mobilized its newly acquired and emergent "means" - connections and ties in the Chinese market - to create new business opportunities. These actions began from available "means" and allowed "ends" to emerge along the way. This reflects "opportunity seeking" behavior based on the effectual reasoning logic proposed by Sarasvathy (2008).

\subsection{Case B (MC2) analysis}

\subsubsection{Overview of MC2}

MC2 was founded as a micro-firm based on a division of a small technology-based firm at the end of 1999. The firm is a leading supplier of optical flatness measurement equipment for the steel and metals industries worldwide. The systems developed by MC2 are also high value-added and few in units. The sales cycle of the system is two to three years, and the firm's clients are leading metals producers worldwide.

MC2 entered the international markets very early. Up until now, its market has reached about 30 countries. MC2 has had interest in the Chinese market since 2003. However, the company did not make any progress during that time. In 2011, its interest in the Chinese market revived again due to strategic reasons. Figure 5.5 shows the turnover and operating profit of $\mathrm{MC} 2$ over time compared to the trade change in its industry.

\subsubsection{Feature changes in the internationalization process of MC2}

Figure 5.6 shows the overall internationalization motion pattern of MC2 in a dual serial of the "perceived risk (uncertainty)" represented by "psychic distance" as a proxy (the blue line with black symbol code for the scope and scale of market commitment) versus the "perceived opportunity" represented by "market size" at the industry level as a 


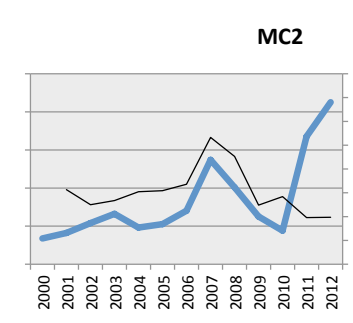

Data source: Retriever

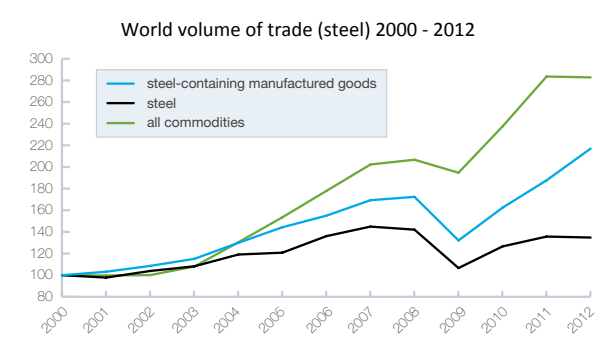

Source: World Steel Association

Figure 5.5: Turnover and operating profit change of MC2 vs. trade change in its industry

proxy (the red line with red symbol code for the scope and scale of market commitment).

Figure 5.6 reflects three large motions along the spatial dimension toward perceived high risk (uncertainty) markets in different time periods. The combination of Figures 5.6 and 5.5 shows that the MC2's timing in market expansion and its corresponding financial performance over time. Figure 5.5 also shows that MC2's performance mirrors the development of the steel industry.

\section{The initial epoch}

MC2 went to an international market right from its start-up period (less than two years). The first peak point was during Year 1-3 (see Figure 5.6). From the spatial dimension along "psychic distance", there was a small range of motion in the first epoch. This means that MC2 went to neighboring EU countries from the beginning. Most of its early trials in different foreign markets during this period were within the second reference line, with a PD score of 1-2. Compared to the market potential index, this shows that only one of MC2's foreign markets within the first reference line of the "psychic distance" (PD score=1) was in the top five of the "market size" index - Germany. From the field study, it was also confirmed that Germany was the only foreign market contributing to MC2's turnover during that time. 


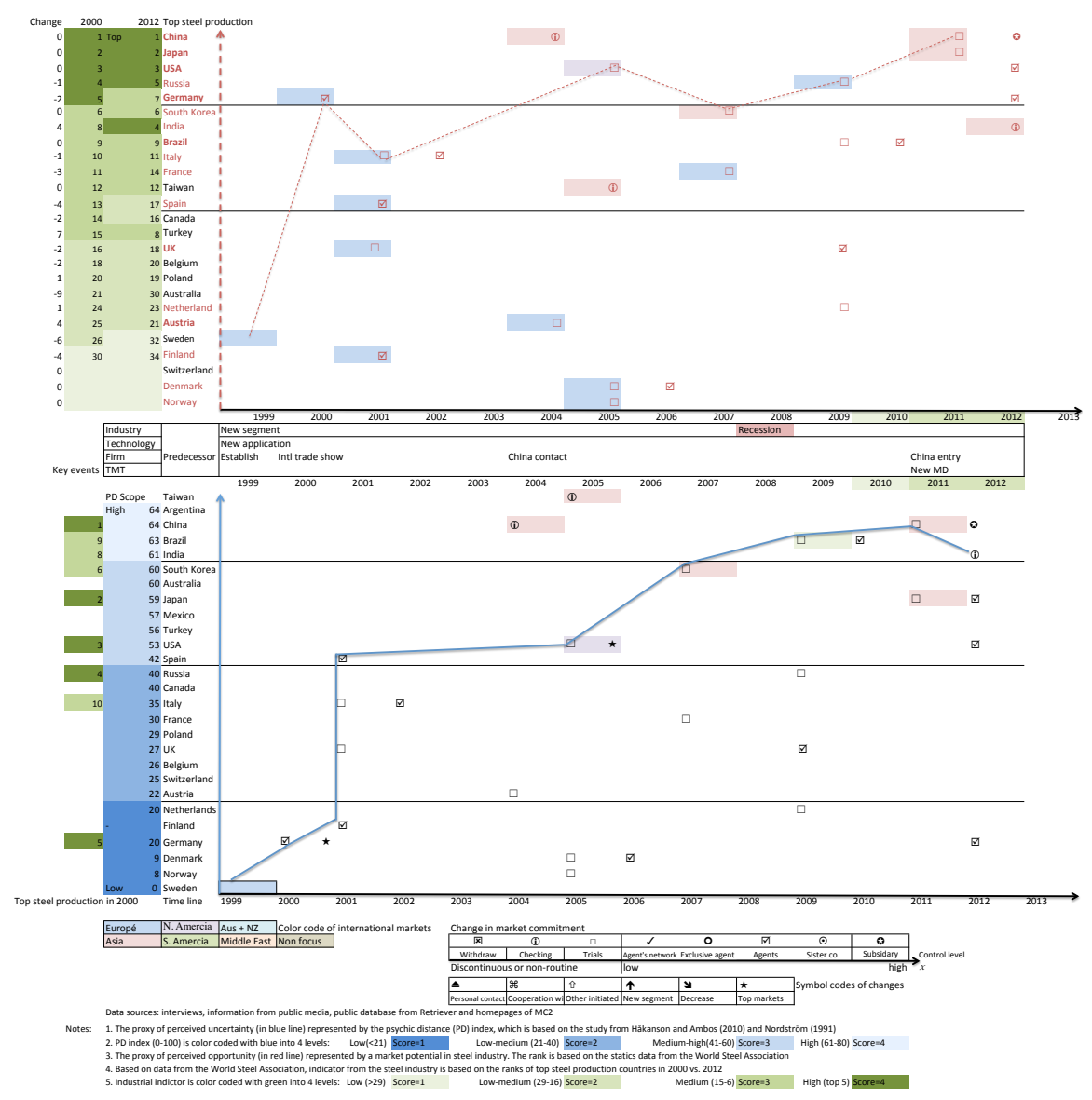

Figure 5.6: The internationalization trail map of $\mathrm{MC} 2$ 


\section{The second epoch}

The second peak point was during Year 7-9. On the one hand, MC2 went to few top markets in the steel industry. These markets were also in a higher "psychic distance" range (PD score: 3-4). On the other hand, MC2 tried to establish itself in close neighboring markets with very low market size in the steel industry. In the second epoch, there was a small episode related to the Chinese market entry. However, the firm had not continued due to perceived low needs from the market during its initial visits. The increased share of turnover from foreign markets contributed to the firm's financial performance during the second epoch (see Figure 5.5).

\section{The third epoch}

The third peak point was around Year 11 to Year 14. The 2008 global economic crisis had a large impact on the steel industry and MC2's clients. The world steel industry had been negatively influenced by the recession, which also pushed MC2 into a deep financial valley (see Figure 5.5). This period was right after the 2008 global economic crisis. During this epoch, MC2 had recovered from the recession and started to stretch out along the spatial dimension toward high PD markets (South Korea, Brazil). This was also a turning point in the firm's financial performance (see Figure 5.5). Early in the third epoch, turnover had increased along with its market expansion. At the end of the third epoch, the firm started to focus on the top markets regardless of the "psychic distance". MC2 reached the top three steel production countries, which included the big EM (China). In this epoch, the firm started to use a high control entry mode in its target EM (the Chinese market).

\subsubsection{Findings in changes of motion pattern}

Based on the main epochs shown in Figure 5.6, Figure 5.7 displays the changing features of MC2's motion pattern in three dimensions of internationalization motion pattern during three epochs. Combined, the two figures reveal the scope, scale and tempo of internationalization during the MC2's international market expansion.

Changes in the scope dimension The scope of the motion pattern is calculated 


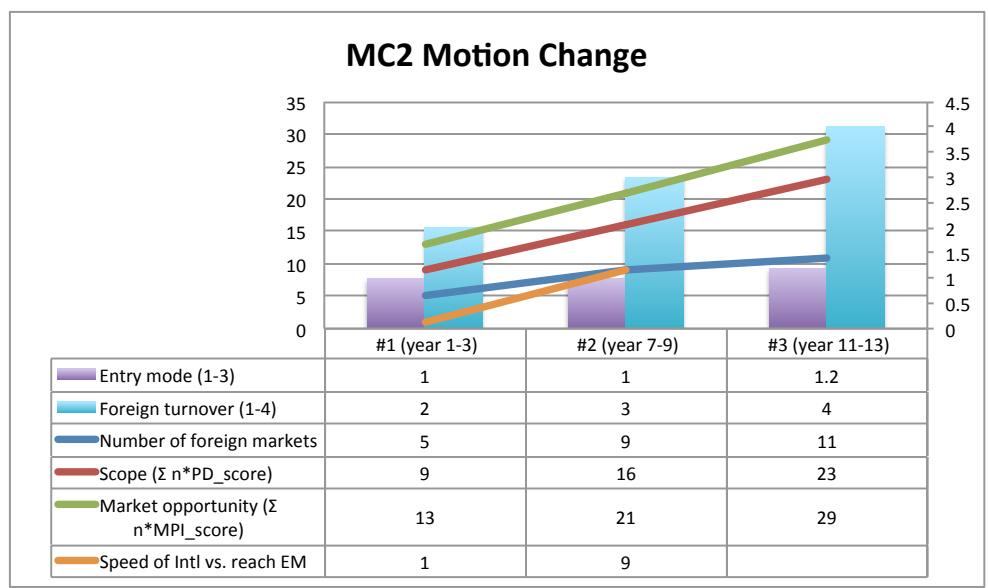

Figure 5.7: The internationalization motion pattern of $\mathrm{MC} 2$

by $S$ cope $=\sum_{n=0}^{i} n_{i} *$ Distance $_{\text {score }}$ in this study. The number of international markets has gradually increased during the three epochs. However, some markets developed during the first epoch did not last to the recent epoch. The scope of its internationalization gradually expanded from a European focus (PD score=1-2) in the first epoch to a leading market focus in the later epochs. These leading markets have greater market potential $($ score $=4)$, while their PD scores are also high $(\mathrm{PD}$ score $=3-4)$. Figure 5.7 shows that an increase in the scope dimension corresponds to an increase in its market potential score.

Changes in the scale dimension MC2 is only involved in the outward and market expansion-related internationalization. Due to size limitations and traits of the sales process, MC2 uses a low-resource commitment mode in the international market. Except for direct sales, the firm mainly uses alliance and sales through agents to reach its end customers in a geographically scattered market (see Figure 5.6). Moreover, due to the low control mode, it is hard for $\mathrm{MC} 2$ to sustain sales activities in each market. Therefore, in terms of the extent of control over value chain activities in foreign markets, MC2's internationalization is rather moderate. Regarding its foreign market turnover, the percentage of its turnover from foreign markets was rather high from the start. At the end of the first epoch, the turnover from Germany had reached about half of MC2's turnover at 
that time. The foreign market turnover of the firm reaches more than $90 \%$ in the recent epoch,.

Changes in the speed/ tempo dimension MC2 went to the international market right from its start. The tempo of internationalization, in general, was rather quick in all the epochs. However, in the first epoch, MC2 was mainly focused on low-PD markets. Not until the last epoch did the firm begin to focus on a few large EMs in high-PD markets with high market potential (see Figure 5.6).

Changes in the financial performance related to internationalization The corresponding financial performance of MC2 (in Figure 5.5) shows that international market expansion in the third epoch started to revive MC2's performance. Focusing on the leading markets during the last epoch helped MC2 to quickly recover from the market recession.

\subsubsection{EM (Chinese market) entry process (MC2)}

In Case B, the major triggers of $\mathrm{MC} 2$ to approach the Chinese market were from both external and internal sources (see Section .3 of Appendix B). MC2 started to approach the Chinese market very early, but the early trial did not last long. In this case, there were two trials. In the second epoch, there was a short episode related to MC1's first trial in approaching the Chinese market. In the last epoch of MC2's international market expansion, there was a longer epoch related to the Chinese market entry. Table 5.4 uses symbol coding to show the changes in conditions between the second epoch and the last epoch, as well as the impact on the Chinese market entry process.

\section{Ex-ante of the Chinese market entry ("means")}

In the first episode related to the Chinese market entry during Year five:

"Means" at the firm's environmental level From an industry level, with the top steel production in the world, the Chinese market became a very interesting target for MC2. The huge potential market size was a major trigger to catch the firm's attention. Professional connections from MC2's domestic alliance bridged 
Table 5.4: Three-layer effect analysis on the Chinese market entry of MC2

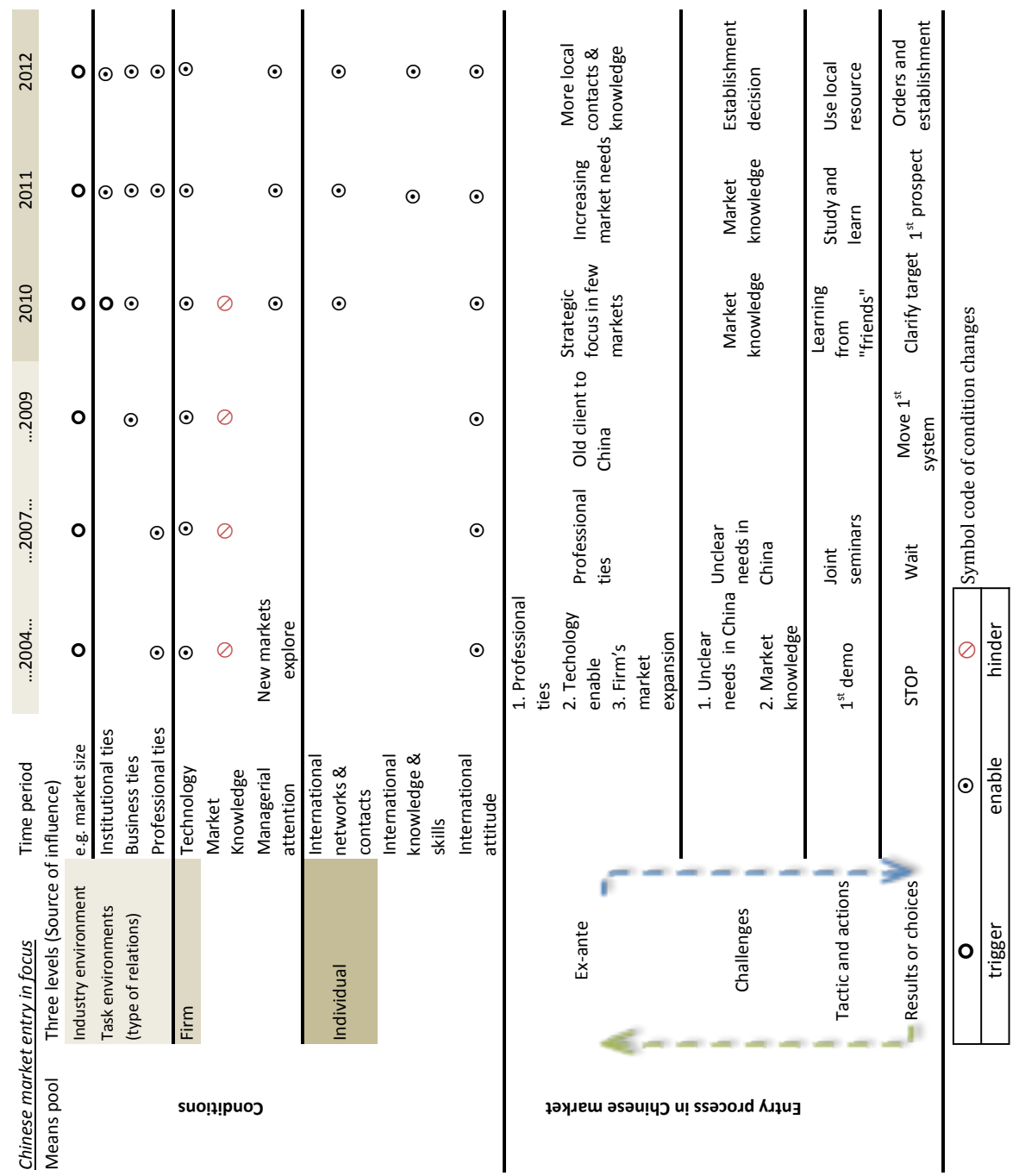


the firm to one of the leading producers in China. Therefore, in this case, triggers from the firm's industrial and task environment played a big role in $\mathrm{MC2}$ approaching the EM (Chinese market).

"Means" at the firm level A trigger from the firm level was its innovative technology. This requires world-leading users' adoption in order to create the needs in MC2's niche market. The managerial attention had focused on the new market exploration at that time.

"Means" at the individual level From an individual level, the previous CEO of MC2 had an open attitude to those markets with high "psychic distance" yet with large market potential in the steel industry. Therefore, the firm from its early days had already expressed interest in the leading markets in its industry (e.g. the US and China).

The conditions in three levels did not change much before the third epoch, except for a perceived low short-term prospect from the Chinese market based on MC2's experience from its earlier trials. The conditions started to change at beginning of the third epoch.

"Means" at the firm's environmental level In the beginning of the third epoch, the whole industry was still recovering from the global economic crisis, while the Chinese steel industry started to upgrade. It was at this point that the potential needs for MC2's offerings in the Chinese market began to emerge.

From the task environment, two western competitors and a Swedish client of MC2 introduced and brought the technology into the Chinese market. The awareness of the technology in the Chinese market was increasing. In addition, MC2's international alliance also held a series of seminars in Asia (e.g. China and India) to introduce the latest technology.

"Means" at the firm level After a difficult time during the economic crisis, the firm started to adjust its strategy. Instead of jumping into many markets with limited market size, MC2 began to focus on a few leading markets in the third epoch.

"Means" at the individual level In the third epoch, MC2's new CEO was mainly in charge of the Chinese market study. He mobilized his previous networks with experience from the Chinese market in similar industries to learn the market. 


\section{Challenges during the entry process}

In the first episode, it was not good timing for MC2 to enter the market. The awareness of the technology was quite low in the Chinese market. The leading producer that MC2 contacted at that time had no urgent need to adopt the technology in its production lines. In addition, the firm used personal contacts from its professional networks. It had neither searched other channels nor contacted other potential clients.

At the beginning of the third epoch, the needs from the market were emerging but there was one major challenge in MC2's Chinese market entry.

Knowledge of the local market Despite a few business trips to China, MC2 had little knowledge about the local market. In the earlier trial, MC2 went through personal channels and had not done a study about the Chinese market before. The previous CEO of MC2 perceived the Chinese market very differently from MC2's nearby European markets in terms of the culture, the industry development level and the influence of some unidentified stakeholders on the buying and decision making of MC2's target state-owned leading producers. However, MC2 did not study the market, the target group or how to handle these difference in the earlier episode. Therefore, the local market knowledge was lacking at the beginning of the third epoch.

\section{Tactics and actions}

In the first episode, $\mathrm{MC} 2$ used a contact person from its professional network to directly reach the potential client in China. However, the leading producer at that time did not seem ready to adopt MC2's technology yet.

In the third epoch:

Dedicate personnel Based on previous the international experience and networks of its new CEO, MC2 appointed him as the key person to study and approach the Chinese market.

Learn from the experience of "friends" The new CEO went to his previous colleagues and friends, who had experience in the Chinese market, to learn and 
ask for information and suggestions. Together with networks and connections of the previous CEO and alliance partners, MC2 learned and used knowledge and information from these "friends" in the business.

Use governmental trade agents Based on suggestions from friends, MC2 identified a capable consultant from the Swedish Trade Council in China to conduct a market study and arrange further meetings with identified stakeholders of target clients.

Contact Swedish experts working in China At the same time, MC2 also used its professional ties to contact Swedish industry experts, who work in the Chinese market as technical consultants, for suggestions and recommendations.

Use local industry experts recommended by partners To overcome the shortage of local market knowledge and a local industry network, MC2 started to search for potential local agents and talent with the right network, competence and communication skills for developing the Chinese market. The firm found a solution based on recommendations from its alliance friends.

Adapt the marketing materials into the Chinese context Based on knowledge gained from friends and business acquaintances, the firm also adapted its marketing materials to Chinese and designed them to fit the Chinese preference.

\section{Changes in results ("ends")}

There were changes in the results after the first episode of trials in the Chinese market and at the end of the third epoch.

After the first episode, the firm stopped its trials in the Chinese market because its perceived market needs were still weak at that time. Nevertheless, MC2 still occasionally went to China and other big EMs in Asia with its alliance partners to foster future needs in these markets.

In the third epoch, after getting the right information, recommendations and help from "friends" and partners, the firm held a round of demonstrations for its identified client 
together with important stakeholders. MC2 started to get invitations in the bidding process and the firm secured contracts in a short time. MC2 began to make further commitments in the Chinese market by establishing its first overseas sales office in China.

\subsubsection{Influence of the EM (China) context on the inter- nationalization of MC2}

In the MC2 case, the firm's CEO paid attention to the Chinese market quite early, due to the market potential in China.

\section{Perceived high risk (uncertainty)}

In Case B "psychic distance" represented by high perceived risk (uncertainty) (Dow, 2000; Nebus and Chai, 2014) influenced the beginning of the sequence of MC2's foreign market entry. MC2 started from its nearby markets with low "psychic distance" in the first epoch. However, except for Germany, the feedback from other neighbor markets was rather limited. Figure 5.6 shows that in its early period of internationalization, the firm intended to cover those nearby European markets. The upper part of Figure 5.6 shows that only Germany was in the top five markets by then. MC2 started to approach other distant markets with a large market size. China was the first EM in a high"psychic distance" market with high market potential, and the firm approached this market during the second epoch. However, during the first business-related encounter, the experienced difference between the Chinese market and other neighbor markets increased the perceived risk (uncertainty) of the CEO. MC2 began to adjust its shortterm prospects from the Chinese market and waited for better timing.

\section{Perceived high opportunity}

In Case B, a perceived "high opportunity" represented by market size (Ellis, 2008) shows a stronger influence on the sequence of MC2's internationalization, especially, after MC2 suffered from the economic crisis. Combined with the financial performance of MC2 (see Figure 5.5), Figure 5.6 shows a clear movement toward the markets with 
large steel production (the top reference line in Figure 5.6), regardless of the "psychic distance" in the last epoch.

\subsubsection{Behavior patterns of MC2}

The MC2 case reflects a Schumpeter type of entrepreneurs behavior, which is to break status quo market equilibrium through an innovation (Kirzner, 1999), until other competitors catch up. The firm and its entrepreneur started by finding a new application for its cutting-edge technology innovation in domestic and nearby markets to generate opportunities. However, its motion patterns and sequence of foreign market entry during the internationalization reflect a variance in behavior patterns.

In Figure 5.6, illustrated motion patterns in different time periods reflect how the firm's behavior patterns over time are not consistent. In the first epoch, MC2 intended to cover nearby markets with low perceived risk (uncertainty) reflected by low "psychic distance", despite their limited market potential. This type of motion reflects the firm's "risk aversion" tendency in order to limit the additional cost associated with the "liability of foreignness" (Eden and Miller, 2004) in the high "psychic distance" markets. It is based on causal reasoning and managerial consideration (Sarasvathy, 2008).

In the second epoch, MC2 began to move toward top market potential countries with high perceived PD, where the firm's MNE clients had their local production lines. Nevertheless, the firm's main attention was still on Europe. Not until the economic crisis, after MC2 faced a serious financial challenge (see Figure 5.5), did the firm begin to strategically focus on the leading markets exploration. This type of behavior started with roughly defined "ends" and followed by gathering "means" to achieve "ends" (see Section 2.5.3). It is a strategic behavior (Sarasvathy, 2008)

From its Chinese market entry process (see Table 5.4), the firm began with an opportunityseeking type of behavior. The firm started with using an encountered "means" (Sarasvathy, 2008) from its existing professional ties during the second epoch, when it found most of its market coverage in nearby European markets did not bring revenue. In the second period of trials, although MC2 did not expect quick feedback from the Chinese 
market and to get established in the market very fast, the firm started with a general "ends" and used its available means from its internal and task environments. As a result, MC2 had a quick entry in the third epoch.

\subsection{Case C (SC1) analysis}

\subsubsection{Overview of SC1}

SC1 is a small ecological consultancy company. It was a spin-off from Linköping University and was founded in 1992 by young research assistants in biology. The firm began as an economic (business) association with three founders but it had no employees until 1999, when it converted into a limited company. Its main clients include municipalities and infrastructure contractors whose projects require environmental evaluation and planning.

The market of SC1 is mainly $\mathrm{B} 2 \mathrm{~B}$ and its focus is domestic. The sales cycle of its service is two to three months. Its international market attention was triggered by an invitation to the "China trip" in 2008. Despite its interest, the firm did not know how to create business opportunities from its professional knowledge in the Chinese market. The firm's interest in China was dormant for two years until it encountered a China-related EU project in the end of 2010. Since then, SC1 has started another trial. Figure 5.8 shows the change in turnover and operating profits of SC1 overtime.

\subsubsection{Feature changes in the internationalization process of SC1}

Figure 5.9 shows the overall internationalization motion pattern of $\mathrm{SC} 1$ in dual serials of the "perceived risk (uncertainty)" represented by "psychic distance" as a proxy (the blue line with black symbol code for the scope and the extent of market commitment), versus the "perceived opportunity", represented by MPI as a proxy (the red line with red symbol code for the scope and the scale of market commitment). 


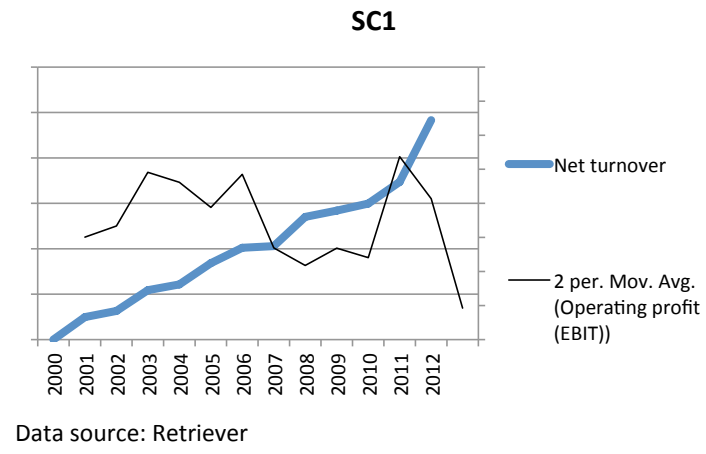

Figure 5.8: Turnover and operating profit change of SC1

Figure 5.9 shows that there are two periods of significant motion in the trail map. The first one was around Year 9, and the other around Year 11 to Year 13. The initial motion was an event and it stopped rather quickly. The second motion lasted until the end of the investigation period.

\section{The initial event}

SC1 has had a long-time domestic focus. The first international business-related episode was in Year 9. SC1's initial thought was to do business in Denmark, one of its Nordic neighbors (see Section .4 of Appendix B). However, the real trial was in the largest EM - the Chinese market. This market is in a high "psychic distance" from Sweden, while it is also the top one regarding MPI. Figure 5.3 shows that SC1 started this trial when its operating profit was declining. This trial stopped within a few months.

\section{The late epoch}

The second peak point was during Year 11 to 13 . The motion pattern is similar to the initial episode (see Figure 5.9). The difference between this epoch and the previous event is that SC1 began to gather market information in the nearby markets as well (e.g. Finland and the UK). 


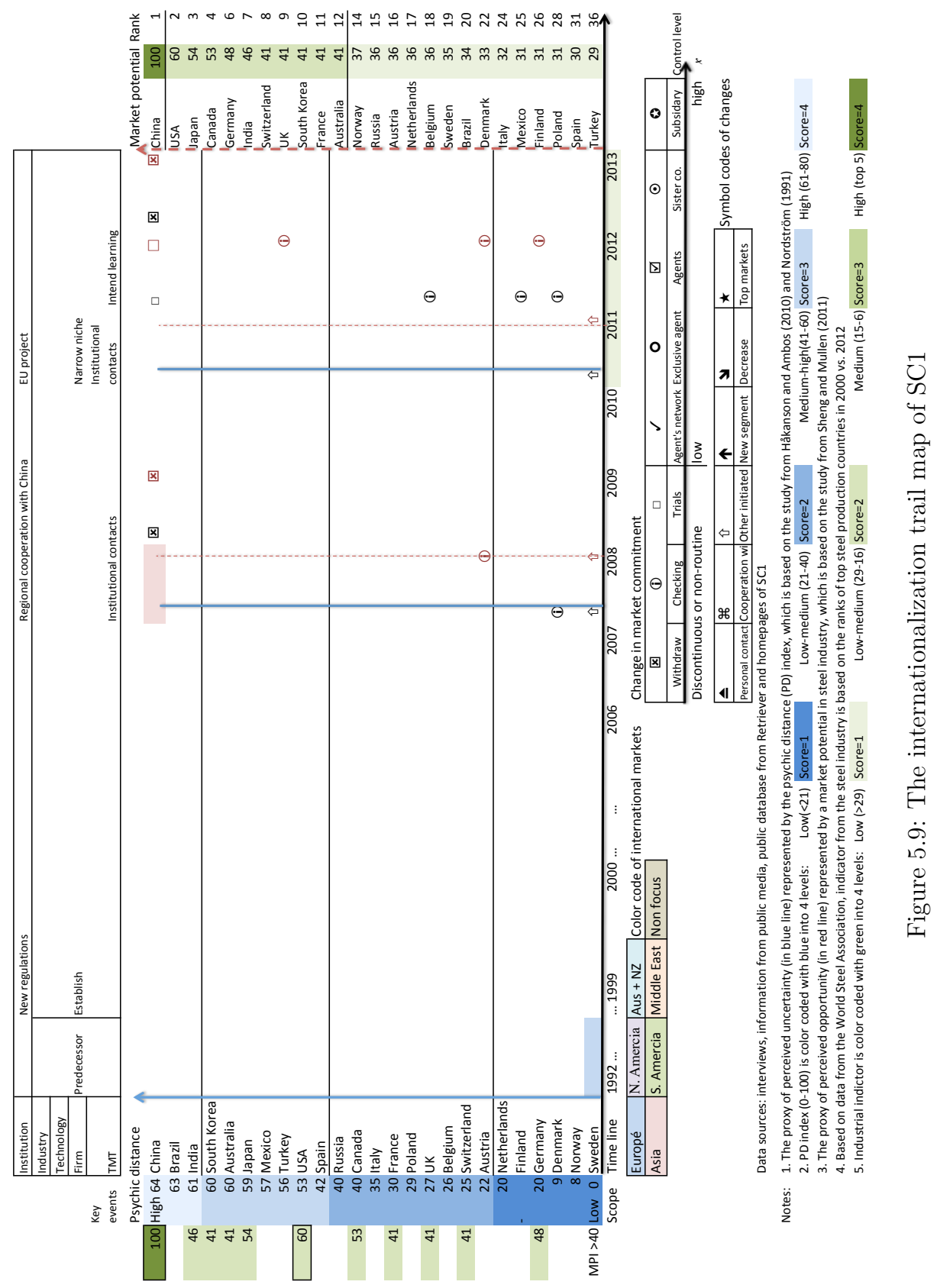




\subsubsection{Findings in changes of motion pattern}

Based on the initial event and latest epoch appearing in Figure 5.9, Figure 5.10 shows changes in MC1's motion pattern in the important event and epoch during internationalization of the firm in the three aspects.

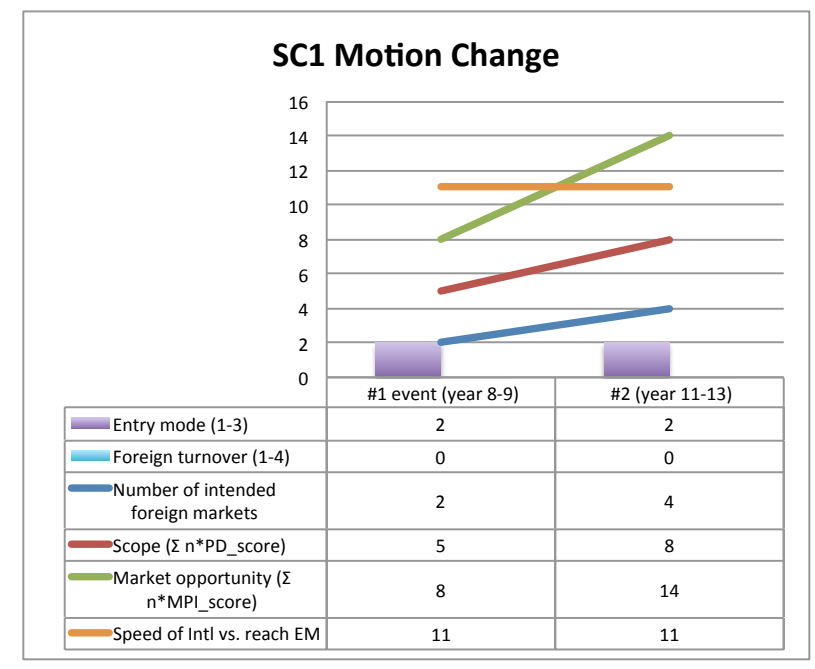

Figure 5.10: The internationalization motion pattern of SC1

Changes in the scope dimension SC1 had very small changes in scope in its two trial periods. There were very few international markets SC1 was interested in; the Chinese market was the only foreign market in which SC1 made concrete sales efforts. Figure 5.9 shows that the Chinese market is also the only foreign market outside the third reference line (PD score $=4)$ in "psychic distance", while having a very high market potential (market potential score $=5$ ). The scope in the recent epoch (the red line in Figure 5.10) is slightly enlarged compared with the initial event.

Changes in the scale dimension Although there was no contract from any international market at this point and no change in entry mode, the real commitment of $\mathrm{SC} 1$ in the international business-related activities changed significantly between the first event and the latest epoch. During the first event, the firm only joined 
one official delegation trip and there was not enough preparation and time invested in the international market development. In the latest epoch, SC2's TMT engaged in preparation and business development for the Chinese market, and a got concrete prospects from the market during the investigation period.

Changes in the speed/tempo dimension The speed of SC1's international market exploration was rather slow. The firm had a long-time domestic focus until recently.

Changes in the financial performance related to internationalization SC1 had no turnover from foreign markets. Figure 5.8 shows the financial situation when the firm conducted its international trials. SC1's turnover increased over the years, but its operating profit fluctuated. The timing of the first event and the latest epoch of its trials in international markets were in the downturn of operating performance.

\subsubsection{EM (Chinese market) entry process (SC1)}

\section{Ex-ante of the Chinese market entry ("means")}

The first event related to the Chinese market entry was in Year 9:

"Means" at the firm's environmental level Despite a huge environmental impact in recent years, the potential market size in China was not the primary trigger for SC1's first trial in China. Its institutional ties and connections were the major reasons for SC1's initial action related to Chinese market exploration. The huge potential needs from the Chinese market were an indirect trigger for the firm.

"Means" at the firm level The methods developed and experience accumulated over the years enabled SC1 to design similar service for potential customers in other regions within Sweden and potential foreign markets. In addition, the managerial attention of SC1 was interested in the idea of a niche market focus. This narrow focus stimulated the firm to reach out from regional markets.

"Means" at the individual level There was no particular means from the individual level. 
Table 5.5: Three layer effect analysis on the Chinese market entry of SC1

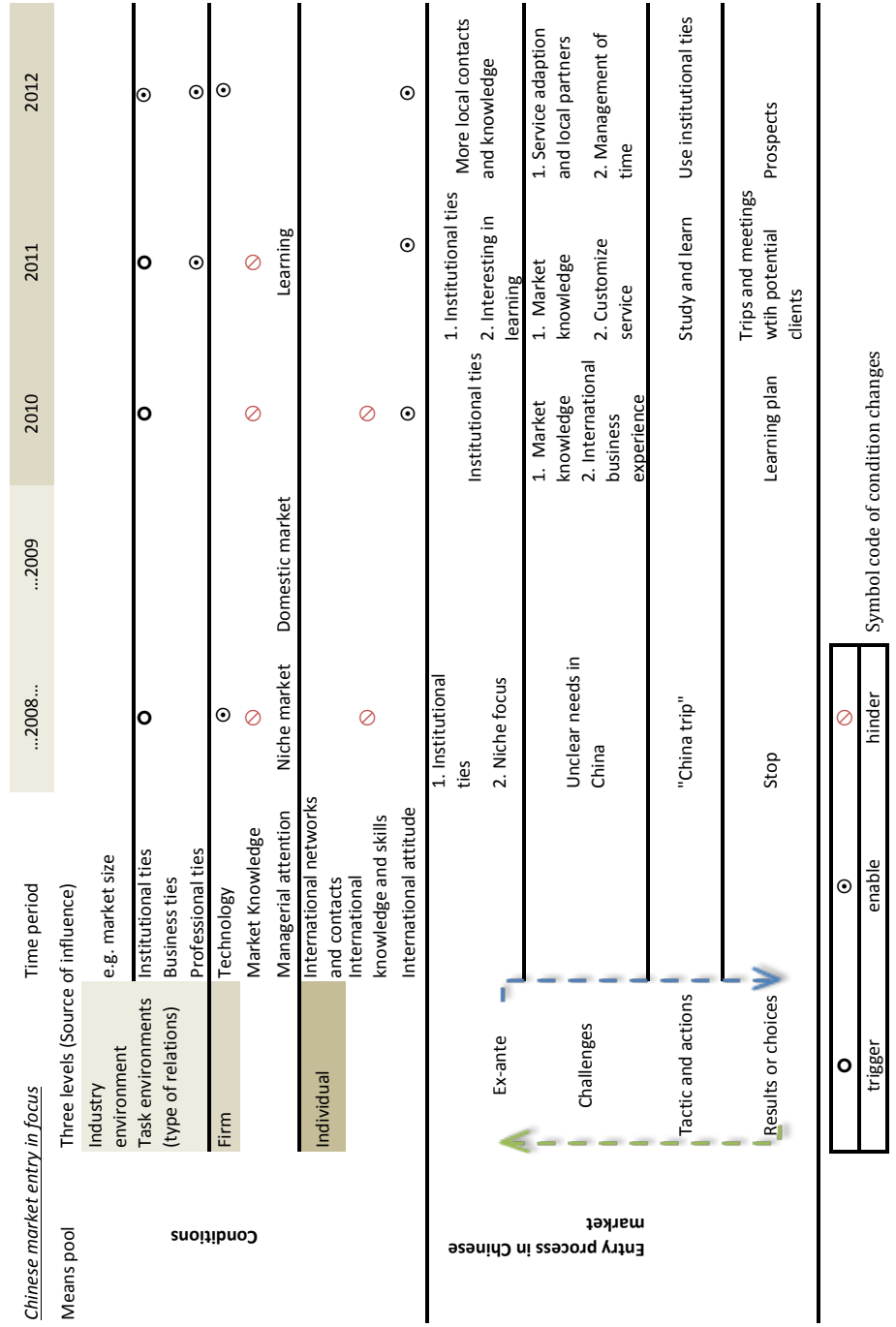


The conditions and motivations have slightly changed in the latest epoch.

"Means" at the firm's environmental level Similar initiatives from SC1's institutional connections triggered the firm's secondary trials late in Year 11. In this latest epoch, increasing cooperation at the provincial level and available public support from an EU project offered additional resources and contacts, which were needed for SC1's international business development but were not available within the firm.

"Means" at the firm level At the beginning of the latest epoch, the firm's "technology" and market knowledge had no big change compared with the conditions in the first episode. However, the managerial attention was slightly inclined to learn and to get basic knowledge and contacts for the firm's potential international market expansion.

"Means" at the individual level Because of external support which the firm could get, the firm's owners' and the CEO's international attitude had positively changed and their interest in foreign markets in general had increased.

\section{Challenges during the entry process}

In the first event, the firm went to China based on an ad hoc event. Without proper preparation, it was very difficult for SC1 to understand the market and its needs. This situation improved during the latest epoch, when the firm narrowed down the target group and target region in China.

Knowledge of the local market In the first event, SC1 did not have any knowledge of the local market. The knowledge about the local market improved in the latest epoch, but the firm was still facing challenges to customize its offerings to the local market.

Service customization Service customization was one of the major challenges. SC1's service was difficult to scale up and it required field studies. Without local experts, it was very hard to design a suitable offering for the Chinese market.

Management of time In the latest epoch, $\mathrm{SC} 1$ was facing increasing time challenges with its Chinese business-related activities; two of the owners, who were also the 
CEO and the Vice CEO, had to divert their time from daily business in Sweden towards the Chinese business.

\section{Tactics and actions}

In the first event, $\mathrm{SC} 1$ only participated in the delegation trip to China and some related activities, such as receiving visitors from an incoming Chinese group. SC1 did not invest more time and effort in conducting further market research and so on.

In the latest epoch:

Getting public supports In the latest epoch, SC1 not only used the external agent for a general Chinese market mapping, but also was supported through training seminars organized by the research team in the BENCH project.

Using institutional contacts and connections In the latest epoch, institutional ties and connections helped SC1 to directly reach the Chinese target group. Since SC1's focus was more on the B2G market in China, it was extremely difficult for it to get prospects without governmental connections. Official cooperation between Sweden and China in environment protection bridged SC1 to the potential local clients.

\section{Changes in results ("ends")}

In the latest epoch, $\mathrm{SC} 1$ got several prospects from China but the firm was still facing difficulty in investing time in the Chinese market-related business. However, the new international experience and a wider network developed during the Chinese market entry helped SC1 in getting the competence to approach a few nearby markets in Europe. 


\subsubsection{Influence of the EM (China) context on the inter- nationalization of SC1}

In Case C, the influence of the EM (China) context had a significant role in explaining the difference between the planned entry of the firm and the actual actions taken by SC1.

\section{Perceived high risk (uncertainty)}

As an EM and a far distant market, the Chinese market implied uncertainty and associated extra cost for SC1, a small company without any previous international business experience. It was not a planned motion to enter the Chinese market. Figures 5.9 and 5.10, show that SC1's intended market was one of low-PD neighbors in the first episode. However, the real actions in the first episode and the latest epoch was in the high-PD Chinese market, due to an external initiative.

\section{Perceived high opportunity}

Despite the perceived large potential need for the firm's service in the Chinese market, SC1 was not primarily triggered by the size of the market; perceived opportunity came from the institutional connections and potential benefits of official cooperation between the two countries. Because of the perceived difficulty for SMEs doing business with EMs, there was more support available from the governmental and EU levels. This institutional influence increased the awareness and the perceived opportunity of doing business with China in this case.

\subsubsection{Behavior patterns of SC1}

From the timing of the internationalization of SC1 shown in Figure 5.9 and Table 5.5, SC1 had very little interest in the international market until the latest years, when the firm had more of a niche market focus. Its market expansion was taken step by step from its hometown to other important cities in Sweden - before the firm began to pay attention to possibilities in one of its closest markets, Denmark. This motion 
reflects "certainty reduction" in the U-model (Johanson and Wiedersheim-Paul, 1975; Figueira-de Lemos et al., 2011). This is an example of managerial causal reasoning (Sarasvathy, 2008).

However, from the timing of the firm's EM entry and the sequence of actions taken during the entry process, this also reflects some traits of effectual reasoning, which starts from the available means at hand and allows the ends to emerge during the process (Sarasvathy, 2008). There were also differences between the first episode and the late epoch, although on both occasions the firm was more or less passive in response to the triggers from its task environment. In the first episode, SC1 encountered potential opportunity but did not take further actions to actualize it. In the last epoch, the firm intended to use the support and resources available from its institutionally-connected network to learn necessary knowledge about international business and to build up international connections and networks for its development. This behavior is similar to opportunity "discovery" or "alert" in the Kiznerian terminology (Kirzner, 1997). Nevertheless, in this case, the concept opportunity was more linked with the firm's competence development opportunity than a real profit opportunity for the firm.

\subsection{Case D (SC2) analysis}

\subsubsection{Overview of SC2}

SC2 is a micro education and knowledge service company, which converted from an economic association in 2000. It has worked with organizational development and education in logistics in an e-learning form for many years.

The main business of SC2 focuses on online training. The firm's main target customers are Nordic multinational enterprises (MNEs) which need training courses for their employees' continuous development. The typical sales cycle of SC2 is about one year. SC2 developed its first international course in 2003 at a client's request and began to offer its online courses to the client's subsidiaries in 25 countries. Chinese business development trials started in 2010. Figure 5.11 shows the change in the turnover and 
operating profits of SC2 over time.

SC2

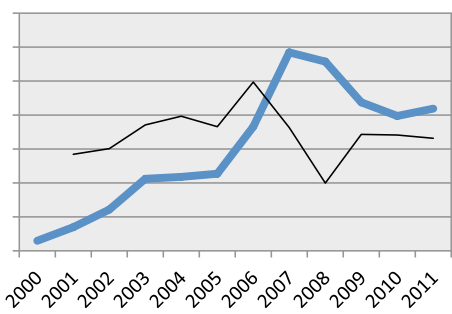

Net turnover

2 per. Mov. Avg.

(Operatin

Data source: Retriever

Figure 5.11: Turnover and operating profit change of SC2

\subsubsection{Feature changes in the internationalization process of SC2}

Figure 5.12 maps the overall motion pattern of SC2's internationalization. There are two peak points in the trail map (see Figure 5.12). The first one was around Year 3, while the other was around Year 10-11. The initial motion stopped rather quickly, but restarted again in the latest years.

\section{The initial event}

SC2 encountered its first international business-related event rather quickly in Year 3. This event was triggered by its client's requests. Facilitated by its e-training platform, SC2's service easily reached its clients' subsidiaries in more than 20 foreign countries. However, SC2 did not pay attention to far-away foreign markets after this event.

\section{The latest epoch}

The second peak point was around Year 10. SC2 had a special focus on the EMs (China and India in the Asian market; Estonia in the EU market). The motion continued 


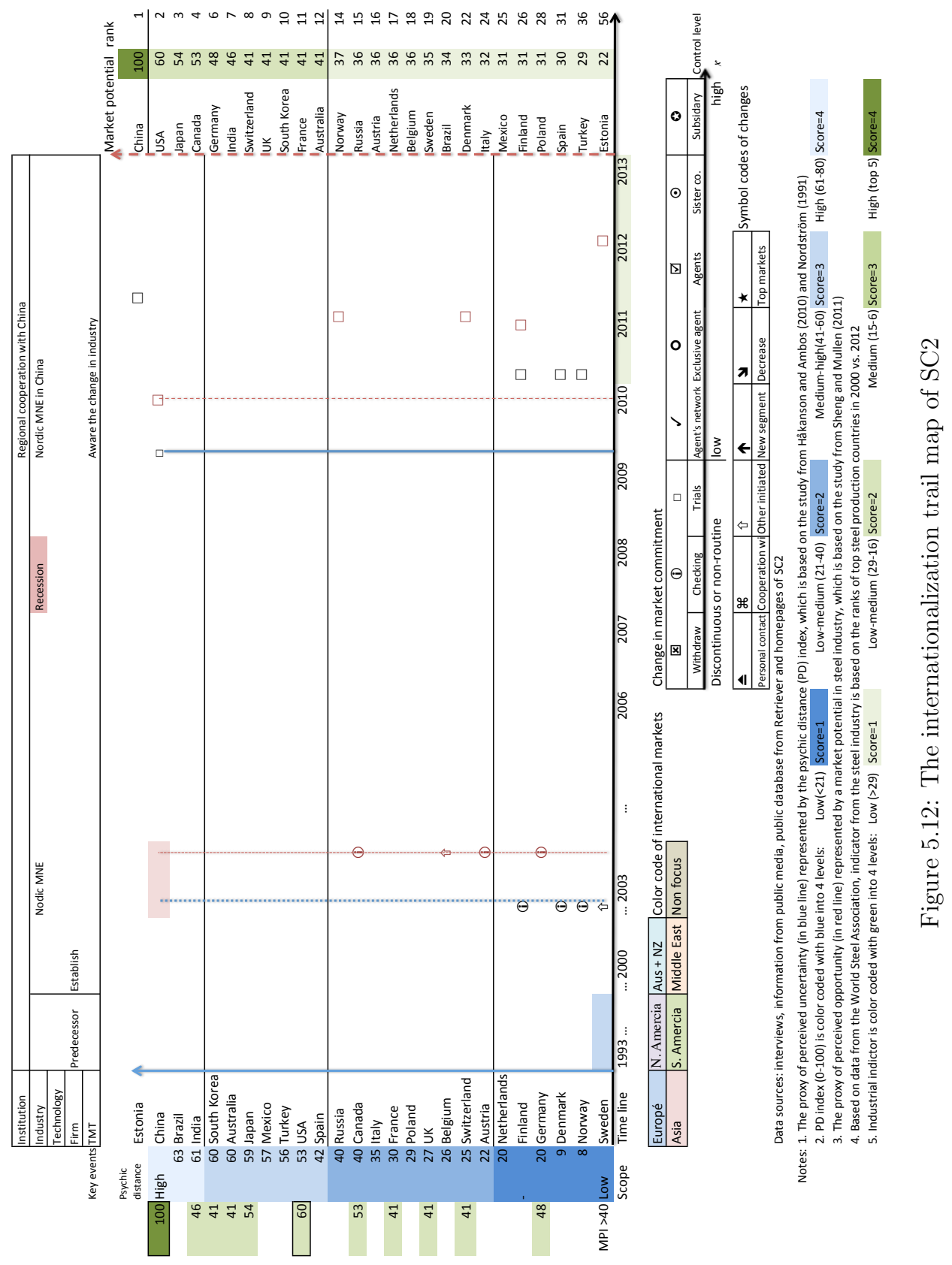


during the investigation period.

\subsubsection{Findings in changes of motion pattern}

Based on the initial event and latest epoch shown in Figure 5.12, Figure 5.13 shows the changes of SC2's internationalization motion pattern.

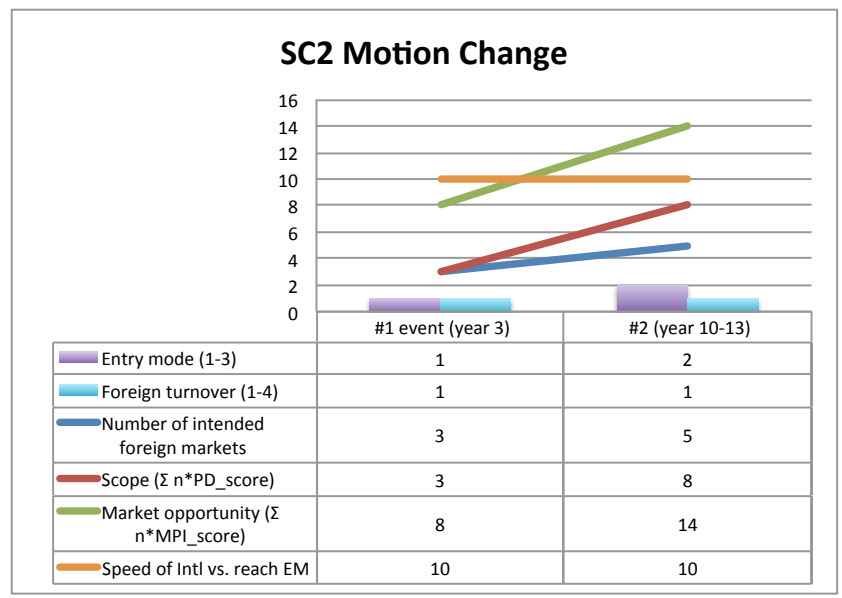

Figure 5.13: The internationalization motion pattern of SC2

Changes in the scope dimension In the first event, SC2 reached more than 20 foreign markets by reacting to its client's requests. The "psychic distance" in this event had no influence due to the client connection. SC2 easily reached a wide scope of market with minimum effort. However, the firm did not continue any active efforts on the international market after this event until recent years.

In the latest epoch, the number of foreign markets SC2 entered was much less than in the first event. However, considering its own initiative, the scope of SC2's focused markets was larger and more dispersed (see the red line in Figure 5.13) than in year 3 .

Changes in the scale dimension In the first event, SC2 had minimum involvement in international business, due to the client's initiative. In the latest epoch, SC2 
made considerable efforts and had a strategic selection of target markets and possible channels to reach the new market. The real commitment of internationalization increased greatly in the latest epoch.

Changes in the speed/tempo dimension Despite earlier encounters with international business in Year 3, the tempo of SC2's internationalization was rather slow. The firm had no intention to enter distant foreign markets until the firm experienced the global economic recession around Year 10 (see Figure 5.11).

Changes in the financial performance related to internationalization Until the end of the investigation period, the percentage of SC2's turnover from the international markets was still limited. However, the timing of its own international business initiative (see Year 10 in Figure 5.11) shows that the economic crisis was one of the overt triggers for SC2 to actively approach the distant EM market (see Figure 5.12).

\subsubsection{EM (Chinese market) entry process (SC2)}

In Case D, SC2 had reached its Chinese clients twice (see Section .5 of Appendix B). The first time was triggered by the client's connection, and the second was from SC2's own initiative after the economic crisis. Table 5.6 uses symbol coding to demonstrate changes in the conditions in the three-level "means pool" during SC2's Chinese market entry process.

\section{Ex-ante of the Chinese market entry ("means")}

The first event related to the Chinese market was in Year 3, while the latest epoch of the Chinese market entry was around Year 10.

"Means" at the firm's environmental level In the first event, SC2 had no interest in the Chinese market until its client initiated the request. In the more recent epoch, the perceived potential market opportunity in China, and especially the perceived increasing Nordic MNEs' operation in China, triggered SC2's interest in the Chinese market. 
Table 5.6: Three layer effect analysis on the Chinese market entry of SC2

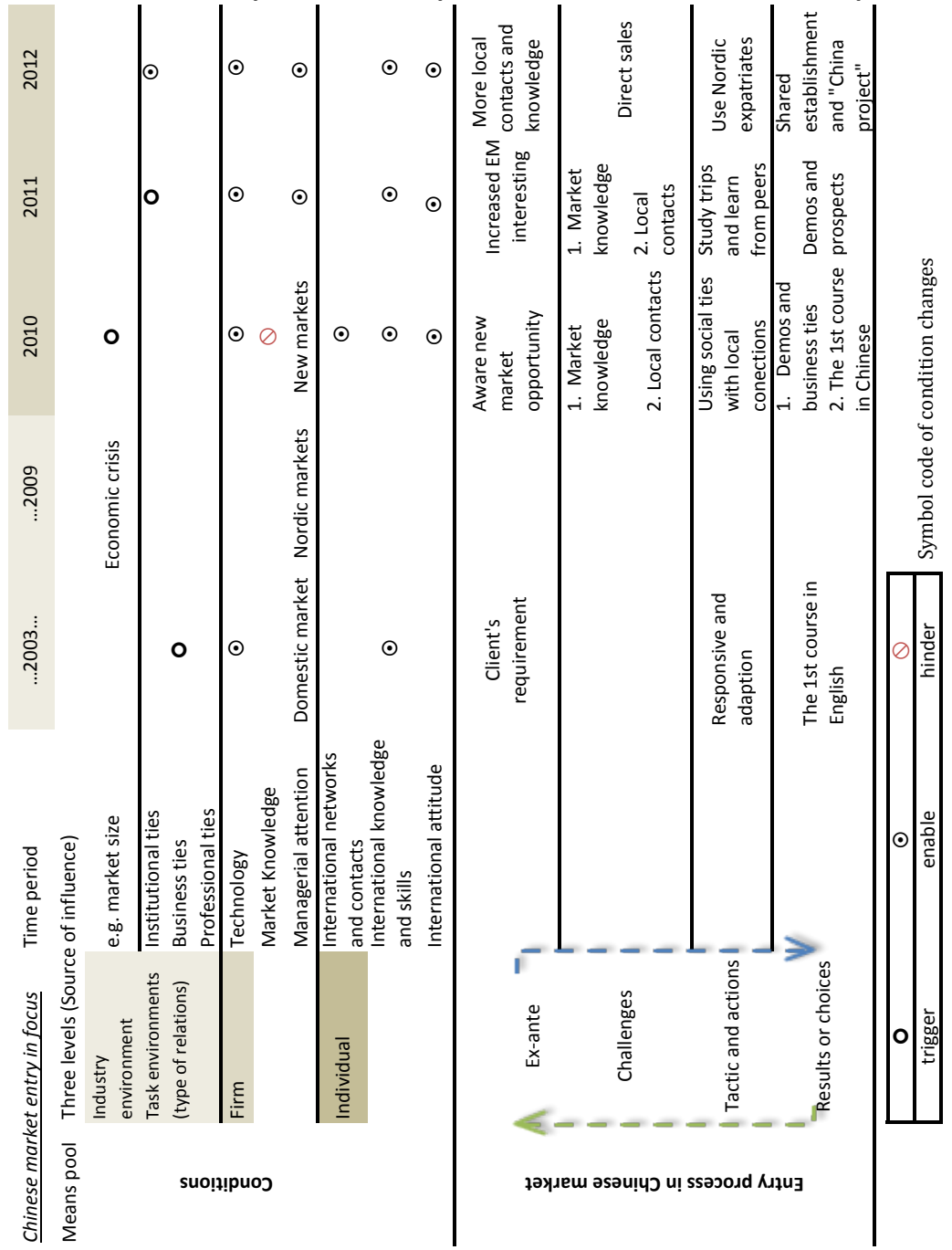


"Means" at the firm level The technology and offerings of SC2 had no big change in the first event and the latest epoch. Its service was very easy to scale up and there was no geographic constraint due to its Internet-based training form. However, SC2 had very little knowledge about the Chinese market.

"Means" at the individual level From the individual level, the owner-CEO of SC2 had acquired many years of international business experience and solid skills before he founded the firm. In the first event, the CEO and his firm focused more on the domestic market. In the latest epoch, when the CEO started to pay attention to EMs such as China, his international experience, knowledge and contacts enabled him and his firm to acquire knowledge and new connections related to the Chinese market rather quickly.

\section{Challenges during the entry process}

In the first event, $\mathrm{SC} 2$ did not have any challenges due to the client connection. However, when the firm needed to enter the Chinese market by its own efforts, there were two major challenges.

Knowledge of the local market SC2 had very limited knowledge about the Chinese market. The first Chinese business-related event did not offer enough knowledge for the latest entry. SC2 had to study the market in order to be focused and find target clients.

Local contacts The firm also had no local contacts in China, and this was difficult for a foreign CEO of a micro firm.

\section{Tactics and actions}

In the first event, SC2 did not make any special effort for the Chinese market. The firm just translated its course to English and offered it to its client's subsidiaries in different foreign markets.

In the latest epoch: 
Use social ties and China trips In the beginning of the latest epoch, the CEO of SC2 mainly used his social ties to find a Chinese immigrated middle-person with Chinese local knowledge and contacts to build connections with potential clients. The CEO took several trips together with his middle-person to visit target clients.

Use Nordic expatriates With increasing experience from his China trips, the CEO of $\mathrm{SC} 2$ began to target Nordic expatriate managers in Nordic MNEs to bypass sales barriers in the Chinese market.

Learn from peers In addition, SC2's CEO also participated in several China marketrelated seminars to gain support and learn from other SMEs' experience.

\section{Changes in results ("ends")}

After the first event, the firm had its first course in English. In the latest epoch, the firm started to offer its first course in Chinese. With the help of the middle-person and Nordic background managers working in the Chinese OEM, SC2 got its demos and prospects from the Chinese market rather quickly. At the end of the investigation period, the firm started to share resources with other Swedish small firms to establish a virtual office in China.

\subsubsection{Influence of the EM (China) context on the inter- nationalization of SC2}

In Case D, the EM context had influence on $\mathrm{SC} 2$ in the sequence of its foreign market entry. The institutional difference between China and Sweden also influenced the tactics and actions that SC2 adopted during its Chinese market entry.

\section{Perceived high risk (uncertainty)}

Combing the motion pattern in Figure 5.12 and Figure 5.13 with SC2's financial performance (see Figure 5.11), it is clear that $\mathrm{SC} 2$ had no interest in the distant (in PD) international markets before the financial downturn. The perceived high uncertainty in the EM, for example China in the first international business-related event, was very 
low due to the client's connection. The perceived high uncertainty did not stop SC2's intended market expansion, but it did influence the firm's strategy to approach the Chinese market.

\section{Perceived high opportunity}

High perceived opportunity in the Chinese market was the major reason for SC2 to actively approach this market after the economic downturn. The increasing operation of big Nordic MNEs in China made SC2 perceive a higher opportunity in the market.

\subsubsection{Behavior patterns of SC2}

Although the traits of the SC2's offering made it easy to enter the international markets and the CEO of the firm had rich international experience, the timing of SC2's active approach to the international markets and EMs was very late. This reflects a "risk aversion" tendency represented by the U-model (Johanson and Wiedersheim-Paul, 1975; Figueira-de Lemos et al., 2011).

Case D also shows the change in the behavior pattern after the economic crisis. SC2 started to strategically target those EMs in which Nordic and other MNEs were clustered. It started with predefined ends and looked for potential means to reach the end. This behavior pattern is close to the strategic behavior discussed by (Mintzberg and Waters, 1982).

The next eight cases are from the EM extension study stage. This part of the analysis applies a simplified within-case analysis (i.e. a simplified version of the "internationalization trail map"). 


\subsection{Case E (MC3) analysis}

\subsubsection{Overview of MC3}

MC3 is a small Swedish carbon brush producer with 127 years of history. The firm has experienced a relatively long period of turnover growth since it moved into two new business segments in the early 2000s. MC3 adjusted its sales strategy and targeted the top OEMs in its new segments, regardless of their locations.

With 28 employees, the firm has generated annual net turnover on average of about 120 MSEK in the most recent 6 years ${ }^{39}$. Today, about $85 \%$ of the total turnover is from international markets and about $99 \%$ of the sales of its main products are from markets outside Sweden. Figure 5.14 shows the trend of change in the financial performance of MC3.

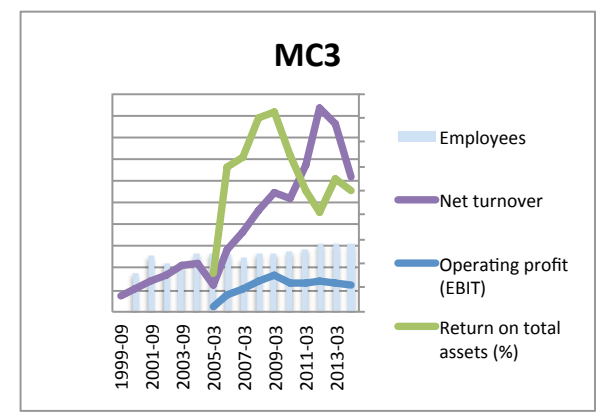

Figure 5.14: Financial performance of MC3

The main product from MC3 is used as a current or electrical signal conductor. Its products have a wide range of applications in different types of electric motors, generators and so on. MC3 has targeted high value-added niche segments such as wind power generators, medical equipment, etc. The company works on the B2B market. The normal sales period from approaching customers to closing a deal for its products

\footnotetext{
${ }^{39}$ Data from the Retriever business database.
} 
is about five years.

Because of a relatively small number of big OEMs in its targeted segment, the firm's international business is conducted mainly through direct sales. The global reach of the firm started from an active targeting and pursuing MNEs' OEMs as its focused clients. Table 5.7 provides a brief profile of MC3.

Table 5.7: Profile of MC3

\begin{tabular}{|c|c|}
\hline Year of establishment & $1985 *(1887)$ \\
\hline No. of employees & 28 \\
\hline Net turnover (MSEK) & $>120$ \\
\hline Industry segments & $\begin{array}{l}\text { 1. Wind power } \\
\text { 2. Medical equipment } \\
\text { 3. Offshore }\end{array}$ \\
\hline Key offerings & Carbon brush and holders \\
\hline \multicolumn{2}{|c|}{ Internationalization profile of MC3 } \\
\hline Start year & $\begin{array}{l}\text { Before } 1985 \text { (new } \\
\text { registration year) }\end{array}$ \\
\hline $\begin{array}{l}\text { International markets/ } \\
\text { partners }\end{array}$ & $\begin{array}{c}\text { OEMs' partners in Europe, } \\
\text { China and US }\end{array}$ \\
\hline $\begin{array}{l}\text { Share of overseas } \\
\text { turnover }\end{array}$ & ca. $85 \%$ \\
\hline Entry mode/ nodes & $\begin{array}{l}\text { Direct sale to OEM } \\
\text { partners }\end{array}$ \\
\hline
\end{tabular}

*Registration record from system

Source: Interview data and data from the Retriever Business 2014

\subsubsection{Motion pattern of MC3's internationalization}

Figure 5.15 maps the overall internationalization motion pattern of MC3 in a dual serial of the "perceived risk (uncertainty)", represented by "psychic distance" as a proxy, versus the "perceived opportunity", represented by MPI as a proxy.

\section{Timing of internationalization}


5. WITHIN-CASE ANALYSIS

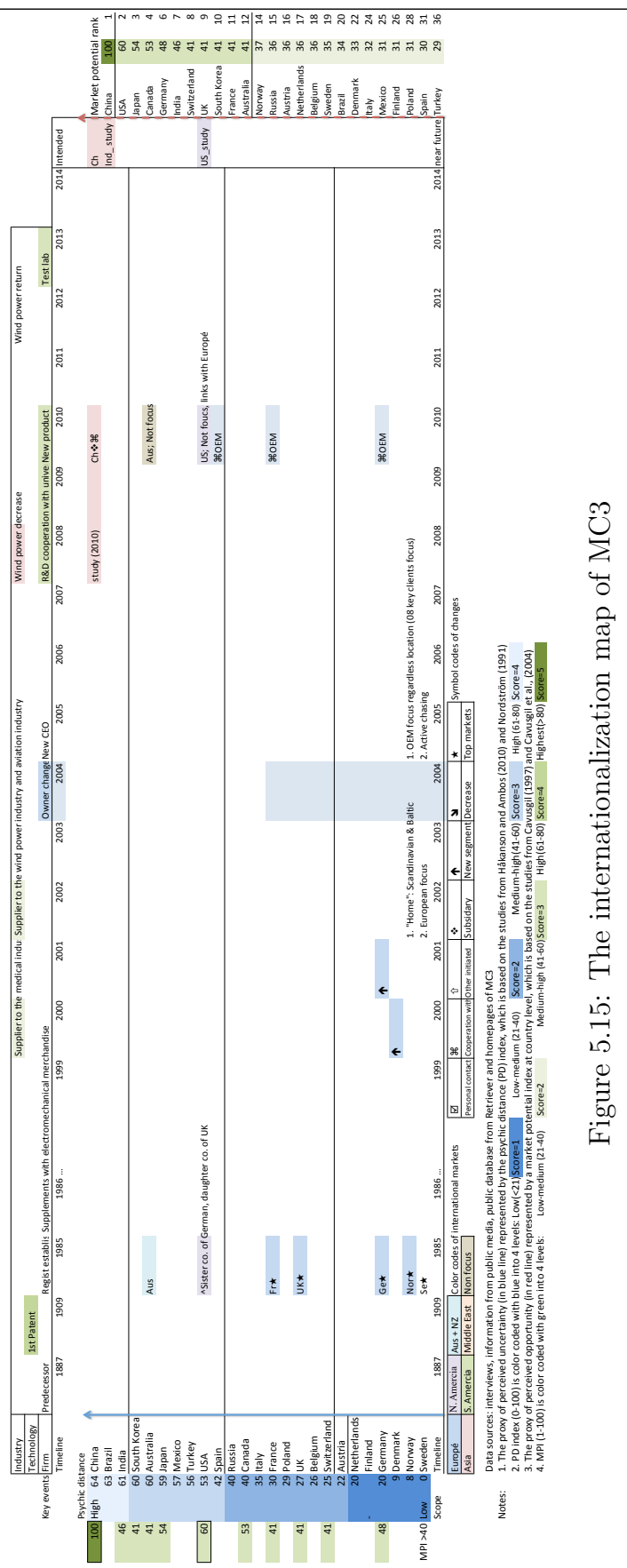


Figure 5.15 shows the motion pattern of MC3's internationalization. Due to the long history of the firm, the information regarding its internationalization in its early period could hardly be traced. Therefore, the study mainly focuses on its internationalization in the last 20 years. The firm had international markets before it got its new registration in 1985. Thus, if based on its registration record, the internationalization process of MC3 started very early.

\section{Scope of internationalization}

The scope of internationalization for the firm has changed. During its early period, from 1985 to 2004, MC3 mainly focused on what it regarded as its "home market", which were Scandinavian markets and a few key markets in Europe. Denmark and Germany were the early important markets for MC3 in the beginning of 2000. These markets are all in the low-"psychic distance" range.

In 2004, when the firm changed ownership from a family business into a small firm within a large business group, the scope of internationalization started to expand. The firm become more active in international expansion to places where OEMs were clustered. The big change happened after the 2008 financial crisis, when major European markets were recessing in the wind power sector. MC3 reached the largest EM, China, which is high in "psychic distance".

\section{Scale of internationalization and mode of entry}

About 85\% MC3's turnover was from its international markets. Top contributors were from its big European markets such as Germany, UK and France, which were the traditional markets of MC3. Due to the traits of its products, MC3 used direct sales from Sweden, with only one exception, China. There was neither a sales organization overseas nor production overseas. Therefore, the resource requirement was comparably low. Direct sales gave MC3 high control in it sales process and contributed to good knowledge with clients.

\section{Endurance of internationalization}


From a general trend of its internationalization, MC3 continued its international growth in terms of turnover and number of foreign markets. The endurance of each international market varied. For example, MC3 chose not focus on more distant markets with very few OEMs. Therefore, its effort in one of its earlier distant markets, Australia, was reduced.

\subsubsection{Behavior pattern of MC3's internationalization}

The behavior pattern of MC3 during its internationalization also changed. During its family ownership period, the internationalization of MC3 showed both incremental learning features from the U-model and entrepreneurial features. The previous owner sensed opportunity in two new segments and enabled the international growth (see Figures 5.14 and 5.15). This is an example of opportunity alertness (Kirzner, 1997). At the same time, MC3 did not actively explore opportunities outside its comfort zone and just passively reacted to the requirements from higher PD markets. This type of action reflects features predicted by the U-model (Johanson and Wiedersheim-Paul, 1975).

After the change in ownership, MC3 acted more strategically in its international expansion. The firm strategically targeted OEMs with European MNE connections. MC3 intentionally built up its network with the R\&D of MNEs and tried to work together for product customerization. It had a strong strategic purpose in using its industrial network, rather than simply following its potential clients.

\subsubsection{Context of EM entry of MC3}

MC's EM entry was rather late. The timing of MC3's first EM entry reflects its entrepreneurial action. Big EMs such as China and India have many OEMs. Not until 2008, when demands from wind power went down in major European markets, did MC3 begin its investigation of the China market. The firm did systemic research not only on the markets but also on the mode of entry. In 2010, MC3 had its personnel in China. In 2014, MC3 also prepared a study on the India market. The context of its 
EM entry reflects how the firm actively pursued opportunity in EMs when there was less opportunity in its status quo markets.

\subsubsection{Summary of findings in MC3's internationalization}

1. Entrepreneurial activity brings international growth opportunity.

2. Ownership change influences preference and strategy during internationalization. Thus, it influences the scope and scale of the internationalization.

3. Negative prospects in status quo markets are more likely to encourage entrepreneurial actions.

4. Emerging market interest came late. Negative prospects in its status quo market were more likely triggers for the firm to seek new opportunities in EMs.

5. System knowledge and technology competence enabled cooperation with big MNE clients and facilitated internationalization in its clients' clusters. This cooperation, in turn, enhanced technology competence, added more knowledge about its clients' needs, and strengthened the network and relationship.

\subsection{Case F (MC4) analysis}

\subsubsection{Overview of MC4}

Founded in 1991 by an innovator who challenged conventional methods in flooring, MC4 invented a new machine and created a new market in the flooring industry in the 1990s. Growing from a small family business with four people in 1991 to about 170 employees in 5 countries today, MC4 has experienced continuous organic growth through innovation and internationalization. From 2011 to 2013, its average annual net turnover was over 250 MSEK. Figure 5.16 shows the trend of change in the financial performance of MC4, while Table 5.8 presents a brief profile of MC4.

The internationalization process of the firm started shortly after its establishment. Concerning the small potential market in Sweden, MC4 targeted international markets 


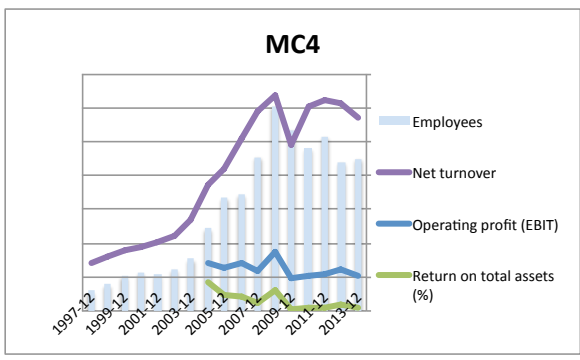

Figure 5.16: Financial performance of MC4

Table 5.8: Profile of MC4

\begin{tabular}{|l|c|}
\hline $\begin{array}{l}\text { Year of establishment } \\
\text { No. of employees }\end{array}$ & $\begin{array}{c}1991 \\
\text { Industry segments }\end{array}$ \\
Key offerings & \multicolumn{1}{c|}{$\begin{array}{c}\text { Flooring } \\
\text { Grinder; equipment and } \\
\text { tools for floor preparation } \\
\text { and solutions }\end{array}$} \\
\hline \multicolumn{1}{|c|}{ Internationalization profile of MC4 } \\
\hline $\begin{array}{l}\text { Start year } \\
\text { International markets/ } \\
\text { partners } \\
\text { Share of overseas } \\
\text { turnover }\end{array}$ & $\begin{array}{c}\text { 1992 } \\
\text { 40reign subsidiaries and } \\
\text { Entry mode/ nodes }\end{array}$ \\
\hline
\end{tabular}

*Total employees with four foreign subsidiaries

Source: Interview data and data from the Retriever Business 2014 
even before its first prototype came out. Its first product was designed for flooring soft stone. Thus, southern Europe became the original target market for its machinery, as many places there are full of soft natural stone. Today, MC4 has four subsidiaries in key European markets and the US market, and over 60 distributors in different international markets. International markets have contributed about $85 \%$ of MC4's total turnover. The target clients of MC4 are the entrepreneurs of small businesses in the flooring industry.

\subsubsection{Motion pattern of MC4's internationalization}

Figure 5.17 maps the overall internationalization motion pattern of MC4 in a dual serial of the "perceived risk (uncertainty)" represented by "psychic distance" as a proxy versus the "perceived opportunity" represented by MPI as a proxy.

\section{Timing of internationalization}

Figure 5.17 shows the motion pattern of MC4's internationalization. MC4 started internationalization right after its establishment. Earlier international experience and perceived small market potential in its domestic market triggered instant internationalization .

\section{Scope of internationalization}

MC4 had a relatively large scope of internationalization from its start. As a young innovative firm, MC4 was very open to early adopters as its potential distributors. Thus, it had distributors in both large but closer European markets and more distant Asian markets. The scope was expanded with the development of the firm.

\section{Scale of internationalization and mode of entry}

In terms of overseas turnover, the scale of internationalization decreased, since its domestic market became stronger in the mid-1990s. The initial segment of MC4 had very little potential in its domestic market. Therefore, the firm's focus was on the international markets from its start. However, with innovation and new product development, MC4 could target a new segment - concrete flooring - which was very common in ev- 


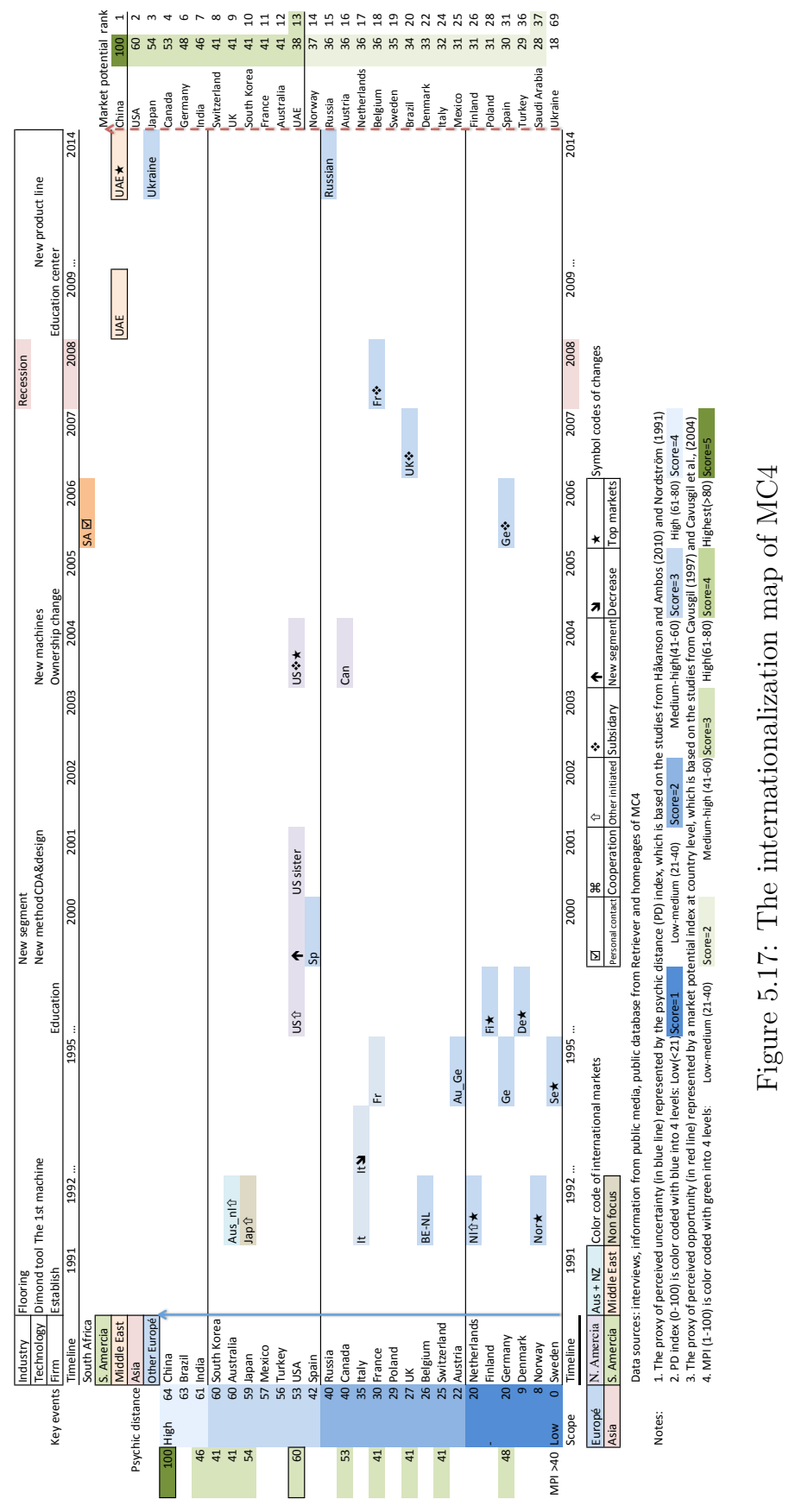


ery market. Therefore, MC4 was able to expand both in its domestic and international markets.

In the beginning, due to resource limitations all of MC4's foreign market used distributorships, which is a low-resource commitment and a low control type of mode (Canabal and White III, 2008). In 2006, when MC4 got enough resources from its new partner, it increased its commitment in its four major markets in the US and Europe. It established its own sales organizations and changed to a high control mode.

\section{Endurance of internationalization}

In general terms, the internationalization of MC4 endures and continues. However, not every distributor in its c. 60 markets performs well. The firm's top 15 markets contribute to a large portion of its overseas turnover. Some distributors just works on the tools and only contribute very marginal turnover to the firm. MC4 is working on building a system to improve its distributors' performance.

\subsubsection{Behavior pattern of MC4's internationalization}

The internationalization of MC4 was strongly driven by entrepreneurship and innovation. Its internationalization can be explained by both opportunity discovery and creation (Kirzner, 1999). The founder got inspiration from news spread in an international trade show. The venture idea was based on the discovery of a new potential application for diamond tools. Using such diamond tools in a new type of grinder was the founder's invention. Therefore, MC4 was able to capture economic rent in the international market by introducing its new machinery.

The firm's further international expansion in 2006 was also triggered by technology innovation. Its invention of a new method for polishing concrete enabled its new product to take off in the US market in a new segment immediately. In addition, its innovative training program also offered good knowledge and built strong client relationships to facilitate international sales. 


\subsubsection{Context of EM entry of MC4}

Since MC4 was very successful in its major markets in the US and Europe, it had very little interest in actively exploring emerging markets. The firm entered a few EMs, but this was more due to chance rather than planned events. South Africa was a good example, as explained further in the case description part (see Section .7 of Appendix B).

\subsubsection{Summary of findings in MC4's internationalization}

1. International experience and entrepreneurial activity bring international growth opportunity.

2. Responding to needs from international clients and having a high ambition of the firm triggers further innovation.

3. Positive prospects in status quo markets are less likely to motivate the firm to actively pursue more distant EMs.

4. Emerging market entry was more ad hoc than planned.

5. Continuous innovation enabled MC4 to explore new segments and further drove the firm's international growth.

6. There was increased commitment in relatively low-PD markets.

7. There were a large number of distributor markets with little influence on the markets.

8. The firm was the born global type.

\subsection{Case G (MC5) analysis}

\subsubsection{Overview of MC5}

MC5 is a small company established in 1997. It works as a supplier of super-absorbing products. The firm started international business from its start-up phase. It experi- 
enced rapid growth from international markets after it entered new business segments. With less than 30 people, MC5 has about 50 MSEK in net turnover. Figure 5.18 shows the trend of change in financial performance of MC5, while Table 5.9 shows a brief profile of MC5.

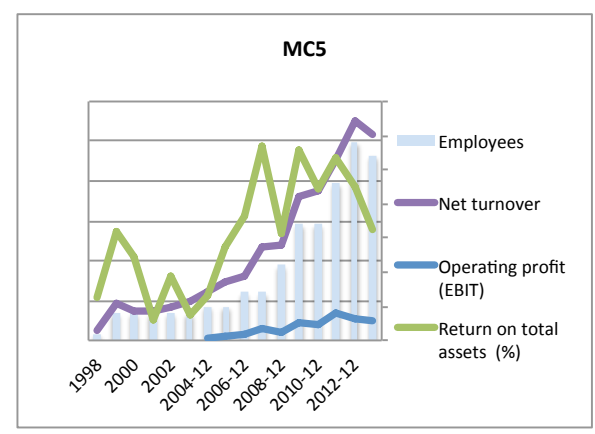

Figure 5.18: Financial performance of MC5

Table 5.9: Profile of MC5

\begin{tabular}{|c|c|}
\hline Year of establishment & 1997 \\
\hline No. of employees & 27 \\
\hline Net turnover (MSEK) & $>50$ \\
\hline \multirow[t]{3}{*}{ Industry segments } & 1. Fish packaging \\
\hline & 2. Operation room \\
\hline & 3. Wound care \\
\hline Key offerings & Super absorbing products \\
\hline \multicolumn{2}{|c|}{ Internationalization of MC5 } \\
\hline Start year & 1997-1998 \\
\hline International markets/ & \\
\hline partners & 15 \\
\hline Share of overseas & \\
\hline turnover & $>90 \%$ \\
\hline \multirow[t]{2}{*}{ Entry mode/ nodes } & Distributors \\
\hline & OEM partners \\
\hline
\end{tabular}

Source: Interview data and data from the Retriever Business 2014

The main products of MC5 are superabsorbent polymer-based tissue products for absorbing liquid. Superabsorbent material has a wide application range in e.g. the medical, agricultural and other industries. The main focused segments of MC5 are the 
medical and fishing industries. Because there was very little marketing of its initial segment in Sweden, MC5 started its internationalization from its inception. The firm uses a distributorship and works with OEM partners to reach out to 15 international markets.

\subsubsection{Motion pattern of MC5's internationalization}

Figure 5.19 maps the overall internationalization motion pattern of MC5 in a dual serial of the "perceived risk (uncertainty)", represented by "psychic distance" as a proxy, versus the "perceived opportunity", represented by MPI as a proxy.

\section{Timing of internationalization}

Figure 5.19 shows the motion pattern of MC5's internationalization. From the time dimension, international business started right after the establishment of the firm. The main trigger of its early internationalization was the initial segment MC5 targeted. There was no big fishing industry in its domestic market.

\section{Scope of internationalization}

The firm's scope of internationalization changed. During the early period, MC5 only had two international markets. Both of the markets offered sufficient size in its target segment at the beginning, and they were also in the low to middle level of the "psychic distance" range.

The scope of MC5's internationalization expanded when it found a new application for its offering and entered new industry segments in 2004. MC5 started from major markets within the EU and gradually moved to big markets outside Europe. Motion pattern in this period moved along the "psychic distance" index from lower range markets such as Denmark and Germany to higher range markets such as the US and Australia. The more distant the market, the later the entry. MC5 entered two emerging markets outside the EU, Malaysia and Brazil, very recently. Both cases were not planned events and were initiated by potential distributors in these two EMs. 


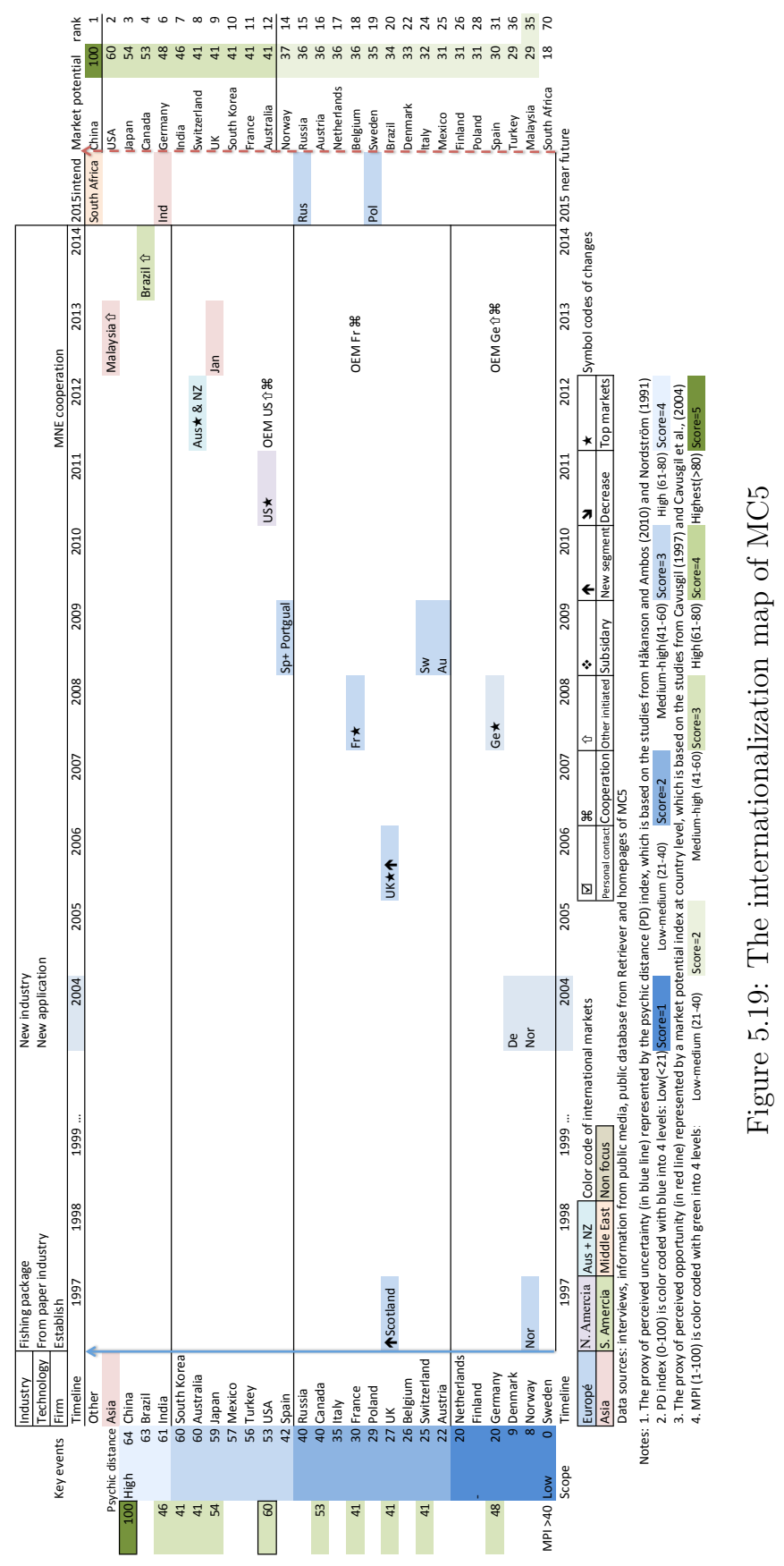




\section{Scale of internationalization and mode of entry}

Since MC5 started its internationalization, the majority of its new turnover was from its international markets. International markets contributed to about $90 \%$ to $95 \%$ of the total turnover of the firm. MC5 used distributors in its international markets. The qualification of distributors in the three segments varied. The wound care business required the most knowledge of the target foreign markets, while the fish packaging segment required the least. The extent of commitment in each of its foreign markets was rather limited. Since MC5 mainly used distributors to reach end users, the firm had very limited influence on the commitment and market knowledge of its distributors. Therefore, the performance of the foreign markets was largely subject to the competency and commitment of the distributors. Despite a limitation in its distributorship, MC5 had no intention to use a direct mode of entry to reach end customers, due to resource limitations. MC5 intends to build up a routine in its distributor selection, evaluation and support to improve performance. In 2012, MC5 started to cooperate with global partners strategically. MC5 acted as a subcontractor of the global players and produced the products under a partners' brand name.

\subsubsection{Behavior pattern of MC5's internationalization}

The behavior pattern of MC5 during its internationalization had mixed features. The trigger of internationalization can be largely attributed to the segments the firm chose. Despite of incremental feature of its internationalization, there were entrepreneurial actions which enabled its continuous international growth. Based on the critical events that emerged during internationalization, the entrepreneur actions can be found in two episodes.

\section{Entrepreneurial actions}

From the venture creation at its start to its new segment entry in 2004, in two important episodes, the entrepreneurs and their firms used the extant technology and knowledge in the paper and package industries in two different applications. The first application in fish packaging created MC5. The industry structure of the segment led to the internationalization of MC5 from its establishment. The actions in the episode were Kirzner-type entrepreneurial in nature, because these activities were related to 
recognizing and matching imprecisely defined needs and finding new applications of a technology (Kirzner, 1997). MC5 identified the status quo market disequilibrium in the medical market faster than other companies. Thus, MC5 could utilize the same technology, competence in different segments and gain profit from its actions. The entrepreneurial activity facilitated and enabled the firm's international market expansion in 2004 .

\section{Context of international entrepreneurial activity}

The timing of the further international expansion in 2004 indicates that a diminishing return from the status quo market triggered the entrepreneurial activity of entry in new segments. Facing limited growth opportunity in the initial target for four years, MC5 started to investigate and identify new opportunities to develop. The negative prospect from the fishing industry was one of main triggers for its entrepreneurial activity to explore new segments and international markets.

\subsubsection{Context of emerging market entry of MC5}

Emerging markets appear in the international process of MC5 quite late. The firm followed an incremental pattern, starting from big and close EU markets step by step to reach out to big international markets with higher psychic distance. This fits part of the prediction by the U-model (Johanson and Vahlne, 1977), which indicates a learning process from international markets with similar context to home markets to more dissimilar and distant markets. Thus, this study would hypothesize that when a small firm has a positive prospect, there is less motivation to pursue potential opportunities in more perceived distant EM markets.

In the MC5 case, not until very recently did the firm start to get involved with big emerging markets, such as Brazil. The timing of EM entry can also relate to the changes in managerial attention. The new CEO from last year started to use a more structured approach in business development. Therefore, a few potential emerging markets started to get attention due to their embedded opportunity in the size of the EM. 


\subsubsection{Summary of findings in MC5's internationalization}

1. Entrepreneurial activities and traits of segments trigger internationalization of the firm.

2. Entrepreneurial activities intermittently taking place during internationalization.

3. Negative prospects in status quo markets are more likely to encourage entrepreneurial actions.

4. Positive prospect encourages the firm to work on nearby markets with less perceived risk (uncertainty).

5. Emerging market interest came late. The firm's EM entries were ad hoc, rather than intended. The firm's managerial attention was slightly directed toward a few key EMs, after its new CEO joined.

6. Technology competence enables early internationalization and change segments during internationalization. Requirements and demand from the international market, in turn, also stimulated continuous focus on the new product development of MC5.

7. The general motion pattern shows different mixed influences from both industrial segments and managerial attention from the firm.

8. Motion patterns have different features during early periods and after entering a new segment. Early period internationalization in each segment consisted of a few key markets in Europe.

9. Low resource commitment and a low control mode of entry combined in the partnership with big MNEs. There was a low degree of influence on the foreign markets.

10. MC5 is of the international new venture type. 


\subsection{Case H (MC6) analysis}

\subsubsection{Overview of MC6}

MC6 is a small high-technology company, established in 2003. It develops and offers unmanned helicopters with associated sensor systems based on clients' needs. The firm began international business from its start-up, and experienced a financial shock from its first international business dealing. The company has managed to come back by listing in the stock market and through cooperation with global partners. The firm has 23 employees and about 24 MSEK in net turnover. Figure 5.20 shows the trend of change in the financial performance of MC6.

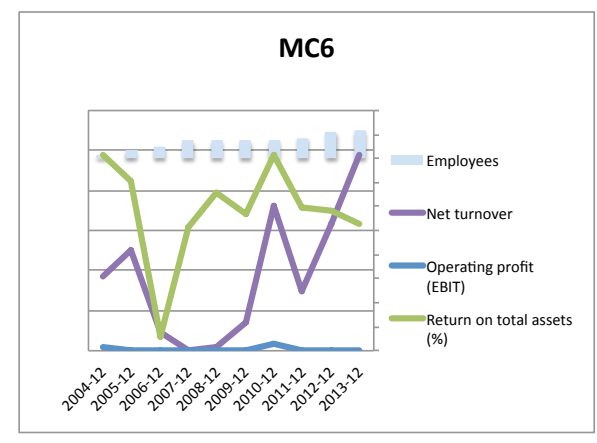

Figure 5.20: Financial performance of MC6

The main products of MC6 are used for monitoring and inspection purposes in defense, civil authority and other commercial applications. Through cooperation with global strategic partners, MC6 offers its products to early adopters in 3-4 international markets at the moment. Table 5.10 shows a brief profile of MC6.

\subsubsection{Motion pattern of MC6's internationalization}

Figure 5.21 maps the overall internationalization motion pattern of MC6 in a dual serial of the "perceived risk (uncertainty)", represented by "psychic distance" as a proxy, versus the "perceived opportunity", represented by MPI as a proxy. 
Table 5.10: Profile of MC6

\begin{tabular}{|c|c|}
\hline $\begin{array}{l}\text { Year of establishment } \\
\text { No. of employees } \\
\text { Net turnover (MSEK) } \\
\text { Industry segments } \\
\text { Key offerings } \\
\end{array}$ & \begin{tabular}{l}
\multicolumn{1}{|c|}{2003} \\
$\qquad 23$ \\
$\qquad 20$ \\
1. Defense \\
2. Inspection of civil usage \\
Unmanned helicopters
\end{tabular} \\
\hline \multicolumn{2}{|c|}{ Internationalization profile of MC6 } \\
\hline $\begin{array}{l}\text { Start year } \\
\text { International markets/ } \\
\text { partners } \\
\text { Share of overseas } \\
\text { turnover } \\
\text { Entry mode/ nodes }\end{array}$ & $\begin{array}{c}\text { ca. } 100 \% \\
\text { International partners }\end{array}$ \\
\hline
\end{tabular}

Source: Interview data and data from the Retriever Business 2014

\section{Timing of internationalization}

Figure 5.21 shows the motion pattern of MC6's internationalization. From the time dimension, international business started from the second year of the establishment of the firm. The main trigger of its early internationalization was an emergent request from an international client from a distant market. There was no domestic market for MC6 after the firm sold its technology to a big company in Sweden. Therefore, the internationalization process continued in a self-reinforced way.

\section{Scope of internationalization}

The scope of internationalization changed during internationalization. Different from normal industry products, the offerings of MC6 consisted of system selling. The whole system often involved the clients or partners in development and delivery. Clients were early adopters to this application and major applications from an early time were in the defense sector. Formal institutional influence, such as export regulation, also restricted the scope of MC6's internationalization. By joining international air shows, the firm was open to potential international clients and partners regardless of the distance at the start. However, the international markets of MC6 were rather limited. All three of the established partnerships were from Europe and the US. The relationships were often initiated from counterparts, except for China. Therefore, the scope of interna- 


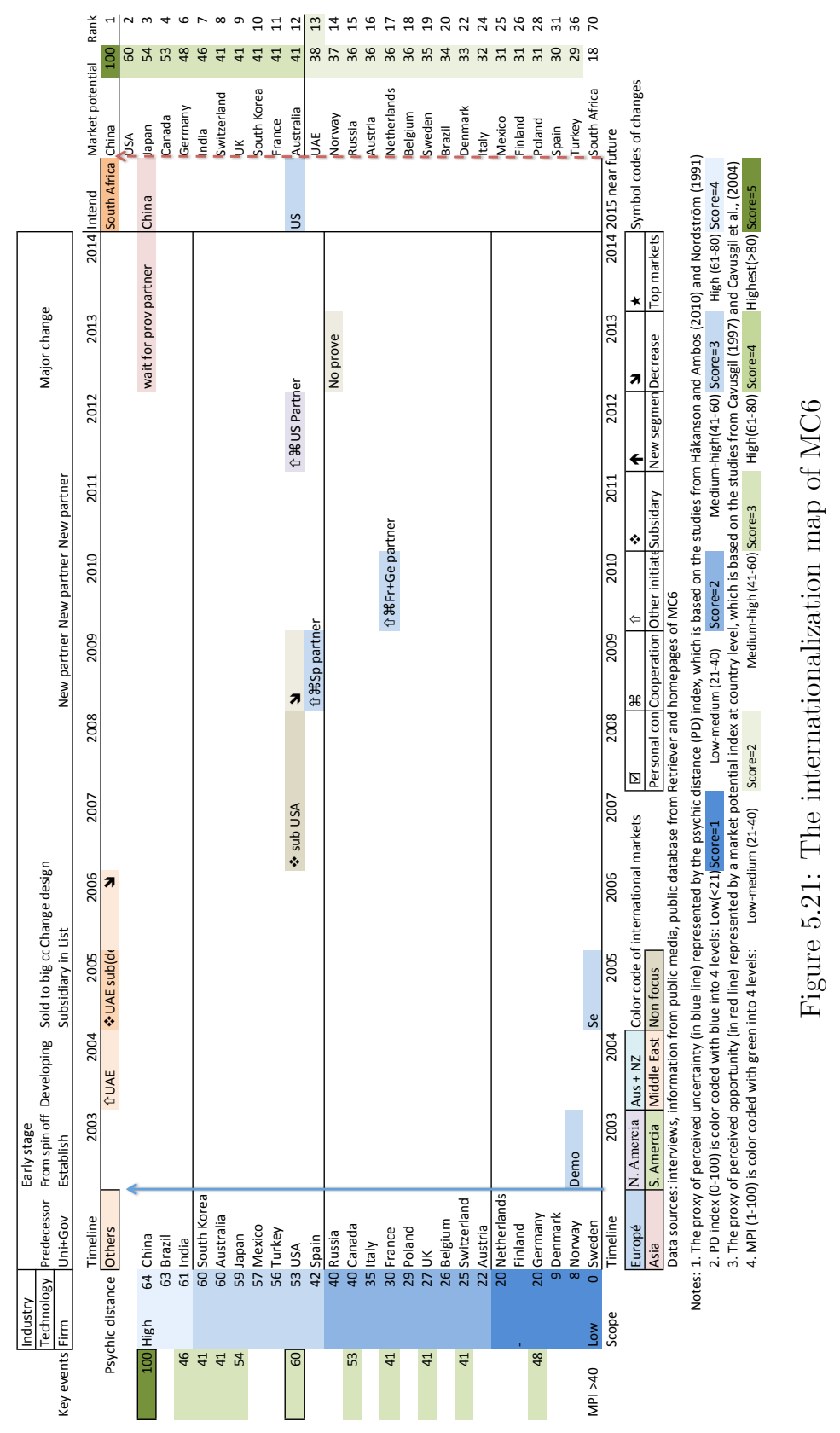


tionalization was formed in an unplanned style. The firm follows calling from few early adopters in both close and distant international markets.

\section{Scale of internationalization and mode of entry}

When evaluating the scale of internationalization in terms of percentage of turnover, MC6 had almost $100 \%$ of its turnover from international markets since 2005, when a Swedish potential partner turned into a future competitor. Its basic mode of entry was through strategic partners from international markets. The firm made a commitment to develop units and the associated system for the specification of its clients. MC6 had two short periods of overseas operations in two countries. However, one of the operations, under pressure from the client, was economically unsustainable; another failed due to the wrong personnel. Except for China, where MC6 is using an agency for marketing and sales-related activities, in other markets where MC6 operated it used a high level of control mode over its technology-related operations, such as development of a system in the UAE. The sales part was often left to local partners' channels and networks.

\subsubsection{Behavior pattern of MC6's internationalization}

The behavior pattern of MC6 had a strong entrepreneurial feature and had a less controlled manner from the start.

\section{Entrepreneurial actions}

As a technology start-up, MC6 had technology competence in the development of its core product and associated system. These competences were the core means of the firm from its start. Before the first order appeared in 2004, MC6 had not deliberated on a plan toward this end. The firm just responded to emergent opportunities from the first international request. This type of action is closer to the Sarasvathy-type of entrepreneurial pattern, which takes from means identified in the current stage and allows un-predefined ends to emerge (Sarasvathy, 2001). This type of pattern repeated during the internationalization of MC6. The first deliberately studied international market was the China market. This was also triggered by an emergent connection from MC6's new chairman. 


\section{Context of international entrepreneurial activity}

The early internationalization of MC6 just happened rather than being a planned event. The results or temporary "ends" of this international entrepreneurial activity had a big impact on MC6's further internationalization. The first international order stimulated new product development for MC6. However, financial unsustainability from the first international project also forced MC6 to seek a new joint venture possibility with a big potential partner at home. When the joint venture failed to form, the technology transfer from MC6 to the big company fostered a big future competitor in its home market. The event triggered the firm to find an alternative method to get financed. Meanwhile, it also decreased a chance in the domestic market and pushed the firm to look for potential partners from international markets.

\subsubsection{Context of emerging market entry of MC6}

The acceptance of the first international order from a more distant country from the start was under pressure to survive as a new venture. In the early period, as a small technology-based firm, MC6 was taking any opportunity which offered financing for new product development and new markets. More intended merging market entry appeared in the international process rather recently. Due to export control in one of main segments of MC6, it excludes a few big emerging markets such as China and Russia from the defense segment. Segments in civil applications have just started to adopt this technology. Therefore, from the innovation diffusion (Rogers, 2003) point of view, the timing of emerging market entry matches the time period when the early adopters appear in the civil usage of segments in emerging markets. In the internationalization of MC6, the EM entry appeared when the firm began to take a more structured approach rather than act in an ad hoc manner during its early period. MC6 saw opportunities in the EM as early adopters in civil segments as more than being a risky place to lose technology in the EM. Therefore, the firm studied a few EMs such as China and South Africa in recent years and planned to use a joint venture form to operate in EMs. 


\subsubsection{Summary of findings in MC6's internationalization}

Findings for MC6 regarding its speed, scope, and scale of internationalization and its reflected behavior pattern:

1. Entrepreneurial activities trigger internationalization of the firm.

2. Entrepreneurial activities are more obvious in the early period of internationalization and under the pressure to survive.

3. Low prospects in status quo markets are more likely to encourage entrepreneurial actions and open different opportunities in international markets.

4. Technology competence enables early internationalization and further cooperation with global partners.

5. Formal institutional regulations limit the choice of international markets.

6. Emerging market interest came late (the last 2-3 years). MC6 approaches EMs in a more structured way.

7. The general motion pattern shows mixed influences from industrial structure, new technology diffusion and managerial attention in different time periods of the firm's development.

8. Motion patterns reflect ad hoc behavior during internationalization.

9. MC6 is of the instant internationalization type with a focus on a few key markets.

\subsection{Case I (MC7) analysis}

\subsubsection{Overview of MC7}

MC7 is a small manufacturer producing mechanical sweepers. The firm, established in 1993, began doing international business very early due to its owners' international connections. MC7 had a sister company in Poland, and the two firms divided their international markets from the start. After 2009, when ownership switched to a different family, MC7 parted ways with its sister company and expanded its international 
markets freely.

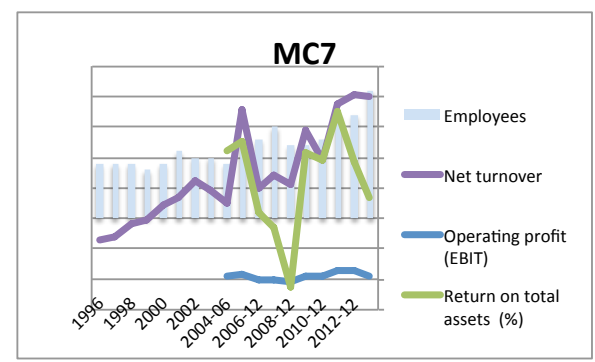

Figure 5.22: Financial performance of MC7

Table 5.11: Profile of MC7

\begin{tabular}{|l|c|}
\hline $\begin{array}{l}\text { Year of establishment } \\
\text { No. of employees } \\
\text { Net turnover (MSEK) }\end{array}$ & $\begin{array}{c}1993 \\
\text { Industry segments } \\
\text { ca. } 60\end{array}$ \\
Key offerings & $\begin{array}{l}\text { Road maintenance and } \\
\text { cleaning vehicles } \\
\text { Mechanical sweepers }\end{array}$ \\
\hline \multicolumn{2}{|c|}{ Internationalization profile of MC7 } \\
\hline $\begin{array}{l}\text { Start year } \\
\text { International markets/ } \\
\text { partners } \\
\text { Share of overseas } \\
\text { turnover } \\
\text { Entry mode/ nodes }\end{array}$ & 1990s \\
\hline
\end{tabular}

Source: Interview data and data from the Retriever Business 2014

The firm has 21 employees and about 60 MSEK net turnover. About $65 \%$ to $70 \%$ of the turnover is from international markets. MC7 uses a distributorship and covers more than 10 international markets. Figure 5.22 shows the trend of change in the financial performance of MC7. Table 5.11 provides a brief profile of MC7. 


\subsubsection{Motion pattern of MC7's internationalization}

Figure 5.23 maps the overall internationalization motion pattern of MC7 in a dual serial of the "perceived risk (uncertainty)", represented by "psychic distance" as a proxy, versus the "perceived opportunity", represented by MPI as a proxy.

\section{Timing of internationalization}

Figure 5.23 shows the motion pattern of MC7's internationalization. From the time dimension, MC7 started internationalization very early. One of its owners' international connections helped MC7's internationalization.

\section{Scope of internationalization}

Due to its agreement with its sister company, the international markets of MC7 were clustered either in Nordic markets or in Middle East markets, where one of the owners had contacts. After, 2009, when the ownership changed, the scope of MC7's international markets began to be less concentrated in the two blocks.

\section{Scale of internationalization and mode of entry}

The scale of internationalization gradually increased for the firm, from about $50 \%$ in the early 2000s to around 70\% in 2014. MC7 used distributorships to cover its international markets. A few new distributors were less active, such as Turkey. MC7 had a very low influence on distributors' performance.

\section{Endurance of internationalization}

After its ownership change, MC7 put increasing effort on its international markets. In addition to existing distributors, MC7 also recruited new distributors in different markets in a short period. A few new markets were opened due to potential distributors' proposals.

\subsubsection{Behavior pattern of MC7's internationalization}

The internationalization of MC7 started from available means. Its owner used previous connections in more distant Middle East markets to introduce its products. In 


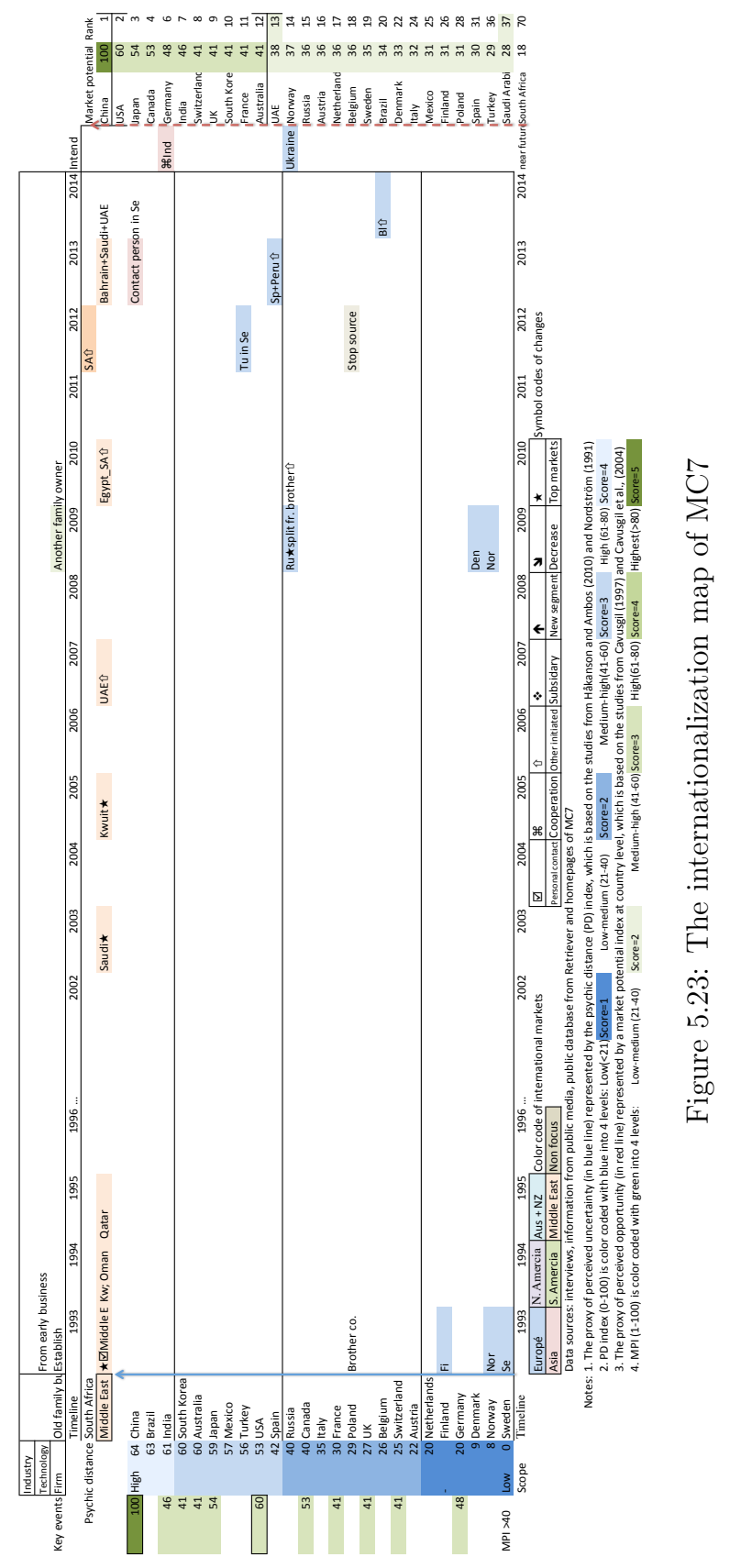


turned out that the product was a good fit with the climate. It matched effectuationtype behavior (Sarasvathy, 2008). Some of its recent markets were more based on ad hoc behavior. Because MC7 was open to different markets, very often the firm just responded to requests from potential distributors.

\subsubsection{Context of emerging market entry of MC7}

Russia was the first important EM for MC7. Due to a previous agreement with its sister company, MC7 was not free to choose a foreign market. After parting ways with the sister company, MC7 was more open and positive to EM opportunity. A competitor's distributor turned to the firm, and MC7 positively reacted to this emerging opportunity.

\subsubsection{Summary of findings in MC7's internationalization}

1. Entrepreneurial activity brings international growth opportunity.

2. Ownership change influences preference and strategy during internationalization. Thus, it influences scope and scale of internationalization.

3. Negative prospects in the domestic market are more likely encourage firms to seek international growth opportunity.

4. Emerging market interest came late, due to internal agreement.

5. International experience and connections are an important means for a small business during internationalization.

\subsection{Case J (MC8) analysis}

\subsubsection{Overview of MC8}

MC8 is a small enterprise which develops, manufactures and markets lubrication equipment. The firm was established in 1908. It has changed ownership several times and received its latest registration as an independent firm in 1993. Figure 5.24 shows the 
trend of change in the financial performance of MC8, while Table 5.12 gives a brief profile of MC8.

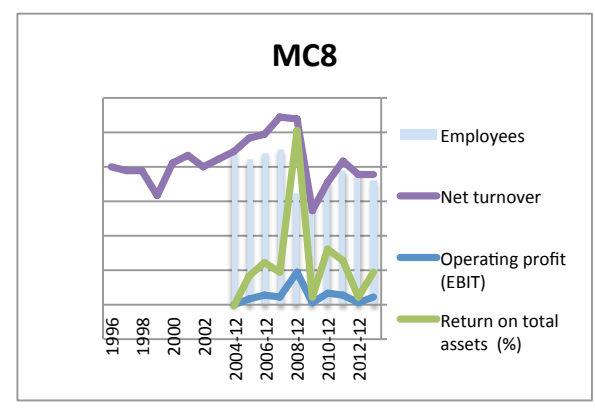

Figure 5.24: Financial performance of MC8

Table 5.12: Profile of MC8

\begin{tabular}{|l|c|}
\hline $\begin{array}{l}\text { Year of establishment } \\
\text { No. of employees } \\
\text { Net turnover (MSEK) } \\
\text { Industry segments } \\
\text { Key offerings }\end{array}$ & $\begin{array}{c}\text { 1993* (1908) } \\
\text { Heavy process industries } \\
\text { Lubrication systems \& } \\
\text { equipment }\end{array}$ \\
\hline \multicolumn{2}{|c|}{ Internationalization profile of MC8 } \\
\hline $\begin{array}{l}\text { Start year } \\
\text { International markets/ } \\
\text { partners } \\
\text { Share of overseas } \\
\text { turnover } \\
\text { Entry mode/ nodes }\end{array}$ & \multicolumn{1}{|c|}{ ca. 1940s (prior period) } \\
\hline
\end{tabular}

*Registration record from system

Source: Interview data and data from the Retriever Business 2014

The firm started international business long before 1993. Export was not the focus in its early period; only around $25 \%$ of its business involved export to a few European countries. Today, the firm uses a distributorship to reach more than 30 international markets. Foreign markets contribute to about $50 \%$ of the total turnover of the firm. The firm has 36 employees and more than 35 MSEK in net turnover. 


\subsubsection{Motion pattern of MC8's internationalization}

Figure 5.25 maps the overall internationalization motion pattern of MC8 in a dual serial of the "perceived risk (uncertainty)", represented by "psychic distance" as a proxy, versus the "perceived opportunity", represented by MPI as a proxy.

\section{Timing of internationalization}

Figure 5.25 shows the motion pattern of MC8's internationalization. From the time dimension, MC8 began internationalization before the firm got its new registration. The firm had long history in export during its prior period.

\section{Scope of internationalization}

MC8 had a wide scope in internationalization. In the beginning, MC8 had a few major markets in Europe. Soon the firm expanded its markets into more distant foreign markets and had increased the number of markets. The expansion of the number of markets continued until last year. MC8 tried to be more focused on a few close markets to work with its distributors.

\section{Scale of internationalization and mode of entry}

MC8 increased the turnover from its foreign markets slowly. Despite having many distributors in 25 to 30 countries, the overseas turnover of MC8 was about $50 \%$ of its total. MC8 used distributorships to cover its foreign markets. Most of its distributors lacked the proper knowledge and training to be able to sell its system. The firm had very limited time to work with a large number of distributors.

\section{Endurance of internationalization}

Despite a wide coverage of international markets, many markets are inactive. Distributors need to have proper knowledge and the right network in order to sell. Thus, MC8 plans to just focus on 2-3 close markets to work with first.

\subsubsection{Behavior pattern of MC8's internationalization}

MC8's international expansion has been in an ad hoc manner. The firm was open to potential distributors, regardless of which markets. However, after the economic crisis 


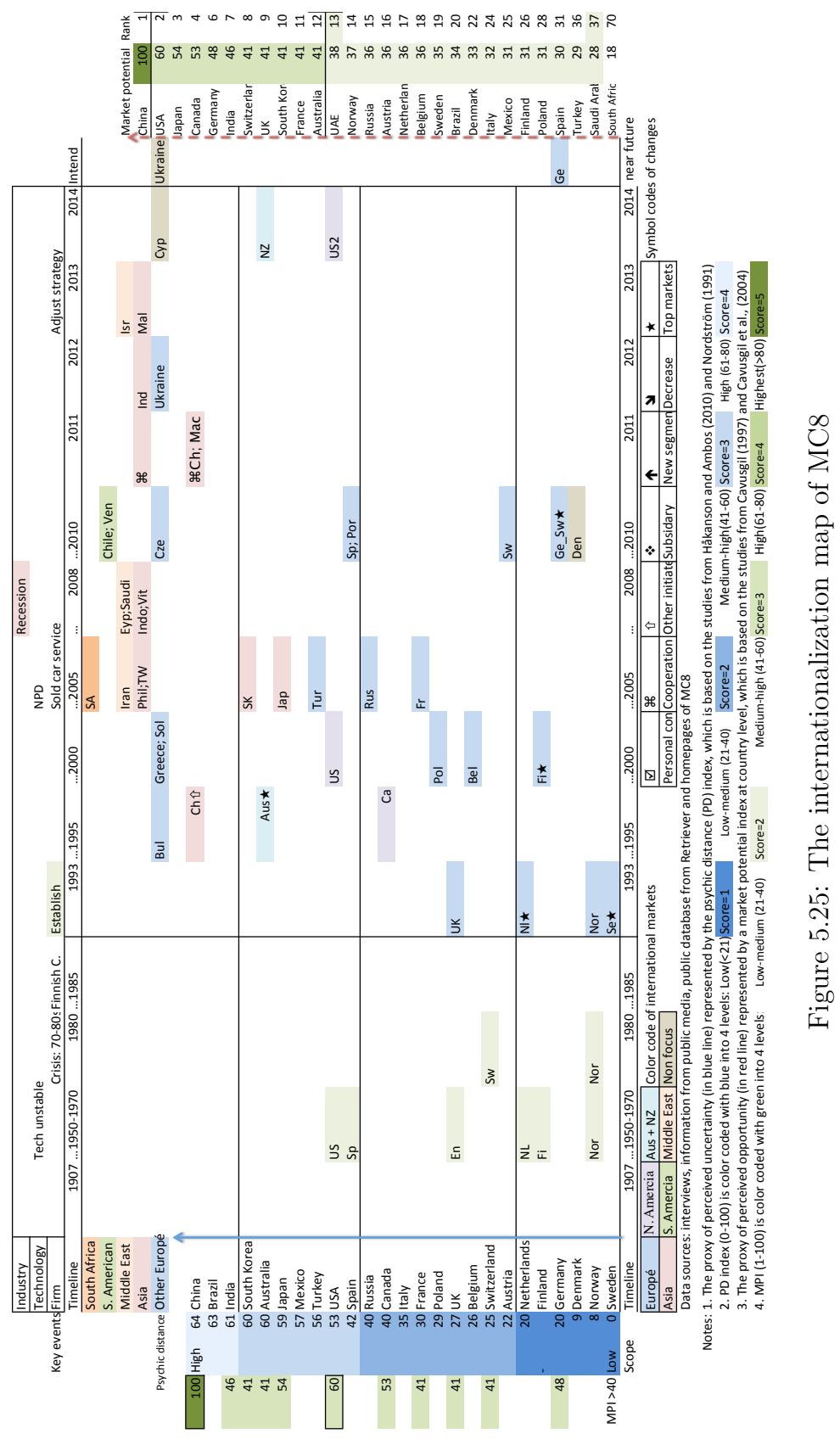


of 2008, MC8 started to adjust its behavior and became more focused on a very few markets with potential in its target segment.

\subsubsection{Context of emerging market involvement of MC8}

Except for Ukraine, which was recommended by a Swedish governmental trade agent, other emerging markets were unplanned. The firm was open to any international market. Some distributors from EMs simply initiated contact and the firm accepted.

\subsubsection{Summary of findings in MC8's internationalization}

1. Historical inputs influence the speed of international growth.

2. Changes in managerial attention in different periods influence the scope of internationalization.

3. Wide coverage of markets needs trade-offs with the firm's influence on the sales channels.

4. Emerging market interesting was moderated.

5. Innovative products enables and supported international sales.

6. High-level requirements for professional knowledge about the system made sales through distributors less effective.

\subsection{Case K (MC9) analysis}

\subsubsection{Overview of MC9}

MC9 is a small manufacturer of DC/DC converters. It also designs an underwater electromagnetic signature management and control system. Currently, MC9 has 29 employees and more than 40 MSEK in net turnover. Figure 5.26 shows the trend of change in the financial performance of MC9, while Table 5.13 shows a brief profile of 
MC9.

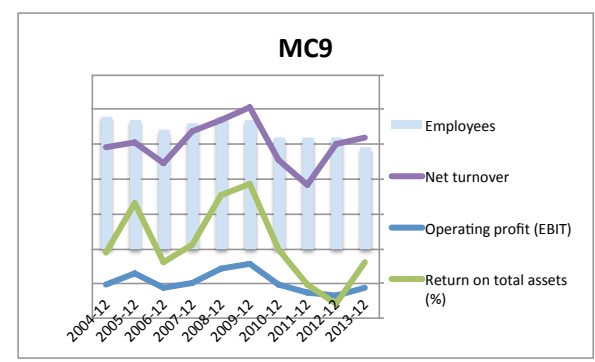

Figure 5.26: Financial performance of MC9

Table 5.13: Profile of MC9

\begin{tabular}{|c|c|}
\hline Year of establishment & 1966 \\
\hline No. of employees & 29 \\
\hline Net turnover (MSEK) & $>40$ \\
\hline \multirow[t]{4}{*}{ Industry segments } & 1. Naval \\
\hline & 2. Train \& track side \\
\hline & 3. Power plant \\
\hline & DC/DC converter; \\
\hline Key offerings & $\begin{array}{l}\text { Electromagnetic signature } \\
\text { management system }\end{array}$ \\
\hline \multicolumn{2}{|c|}{ Internationalization profile of MC9 } \\
\hline Start year & $1966-1967$ \\
\hline $\begin{array}{l}\text { International markets/ } \\
\text { partners }\end{array}$ & $>15$ markets \\
\hline $\begin{array}{l}\text { Share of overseas } \\
\text { turnover }\end{array}$ & ca. $70 \%$ \\
\hline Entry mode/ nodes & $\begin{array}{c}\text { Distributorship \& agency; } \\
\text { one FDI }\end{array}$ \\
\hline
\end{tabular}

Source: Interview data and data from the Retriever Business 2014

MC9 was founded in 1966 by an engineer with many international connections, with his son assuming the leading position in 1995. Because of founder's international connections from his early career, MC9 started international business even before domestic business. 
MC9 has only one foreign organization, which was a production facility established in 1979. Its international sales are mainly through distributors and agents to cover more than 15 international markets. International business contributes about $70 \%$ of the firm's total turnover.

\subsubsection{Motion pattern of MC9's internationalization}

Figure 5.27 maps the overall internationalization motion pattern of MC9 in a dual serial of the "perceived risk (uncertainty)", represented by "psychic distance" as a proxy, versus the "perceived opportunity", represented by MPI as a proxy.

\section{Timing of internationalization}

Figure 5.27 shows the motion pattern of MC9's internationalization. From the time dimension, MC9 started internationalization right after its establishment. International experience and the contacts of its founder triggered MC9 to use its founder's network in international markets.

\section{Scope of internationalization}

In the first 15 years, the scope of internationalization was narrow. The early markets were mainly concentrated on the countries where the founder had his personal networks from previous colleagues. After the new generation started to run the firm, the scope started to expand. New segments, cooperation with other small firms and being a supplier to a big MNE helped MC9 to expand its scope in internationalization.

\section{Scale of internationalization and mode of entry}

MC9 had its production overseas rather early, due to its founder's personal preference from previous international experience. In its marketing and sales, MC9 mainly used distributors in the DC/DC segment and agents for system sales in the military segment. Overseas turnover contributed to $70 \%$ of the firm's total turnover. In the distributorship market, the turnover per captia was far less than in the domestic markets.

\section{Endurance of internationalization}




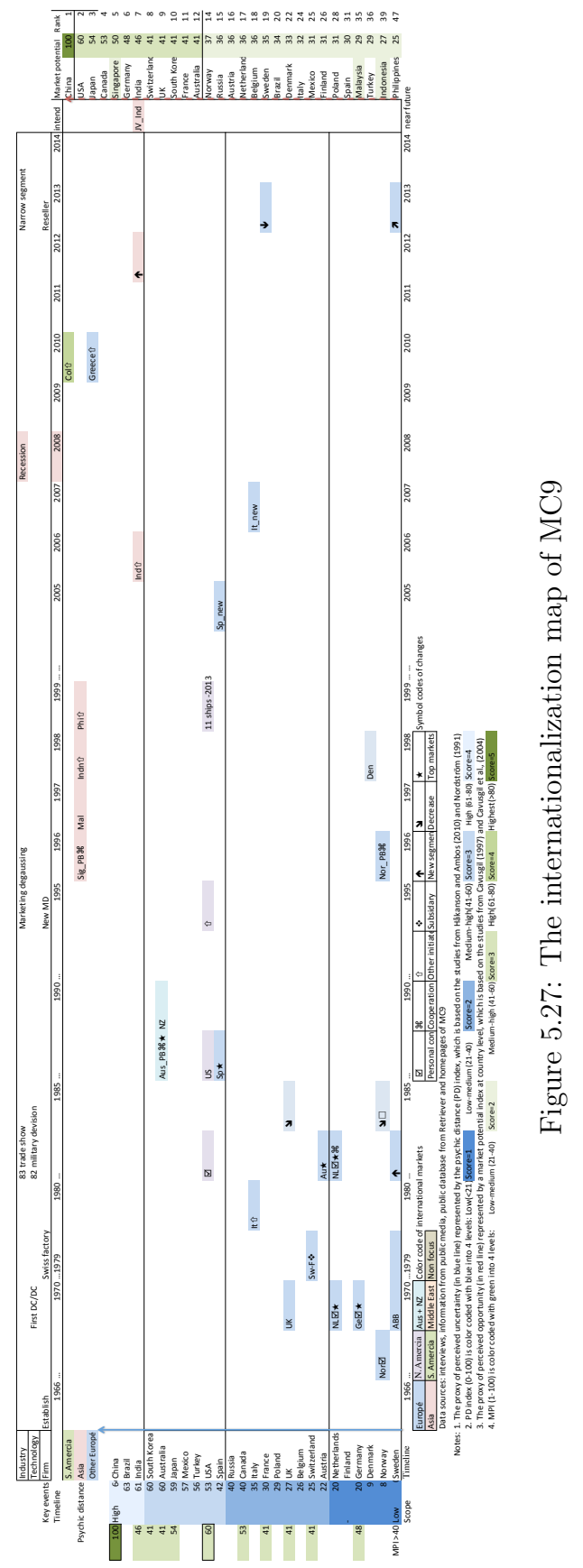


Endurance in each market varied with time and personnel change in the distributorship. For example, two of its earlier important markets, Norway and UK, slide down because the previous personal contacts passed away. More distant Asian markets, where MC9 could hardly influence its distributors, were also less durable. In the military segment, some markets were excluded due to export control. Even in a the market like the US, it is difficult for a small foreign firm to get continuous orders in a highly regulated segment.

\subsubsection{Behavior pattern of MC9's internationalization}

The behavior of MC9 during internationalization was more entrepreneurial in nature. The internationalization of MC9 started from available means. Its founder's international connections and previous work and life experience triggered MC9 to go after international business even before its domestic market. The first overseas production was set up in a high-cost country, Switzerland. This was also due to personal preference. This matches with effectuation type behavior (Sarasvathy, 2008). Developing its competence in a new segment enabled MC9 to discover new opportunities in international markets, and fits the feature of Kirzner-type entrepreneurship (Kirzner, 1997).

\subsubsection{Context of emerging market entry of MC9}

MC9 actively approached emerging markets, like India, rather late. The firm had conducted business in Malaysia and India in the past, however those dealings were project-based. MC9 did not find a way to move forward. The recent project in India was based on business connections. MC9 was recovering from the negative impact of the 2008 crisis. Meanwhile, India also had a new government. There were many new project opportunities, which made MC9 motivated to move forward in the Indian market.

\subsubsection{Summary of findings in MC9's internationalization}

1. Entrepreneurial activity brings international growth opportunity. 
2. The founder and owner's international experience, preferences, connections and attitudes influence the speed and scope of internationalization.

3. Negative prospects in the status quo market are more likely encourage entrepreneurial actions.

4. Emerging market interest came late. Negative prospects in the status quo market more likely triggers the firm to seek new opportunities in EMs.

5. Development in technology competency enables opportunity discovery in international markets.

6. The indirect entry mode requires more effort on training and governance of distributors and agents.

7. MC9 was of the international new venture type.

\subsection{Case L (TC) analysis}

\subsubsection{Overview of TC}

TC is a small independent distributor of electronic components. It started as a trading company in the beginning of the 1990s. Today, TC has 17 employees and more than 45 MSEK in net turnover. Figure 5.28 shows the trend of change in the financial performance of TC, while Table 5.14 gives a brief profile of TC.

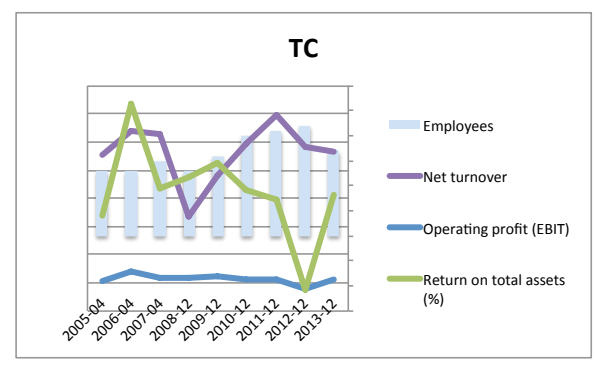

Figure 5.28: Financial performance of TC 
Table 5.14: Profile of TC

\begin{tabular}{|l|c|}
\hline $\begin{array}{l}\text { Year of establishment } \\
\text { No. of employees } \\
\text { Net turnover (MSEK) } \\
\text { Industry segments } \\
\text { Key offerings }\end{array}$ & $\begin{array}{c}1995^{*}(1989) \\
\text { Electronic components } \\
\text { Distributors of electronic } \\
\text { components }\end{array}$ \\
\hline \multicolumn{2}{|c|}{ Internationalization profile of TC } \\
\hline $\begin{array}{l}\text { Start year } \\
\text { International markets/ } \\
\text { partners } \\
\text { Share of overseas }\end{array}$ & $\begin{array}{c}\text { 1990 major markets } \\
\text { turnover } \\
\text { Entry mode/ nodes }\end{array}$ \\
\hline
\end{tabular}

*Registration record from system

Source: Interview data and data from the Retriever Business 2014

TC was founded by a former purchaser of a big Swedish MNE in the telecommunications sector. Because of the founder's international connections and experience from the international supply chain in his previous career in the telecommunications industry, TC started international business right after its establishment.

TC has sourced worldwide. Although it also reaches more than 15 foreign markets throughout Europe, Asia and North America, its international turnover is mainly generated from a few markets. Currently, $35 \%$ percent of firm's total turnover is from its overseas markets.

\subsubsection{Motion pattern of TC's internationalization}

Figure 5.29 maps the overall internationalization motion pattern of TC in a dual serial of the "perceived risk (uncertainty)", represented by "psychic distance" as a proxy, versus the "perceived opportunity", represented by MPI as a proxy.

\section{Timing of internationalization}

Figure 5.29 shows the motion pattern of TC's internationalization. From the time dimension, TC as a trading company started its internationalization right from its 
5. WITHIN-CASE ANALYSIS

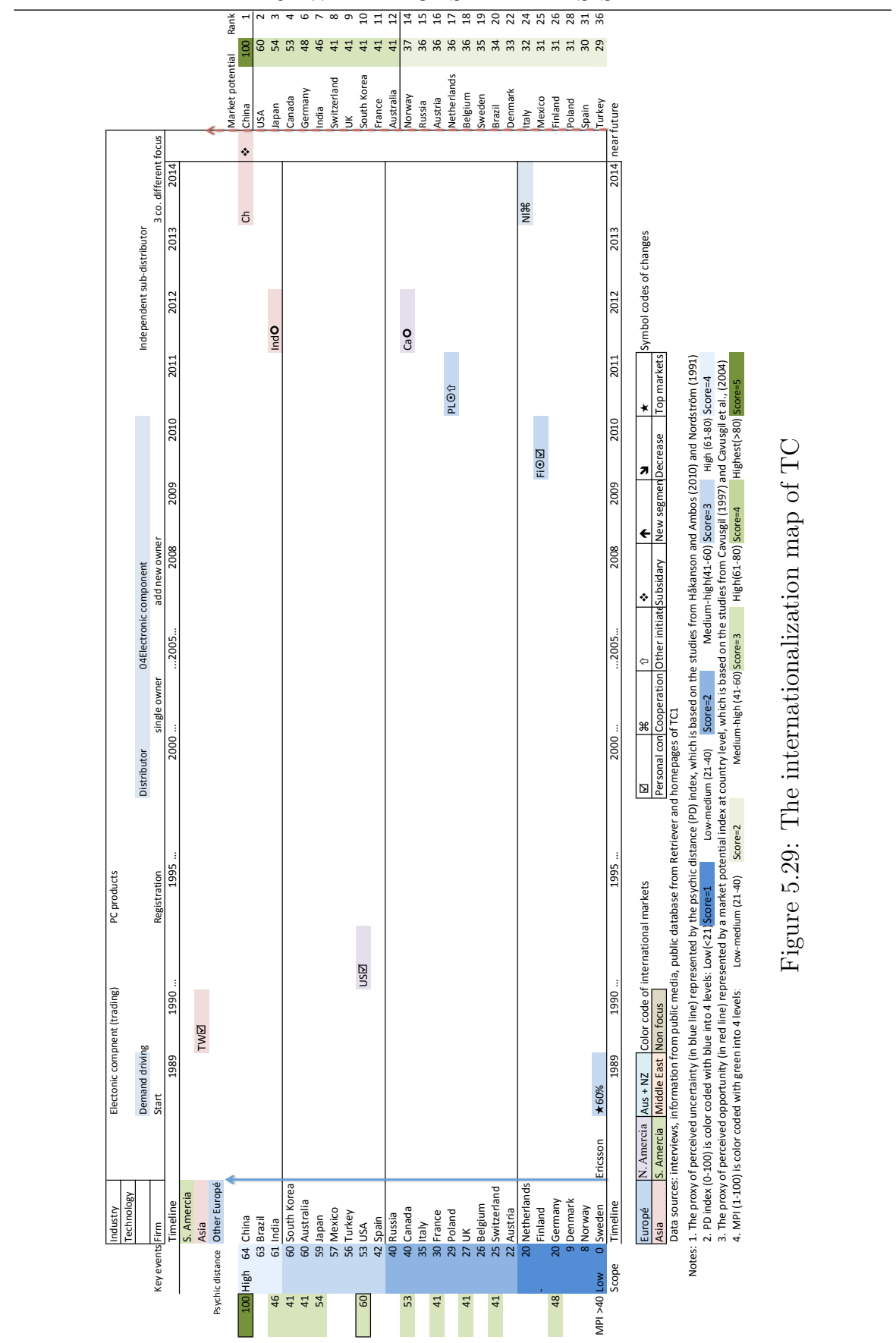


establishment. Its business model was actually built on the price difference in the international distribution channel.

\section{Scope of internationalization}

Although TC had done business worldwide, with the exception of Africa, most of its business was related to purchasing, which is inward internationalization. Its scope of international market was concentrated on a few markets, which clustered with many electronic products producers. The founder had working experience and connections in the Far East. Thus, he did not have the perception of a high "psychic distance" market, such as Taiwan, as many others did.

\section{Scale of internationalization and mode of entry}

TC mainly used direct sales and agents to conduct business in its international markets. Turnover was mainly generated from its domestic market. Foreign market turnover contributed to about $35 \%$ of the total turnover. More distant markets, for example in the US and the Far East, had higher margins but contributed less compared with the firm's two major markets in Europe.

\section{Endurance of internationalization}

Endurance in each international market varied. TC mainly relied on its agents' knowledge, ambition and networks in the local market. Finding the right personnel was not easy for TC as a small distributor; its India and Canada operations, for example, were not sustainable due to such agent problems.

\subsubsection{Behavior pattern of TC's internationalization}

The internationalization of TC reflected its entrepreneurial behavior. The founder recognized the potential opportunity embedded in the international distribution channel. Thus, he created a venture to offer its service and capture such opportunity. This fits the Kirzner-type entrepreneurial action, in terms of opportunity alertness (Kirzner, 1997). When TC sensed a changing trend in outsourcing, the firm also moved fast to target Poland as its major market. The firm could sense and alert potential opportunities embedded in these changes and take action on them. 


\subsubsection{Context of emerging market entry of TC}

The timing of the firm's big EM entry was rather late. TC planned to expand after recovering from the economic crisis. Although the CEO of TC had a lot of concerns regarding uncertainty and competition in China, the big market size of China still attracted him to take action in 2014. Combining information from Figures 5.28 and 5.29 , it is clear that the timing of its exploration in the China market was during a comparably low period of turnover growth. This indicates potential motivation in the firm's EM exploration.

\subsubsection{Summary of findings in TC's internationalization}

1. Entrepreneurial activity brings international growth opportunity.

2. Past international experience and knowledge contribute opportunity recognition in international market.

3. Negative prospects in status quo markets are more likely to encourage entrepreneurial actions

4. Emerging market interest came late. Negative prospects in status quo markets are more likely triggers for the firm to seek new opportunities in EMs.

5. TC is of the international new venture type. 


\section{Chapter 6}

\section{Cross-case Analysis and Findings}

This chapter is the second part of the analysis of the empirical data. It compiles and compares the four in-depth cases at the Kina study stage together with eight additional cases in the EM extension study stage, based on the within-case analysis in Chapter 5. In the chapter a cross-case analysis is conducted and a summary of findings is presented.

\subsection{Cross-case comparison of the motion pat- terns}

To facilitate motion pattern identification across 12 case companies, the cross-case analysis began with performing an unsupervised statistical analysis and visualization technique. The cluster analysis method is one of the commonly-used methods for identifying patterns (Halkidi et al., 2001) and the development of segments and clusters in business studies (Hagen et al., 2012; Zahra and Covin, 1993). Thus, this study uses cluster analysis for pattern identification. The sample size for clustering is 12 . The features selected for the cluster analysis are based on the three dimensions of motion patterns. 


\subsubsection{Data preparation}

As explained in Section 4.6.3, the cluster analysis started with transferring and pooling data from each case analysis into quantifiable scores. Data from the three dimensions of motion were extracted from the mapping of each case; see for example Figures 5.4, 5.7, 5.10, and 5.13 etc. Those data were processed according to the operationalization of construct in Section 3.2.2 for further statistical analysis. A brief summary of the processed feature variables is as follows:

Scope of internationalization was calculated by a sum of the number of the firms' foreign markets multiplied by their corresponding score of PD (Håkanson and Ambos, 2010), i.e. Scope $=\sum_{n=0}^{i} n_{i} *$ Distance $_{\text {score }}$ (see Section 3.1.1). Two variables were extracted from the within-case analysis to represent the scope dimension in the initial epoch and the latest epoch (the last 5 years covering the investigation period).

Scale of internationalization was scored from two sub-dimensions. The first one was the degree of resource commitment represented by the entry modes (Sharma and Erramilli, 2004). The arbitrary score of the different entry mode is shown in Table 3.5. The second one was evaluated by the percentage of the firms' foreign market turnover (Zahra, 2005). The arbitrary score of the foreign market turnover is shown in Table 3.4. Four variables were created to represent the two sub-dimensions of the scale dimension in the initial epoch and the latest epoch.

Speed of internationalization represents how quickly the firm becomes actively involved in its first international business. Since this study has an emerging market focus, it also measures how quickly the firm approached those high PD emerging markets. Speed of internationalization is measured by both normal and standardized terms. For instance, the normal term uses a time span between the establishment year $\left(T_{0}\right)$ of a firm and its first international business involvement $\left(T_{\text {Intl }}\right)$ as the speed of internationalization $\left(\right.$ Speed $\left.=T_{\text {Intl }}-T_{0}\right)$. The first international business involvement refers to a firm's active efforts to promote its products or service in foreign markets. The standardized term is to transfer these time spans into a $0-1$ interval range to compare the 12 studied firms in a standardized way. Therefore, it measures Speed $_{s t}=\left(T_{\text {Intl }}-T_{0}\right) /$ Age, while Age $=T_{\text {year } @ s t u d y}-T_{0}$. 
Table 6.1 shows a summary of the eight main input feature variables for the cluster analysis.

Table 6.1: Summary of cluster variables

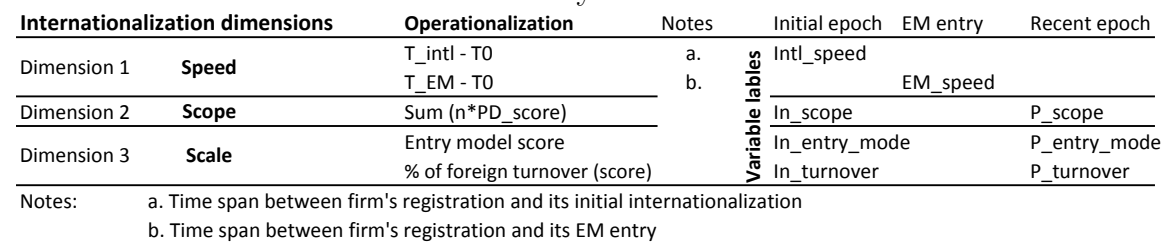

\subsubsection{Data analysis method}

Since the two-step cluster method can cluster both categorical and scale variables (Shih et al., 2010), this method was applied in this study. As mentioned above, the cluster analysis included eight feature variables (see Table 6.1), which covered the three dimensions of the motion pattern in two epoch time periods for each company. The categorical industry variable and age at investigation year were included in the evaluation field. Before performing the analysis, a 3D graphic plot (see Figure 6.1) was generated by JMP version 9 to get an intuitive judgment on the initial cluster number based on visual inspection on changes in the motion dimension across cases. Thus, the analysis procedure was as follows:

1. Visually inspect guided by a 3D plot to get an initial number of clusters to start the analysis.

2. Perform the cluster analysis based on the pre-determined cluster number from the graphic plot.

3. Evaluate the results from the initial analysis-based relevant criteria, such as compactness, separation (Halkidi et al., 2001) and ratio of size, to make further decisions on the repetition of analysis with varying numbers of clusters.

4. Interpret the final findings. 


\subsubsection{Results}

Figure 6.1 shows the changes in the motion pattern among the 12 investigated firms, from their initial period to a recent period of internationalization, in graphic plots. The initial epoch period of motion pattern is shown on the left part of Figure 6.1 in (a) and (c), while the recent epoch period of motion pattern is shown on the right part of Figure 6.1 in (b) and (d). The initial period plots show that from the speed dimension, there are two major clusters. Compared with other firms with less than 0.3 in the standardized speed, the blue-coded service firms are very late (close to 1 ) in the initial internationalization (see Figure 6.1 (c)). From the scope dimension (shown in the lengthening of the drop line) there are three clusters, from low to middle to high range of scope. On the right part of the plot, in (b) and (d), the motion pattern in the recent period is shown. Almost all of the investigated firms have increased their foreign turnover (shown in the bubble size). On the scope dimension, compared with the initial period, the distance among the clusters becomes less. Based on the observation, the study assigned an initial cluster number of three to perform further analysis.

Initial three clusters Based on the initial cluster number defined from the previous step, the analysis began with 3 clusters for the 12 cases. The Silhouette (with a range from -1 to 1 ) was a recommend measurement, as it measures both cohesion and separation for evaluating overall cluster quality (Norušis, 2011b). The Silhouette measurement for the 12 case firms was $0.5069(>.5)$, which implied good quality in differentiation (Norušis, 2011b). However, the ratio of cluster size (the largest to the smallest) was $4(>3)$. This indicates a possibility to further break down the largest cluster identified in the initial analysis. Therefore, the study continued the analysis with 4 clusters.

Final 4 clusters Table 6.2 shows the results of the initial and selected cluster analysis. With four clusters, the Silhouette value improved to 0.5264 , while the ratio of cluster size decreased to two. In addition, compared with the initial three clusters, the largest original cluster split into two clusters, while cluster membership from the other initial cluster remained the same. This implies a stability of clustering. Therefore, the four clusters were the final identified groups with similar features in their motion patterns. 


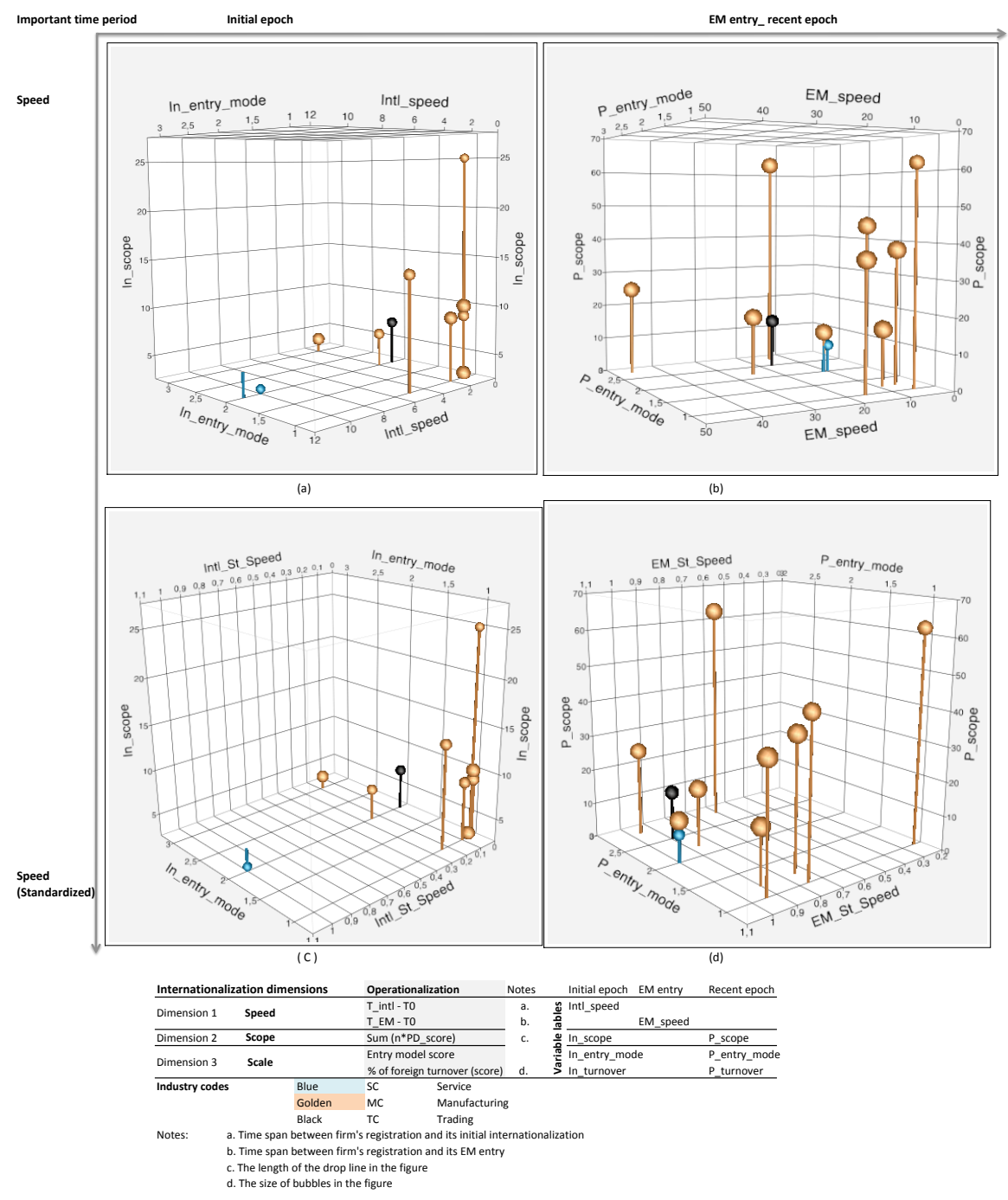

Figure 6.1: Changes in the motion dimensions 
Table 6.2: Comparison of cluster analysis

\begin{tabular}{|l|r|r|}
\hline & Initial & Selected \\
\hline Cluster number & 3 & 4 \\
Input variables & 8 & 8 \\
Silhouette measure of & & \\
cohesion and & & \\
separation & 0.5069 & 0.5264 \\
Ratio of cluster sizes & & \\
(largest to smallest) & 4 & 2 \\
\hline
\end{tabular}

Figure 6.2 shows the results of key characteristics of the four clusters among the 12 cases. In Figure 6.2, the left side of the figure (a) shows the cluster membership, the size of each cluster, eight input feature variables and two variables in evaluation fields with the mean score value for each in the corresponding cluster. These are listed based on their weights of importance for clustering. The right side (b) of Figure 6.2 shows a comparison of four clusters in boxplots. This corresponds to every input feature variable and variables in the evaluation fields in Figure 6.2 (a) and covers all of the data with superimposed boxplots for each of the clusters. The visual comparison of the four clusters shows the mean and range of score value of each cluster in each variable. Each cluster with different color code is shown in its position in the boxplot of the total 12 cases. Figure 6.2 shows the top three input feature variables based on their the weight of importance in the clustering:

1. The most important differentiation feature was the initial speed.

2. The second most important feature was the foreign market entry modes in the most recent period.

3. The third most important feature was the foreign market turnover in the most recent period.

Based on the key characteristics of each cluster, this study labeled cluster number one as C1 "Late starter". This cluster consisted of two service firms, SC1 and SC2. Compared with the first cluster, the other three clusters were much faster (see the first row of Figure 6.2 (b)), especially the second and third clusters, which on average started 
Clusters

Input (Predictor) Importance $\square 1.0 \square 0.8 \square 0.6 \square 0.4 \square 0.2 \square 0.0$

\begin{tabular}{|c|c|c|c|c|}
\hline Cluster & 1 & 2 & 3 & 4 \\
\hline Label & 1_Late starter & 2_Instant starter & \begin{tabular}{|c|} 
3. Instant starter \\
(increase control)
\end{tabular} & \begin{tabular}{|c|} 
4_Start with a large \\
scope
\end{tabular} \\
\hline \multirow[t]{2}{*}{ Description } & \multirow[b]{2}{*}{$\mathrm{SC1} ; \mathrm{SC2}$} & \multirow[b]{2}{*}{$\begin{array}{l}\text { MC1; } \\
\text { MC2; }\end{array}$} & \multirow[b]{2}{*}{$\begin{array}{l}\text { MCs; MC4; MC9; } \\
\text { TC }\end{array}$} & \multirow[b]{2}{*}{ MC7; MCB } \\
\hline & & & & \\
\hline Size & $\left|\begin{array}{r}16.76 \\
(2)\end{array}\right|$ & $\mid \begin{array}{r}33.36 \\
(4)\end{array}$ & $\begin{array}{r}33.36 \\
(4)\end{array}$ & $\int \begin{array}{r}16.79 \\
\text { (2) }\end{array}$ \\
\hline \multirow[t]{8}{*}{ Inputs } & $\begin{array}{l}\text { Int speed } \\
10.50\end{array}$ & $\begin{array}{l}\text { Int speed } \\
1.50\end{array}$ & $\begin{array}{l}\text { Int speed } \\
1.25\end{array}$ & $\begin{array}{l}\text { Int speed } \\
3.00\end{array}$ \\
\hline & $\begin{array}{c}\text { P_entry mode } \\
2.00\end{array}$ & $\begin{array}{l}\text { P_entry.mode } \\
1.35\end{array}$ & $\underset{2.58}{P \text { Pentry mode }}$ & $\begin{array}{l}\text { P_entry mode } \\
1.00\end{array}$ \\
\hline & $\begin{array}{c}\text { P_turnover } \\
0.50\end{array}$ & $\begin{array}{c}\text { P_turnover } \\
4.00\end{array}$ & $\begin{array}{l}\text { P.turnover } \\
3.25\end{array}$ & $\begin{array}{c}\text { P.turnover } \\
2.50\end{array}$ \\
\hline & $\ln _{4.00}$ scope & $\ln _{5.50}$ & In scope & $\begin{array}{l}\text { In } \_ \text {scope } \\
19.50\end{array}$ \\
\hline & $\begin{array}{l}\text { In turnover } \\
0.50\end{array}$ & $\begin{array}{l}\text { In curnover } \\
3.00\end{array}$ & In_wirnover & In turnover \\
\hline & $\begin{array}{c}\text { P_scope } \\
8.00\end{array}$ & $\begin{array}{l}P_{\overline{2}} \text { scope } \\
25.50\end{array}$ & $\begin{array}{l}\text { Pscope } \\
\overline{2} 29.75\end{array}$ & $\mathrm{P}_{\overline{5} 3 \mathrm{scope}}$ \\
\hline & $\begin{array}{c}\text { EM_speed } \\
10.50\end{array}$ & $\underset{10.50}{E M_{1} \text { speed }}$ & $\begin{array}{l}\text { EM speed } \\
25.50\end{array}$ & $\underset{10.50}{E M_{1} \text { speed }}$ \\
\hline & $\begin{array}{l}\text { In_entry_mode } \\
2.00\end{array}$ & $\begin{array}{l}\text { In_entrymode } \\
1.75\end{array}$ & $\begin{array}{c}\text { In_entry.mode } \\
1.25\end{array}$ & $\begin{array}{l}\text { In_enty_mode } \\
1.00\end{array}$ \\
\hline \multirow[t]{2}{*}{ Evaluation Fields } & $\begin{array}{l}\text { Age@study } \\
10.50\end{array}$ & $\begin{array}{l}\text { Age@sstudy } \\
11.50\end{array}$ & $\begin{array}{l}\text { Age@study } \\
29.75\end{array}$ & $\begin{array}{l}\text { Age日sstudy } \\
21.00\end{array}$ \\
\hline & $\begin{array}{l}\text { Industry } \\
s(100.0 \% 6)\end{array}$ & $\begin{array}{l}\text { Industry } \\
M(100.0 \%)\end{array}$ & $\begin{array}{l}\text { Industry } \\
\text { M (75.0\%) }\end{array}$ & $\begin{array}{c}\text { Industry } \\
M(100.0 \%)\end{array}$ \\
\hline
\end{tabular}

(a)
Cluster Comparison

I_Late starter $\quad$ 2_Instant starter $\quad$ 3_Instant starter (increa... $\mid$ in 4_Start vith a large scope
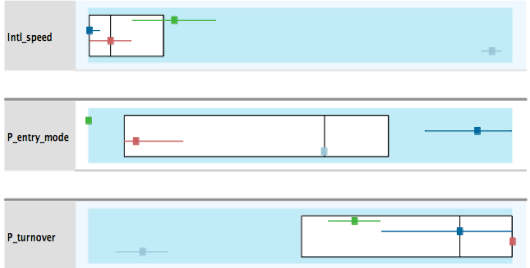

In_scope $\rightarrow+\rightarrow$
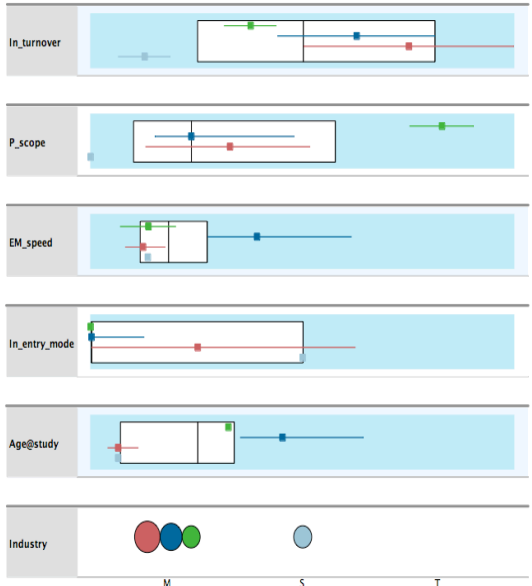

(b)

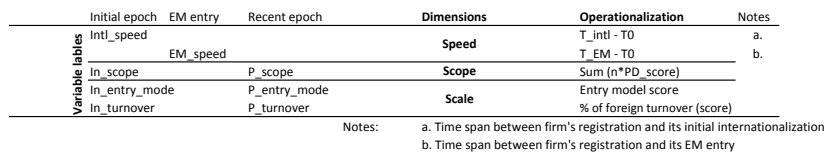

Figure 6.2: Key characteristics of the four clusters 
internationalization 1.5 and 1.25 years, respectively after the legal establishment. Despite the similarity in the speed dimension, unlike the third cluster, on average cases in the second cluster did not increase their control level in the entry mode. Therefore, the study labeled the second cluster as C2 "Instant starter", while it labeled the third cluster as C3 "Instant starter (increase control)". The only trading firm was in the third cluster. The last cluster with the remaining two manufacturing firms was labeled as C4 "Start with a large scope", due to its highest mean value in the initial scope during internationalization.

\subsubsection{Findings from clusters of motion pattern}

\section{Cluster 1: "Late starter"}

The first cluster was labeled C1 "Late starter" (light blue in Figure 6.2 (b)) to describe its slow initial actions in the internationalization. Two service firms were in this cluster. Firms clustered in this group had a long period of domestic market focus before they started to engage in international business development. Compared with the other two clusters, "Late starter" tripled the time in their initial international market involvement. Their internationalization had not reached a consolidated level. Therefore, the mean score value in the scale of their internationalization in terms of foreign market turnover was very low. Since they started rather late, they were still in the process of experimenting. This cluster often used direct sales, which has a higher level of control than using agents. From the lower section of Figure 6.2 (b), it shows that there was a very small difference between "Late starter" and the other clusters regarding speed of EM entry (labeled as EM-speed ). It shows, in terms of the time, all the 12 investigated firms approached EM in a more recent period. This shows that despite the late internationalization, the "Late starter" took much less time to approach an EM. Compared with the other clusters, cases in "Late starter" had a different sequence in distant market entry. In sum, their characteristics of motion pattern suggest that "Late starter" was not actively involved in the internationalization from an early period. Its scale of internationalization in terms of foreign market turnover was very low. However, the speed of approaching EM markets was comparably fast, once the "Late starter" began to engage in internationalization. 


\section{Cluster 2: "Instant starter"}

The second cluster was labeled C2 "Instant starter" (red square in Figure 6.2 (b)) to show its instant initial actions in the internationalization. Four of nine manufacturing firms were in this cluster. The mean scores for the eight input feature variables of this cluster are shown in the second column of Figure 6.2 (a). Those in the "Instant starter" cluster started international business shortly after their formal registration (within 1.35 years on average). In addition, compared with the other clusters, the "Instant starter" cluster had the highest scale of internationalization in terms of foreign market turnover. The entry mode taken in this cluster on average had a lower control level than the other clusters in the recent period. Moreover, the scope of this cluster had a rather moderate increase.

\section{Cluster 3: "Instant starter (increase control)"}

The third cluster was labeled C3 "Instant starter (increase control)" (dark blue in Figure $6.2(\mathrm{~b}))$ to show its instant initial actions in the internationalization and its increasing control in the change of entry mode. Three of nine manufacturing firms and the trading firm were in this cluster. Compared with the second cluster, the "Instant starter (increase control)" cluster started international business slightly earlier (within 1.25 years on average). It was the fastest group in the initial internationalization among the four clusters. It also showed on increase in the scope dimension during internationalization. The clear difference that separated "Instant starter (increase control)" from the other three clusters was that it had the highest average score in the control mode in the recent epoch period (see the second row in Figure 6.2 (b)). In addition, compared with the other clusters, the average age of "Instant starter (increase control)" was also the oldest among the other clusters.

\section{Cluster 4: "Start with a large scope"}

The last cluster was labeled C4 "Start with a large scope" (green square in Figure 6.2 (b)), because it reached the largest scope of international markets in the initial epoch among the other clusters. Two manufacturing firms (MC7 and MC8) were in this cluster. The difference between the "Start with a large scope" and the other clusters 
is shown in the fourth row of Figure 6.2 (b). The mean score of its scope was more than two times that of the other clusters. In addition, compared with the two early internationalized clusters, this cluster was just slightly slower than the "Instant starter" and the "Instant starter (increase control)" in the initial speed of internationalization. Despite having a large scope of internationalization, its mean score in share of foreign market turnover was lower than the other early starter groups. Moreover, its mean score in entry mode-related control level was also the lowest. This indicates that the large scope of internationalization in this group was sustained by the low control type of entry mode.

\subsubsection{Interpretation of results}

Using the construct derived from the literature review (see Section 2.1.3), this part of the cross-case comparison gives an overview of the feature in the motion pattern. Table 6.3 shows an overview comparison of motion patterns in the 12 case companies with the cluster codes.

Speed dimension From the Speed dimension, this study paid attention to the initial speed of internationalization and the timing of the EM entry. The average age of the investigated 12 case companies was 19 years in the corresponding study years. The average initial speed of internationalization was less than three years after their respective establishment registration (see Table 6.3). Among the 12 case companies, 7 of them had different prior forms before the formal registration of the firms. Three of the investigated case companies had been involved in international business in their prior period. The cross-case analysis shows two major groups in the initial speed of internationalization (see the first row in Figure 6.2 (b)). The "Late starter" distinguished itself from the rest of the 10 firms in the other three clusters. The "Late starter" paid less intention to foreign markets until recent years; it only got prospects or very little turnover from foreign markets until the investigation period. The remaining ten firms in the other three clusters started internationalization very early, and all of them fit the definition of "Born Global" (Knight and Cavusgil, 2004; Moen and Servais, 2002) and INV (Zahra, 2005; McDougall et al., 1994). Different motivations triggered these firms' internationalization within the first five years. They had a relatively 
Table 6.3: Overview of the internationalization motion pattern of 12 case companies

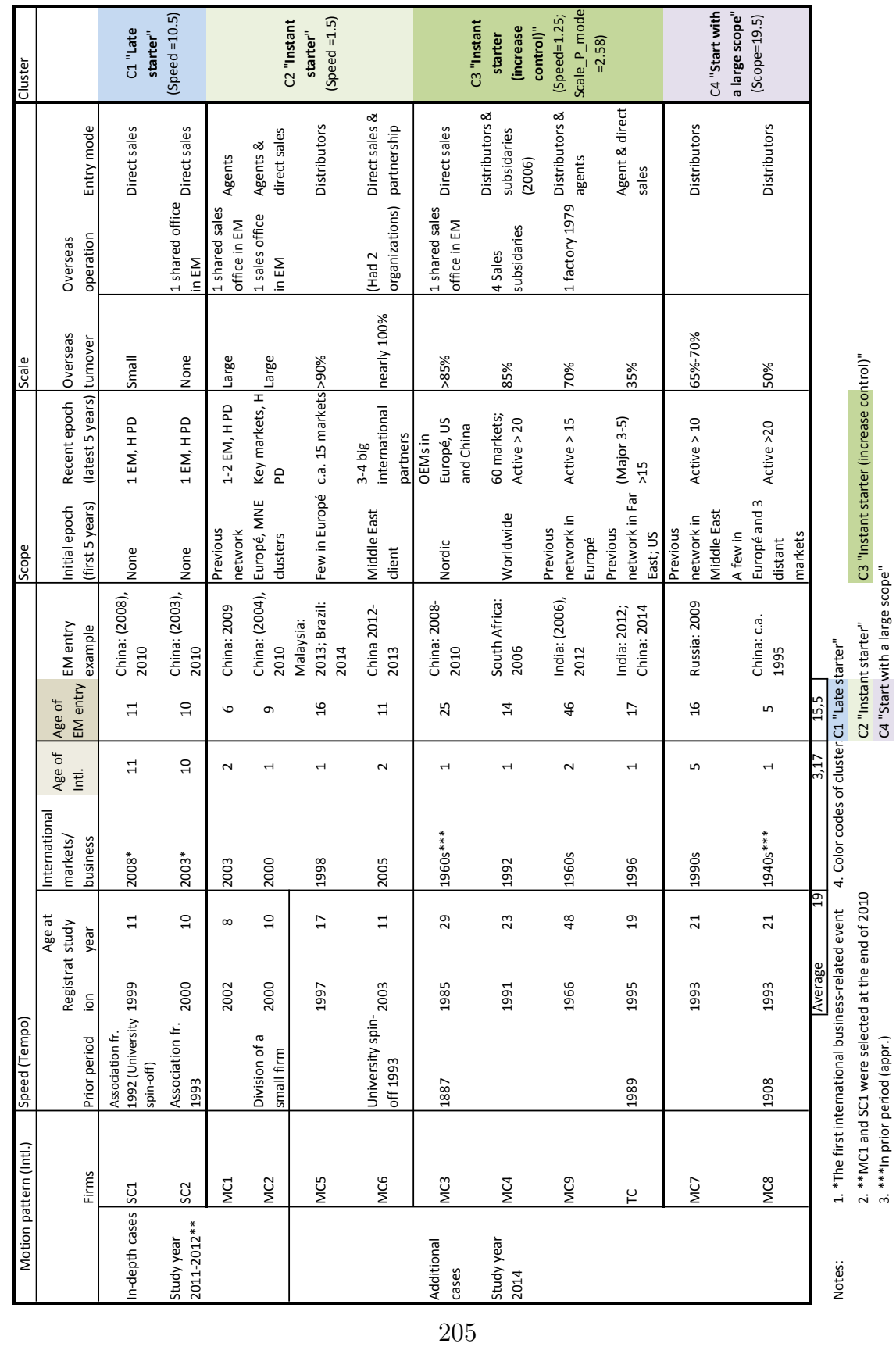


large share of their turnover (more than 25\%) from foreign markets in the initial epoch of internationalization.

Regarding the EM entry, the early internationalized firms in the three clusters showed different preference in sequence of entry from the "Late starter" (see the seventh row in Figure $6.2(\mathrm{~b})$ ). This indicated that EMs were among the earliest foreign markets for the "Late starter", while they were the latest choices for the early internationalized small firms. In all of the cases, the average firm age was more than 10 years when entering EM markets. This implies that the timing of EM entry is after having organizational and business experience for some years. Most firms in the three early internationalized clusters had no active involvement in EM business development from the start. This feature could be attributed to at least two reasons for the early internationalized small firms. From an external context, opportunities from EMs had not fully emerged before the mid-1990s. Based on the macro GDP data from the World Bank ${ }^{40}$, the economic boom of the EM in terms of total GDP growth has become more evident since 1995. In particular, after the recent global economic recession, the largest EM, China, started to bypass major economies in Europe (e.g. Germany, France and the UK) and in Asia (Japan). China became the second-largest economy in the world in 2010. The average age of about half of the early internationalized small firms in this study was above 20 (see the second row from bottom in Figure 6.2 (a)). When these firms began their internationalization, the development of EMs was still unclear. Thus, the late EM entry of these small firms is understandable. From an internal angle, resource constraints of the small and micro firms made them more regionally focused from the beginning. European markets and a very few distant markets with TMT's previous connections were the primary choices for most of the early internationalized small and micro firms in this study. Thus, the sequence of EM entries among early internationalized small firms came late, at least until around 2008, when most European markets and the US market were in recession, and firms started to pay more attention to the EMs. This indicates that contrary to the extant BG and INV theories, which have more emphasis on risktaking and opportunity-seeking aspects of the internationalization of small firms (Fletcher, 2004; Chandra et al., 2009), even the early internationalized firms also

\footnotetext{
${ }^{40}$ Data: GDP. Available from: http://data.worldbank.org/indicator/NY.GDP.MKTP.KD/countries/. [23 March 2015]
} 
showed risk reduction and even risk aversion features during internationalization.

For the "Late starter", EMs were among their earliest choice. Influence from the companies' network provided one of the reasons for the "Late starter" to start with distant EMs. An earlier study by Johanson and Mattsson (1988) showed that some firms with a low degree of internationalization, while having a higher degree of internationalized network, could reach the distant international markets easier due to such a connected network. Empirical evidence from this study also demonstrated that the "Late starter" cluster could take some advantages from their connected international network to gain foreign market knowledge and contacts. Therefore, despite the large inertia of the "Late starter", they are able to skip a few steps suggested by the U-model (Johanson and Vahlne, 2009) and overcome the "liability of foreignness" to reach EMs in their initial epoch of internationalization.

Spatial dimension This study depicts the spatial dimension based on two sub-dimensions "scale" and "scope" (Jones et al., 2011). As operationalized in Section 3.2.2, the study refers to the high degree of the foreign market commitment in terms of a resource commitment in the coordination of value chain activities, and a high percentage of foreign market turnover as a high scale of internationalization of the firm. In addition, the study regards many foreign markets with a larger "psychic distance" as having a wide scope.

\section{Scale of internationalization}

This study uses the entry mode to represent the first sub-dimension of scale in the resource commitment in a coordination of value chain activities. Among the 12 companies, only two (MC4 and MC9) used equity-based high resource commitment and high control modes (Brouthers and Nakos, 2004) in a few of their target markets after an initial epoch of internationalization. Others were commonly using non-equity based, low-resource commitment entry modes (e.g. indirect sales via foreign agents and distributorship). From the level of control over foreign market activities aspect, MC4 and MC9, together with two other small firms (MC3 and TC) which use a high level control via direct sales, were labeled in Cluster 3 (C3) as "Instant starter (increase control)". This cluster 
differentiates itself from the "Instant starter" (C2) in the entry mode. Unlike the "Instant starter" cluster, which either kept low control modes in most of its foreign markets (e.g., MC1, MC2 and MC5) or decreased its control level in its distant markets (e.g., MC1 and MC6), "Instant starter (increase control)" had increased its commitment and control during the internationalization process. Compared to other clusters with a low control type of entry mode, the average age of "Instant starter (increase control)" was the oldest (29.75 years) among all the clusters (see Figure 6.2 (a)), and it implies that liability of newness and adolescence have an impact on firms' choices of entry modes (Laufs and Schwens, 2014). In addition, it also indicates the impact of resource constraints on small firms' internationalization. The empirical evidence of this study shows that firms with large resource constraints can hardly afford resource-demanding types of entry modes in their initial epoch of internationalization. For example, until getting a new owner to invest in the firm, MC4 was still a small firm and was unable to establish overseas sales organizations. Thus, resource scarcity limits small firms' choice of entry mode during internationalization.

Since the study focus was on the outward internationalization, another subdimension of the internationalization scale was the share of foreign market turnover. All the manufacturing firms in the "Instant starter" and "Instant starter (increase control)" clusters had a comparably high percentage of foreign market turnover from the start. For MC4, MC5 and MC9 in particular, they did not have the prior period and they targeted international markets from day one. The trading firm TC, although involved in outward (i.e. export) internationalization, was mainly involved in sourcing from international markets (i.e. import). Therefore, the share of turnover from its export to international markets was rather low. Compared with other firms in these two instant starter groups, TC was at the time the only one with less than half of its turnover coming from its foreign markets. The "Late starter" cluster had the least scale of internationalization in terms of share of turnover from overseas. SC1, for example, only got prospects from international markets at the end of the investigation period. Compared with the "Late starter", the other clusters gained a much larger share from their international business. Comparing the firms within the two "Instant starter" clusters (except for TC), the "Start with a large scope" had a lower share from overseas markets. 
Empirical evidence indicates that industrial context has an impact on the share of foreign market turnover. Regardless of scope and entry mode dimension, early internationalized manufacturing firms in the three clusters had a comparably large scale of foreign turnover. They had more focus on the outward internationalization in the B2B market, and their industrial products were standardized. Thus, it required less adaptation to different markets. Some of the firms were technology-orientated and targeted special niche segments (e.g. MC2, MC5 and MC6 in C2 and MC4 in C3), which gave them strong incentive to build competitive advantage and to look for opportunities outside the small domestic market from the start. As a result, they put more focus on the international markets from the start and had more share of their turnover from overseas. They were typically BG-type firms (Knight and Cavusgil, 1996). The trading company belonged to the multinational trader type of INV defined by Oviatt and McDougall (1994). International trade is a main component of the business model for firms in the trading industry. Due to the outward internationalization focus of this study, the inward internationalization has not been taken into account in the scale of internationalization for trading firms. Thus, compared with other manufacturing firms in the same cluster, TC had a smaller share of overseas turnover. All the firms in the service industry were in the "Late starter" category. The traits of their service (especially for SC1) created more hurdles in the internationalization of this industry.

\section{Scope of internationalization}

This study used the PD index to gauge the scope of internationalization as Scope $=\sum_{n=0}^{i} n_{i} *$ Distance $_{\text {score }}$. Since big emerging markets such as BRICS are all in the high PD range ( $\geq 40$ in the PD index), firms with EM business involvement often have a high scope in internationalization. Except for SC1, which has not made any business with EMs yet, the other 11 firms in this study more or less cover EMs with a high scope of internationalization in the recent epoch period.

The lengthening of the drop lines in Figure 6.1 (a) and (b) presented earlier show a change of scope for each of the 12 investigated companies. All the case compa- 
nies, especially those companies in the three early internationalized clusters, have increased their scope in the recent epoch period. This indicates that even for INV and BG-types of firms, there is still an incremental feature in their changes in scope of internationalization, as the early U-model (Johanson and Vahlne, 2009) suggested. The difference is that the time span in the changes during internationalization is short in the INV and BG firms. One reasonable explanation for the short time is the commonly used low resource commitment and low control mode of entry in the early internationalized clusters. Low resource commitment and low control type of entry modes (e.g. export via distributorship and agent) rely on the knowledge and network of distributors and agents in the local foreign market. Thus, these entry modes did not require a long-time experiential knowledge accumulation (Johanson and Vahlne, 1977) in the foreign markets by the small firms. As a result, early internationalized clusters can expand their sales activities in a comparably large scope of international markets in a relatively short time span.

Based on the cluster analysis, the last cluster $(\mathrm{C} 4)$ is labeled "Start with a large scope" (MC7 and MC8). This cluster differentiates itself from the other two early internationalized clusters in the scope dimension. The "Start with a large scope" companies had a comparably large scope when they started internationalization (see the fourth row of Figure 6.2 (b)). However, a large scope covering numbers of geographically disperse markets did not correlate proportionally to an increase in their share of overseas turnover to a level as other early internationalized clusters with a narrow scope. Meanwhile, this cluster also had a lower score on the other sub-dimension of scale, entry mode. The findings point to how resource scarcity of a small firm also hinders fast expansion in the scope dimension. Earlier studies show that small firms have difficulty in managing time when they are involved in international business (Buckley and Ghauri, 1999) and their growth is subject to its available managerial service (Pitelis, 2004), a large number of disperse markets make it difficult for small firms to manage and influence the commitment and performance of their distributors and agents in foreign markets. As a result, the scale dimension could not increase correspondingly with the large scope. 


\subsection{Variance in the features of internationaliza- tion patterns}

The cross-case cluster analysis identified four major clusters in the 12 investigated case firms based on the features in their motion patterns. This section implements the process analytical model built in Section 3.4 to probe how the identified features in motion patterns of different clusters were formed. Table 6.4 provides a summary of the contextual conditions of the initial epoch period of internationalization across the 12 cases.

\subsubsection{Initial context of small firms' internationalization}

Extant literature on the internationalization of small firms suggests that it is as not simple as just looking at the age of these INVs (Oviatt and McDougall, 1994), since some "new" ventures are not really new. Rather, some may have had a long period of gestation time before they started up (Zahra, 2005). Thus, this study also takes a firm's previous history into consideration and explores the ex-ante context of internationalization.

Ex-ante of internationalization The 12 firms have different backgrounds; only five of them started without any previous experience. The experience accumulated from the previous period could largely influence the critical resources a firm could mobilize from the start (Reynolds and Miller, 1992) and their decisions on internationalization. The upper part of Table 6.4 shows the cross-case comparison of the ex-ante context of internationalization during the initial epoch period.

Influence from the previous experience Two "Late starter" firms in C1 had previous experience as economic associations for around seven years before they converted into limited companies. They have had a domestic focus since their prior period. A strong inertia enabled these two micro firms to continue working on the previous focus market, which is the domestic market. Similarly to these two "Late starter" firms from C1, MC3 (from C3) and MC8 (from C4) in the early internationalized clusters also continued working on the markets, which they inherited from their prior periods. 
Table 6.4: Contextualization of motion patterns in initial internationalization

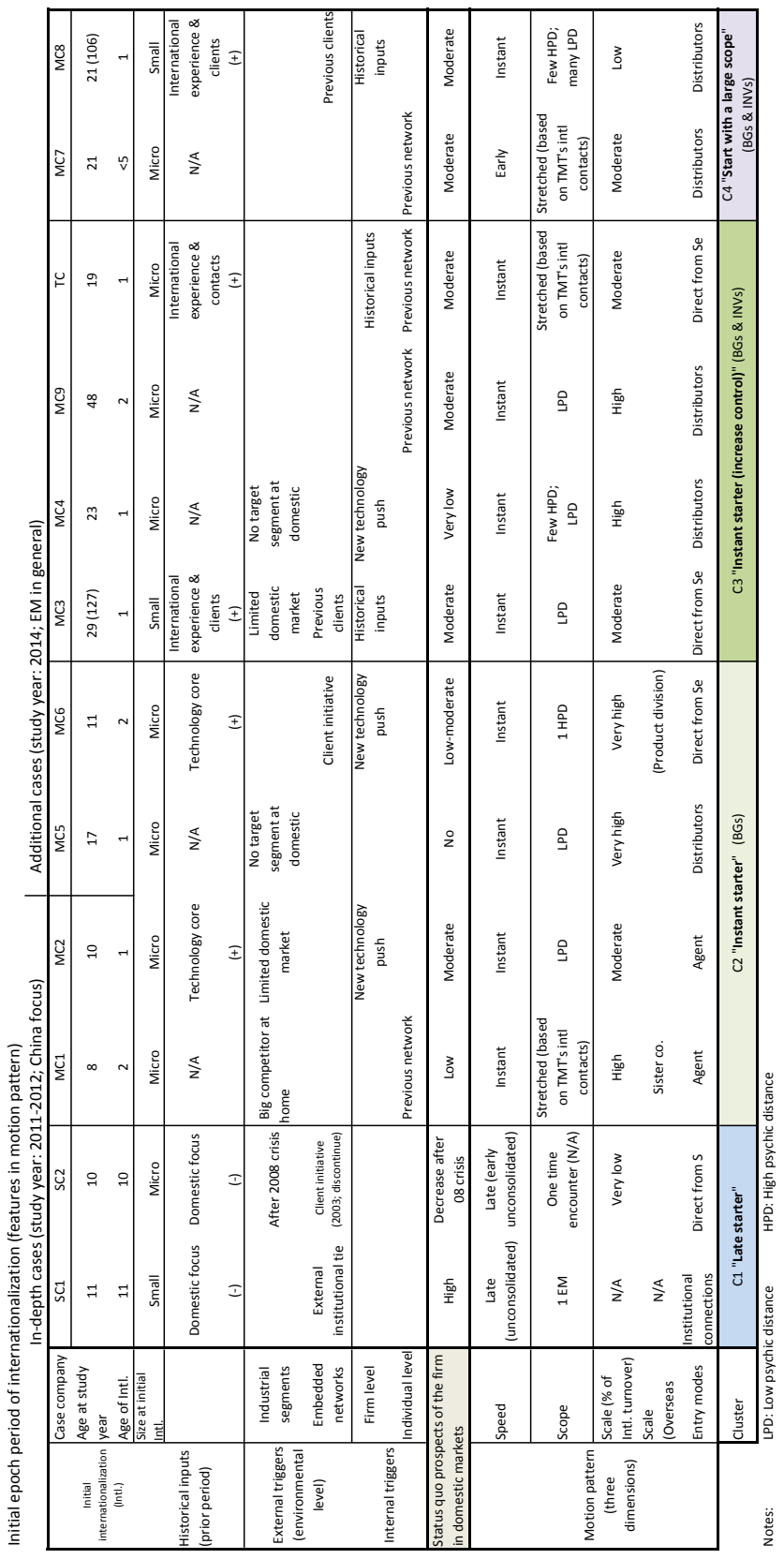


However, they are in a contrary situation to the $\mathrm{C} 1$ firms. Both companies had around a hundred years' experience from their prior periods. They were active in international markets far before the legal registration under their current names. Thus, they have been involved in international business from the formation of the firms, due to an inherited continuity from the previous period. The inertia caused path dependence attributes for those two difference patterns. The two high technology companies MC2 and MC6, as the "Instant starter" firms, had developed key technology during their previous periods. The basic technology core inherited from their previous periods enabled the firms' internationalization to proceed at a fast speed. Thus, this study shows how the knowledge, experience, and business relationships accumulated in the previous periods have a large influence on the small firms' initial choice regarding internationalization. Depending on the situation, such experience forms inertia for the new firms. Such inertia either hinders (i.e. the negative sign in the prior period row of Table 6.4) or facilitates (i.e. the positive sign in the prior period row of Table 6.4) the internationalization of the new firms.

Influence from external triggers Based on the source of triggers in the internationalization, the "Late starter" firms are largely influenced by external triggers. The remaining 10 firms in the other three clusters have either strong internal triggers or mixed triggers from both external and internal motivations.

External triggers have considerable influence on the initial internationalization of those "Late starter" firms. The first international business-related event and incident of the "Late starter" (i.e. SC1 and SC2) were triggered by their external task environment: the institutional tie for SC1 and the client of SC2. However, the "Late starter" did not continue to develop the international business until the next external triggers appeared. For example, SC2 started to actively engage in international business after the 2008 crisis, when the demands of its status quo market at that time were decreasing.

Regarding the other 10 firms in the three early internationalized clusters, 
one of the most common external triggers was the limited market size in the firms' initially selected segment. For example, MC4 in the "Instant starter (increase control)" cluster and MC5 in "Instant starter" cluster were the two extreme cases. Their initial segments were the fishing industry and soft stone flooring industry, respectively. There were extremely limited domestic markets in their segments. A very low prospect from the status quo market at home gave them a very strong motivation to engage in internationalization from day one. In addition to the small segment size in the domestic market, other external triggers also came from the external task environment and were the most common external triggers: strong competitors at home in the same segment (e.g. MC1 and MC6 in "Instant starter"); existing foreign clients from the prior period (e.g. MC3, MC8 and TC); and emergent new inquiries and big orders from foreign clients (e.g. MC6).

Influence from internal triggers At the individual level, the critical role of the founders, owners and TMTs of the firms had a big influence on the firms' responses to the external triggers and their own active choices in internationalization. Four of 10 investigated early internationalized firms (MC1, MC9, TC, and MC7) expressed that they intentionally used their founders' and TMT's previous international contacts and knowledge to develop their international markets from the start.

Other common internal triggers were from the firm level. Technology push was a common trigger among the technology-oriented firms. MC2 and MC4, for example, had no previous international contacts. However, both of the firms were strong in technology innovation. They belonged to the Schumpeterian type of creative entrepreneurial new venture (Kirzner, 1999). Both of them created a new segment and market by introducing a new technology to a new industrial application. They were doing missionary sales to create market needs; therefore, they targeted a wider audience, regardless of national borders, from the very beginning.

The cross-case comparison reveals heterogeneity in the ex-ante context of the initial epoch period internationalization of the investigated firms. The "Late starter" was either passive to react on the external initiatives, such as SC1 and 
the first international incident of $\mathrm{SC} 2$, or acted as a post-crisis response (i.e. $\mathrm{SC} 2$ ). They were lacking an internal motivation from the start to actively continue the internationalization. The "Instant starter", "Instant starter (increase control)" and the "Start with a large scope", on the other hand, were facing a multiplelevel influence. The interaction between the internal resource and triggers from the external industrial segments and task environment, together with historical inputs, motivated them to more actively and quickly engage themselves in the internationalization process.

\subsubsection{Difference between the industrial sectors}

The industrial sector was one of two predictors which have shown strong evidence of having impact on the investigated EM entry decision in the pre-study (see Section .5 of Appendix A-1). Multiple case studies further explore the connection between the industry segment and the initial internationalization. The middle section of Table 6.4 summaries the ex-ante conditions on three levels, environment, firm and individual (TMT), in relation to the motion pattern in the initial epoch period of internationalization.

As the pre-study reveals, there is a big gap among the industry sectors regarding their attitude towards EM (i.e. China) involvement. The main study further reveals such a variance caused by industrial differences in the initial internationalization. Compared with the three early internationalized clusters, which consisted of manufacturing and trading sectors, the "Late starter" had only the service firms. Traits of the professional service sector give SC1 and SC2 less motivation for early internationalization. The two firms had enough needs from the domestic market from their prior period and the new venture period. For SC1 in particular, its service relied on ecologists' field study. It is difficult to scale up, even in the domestic market. In addition, this industrial segment was created by institutional influence such as strict regulations on environment protection. Only foreign countries with a close institutional distance might create a similar need for its service.

Some manufacturing firms targeted narrow segments with none or very small market 
size in the domestic market. They had to go to international markets to find more business opportunities. The trading firm was established based on the insights of price difference in the global supply chain of its segment. Therefore, entering international markets was built into its venture idea and business plan.

The above comparison shows that the industrial sectors and the traits of market segments, in which a small firm is operating and competing, offers different opportunities for small firms' growing domestically and internationally. An industrial segment which offers limited domestic opportunities could "push" a small firm to internationalize earlier and quicker than others. In addition, the traits of the offerings could also explain the fast speed and large scope of internationalization of the five manufacturing firms ( $\mathrm{MC} 1, \mathrm{MC} 2, \mathrm{MC} 5, \mathrm{MC} 6$ in $\mathrm{C} 2$ and $\mathrm{MC} 4$ in $\mathrm{C} 3$ ), while explaining why the service firm ( $\mathrm{SC} 1$ in $\mathrm{C} 1$ ) was less motivated towards internationalization.

\subsubsection{Difference in status quo prospects}

Cross-case analysis further reveals that status quo prospects in firms' industrial segments influence the speed of internationalization in the early periods (see the middle section of Table 6.4). Small firms with a relatively high status quo positive prospect in the domestic market at the new venture period were less motivated to develop international markets (e.g., the "Late starter", SC1 and SC2 in C1).

Unlike SC1 and SC2 in the "Late starter" cluster, which had a relatively high status quo positive prospect, a low to moderate status quo prospect in the domestic market during the start-up period was the main driver for firms in the early internationalized two instant starter clusters (MC1, MC2, MC5, MC6 in $\mathrm{C} 2$ and MC4 in C3) to actively and quickly seek international opportunities. MC1 had a big competitor in its home market. The initial segment of MC4 and MC5 was very small in the domestic market. MC2 started from its home market, but soon realized that the firm needed to reach those leading markets to get its innovative offerings adopted and diffused. In addition, similarly for technology-based start-ups (MC2, MC4, and MC6), their offerings needed as many early adopters as possible in order to get enough financial support in technology improvement. Thus, the firms in these two instant starter clusters had to go directly 
to international markets. Based on the above analysis, this study shows that small and micro firms' status quo prospects from the industrial segment in their domestic market influence the initial speed of internationalization. The lower the status quo prospects from the domestic market, the higher motivation for the micro and small firms to quickly go to international markets.

\subsubsection{Difference between initial period and continuous pe- riod}

Evidence from within the case analysis shows that the feature of internationalization motion pattern changes along the development process of small firms. Early internationalized firms in the three clusters (MC1, MC2 and MC5 in $\mathrm{C} 2, \mathrm{MC} 4$ in $\mathrm{C} 3$, and $\mathrm{MC} 8$ in $\mathrm{C} 4$ ), for example, reveal more variance than BG or INV-simplified indications. Both BG and INV theories just differentiate the initial speed of the internationalization with criteria in part of the scale dimension: percentage of turnover from overseas in the first three to five years (Madsen, 2013; Zahra, 2005). They did not go further (Cesinger et al., 2012), for instance, to investigate whether the scope and tempo (speed) of internationalization changes (Kuivalainen et al., 2012). This study reveals more variance and changes in motion pattern and behavior patterns.

\section{Changes in motion pattern}

BG and INV could not provide sufficient guidance on the motion changes after their start-up (Kuivalainen et al., 2012). The cross-case analysis of the 10 early internationalized firms in the three clusters reveals that there were changes and variance in the motion patterns between the start-up period and a more mature period of firm development.

In the start-up period, many early internationalized firms, especially firms in the $\mathrm{C} 2$ "Instant starter" and C3 "Instant starter (increase control)" clusters, began their market expansion to close neighboring markets or the markets in which the TMT of the firm had prior contacts (see the lower section of Table 6.4). This pattern partially mirrors the U-model, which suggests that the internationalization of the firm started from 
low "psychic distance" markets (Johanson and Wiedersheim-Paul, 1975; Johanson and Vahlne, 1977; Figueira-de Lemos et al., 2011) to avoid high perceived risk (uncertainty). On the other hand, it also partially reflects the important influence from the personal networks and social capital of the TMT on small firms' internationalization in the BG theory (Chetty and Agndal, 2011; Ellis, 2011).

Nevertheless, low "psychic distance" markets do not necessarily offer sufficient business opportunities (e.g., in MC2's internationalization). In a more mature period or in a period of major crisis, for example later epochs of internationalization in the "Instant starter" and "Instant starter (increase control)" clusters (MC1, MC2, MC5 in C2, and MC9 in C3), small firms tend to approach the markets with more business opportunities. Perceived business opportunity from the market size or expanded relation links with the foreign markets reduce the perceived risk (uncertainty) associated with high psychic distance.

Furthermore, the early internationalization cases in the three clusters (C2, C3 and C4) reveal a few more reasons for changes in motion patterns between the initial period and later periods.

Changes in ownership Cases from the three early internationalized clusters (MC3, $\mathrm{MC} 4$ in $\mathrm{C} 3$ and $\mathrm{MC} 7$ in $\mathrm{C} 4$ ) show that an ownership change leads to a managerial attention change. As a result, firms' focus in the international markets changes. Before the ownership change, MC3 was a family business and had a focus on the Nordic markets, which are low PD markets. During this period, the firm was not actively chasing business outside this zone and just passively reacted to the sporadic requests from more distant markets. After the ownership change, MC3 began to more consciously focus on the MNEs' OEMs. Therefore, in the later period, MC3 went to markets with many OEMs. PD was less of a concern due to business connections between the MNEs and their OEMs. Such connections facilitated MC3 in approaching more distant OEMs. MC7's ownership change in 2009 released its restriction from the previous agreement with its sister company. The firm began to seek new business opportunities in foreign markets without self-constraint. The ownership change of MC4 had a mixed impact on its internationalization. On the one hand, the new joint owner brought required financial 
resources to increase its control of the key international markets. On the other hand, different management style brought by the new owner made MC4 more cautious in its international expansion. These cases show that ownership change has a big impact on the motion pattern, because a major change in the key TMT and owners at the individual level directly leads to changes in managerial attention at the organizational level. As a result, inertia from the initial epoch of internationalization could be changed by a shift in managerial attention (Dasí et al., 2015).

Changes in target segments and technology competence As discussed in an earlier section (see Section 6.2.2), conditions and characteristics in extant industrial segments have an impact on the speed of the initial period of internationalization. A change in small firms' target segments may also create changes in the motion pattern. Cases from three early internationalized clusters (MC5 in C2; MC4 and MC9 in C3; and MC8 in C4) offer such evidence. MC4, for example, started with four people. Its initial segments (soft stone flooring) had a very small market in Sweden. Therefore, the firm went to international markets directly and was open to any distributors who would adopt its first innovative product. MC4 had a fast speed, a large scale and relative large scope in its motion pattern in the initial period. Later, as a response to international clients' requests, the firm kept developing new product. As a result, the firm was able to approach a new segment (i.e. concrete flooring). The new segment opened up possibilities in the domestic market as well. Consequently, its scale of overseas turnover actually decreased when the firm became strong in the domestic market. MC5's initial segment was fish packaging. Only a few markets in Europe have a big fishing industry. Once the firm moved to a new medical application segment, its scope in internationalization grew. Therefore, changes in the firm's segments influenced changes in motion pattern as well.

Changes in business network Cross-cases analysis also shows how changes in business networks cause a difference in motion patterns between the initial period and a more mature period. Cases from the three early internationalized clusters (MC2; MC5 in C2; and MC3, MC9, and TC in C3) are such examples. TC, for instance, was a supplier of a big Swedish MNE in the early 1990s. When the MNE started to outsource its production overseas in the late 1990s, the MNE asked TC to follow its global footprint. However, due to resource constraints, 
TC could not afford to simply follow in the steps of its big client. Therefore, TC started to target and serve smaller clients instead. As a result, the scope of motion pattern narrowed down during the later time. Compared to TC, MC3 did the opposite. Not until the most recent decade did the firm intentionally establish its business network with OEMs of European-based MNEs. The firm intentionally built connections and used such business networks from Europe to effectively reach OEMs in other more distant markets. This is similar to the U-network model suggested to overcome a liability of "outsidership" (Johanson and Vahlne, 2009) by establishing supplier relations in the target OEM network. Therefore, joining or withdrawing from important industrial and business networks will influence the direction of the motion pattern. Being part of the MNEs' global value chain (e.g., MC2, MC3 and MC5) may bridge the perceived distance and more quickly facilitate the international expansion.

\section{Changes in behavior pattern}

Based on whether the firms' started their actions in approaching international markets from a sequence of appeared "means" and "ends", the study reveals adaptive and mixture features in their behavior patterns. The lower sections of Table 6.5 and Table 6.7 show different behavior patterns under different contexts.

The lower section of Table 6.5 summarizes the difference in the behavior patterns across the 12 cases from motion pattern based on the four clusters. The "Late starter" firms (SC1 and SC2) had a strong risk avoidance tendency in their initial internationalization. This cluster's firms began to get involved in international business in response to external triggers. These firms had no intention of actively approaching the international markets for a long time (about 10 years) until external initiatives - "means" appeared (e.g., SC1' first China trip, see Section .4 of Appendix B) or in response to the emergent critical episode (e.g., SC2's response to sporadic requests from a MNE in year three and SC2's response after an economic crisis in year 10, see Section .5 of Appendix B). The attributes of behavior from the "Late starter" in the internationalization reflects typical managerial style. Their behavior shows more concerning the risk side of internationalization, because of their risk avoidance tendency. However, the "Late starter" also has international connections and an embedded task environment 
Table 6.5: Contextualization of behavior patterns in initial internationalization

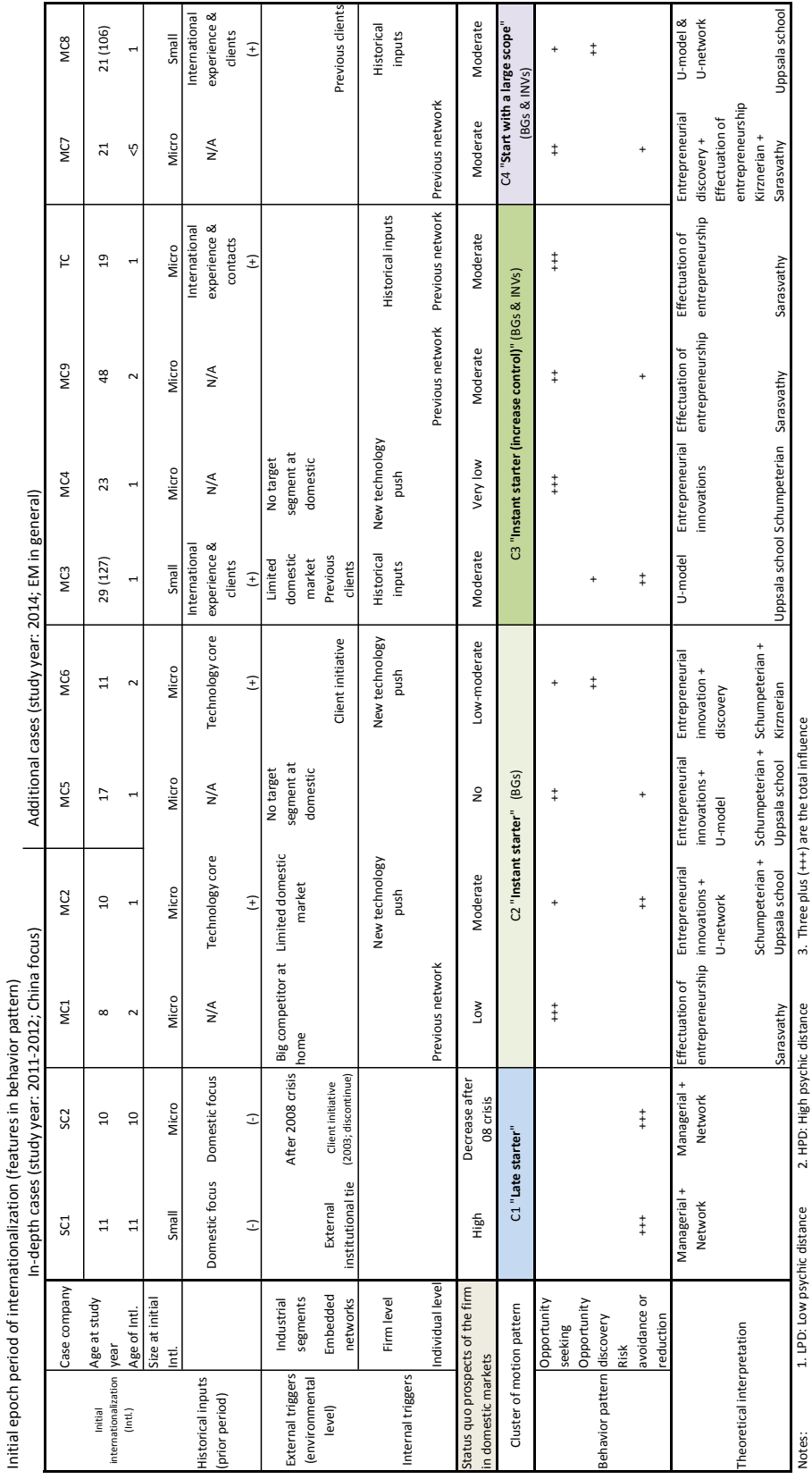


(Johanson and Mattsson, 1988). These connections can facilitate internationalization of the small firm by providing new knowledge and contacts relevant to foreign markets. When this group began to actively respond to triggers from the internationally connected network, the group was able to reach distant markets directly due to such networks.

\section{Behavior patterns in the initial period}

Under the initial internationalization context, cases from the three early internationalized clusters show a fast tempo in internationalization with regard to motion pattern. Despite a common feature in the speed dimension of the motion pattern, many cases (MC1, MC2, MC4, MC5, MC6, MC7, MC9 and TC) showed different types of entrepreneurial features in their behavior patterns of internationalization. Four cases (MC1 in C2 "Instant starter", MC9 and TC in C3 "Instant starter (increase control)", and MC7 in C4 "Start with a large scope") are closer to the Sarasvathy type of entrepreneurial effectuation (Sarasvathy, 2008). Facing uncertainty in international markets, these new ventures started with the "means" at hand, which were extant international networks from their founders' and TMT's previous work, to reach international markets. On the other hand, the other four cases (MC2, MC5, MC6 in C2 and MC4 in C3), which had no previous international networks, actively sought and mainly created "means" from public channels, such as international trade shows, to introduce their new products to a wide international audience. MC2 and MC4 introduced a relatively new technology into a new application; their internationalization was driven by "technology push". This is very close to Schumpeter's opportunity creation type of entrepreneurship, i.e. introducing new solutions to latent needs of customers (Kirzner, 1999; Roininen and Ylinenpää, 2009).

The cross-case comparison points to how in the initial epoch period, across early internationalized clusters, the Schumpeterian type of entrepreneurial actions were the drivers which motivated and facilitated the early internationalization of technologydriven micro firms. For the other micro and small firms, whose founders had previous international business experience and contacts, the Sarasvathy type of effectuation was a common trigger and means for their early internationalization. The Kirznerian type of entrepreneurial discovery is common once micro and small firms have gained some 
knowledge about international markets or received sporadic requests from international clients.

\section{Behavior patterns in continued period}

With the development of the firms and the evolving process of their internationalization, their behavior patterns started to mix with other features. The "Later starter" firms (SC1 and SC2 in $\mathrm{C} 1$ ) started (i.e. $\mathrm{SC} 1$ ) and re-started (i.e. $\mathrm{SC} 2$ ) their internationalization in a rather mature period under external triggers. SC2 in particular became more alert and active in seeking opportunities in international markets. Such actions reflected the Kirznerian type of opportunity discovery feature. Other early internationalized clusters, on the other hand, continued their internationalization with more managerial and strategic considerations. For example, in a later period, most of the firms in the three early internationalized clusters (MC2, MC5, MC6 in C2, MC3, MC4 and MC9 in C3 and MC8 in C4) began to use a more structured approach and to act more strategically, rather than in an ad hoc manner, in developing international markets. For example, MC4 (in C3) had more focus on key markets in the US and Europe as well as relatively low PD markets. This firm started exploitation of a few key markets and emphasis on control of the distributors, while MC2 (in C2) and MC3 (in C3) began to focus on the key markets with large market potential (MC2) or key target clients (MC3).

Cases from the two Instant starter clusters (MC2, MC5 and MC6 in C2 and MC4 in C3) started international business by being open to opportunities and international contacts. Other cases from the three early internationalized clusters (MC1 in C2, MC9 and $\mathrm{TC}$ in $\mathrm{C} 3$, and $\mathrm{MC} 7$ in $\mathrm{C} 4$ ) started international business by using previous networks. Including MC3 (in C3) and MC8 (in C4), all of the cases in the three early internationalized clusters changed or adjusted their behavior during internationalization. These changes were mainly triggered by critical events from both internal firm and external environments. Due to changes in ownership and/or top management, cases in the two Instant starter clusters (MC2, MC5 in $\mathrm{C} 2$ and MC3, MC4 in C3) started a structured approach in recent years. Due to the economic crisis, cases in Cluster 3 (TC, MC6 and MC9) became more strategic in seeking new opportunities. The "Start with a large scope" cluster (C4) firms had also narrowed their scope after the 2008 
crisis. For example, MC8 had covered many international markets and could not offer enough support. Therefore, in the last two years, the firm turned back to a low PD European market focus.

In sum, with increased organizational experience and under the influence of some critical events, behavior patterns across the cases in the four clusters have changed during internationalization. Cross-case analysis shows that in the initial internationalization period, three different types of entrepreneurship activities were dominant in the early internationalization firms. However, there was an adaptive feature in behavior patterns during internationalization after the initial period. It was found that firms do not rigidly stick to a same behavior pattern over the time.

\subsection{Influence of EM context on the changes in the patterns of internationalization}

As discussed in Sections 2.4 and 2.5, earlier theories have imbalanced views on explaining the behavior of a firm in the internationalization process. Extant theories have a latent assumption that the behavior pattern in terms of the appetite in the perceived risk versus the opportunity of a firm during internationalization is persistent. A firm either is consistently driven by uncertainty aversion and risk deduction as suggested by the U-model (Figueira-de Lemos et al., 2011), or is opportunity-seeking (Chandra et al., 2012), or even risk-seeking (McDougall and Oviatt, 2000), as IE theory (Zahra, 2005; Jones et al., 2011) suggests. In this study, the investigation of the internationalization patterns of the 11 small and micro firms and one middle-sized firm related to EM entry reveals timely changed preference regarding risk (uncertainty) versus opportunity during the internationalization of the firm.

\subsubsection{Timing of EM entry}

Table 6.6 provides a statistical summary of internationalization speed in the initial internationalization and EM entry epoch, while Figure 6.3 visualizes the speed differences 
among cases in three different industries.

Table 6.6: Summary statistics of internationalization speed in two epochs (unit: years)

Descriptive statistics of internationalization speed

\begin{tabular}{|l|r|r|r|r|r|}
\hline & $\mathrm{N}$ & Minimum & Maximum & Mean & Std, Deviation \\
\cline { 2 - 6 } Age@study & 12 & 8 & 48 & 19.00 & 11.20 \\
Initial speed of IntI & 12 & 1 & 11 & 3.17 & 3.61 \\
EM entry speed & 12 & 5 & 46 & 15.5 & 11.03 \\
\hline
\end{tabular}

The statistics in Table 6.6 show that across 12 cases, compared to a fast average initial internationalization speed of 3.17 years (with standard deviation (SD) of 3.61), the average EM entry speed is much slower (15.5 years with SD of 11.03). Figure 6.3 (a) illustrates a big gap in initial speed of internationalization between service cases (see the middle Boxplot in Figure 6.3 (a)) and the other two sectors (manufacturing and trading). However, in the EM entry context, this gap becomes small (see Figure 6.3 (c)). The comparison reveals that the EM context has a larger influence on the early internationalized cases in terms of the late sequence of entry. Table 6.7 shows the contextual conditions of firms' EM entry.

The upper section of Table 6.7 shows the timing and sources of triggers in the EM entry. The timing of EM entries in this study reflects that despite being fast and quick in internationalization, as is the case for all of the manufacturing firms and the trading firm in the three early internationalized clusters of this study, these BG or INV firms still reflect some uncertainty avoidance and risk reduction tendency in their sequence of entry.

Among the 10 cases in the three early internationalized clusters, the majority of the cases got involved in the EM business relatively late. Furthermore, about half of these late EM entry cases were unplanned events (MC1, MC5 and MC6 in $\mathrm{C} 2$; MC4 in C3; and MC7 in C4). Only one case (MC8 in C4) had EM business relatively early. The China market involvement of this case was also an ad hoc event. This contradicts with International Entrepreneurship theory, which suggested a "risk-seeking" tendency in BG and INV firms' "entrepreneurial orientation" (Oviatt and McDougall, 1997, 2005). 


\section{CROSS-CASE ANALYSIS AND FINDINGS}

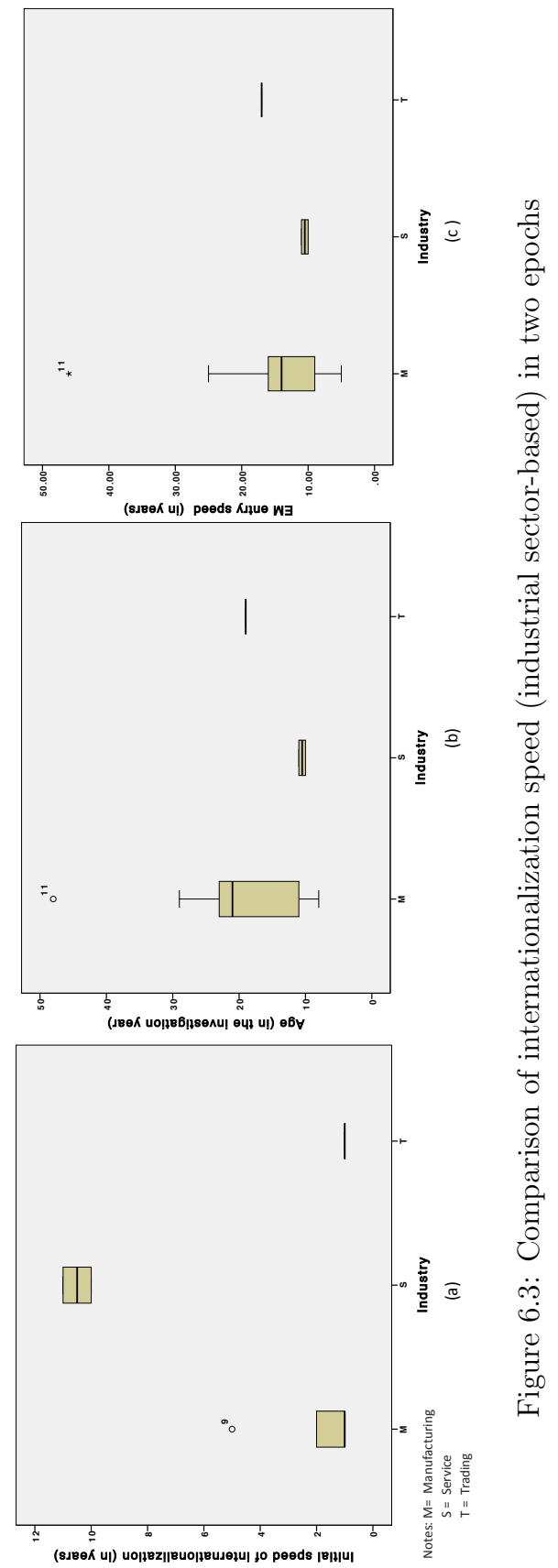


Table 6.7: Contextualization of EM entry during internationalization

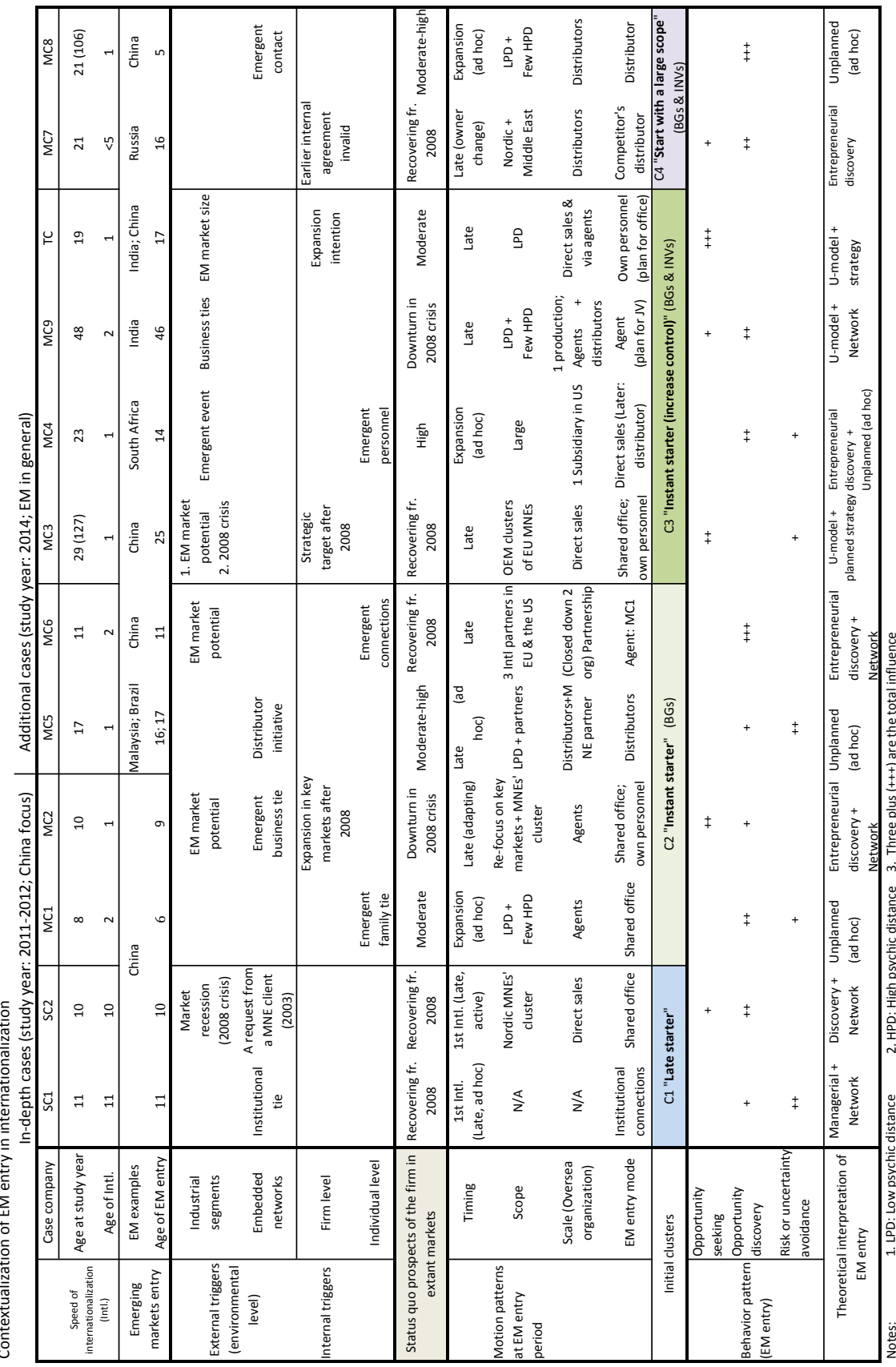


In contrast to the three early internationalized clusters, the "Late starter" (C1) had a different entry sequence. The EM (e.g. China) was the firms' (in C1) first step of internationalization. The timing of the EM entry of the "Late starter" C1 reflects influences from small firms' task environment on their important decisions in internationalization. Relations and other connections from firms' embedded networks with EMs could moderate the perceived risk (uncertainty) in those markets. This partially satisfies the U-network model (Johanson and Vahlne, 2009). However, this study shows that it is not only about relationship and "insidership" in the foreign market-related networks or the "client followship"; it is also about small firms' response to the institutional influence from their environment. For example, SC1's EM entry was due to its institutional connections. The firm responded to the stimulation with normative guidance (Scott, 2002), which is a behavior based on stakeholders' expectations. SC2, on the other hand, tended to mimic other big MNEs' market selections. The small firm did not simply follow a firm's existing clients. It is a conscious action in using MNEs as a bridge to reach the EM.

\subsubsection{Ex-ante of the EM entry}

Table 6.7 (see the upper section marked as "triggers") shows that 10 out of 12 of the case firms' EM entries from the four clusters were either triggered by a few important events to the firms and their TMT, or solely by ad hoc events through external initiatives. As described earlier, the EM was the initial choice of "Late starter" (C1) firms, and they were triggered by either external initiatives (SC1) or the 2008 crisis (SC2). Most cases from the other three clusters were also more or less due to unplanned events, such as emerging EM connections. Only three cases (MC2 in C2, MC3 and TC in C3) intended to enter EMs due to the market potential, and they became more active in EM entry after the 2008 crisis.

\section{Status quo prospects during EM entry}

Combining the information from the financial performance of all 12 case firms (see Figure 5.2, 5.5, 5.8, 5.11 and financial figures of other 8 case firms in the within-case analysis in Chapter 5), offers an additional angle on the status quo prospects to probe the ex-ante and timing of the EM entry. One of the most common critical events for all 
the cases in the four clusters was the 2008 economic crisis. The crisis deteriorated many small firms' prospects from their extant markets at that time. Except for three case firms (MC1, MC4 and MC8), the other nine cases either actively made EM entry or simply responded to external initiatives from the EMs after the 2008 crisis. The three case firms which had their EM entry before the crisis were due to emerging connections rather than intended actions. The middle section of Table 6.7 shows a summary of the 12 firms' status quo prospects in their extant markets during their EM entry. The majority of cases had low-to-moderate status quo prospects in extent markets during their EM entry. A few case firms with relatively high status quo prospects (MC4, MC5 and MC8) had not intended to enter an EM until emerging contacts appeared. The cross-case comparison reveals that regardless of their initial clusters, the EM entries of these investigated case firms were more or less reactive when there were higher status quo prospects from the firms' extant markets. A few small firms became more actively engaged in EM-related business after experiencing the 2008 recession.

\section{Conditions in "means pool" during EM entry}

As Table 6.3 shows, the average EM entry age was rather late across the 12 cases. This shows that all of the firms reached a certain level of maturity in their products or service development and had accumulated some managerial experience. From the firm level, all of the firms had developed products and service offerings for their extant markets before their EM entry. These "means" and competence enabled the firms to develop offerings adaptable to EMs. For all the cases in the three early internationalized clusters, they entered other international markets before their EM entry. The mature level of "technology core" enabled the firms' EM market entry. Only one case firm from the "Later starter" (SC1) had no previous experience outside of Sweden. More effort was required for this firm to develop adaptable service for its potential clients in the EM, and it became one of the hindering factors for its EM entry. Thus, technology in terms of adaptable offerings from small and micro firms was an important enabling factor in the EM entry of these small firms.

Market knowledge and managerial attention are the other two elements in the threelevel frame (see Figure 2.4) developed from the theoretical frame. Except for one case (MC1 in $\mathrm{C} 2$ ), where there were family connections with the EM, the cases had very 
little knowledge or non-specific market knowledge about the EM when they entered such markets. Only three cases (SC2 in $\mathrm{C} 1, \mathrm{MC} 2$ in $\mathrm{C} 2$ and $\mathrm{MC} 3$ in $\mathrm{C} 3$ ) actively put effort into acquiring market knowledge and building potential connections with their targeted EM, China. The other firms were either learning by doing or solely relying on their local agents in the EMs. Corresponding to the limited knowledge on the EMs, the managerial attention in most of the case firms had not been on the EMs until a crisis occurred in their extant markets or there were emerging initiatives from EM-related task environments (e.g., from distributors, agents and institutional actors). However, once the small firms began to steer their managerial attention toward the EMs, they also began to acquire relevant knowledge about them.

Influence from the environmental level showed a strong influence on these EM entries across the cases in the four clusters. As described earlier, the 2008 crisis was one of the common triggers for EM entries in the majority of the investigated cases. Conditions changed during the economic crisis in industry and negatively influenced the abundance of resources and opportunities in the firms' operational environments. In other words, such changes in industry will influence the so-called environmental munificence (Dess and Beard, 1984) of the small and micro firms. The term refers to the capacity of resources and opportunity in the environment which could influence the survival and growth of firms (Castrogiovanni, 1991). Consequently, it stimulates small firms looking for new opportunities or being more alert to potential new resources and opportunities in the EMs. In addition, EM-connected actors (e.g., the trade support agency) and agents in firms' embedded task environments (e.g., different networks) also simulated and facilitated the EM entry of small firms.

\subsubsection{Influence from perceived risk versus perceived op- portunity from EMs}

\section{Strong influence from perceived risk (uncertainty)}

From the triggers and timing of the EM entry (see Table 6.7, upper section), high perceived risk (uncertainty) in the EM context had a large influence on the sequence of the international markets' entry and the timing of EM entry. The EM entry in most of the cases across the four clusters was late. Even for the early internationalized cases, 
they were cautious in approaching the EM, when firms had other options available in perceived lower PD markets. Two cases (MC1 and MC2) in the "Early starter" cluster offer such examples. MC1 had no interest in the EM until a strong family tie emerged. $\mathrm{MC} 2$, on the other hand, had interest in the EM but did not actively take action in acquiring specific market knowledge until its status quo prospects deteriorated after the economic crisis in 2008. Other cases, such as MC4 and MC8, were not intentionally targeting EMs; they were just reacting to emergent opportunities. This study reveals that even the rapid internationalized firms were still sensitive to the perceived high uncertainty related to potential risk in the EM context. This contradicts IE theory, which suggests proactive and risk tolerant, or even risk-seeking behavior (Oviatt and McDougall, 2005) in general.

The EM (Chinese market) was the first international market for the "Late starter" (SC1 and SC2) cluster firms. Their perceived risk (uncertainty) in the EM was mitigated by the institutional linkage ( $\mathrm{SC} 1$ ) and potential business connections (SC2). Both SC1 and SC2's EM entry was more or less reactive to the influence from the environment. $\mathrm{SC} 1$ reacted to the initiative from its connections with institutional actors, while SC2 reacted to a diminishing prospect in its existing markets.

Perceived risk (uncertainty) in the EM context not only influenced the motion pattern of internationalization with regard to the timing in the approach to the EM; it also impacted the choice of control mode. The cases which have put some effort into developing business in the $\mathrm{EM}$ use ( $\mathrm{SC} 2$ in $\mathrm{C} 1, \mathrm{MC} 1$ and $\mathrm{MC} 2$ in $\mathrm{C} 2, \mathrm{MC} 3 \mathrm{in} \mathrm{C} 3$ ) or are considering to use (MC6 in C2, MC9 and TC in C3) a higher control mode (e.g. establish their own or share their partners' sales office, and potential joint ventures with local partners in EMs) for sustaining their business. This is contrary to their entry modes in other more mature international markets, where they often use a low control mode (e.g. sales via local agents or distributors).

\section{Changing influence from perceived opportunity}

The study shows that perceived opportunities in the EM context are evolving. The perceived opportunities in EMs are aligning not only with the potential market size and firms' potential connections with the EM, but also with small firms' own manage- 
rial attention and their capability in mobilizing internal and external resources.

Potential market size alone only partially triggered one trial (MC2) for small firms approaching the EM in the earlier period (less than five years). The actual efforts for the EM entry in most cases were made after the firms and their TMTs had a change of interest in responding to either emergent "means" (e.g., new connections and relationships related to the $\mathrm{EM}$ ( $\mathrm{SC} 1$ in $\mathrm{C} 1$; MC1, MC5, MC6 in $\mathrm{C} 2$; $\mathrm{MC} 4, \mathrm{MC} 9$ in $\mathrm{C} 3$; and $\mathrm{MC} 7, \mathrm{MC} 8$ in $\mathrm{C} 4)$ ) or triggers from the firms' environments (SC2 in $\mathrm{C} 1$; MC2 in $\mathrm{C} 2$; and MC3, TC in C3) (see sources of triggers in the upper section of Table 6.7).

Based on the above analysis of perceived risk (uncertainty) versus opportunity for the EM entry, Figure 6.4 shows a shift of perceived risk versus perceived opportunity for the EM. During the start-up period $\left(T_{0}\right)$, all cases across the four clusters had a strong concern on the risk side of the EM. Until the firms met external triggers (e.g., market recession) and means (e.g., emerging contacts) in a prior EM entry period $\left(T_{E M}\right)$, small firms became alert to the potential opportunity in the EM. The perceived high risk of the EM has been mitigated by connections with agents who have EM knowledge and contacts.

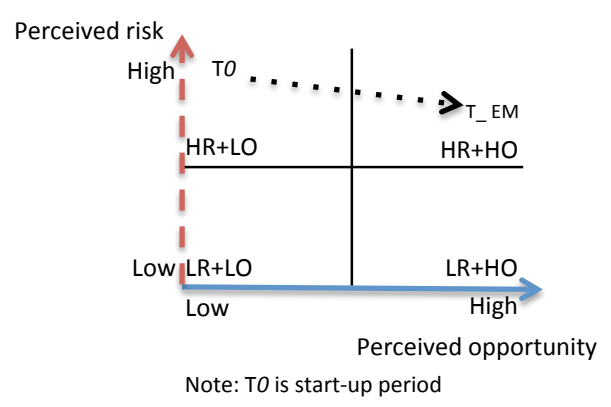

Figure 6.4: Changes in risk versus opportunity perception for EM entry

\section{Features of behavior patterns in EM entry}

The lower section of Table 6.7 shows a cross-case comparison of behavior patterns during EM entry. The late EM entry on the sequence of internationalization from most 
cases in the three early internationalized clusters reflects their risk-avoidance tendency in the EM entry context. This is closer to behavior pattern with managerial behavior feature. However, once there was negative change in the environmental munificence, the investigated case firms became more alert to emergent "means" and even started to actively seek new "means" to pursue potential opportunities. Therefore, many cases had mixed features with the Kirznerian-type of entrepreneurial opportunity discovery. The changes and mixed features in the behavior pattern in the EM entry also reveals an adaptability in the internationalization process.

\subsection{Summary of findings from the cross-cases analysis}

Through investigation, this study reveals how the patterns in the internationalization of small firms under their EM entry context have evolved and unfolded during the internationalization of small firms in order to create a better understanding regarding influences from important contexts in the internationalization of small and micro firms with large resource constraints. The findings from the cross-case analysis are summarized below.

\subsubsection{Dynamic changes in forming motion patterns of in- ternationalization}

Changes are one of the main themes in the study of internationalization. Extant theories, such as the U-model and the U-network model, suggested incremental changes in the international expansion of a firm (Johanson and Vahlne, 2009; Eriksson et al., 1997; Chetty and Blankenburg Holm, 2000). The U-model and the U-network model indicate that the experiential knowledge accumulation from foreign markets and trust-building in foreign market-connected networks take time. Thus, the internationalization process shows a slow pace. BG and INV, on the other hand, suggested internationalization could be at a fast speed and concurrent in many foreign markets (Oviatt and McDougall, 1994; Madsen and Servais, 1997). Taking a longitudinal approach, the findings from this study reveal that there is a mixed feature in changes of the motion pattern in 
the early and rapid internationalization clusters. The influential changes were from an interaction between small firms' resources and their operating contexts.

The cross-case analysis of the changes in motion pattern between the initial and later periods reflects hybrid traits from both the INV and the U-model. This seems to be a concurrent entry in different markets in the initial period. However, from the sequence of entry of these early internationalized small firms, these cases still showed a stronger preference for the low PD markets. The majority of the early and rapidly internationalized small firms tried to enter foreign markets which were similar to Sweden, or where the TMT had previous connections and knowledge. Before these "Instant starter" (C2) and "Start with a large scope" (C3) clusters approached other foreign markets with a high "psychic distance", Nordic neighbors and Germany were their primary choices as a first step. Countries with a low "psychic distance" range (low in perceived risk) and a relatively high market potential (high in perceived opportunity), such as Germany, were in particular the most common earlier targets for these small Swedish firms. Nevertheless, an individual preference and the previous experience of the founders and $T M T$ were the most common sources for the small firms to reach high PD markets earlier ( $\mathrm{MC} 1$ in $\mathrm{C} 2$; $\mathrm{TC}$ in $\mathrm{C} 3$; and $\mathrm{T} 7$ in $\mathrm{C} 4$ ). In addition, technology-oriented firms with innovative products were more open to any markets with early adopters.

There were many changes after the initial period, and these changes were more dynamic in different dimensions of the motion patterns of these early internationalized clusters. The dynamic changes in the motion pattern could be attributed to the resource constraints of the small firms. The fast and concurrent entries in many foreign markets during the initial epoch created tension between the availability of managerial service and fast international growth. Small firms could hardly sustain their commitment in different markets without the help of local agents in the foreign markets. The low-resource commitment entry mode via agents or via partnership became pragmatic choices for many small firms. However, largely depending on the agents also caused some agent problems. Thus, the empiric findings reveal many adjustments and refocus in forming the motion pattern under different contexts. A combination of learning, adaption and resource constraints plays an important role in the emergent transition between exploration and consolidation periods during internationalization. It is not a uniform, one-directional type of linear change with increasing experiential knowl- 
edge within foreign markets or networks as the incremental model (e.g., the U-model) suggests.

\subsubsection{Disproportional change among the three dimensions of motion pattern during internationalization}

Based on further differentiated dimensions of motion pattern, this study reveals disproportional changes among the three dimensions of motion pattern in internationalization - scope, scale and speed. The earlier U-model had more focus on the scope and scale dimensions of internationalization. The U-model shows an incremental feature from low to high commitment in the scale dimension and from low PD to high PD markets in the scope dimension. BG and INV-related IE theory has more focus on the speed dimension of internationalization. It shows an instant feature. This study reveals that taking the three dimensions together into consideration, a disproportional change appears. Due to a large resource constraint in terms of financial and human resources during the internationalization of the small firms, there is a trade-off on these three dimensions.

As shown in Table 6.3, there are changes in all three dimensions of internationalization in the case firms between the initial period and the later period. Compared with the other 10 early internationalized case firms in three of the clusters, the "Late starter" firms (SC1 and $\mathrm{SC} 2$ ) had fewer international markets, were slower in tempo and had a smaller scale of internationalization.

From the scope dimension, half of the early internationalized case firms had more of a European or even Nordic focus (e.g. MC3) in the earlier period of internationalization. From the scale dimension, in terms of overseas turnover, most of the early internationalized case firms had a relatively large scale of overseas turnover. Only two firms (MC8 and TC) had no more than half of their turnover from foreign markets. However, in terms of the scale of operational involvement represented by the entry mode in different foreign markets, only two small firms (MC4 and MC9) in the "Instant starter (increase control)" cluster increased their control by using equity-based entry modes in the continued period of internationalization. Other firms did not have or could not 
sustain (e.g. MC6 in C2) fully-owned sales or production organizations overseas. Their resource commitment to foreign markets operation was generally low. As discussed earlier, a low-resource commitment-type of entry often relies on the knowledge, networks and commitment of local agents and partners. Small firms often lack of an effective control mechanism to influence the commitment and performance of agents and distributors. There is a large difference in the market performance between low control and high control entry modes. For example, MC4 was the only firm with established sales organizations in more than one country. The share of turnover contributed from its four subsidiary markets was nearly the same as its 50-plus distributorship markets combined. The establishment of four sales subsidiaries overseas was a turning point for MC4, transforming it from a small-sized company into a middle-sized enterprise in terms of turnover and employment.

The "started with a wide scope" cluster (MC7 and MC8 in C4) further demonstrates that a large scope of internationalization could not proportionally lead to an increase in the share of foreign turnover. Firms with a relatively large scope (MC1, MC2, MC4 and MC8) in their earlier periods also began to narrow down to strategic target markets in their later periods of internationalization. The tempo of internationalization slowed down as well. Thus, due to a large resource constraint, small firms had to make a trade-off among the tempo (speed), scope (international markets coverage) and scale of internationalization (resource commitment and the control level in the operation overseas).

\subsubsection{Conditional preference on the perceived risk (un- certainty) and opportunity}

Different from extant theories, this study shows a situation-related conditional preference regarding risk avoidance/reduction under uncertainty or opportunity-seeking under uncertainty during internationalization. The extant theories, such as the Unetwork model and INV, have a latent assumption that the firms' preference regarding the perceived uncertainty and perceived opportunity is persistent during internationalization. 


\section{CROSS-CASE ANALYSIS AND FINDINGS}

The cross-case comparison reveals a situation-related conditional preference across four clusters. Cases from the "Instant starter" and "Instant starter (increase control)" (e.g. $\mathrm{MC} 1, \mathrm{MC} 2$ in $\mathrm{C} 2$; and $\mathrm{MC} 4$ in $\mathrm{C} 4$ ) clusters offer good examples: "Instant starter" firms (e.g. MC1, MC2) were facing limited segment size in their domestic markets. They had to search for new business opportunities outside their domestic markets to survive. However, as described in Section 6.2.4, the firms were not persistent in their risk versus opportunity preference during different periods of development. MC4, for instance, was very opportunity-driven from its start-up. However, with the development of the firm and its key markets, it began to become more formalized and consolidated in internationalization. The firm's perceived risk (uncertainty) in more distant markets increased during this period. As a result, MC4 became more focused on the markets with low perceived risk (uncertainty). A similar pattern can be seen in the "Start with a large scope" cluster (MC8) as well. Case firms from the "Instant starter (increase control)" cluster (MC3 and TC), on the other hand, changed their preference after the 2008 economic crisis. They became more opportunity-driven, while more risk (uncertainty)tolerant in approaching EMs. Two cases (MC3 in C3 and MC7 in C4) also showed preference changes after changes in ownership.

The "Late starter" cluster firms (SC1 and $\mathrm{SC} 2$ in $\mathrm{C} 1$ ) also changed their preference regarding EM entry. They changed from uncertainty avoidance to more opportunitydriven behavior in approaching an EM as their initial international market. Timing of EM entry and choice of control modes across clusters reflect how perceived high risk (uncertainty) in the EM makes small firms more prudent in approaching the market, until critical changes in their operational environment or emergent means.

The pre-study reveals that the recent performance of the managerial efficiency of the investigated firms had an inverse influence on their likelihood of EM (i.e. China) business involvement. Taking this input into consideration, the main study shows that a transition between a risk versus opportunity focus depends on the prospects from their status quo markets. When there are positive prospects from the status quo markets, small firms tend to be more cautious in risk management regarding high PD EM entry. They also become more reactive to the EMs. Once there are diminishing prospects in the status quo markets, the preference transfers and converts to the opportunity focus. As a result, small firms become more active in opportunity seeking in those EMs. 
In sum, although EMs associated relatively higher risk (uncertainty) and opportunity always exists, small firms' preference on the risk (uncertainty) and opportunity might change under different contexts. This, in turn, influences the patterns of the firms' internationalization. 


\section{Chapter 7}

\section{Concluding discussions and implications}

This final chapter offers an interpretation of findings and implications of the study in relation to the study purpose, possible contributions to the research field, and potential implications for the SMEs and supportive agents. The chapter ends with the direction of further study.

\subsection{Summary of the study}

The overall purpose of this study is, through pattern identification in the internationalization of small firms, to get a better understanding of change mechanisms which may influence the sequence, scope, scale, timing and pace of small firms' internationalization. Based on a critical review of the three major internationalization theories, the study incorporates influence from both the small firm's external environment and its internal "means" to create a synergy of the three perspectives (i.e. behavioral learning, network and entrepreneurship) for the investigation. The study probes the patterns of internationalization on a common ground - influence from both perceived risk and perceived opportunity - in different international markets.

To achieve the purpose of the study, the research adopts a longitudinal approach in 
an overall qualitative multiple case study design to investigate small firms' internationalization processes in order to capture possible changes in features of motion pattern in three dimensions (speed, scope and scale) during the internationalization process. Furthermore, the study also explores changes in the behavior patterns along the internationalization process in order to understand mechanisms underlying the evolution of the motion pattern. A mixed analytic method consisting of quantitative analysis embedded in overall qualitative research methods is used to fulfill different research objectives.

Four research questions were formulated to help achieve the overall purpose of the study:

1. What are the major features in the pattern of small firm internationalization?

2. How can evolving patterns of the internationalization of small firms be described and captured?

3. How do contextual factors influence evolving patterns of internationalization?

4. How does the perceived high market potential, with a high perception of risk (uncertainty) in the context of emerging markets, influence the changes in the internationalization patterns of small firms?

The findings from this study are discussed and answers to the above research questions are given in the following sections. The answers to RQ1 and RQ2 are the conclusions related to the primary objective of this study regarding internationalization pattern identification. The answer to RQ3 and RQ4 are the conclusions related to the second objective of this study regarding to why the pattern has evolved in certain way. The final overall conclusions are given after answers to all RQs to present a holistic framework of internationalization pattern study and to facilitate a better understanding of change mechanisms which influence evolving patterns of small firm internationalization. 


\subsection{Discussion and interpretation of the find- ings}

Cross-case findings reveal dynamic and hybrid features in the motion pattern of small firm internationalization toward EMs. The findings also reveal a situation-related conditional preference in the behavior pattern during the internationalization of small firms. The study points to how the dynamic changes in the patterns of internationalization are caused by an intermittent influence from perception of both risk and opportunity in international markets. This is different from the three major patterns identified in existing theories, which are either from an opportunity-driven (e.g. IE theory) and relationship-driven angle (e.g. network approach), or from a risk (uncertainty) aversion and reduction angle (e.g. U-model), to explain the feature of motion pattern. The timing and entry decision on the international expansion toward EMs results from an interplay between the firms' status quo prospects and interactions between the firms and their industrial and task environment.

\subsubsection{Dynamic and mixed features of the international- ization patterns (Answer to RQ1)}

Findings from the cross-case analysis give the answer to the first research question regarding features in the patterns of internationalization. As summarized in Section 6.4, there is a dynamic and mixed feature in the pattern of internationalization. In addition, there is a disproportional change in the three dimensions of motion pattern.

\section{Features in motion pattern}

From the literature review of extant internationalization research, three major patterns were identified based on the features of the motion pattern in Section 2.2. This study further differentiates motion pattern into three different dimensions - scope, scale and speed (tempo) - to investigate the features of the motion pattern.

The findings from the study show that there is variance and dynamic in the motion 
pattern during internationalization (see summaries in Table 6.4 and 6.7). Unlike extant theories, which suggest either incremental, instant or leap-type motions, this study reveals that there are hybrid features in the motion pattern during different international development periods of the firms. For example, three early internationalized clusters can be categorized as the BG and INV-type firms. However, despite being fast in the speed dimension, some cases still reflect some incremental features in the scope dimension. In the initial internationalization, these cases still had preference in either the low psychic distance neighbor markets (MC2 and MC5 in C2, and MC3 in C3) as the U-model suggested (Dow, 2000; Figueira-de Lemos et al., 2011) or in the markets with potential connections ( $\mathrm{MC} 1$ in $\mathrm{C} 2, \mathrm{MC} 9$ and $\mathrm{TC}$ in $\mathrm{C} 3$, and $\mathrm{MC} 7$ in C4) as the U-network model suggested (Johanson and Vahlne, 2009) in the initial internationalization. Their relatively narrow scope of initial internationalization can be seen as a result of the resource scarcity of small and micro firms. Such constraints also influence the entry mode, a sub-dimension of scale. All cases in the four clusters started with the low resource commitment entry mode (e.g., use foreign agents and distributors; score=1) in the initial period. Except for the "instant starter (increase control)" (C3), which increased its control modes in a few key markets after initial internationalization, the other clusters could only continue the low resource requirement entry mode after the initial internationalization. The pattern of Cluster 3 mirrors the incremental increase resource commitment as the U-model suggested (Johanson and Wiedersheim-Paul, 1975; Johanson and Vahlne, 2009). In addition to the mixed feature of both incremental pattern and instant pattern, there are also dynamic changes after initial internationalization. Many early internationalized cases could not sustain their control in different international markets after initial internationalization. Thus, there is also contraction in some markets after the initial periods. In the latest period of internationalization, many early internationalized cases have adjusted their focus on a few key international markets to improve their knowledge about local markets and their influence on intermediaries and end-customers.

The hybrid and dynamic features of motion patterns show that resource constraint is still an influential factor on the evolving motion patterns of internationalization. Resource constraints force small and micro firms to use a low resource commitment-type of entry to reach different markets. Many cases in the three early internationalized clusters in this study could quickly internationalize by using knowledge and networks from 


\section{CONCLUDING DISCUSSIONS AND IMPLICATIONS}

different intermediaries (e.g., foreign agents and MNEs). Although mobilized external resources can help in the early internationalization of small firms, these firms face challenges to influence and gain commitment from intermediaries. As a result, small firms' experiential knowledge about foreign markets and the development of local networks is rather low under the low control mode of entry. Such situations trigger many trial and error types of learning and adjustment during internationalization. Therefore, there are dynamic and mixed features in the motion pattern.

\section{Features of behavior pattern}

The behavior pattern during internationalization is differentiated from the motion pattern in this study. Based on the sequence of "means" and "ends", the study differentiates managerial, strategic and entrepreneurial behaviors. The study also reveals dynamic and mixture features in the behavior pattern in the internationalization process. This is very context-dependent, with a mixture of managerial behavior as the U-model reflected and entrepreneurial behavior as IE theory reflected.

In the initial internationalization period, the fast internationalization clusters reflected a more entrepreneurial-type of behavior. There were three major types of behavior shown in the fast internationalization clusters; the first was Schumpeterian entrepreneurship. The innovative technology firms ( $\mathrm{MC} 2$ in $\mathrm{C} 2$ and $\mathrm{MC} 4$ in $\mathrm{C} 3$ ) showed a clear characteristic of Schumpeterian entrepreneurship. Motivated by "technology push", the firms were able to create opportunities through forming a new segment in the international markets. The second type of behavior was a combination of the Kirznerian type of opportunity alertness (Kirzner, 1999) and the Sarasvathy type of effectuation (Sarasvathy, 2008) (MC1 and MC6 in C2; MC9 and TC in C3; and MC7 in C4). When the founders and TMTs of the small firms had international experience and networks, they were more alert to the potential opportunities from international markets. Thus, they intentionally used their international connections and knowledge in the internationalization of their firms. The third type of behavior type was a result of the inertia and existing industry networks inherited from the firms' previous periods (MC3 and MC8).

After the initial period, the firms intermittently responded and interacted with triggers emerging from both external (e.g., changes in the segment and the 2008 economic crisis) 
and internal (e.g., ownership change) sources. As a result, the firms have changed their behavior patterns and have mixed features (see summaries in Table 6.5 and 6.7).

\subsubsection{A balanced approach in pattern investigation (An- swer to RQ2)}

Research question two (RQ2) was related to the methodology issue in the investigation and analysis. Extant studies of internationalization focus on either risk (e.g. the U-model) or opportunity (e.g. BG and INV). In addition, the three major patterns identified in the literature did not cover the three dimensions of motion simultaneously. Based on the literature review, this study used two major indicators side by side - perceived risk (uncertainty) and perceived opportunity - to map trails of firms' motion in the scope and scale dimensions, aligned with a biographic timeline, to capture features of the motion pattern during internationalization.

Furthermore, the study developed a process-based analytic tool in Section 3.3.1 and a three-layer analytic frame in Section 2.8 to capture the sources of influence and inputs from interactions between firms and their environment on the temporary state of the internationalization process under the EM entry context. The analytic model (Figure 3.3) developed and implemented in this study shows that the evolving patterns of internationalization can be investigated through the three dimensions of speed, scope and scale. This can be captured via a longitudinal processual analysis, which incorporates both risk and opportunity indicators.

\subsubsection{Multiple influences on the context of international- ization (Answer to RQ3)}

Based on a critical review of the internationalization literature (see Chapter 2), the study proposes that the patterns of internationalization are subject to multiple influences. This is neither merely from entirely internal (e.g., behavior learning and entrepreneurial) nor entirely external (e.g., network approach) influences. Considering 
both the merits and potential limitations of extant literature in the internationalization process research, this study took a balanced view during its investigation. Thus, the study uses a "fit"-based approach and has a focus on the interactions between a firm, its TMT, and the industrial and task environment in which the firm is operating. The study acknowledges the importance of situational influences on evolving patterns of the internationalization. Therefore, it studies patterns by understanding the context in which the internationalization process is taking place. The essential idea of interaction focus on both internal and external influence is to highlight the adaption (Scott and Davis, 2006). The study reveals that the motion and behavior patterns during the internationalization align with evolving traits of the environment with which small firms are enacted. Some important decisions during internationalization, such as the foreign market selection and entry mode, are made on the basis of adaption.

\section{Influence from environment level}

Two major contextual factors from environment level show their influence on the pattern of internationalization. One is the industrial traits, which influence the competitive landscape. Another is the firms' task environment and embedded organizational networks.

\section{Industrial traits}

In the extant literature, the influence of dynamics in the industrial segment has been recognized among those external factors which may influence internationalization. Empirical studies show that a high level of environmental dynamism could explain the initial choice of going abroad (Andersson et al., 2004). Knowledge intensity and the competitive situation also influence the internationalization of small firms (Oviatt and McDougall, 1997). In addition, limited market size, such as smallness and saturation in the domestic market, represents a strong driving force (Chetty and Campbell-Hunt, 2004) for early internationalization. The results from this study also confirm the strong influence from the traits of industry on the internationalization of small firms.

Findings from this study offer strong evidence of the influence from the industrial segment on the speed of internationalization and firms' preference for different inter- 
national markets. The pre-study shows that some industries (e.g. wholesale and retail; manufacturing) are more than three times greater (in odds ratio) than others (e.g., professional service) be more positive toward the EM (i.e. China) business. The cross-case analysis further reveals that traits and the development stage of the firms' operating industrial segment have a large influence on the internationalization of the firm. The industrial sector in which a micro start-up operates sets a competitive and cooperative stage for the firm. Based on cross-case findings (e.g., external triggers), industrial traits influence the initial internationalization in three ways.

The most common influence is the market size and growth potential. Some industrial segments either have relatively small or saturated domestic needs. The limited needs from the domestic market cannot offer sufficient growth opportunity for small firms. Thus, this pushes small and micro firms to look for other international markets at an early stage.

In addition, some industrial sectors have a high degree of internationalization (Johanson and Mattsson, 1988). Small firms operating in such industries are more likely to internationalize earlier and quicker due to their connections with MNEs as suppliers or competitors in the same industry. However, their scope of internationalization is also concentrated on these MNEs' clusters of international markets, at least in the initial internationalization.

Furthermore, the development phases of the industrial sector determine the intensity of innovation and knowledge, the technology level, and the standardization level of firms' offerings in the sectors (Dess and Beard, 1984). Cross-case findings show that small and micro technology-oriented firms working in a narrow segment with a high demand for adaptability of technology are internationalized earlier. In order to sustain the development of these technology-oriented small firms, their innovative offerings need a wider audience in different international markets for fast diffusion. Due to such a technology push, they are fast in their initial internationalization.

\section{Embedded networks}

The industrial network (Johanson and Mattsson, 1988) and dyadic task environment, 


\section{CONCLUDING DISCUSSIONS AND IMPLICATIONS}

especially external task agents (Dill, 1958), have strong influence on the internationalization of firms. The U-network model puts the network in a central position to explain the internationalization process (Johanson and Vahlne, 2009). It argues that the business environment can be seen as a web of relationships or a network. The liability of "outsidership" in the network is the main additional cost in the internationalization. Thus, relationship knowledge and trust are very important to overcome such outsidership. In the extant literature, empiric studies show the importance of networks which facilitate the international expansion of SMEs (Mort and Weerawardena, 2006; Freeman et al., 2010; Schweizer, 2013). This study provides evidence showing that a considerable influence on important decisions in the internationalization of small firms is not only from their directly connected business networks, but also from their loosely connected institutional networks.

This study finds three roles of small firms' embedded networks which influence the patterns of their internationalization. The first role is a "trigger". The "trigger" refers to something that causes something else to happen. The initial internationalization of the "Late starter" cluster, for examples, was triggered from the firms' networks. However, the initial internationalization of this cluster was only sustained for a short time as an incidents or events. This is because when "Late starter" had a positive prospect from their domestic market, they only passively responded to these triggers from different networks at that time and failed to continue internationalization afterwards.

This study reveals that the second role of networks and dyadic relationships in the task environment is to "abridge". "Abridge" refers to lessening the strength or effect of something. All the cases in this study are in the B2B context. Industrial networks in B2B offer a more convenient pathway for small firms to reach distant markets. Early internationalized clusters of this study provide such evidence. A few examples from "Instant starter" and "Start with a large scope" have been or intended to be suppliers and partners of Swedish or European MNEs. By serving MNEs, small firms got recognition in distant markets even before they actively approached these markets. Thus, it can be argued that networks and dyadic business and institutional relationships are an important source of opportunity discovery in foreign markets. 
This study finds that the third role of networks and dyadic relationships in "task environment" is a supportive role in experiential knowledge and resource sharing. Slowness in experiential knowledge accumulation is one of main reasons for a gradual feature in the U-model (Eriksson et al., 1997; Johanson and Wiedersheim-Paul, 1975). Studies on BG reveal that there is rapid experiential knowledge development for the BG (Freeman et al., 2010). Evidences from early internationalized clusters in this study show that many small firms form and use their networks to exchange experiential knowledge and share resources in foreign market entry. This inter-organizational knowledge and resource sharing could speed up and save costs in acquiring necessary experiential knowledge in internationalization.

Based on the above discussions of findings regarding influence from both the industrial and task environments of small firms, this study shows that a level of abundance of resources and opportunities available in firms' operational environment (e.g. industrial segment and embedded network) have a strong influence on the initial pattern of internationalization. This is so called environmental munificence influence growth prospect of small firms (Castrogiovanni, 1991; Dess and Beard, 1984). A higher capacity of environmental munificence for growth in the domestic market, in low-PD markets (e.g., the Nordic market and Sweden) or in cluster markets of MNEs' clients could discourage small firms from taking on extra risk in internationalization. This influences both the speed and scope dimensions of motion pattern. Therefore, this study draws its first proposition from the influence from the environmental level.

Proposition 1 A declining or limited capacity of environmental munificence in the domestic market or in low-PD international markets would positively influence the speed (e.g. faster) and scope (e.g. toward markets which high opportunity) of internationalization.

This proposition suggests that there is an inverse relationship between environmental munificence in the domestic market or low-PD international markets, and the speed as well as scope of internationalization. A higher capacity of environmental munificence in the domestic or low PD market can encourage small firms to develop locally or regionally. As a result, slower speed and a narrow scope of internationalization are more likely to prevent unnecessary risk-taking in internationalization. However, it 
should also be noted that how a small firm responds to the conditions and triggers from its environment forms its unique footprint in internationalization.

\section{Influence from the intra-firm level}

This study probes the influence of the intra-firm level from two layers. The first layer is from an individual aspect, while the second layer is from a firm aspect. In addition, this study also takes the historical inputs from the firm's prior period into consideration.

\section{Individual-level influence (Entrepreneur and TMT)}

A strong influence from the entrepreneur and TMT is probably one of the distinguishing features in the internationalization of a small firm. Especially during the new venture period, knowledge, skills, networks and competence of the founder and TMT of a small firm are its most valuable resources. Extant empirical studies show that social capital (Melén, 2009) and relationship can open the door to distant markets (Komulainen et al., 2006; Ellis, 2011). Founder teams' previous international experience and vision also set a direction for their firms' internationalization (Freeman and Cavusgil, 2007). Cases from this study also reveal such a vital influence of founders and TMTs. Crosscase findings show that among the three important elements identified in the individual level of the "means pool" (see Figure 2.4), the international vision and attitude of the entrepreneur and TMT are the critical elements.

All of the case companies across the four clusters showed their entrepreneurial capabilities in the innovativeness of their products and service offerings. Most of the founders and TMTs in the investigated firms either had international knowledge and skills, or acquired such knowledge quickly during internationalization. The majority of them also had previous international networks and contacts, except for one case (SC1) in the "Late starter" cluster. An interesting case from the "Late starter" cluster (SC2) shows that despite having adaptable and scalable offerings, international knowledge, experience and connections, this micro firm was still late in its internationalization. The important hindering factor was a lack of international vision. Having the firm's needs from the domestic market sufficiently met weakened the international vision of the founder. This lack of international vision made the firm very reactive in its inter- 
nationalization until the 2008 crisis.

Findings from this study show that once the entrepreneurs in small firms have a strong awareness of the limited opportunities in their domestic market, they can develop their international vision rather quickly. Thus, those entrepreneurs either actively utilized their extant international knowledge, skills and connections for internationalization, or they began to acquire necessary knowledge and develop their skills and international networks by conducting international business. These firms started internationalization by experiential learning, which is learning by doing or through experiencing it. Through taking internationalization actions, the firms further developed a set of skills and acquired needed knowledge and resources for their internationalization. Therefore, it can argue that the previous international knowledge and network were not necessary to be a premise of internationalization, although the founders' and TMTs' previous international experience and networks would facilitate the internationalization of their firms. International vision or positive attitude on the internationalization are more important in the initial period of internationalization. Thus, this study draws its second proposition from the influence from the individual level.

Proposition 2 A strong international vision of small firms' entrepreneurs and TMTs will positively influence the initial speed of internationalization of the firms.

A strong international vision and the positive attitude of entrepreneurs and TMTs toward international markets will motivate their small firms to either take initiative via effectuation (Sarasvathy, 2008) or to actively respond to external triggers, such as unconsolidated requests from international markets or emerging international connections. It could reason that with a strong international vision, the entrepreneurs and TMTs will be more alert to potential opportunities from international markets. Thus, they are more likely to actively acquire relevant knowledge through networks and to mobilize necessary resources quickly to evaluate and further exploit such opportunities. This proposition suggests that the strong international vision and positive attitude of entrepreneurs and TMTs are important facilitators for both the Sarasvathy type of effectuation, when entrepreneurs have previous international knowledge and contacts, and the Kirznerian type of entrepreneurial opportunity discovery, when entrepreneurs have very limited international knowledge and contacts in initial internationalization. 
This supports some findings from BG and INV that INVs do not have to own the resources for initial internationalization (Zahra, 2005). However, whether the initial internationalization can be sustained depends on the further development of the small firms after the initial epoch of internationalization.

\section{Organizational-level influence}

In the extant literature, early internationalized firms were often found from technologyoriented small firms (Aspelund and Moen, 2003; Keupp and Gassmann, 2009). This study regards technology as a broader term and covers both organizational tasks and technology (Scott, 2002), as they are a major source for further value creation. The study finds that technology is both a trigger and an enabler for the internationalization of the small firm.

This study shows that the technology-based start-up cases were more open to a wide scope of international markets from the start. As mentioned earlier, these firms needed to get a wider and quicker diffusion of their technology and innovative products. By competing in higher demanding international markets, the small firms have also been motivated and pushed to keep updating their technologies. Thus, this study shows that "technology push" triggers and enables early internationalization with a relatively large scope. Increasing competition and technology demands from internationalization markets, in turn, trigger further developing and increasing technology capability of the small firms for continuous internationalization. Nevertheless, it is also worthy to be aware that the stability and adaptability of the technology influence firms' internationalization. One example can be found from a case in the "Instant starter" cluster. Here, the firm had encountered a big challenge during its early internationalization because its innovative technology did not reach an acceptable level of stability for commercial use. Based on these findings, this study draws the third proposition from the organizational level as follows:

Proposition 3 Technology innovation with a high level of adaptability will positively influence the speed and scope of internationalization.

This proposition suggests that the Schumpeterian type of innovation is still a strong 
trigger and enabler for early and continuous internationalization of technology-oriented firms. This fast speed of internationalization is driven by technology push. Furthermore, this technology-driven early internationalization tends to reach many early adopters from different markets. Therefore, the feature of internationalization pattern also shows a relatively large scope. This is an entrepreneurial opportunity creation (Roininen and Ylinenpää, 2009) action shown in the international markets.

In addition to technology, market knowledge and focus together with managerial attention are two identified influential elements at the organization level in the literature. This study finds that the market focus of the firms is closely related to the managerial attention. The managerial attention element in this study is derived from the attention-based view (Ocasio, 1997). This study uses this concept to help understand changes in the behavior pattern during internationalization. The study uses the managerial attention to cover the focus of both attention and situated attention (Ocasio, 1997). The managerial attention in internationalization of the small firms regards that important decisions and actions related to the internationalization depend on firms' situational focus in particular context. Based on the cross-case findings, the study reveals that managerial attention in different contexts, such as start-up, after crisis or EM involvement, have been changed. These changes relate to the status quo prospect from the extant market of the firms at that period. The influence from the status quo prospect is discussed in the following section.

\section{Influence from prior experience}

Some INV and BG studies find that the age of these firms is a source of controversy because of large variations in the gestation period of INVs and BG firms (Zahra, 2005). This study finds that resources and experiences accumulated in the pre-establishment period have a major influence on important decisions in the initial internationalization. The longer the gestation period with more previous experience, the greater the chance for the new firm to continue on the old path, due to a larger influence from inertia. In this study, the "Later starter" cluster and cases with previous experience in the early internationalized three clusters provide such examples. These cases show that inertia from previous experience influences the initial speed and scope of internationalization. New firms with a long period of domestic focus in the previous period are more likely to be late in the their internationalization, assuming no other moderator (e.g., interna- 
tional connected network) appears.

In sum, to answer research question three (RQ 3), this study investigates the interaction of a few contextual factors from both the environmental and intra-firm levels. The findings show that internationalization of the small firm is subject to multiples level of influence. In different contexts, an interaction between different contextual factors directs managerial attention related to important decisions on internationalization. Thus, there is an intermittent adaption, which leads to a changing motion pattern during internationalization. Three propositions regarding how contextual factors affect different dimensions of internationalization patterns are drawn based on influence from environmental, organizational and individual levels.

\subsubsection{Influence from the status quo prospect (Answer to RQ4)}

Three major extant internationalization theories offer inconclusive explanations on the incremental changes and the rapid pace of movement in the internationalization process. As discussed in the above sections, the findings of this study reveal that the evolving patterns of the small firms' internationalization are a result of an intermittent adaption between the small firm and its operating environment. In order to understand the mechanism underlying such dynamic adaption, which causes differences in the motion and behavior patterns under different contexts, the study goes further to probe the sources of dynamics and variance in the motion and behavior patterns in the internationalization. The status quo prospect in extant markets had been identified as an important factor which influences feature changes in the patterns of internationalization.

\section{Status quo prospect on risk framing}

Inspired by the behaviorial economics theories related to the context-dependent decisionmaking under uncertainty, such as the prospect theory (Kahneman and Tversky, 1979; Tversky and Kahneman, 1992) and the threat-rigidity hypothesis (Staw et al., 1981), 
this study investigated critical events and important epochs in the internationalization process under the course of firms' development. The cross-case analysis finds that under the influence of critical events, especially adverse situations, small firms are more active in searching for or responding to new perceived opportunities from international markets. This points to how the small firms' preference and attitudes toward risk (uncertainty) and opportunity are not persistent. A status quo prospect from the firms' extant markets shows its explanatory power on the firms' conditional preference in avoiding risk (uncertainty) or seeking opportunity during the internationalization process.

\section{Status quo prospect}

The prospect theory (Kahneman and Tversky, 1979; Tversky and Kahneman, 1992) suggests that facing uncertainty, the attitudes of decision makers on a potential loss or gain are different under different risk versus opportunity framing contexts. This study investigates small and micro firms with a large resource constraint during internationalization. The study assumes that compared with domestic operations, the internationalization is costly to this group of firms. This is especially true in these high perceived psychic distance EMs, in which institutional voids (Khanna and Palepu, 2010) or other sources of uncertainty might increase the liability of foreignness (Håkanson and Ambos, 2010) and liability of smallness (Lu and Beamish, 2001). If no other moderating factors (e.g., mobilizable resources from the network) exist, the perceived high-PD market implies higher risk (uncertainty) in the foreign markets for the small-sized firms. RQ4 of this study helps in understanding the timing and context in which small firms are either willing to bear such risk to search for new market and business opportunities in the high-PD markets with higher market potential, or intend to avoid such risk and stay in domestic or familiar low-PD markets.

Following the reasoning from behavioral economics theory, the risk preference of small firms in international markets, especially in high-PD markets, changes with context. Results from the pre-study reveal an inverse relationship between increasing operating performance and decreasing likelihood of EM (China market) involvement. Therefore, the main study includes the small firms' financial performance as an additional reference indicator to reflect the firms' status quo prospect from their extant markets in the case study analysis. Cross-case findings (see the middle sections of Table 6.4 and 6.7) show 
that compared to other early internationalized clusters, the "Late starter" had a higher perceived status quo prospect from the domestic market than others at the start-up period. It could reason that a relatively low perceived status quo prospect from domestic markets pushed or motivated the 10 cases in three early internationalized clusters to go to international markets very quickly to search for additional business opportunities. The "Late starter" cluster, on the other hand, had a higher status quo prospect from its domestic market and had less pressure regarding internationalization. Even one of the "Late starter" firms (SC2) had encountered an international business-related event in an early period, and it was easier for the firm to offer its service online; the firm did not take any further action after the event. Higher perceived status quo prospect could not offer enough motivation for the "Late starter" firms to go to perceived higher risk international markets during the start-up period. However, when the context changed, for example after the 2008 economic crisis, some case firms (e.g., MC2 in C2, MC3 in $\mathrm{C} 3$ and $\mathrm{SC} 2$ in $\mathrm{C} 1$ ) suddenly experienced deteriorated status quo prospect from their existing markets, and these firms began to take concrete action in approaching high perceived PD with high perceived opportunities in EMs (e.g. the Chinese market). In this study, there is a consistent pattern across 12 cases in 4 clusters showing that context matters.

\section{Risk framing}

The influence from the status quo prospect on the motion pattern and behavior pattern during the internationalization of small firms can be further examined via a reference point. According to the framing effect from the prospect theory, decision markers tend to be more gain focused when facing a perceived negative status quo prospect (Kahneman and Tversky, 1979; Tversky and Kahneman, 1992) in an uncertain investment decision. On the other hand, when facing the perceived positive status quo prospect, decision makers tend to be more loss focused in the decision under uncertainty (Kahneman and Tversky, 1979; Tversky and Kahneman, 1992).

This study adopts the basic idea about the framing effect from the prospect theory into the context of the internationalization of small firms. Based on the findings from the cross-case analysis, the study finds two framing situations showing influence from risk framing on the evolving patterns of internationalization. 
In the first risk versus opportunity framing, a perceived low status quo prospect from the firms' current markets may make these small firms and their decision makers feel that there would be nothing they could lose in the current markets. Thus, the firms need to explore and look for new business in unexplored higher PD markets with perceived high market opportunity or relationship opportunity. Therefore, firms tend to outweigh potential gains from perceived high opportunity. This leads these decision makers to be more tolerant of potential risk.

In this study, the motion pattern of some cases (MC2 in $\mathrm{C} 2, \mathrm{MC} 3$ in $\mathrm{C} 3$ and $\mathrm{SC} 2$ in C1) after the 2008 economic crisis and one case (MC5) shifting to a new industrial segment in 2004 are such examples. Motion pattern changes toward EMs (MC2, MC3 and SC1) or other more distant markets (MC5) reflect a change toward an active, opportunity-seeking type of entrepreneurial behavior under this context. Based on an interpretation of the findings, this study draws the fourth proposition from the influence of changes in the risk-framing on the evolving patterns of internationalization.

Proposition 4 When small firms face a perceived low or negative status quo prospect from their current markets, their decision makers tend to be in favor of potential opportunities, which leads them to be more tolerant of potential risks in international markets with both higher perceived risk (e.g. high-PD markets) and higher perceived opportunities (e.g. EMs).

In the second risk versus opportunity framing, perceived high and sufficient status quo prospects from current markets make taking risks to approach perceived high psychic distance international markets seem more costly. Under this risk framing, small firms might outweigh potential loss instead of gains in international markets, especially in high-PD markets. Thus, firms might become risk-averse and be more reactive in pursuing opportunities in international markets with higher perceived risk (uncertainty).

Two cases ( $\mathrm{SC} 1$ in $\mathrm{C} 1$ and $\mathrm{MC} 4$ in $\mathrm{C} 3$ ) in this study represent such examples. The "Late starter" firm (SC1) had high status quo prospects from its domestic market and had no intention of entering the distant international markets, until an external initiative triggered the firm's unplanned motion toward the high-PD emerging market. The 
firm reacted to the stimulation from its task environment. This was an opportunity discovery type of behavior. During its international trials, the firm's TMT was constantly cautious about the opportunity cost of their time invested in international business development. Their efforts and commitment in the foreign market-related business could hardly be sustained because of the distraction from their current business. The case firm from the early internationalized clusters (MC4), on the other hand, had very good status quo prospects from its targeted key markets. Its EM entry was purely ad hoc. The firm simply reacted to the emerging personnel connection with the EM (the South Africa market in 2006). Based on these findings, this study draws its fifth proposition from the influence from changes in the risk framing during internationalization.

Proposition 5 When small firms face perceived high or positive status quo prospects from current markets, their decision makers might be in favor of securing current gains and tend to be risk averse in approaching perceived high risk (e.g. highpsychic distance) international markets.

Propositions 4 and 5 suggest that small firms' perception of status quo prospects in extant markets influence their risk framing of perceived risk (uncertainty) from international markets with high PD during internationalization. Different from extant theories, which suggest consistent preference on risk reduction (e.g. the U-model) (Figueira-de Lemos et al., 2011) or that firms are opportunity-driven (Chandra et al., 2012), these two propositions point to changes in risk framing which lead to a shift of preference between risk versus opportunity in the internationalization. It answers the research question four (RQ4), that small firms' perceived opportunity and risk (uncertainty) in EMs shift based on risk framing. When there are low and negative status quo prospects from extant markets, small firms tend be to more alert to potential opportunities in EMs. Small firms become more positive to approaching EMs and expand their scope of internationalization to new perceived opportunities. However, once there are highstatus quo prospects from extant markets, small firms become risk conscious when approaching EMs. 


\section{Prospect-guided internationalization process model}

Based on the above discussion of status quo prospects on the risk framing in small firms' decision-making during internationalization and two risk framing-related prepositions, this study suggests a basic mechanism underlying changes in the evolving patterns of small firms' internationalization in the following two major scenarios:

Scenario one: international exploration

1. A low or negative perceived status quo prospect from extant markets will motivate the small firm to become more opportunity focused and to overweigh potential gains from international markets expansion under uncertainty.

2. When a small firm is more opportunity focus, the firm becomes more alert to potential opportunities from international markets. As a result, firms are more likely to actively respond to expansion opportunities or even take active or proactive actions for international market expansion. This cycle leads to an entrepreneurial oriented behavior in mobilizing and acquiring relevant means (e.g. market knowledge and relevant networks) in an international exploration phases.

\section{Scenario two: international consolidation}

1. A high perceived status quo prospect from extant markets will trigger small firms to become risk-cautious, which leads to risk reduction and even an avoidance focus. As a result, the firms tend to outweigh potential loss from international market expansion under uncertainty.

2. When a small firm becomes more risk reduction-focused on international market expansion, the firm is more likely to be reactive in such expansion. This cycle leads to managerial-oriented behavior in the consolidation phase. Under this context, a small firm is more likely to focus on low-risk (uncertainty) markets and narrow the scope of internationalization.

Based on the two basic scenarios above, this study constructs a prospect-guided process model as shown in Figure 7.1. 


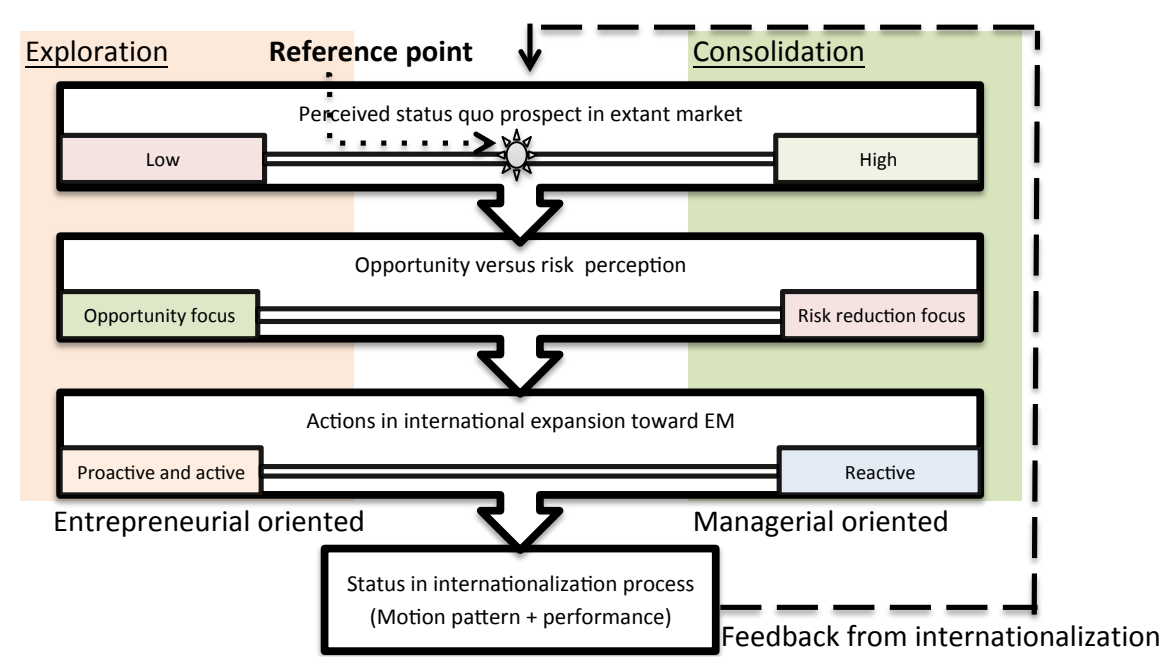

Figure 7.1: Prospect-based internationalization process model

The prospect-guided internationalization process model intends to explain changes in risk versus opportunity perception regarding distant international market entry. It illustrates the mechanism underlying variance in motion pattern and intermittent changes in behavior pattern during the internationalization process of small firms. The model consists of three sets of status and actions, which lead to temporary results for motion pattern in the internationalization. The three sets of elements include status quo prospect, risk versus opportunity perception and actions in international expansion toward EMs.

Status quo prospect is an ex-ante stage of evaluation. A small firm either consciously or subconsciously evaluates its status quo prospect from its extant markets. The spectrum of scale in this stage is from low (color-coded as red on the left) to high (color-coded as green on the right).

Opportunity versus risk perception is a cognitive evaluation stage. Based on the perceived status quo prospect from its extant markets, a small firm has situational risk framing regarding whether a potential international expansion is too risky or if it is a rewarding opportunity. The spectrum of scale in this stage is from an 
opportunity focus (color-coded as green on the left) to a risk focus (color-coded as red on the right).

Action is the implementation stage, based on the product of the two previous stages of evaluation. The spectrum of scale in this stage is from proactive (color-coded as orange on the left) to reactive (color-coded as blue on the right).

Status of internationalization is a temporary result from the actions a firm has taken during internationalization. It covers three dimensions of motion pattern and results in the internationalization process.

The prospect-based internationalization process model explains the basic mechanism underlying changes in the pattern of internationalization as follows:

1. A small firm's reference points of perceived status quo prospects from extant markets influence its risk versus opportunity perception and preference.

2. Due to the risk versus opportunity framing demonstrated in the two propositions, two major scenarios are created during internationalization as proposed earlier: the exploration phase in internationalization (color-coded as an orange shadow on the left part of Figure 7.1) and the consolidation phase of internationalization (color-coded as a green shadow on the right part of Figure 7.1).

3. Results from the different types of actions and behaviors shape a temporary motion pattern and contribute to the financial and market performance of the firm.

4. Feedback from the performance during internationalization creates new inputs to form an updated perceived status quo prospect for extant markets.

In sum, by incorporating a combined view from three major perspectives in the research on the internationalization of small firms, the study investigates the internationalization of small firms under different contexts (e.g. initial, after crisis, and EM entry context). The results show a dynamic feature in the motion pattern and intermittent changes in behavior patterns of small and micro-sized firms. The changes are under multiple influences from an interaction between small firms and their environments. This aligns with the firm's development course and is related to evolving status quo prospects 
from the firms' current markets. The results further reveal the risk versus opportunity preference in the internationalization of small firms, which changes due to risk framing in different contexts.

\subsection{Conclusions}

Due to their large percentage in the total population of enterprises, SMEs have been recognized as an important group, one with a large potential to contribute to the national economy in every EU country. Internationalization is identified as important for small firms' development and growth, especially for countries with small domestic markets such as Sweden (Naldi, 2008). However, facing resource scarcity, internationalization is a resource-demanding process (Buckley and Ghauri, 1999), and is also very challenging for SMEs, especially the smaller ones. This study gives a special focus on these small and micro firms and probes the involved patterns of internationalization. The study uses internationalization toward EMs, which have both high perceived risk (uncertainty) and high perceived opportunity, as a main context to probe a few key contextual factors from both environmental and intra-firm influence on the pattern of internationalization. By a contextualization of internationalization in differential critical periods (i.e. initial, continued and EM entry), this study contributes to further understanding the mechanism underlying changes during internationalization in different contexts.

\subsubsection{A holistic framework on the patterns of internation- alization}

Reflecting on the merits and limitations of the extant literature, which either has an internal focus (e.g. the U-model and IE theory) or external focus (the U-network model), this study takes a holistic view on the impacts from interactions between small firms and their external environments in internationalization. In addition, the study also incorporates historical inputs from their prior experience to cover the evolution of patterns in the entire internationalization process (e.g., pre-venture, initial interna- 
tionalization and continued internationalization). The holistic framework developed in this study extends and contributes to the extant literature on the internationalization of SMEs as described below.

The study shows a strong influence from inertia accumulated in the firm's prior experience on the speed dimension of the initial internationalization pattern. Some INVs are not that "new" because of their experience in a long gestation period (Zahra, 2005). Given their heterogeneous backgrounds before the new venture establishment, micro and small firms started with a different resource base (e.g. knowledge, network and technology) and managerial experience. These accumulated experiences and resources have a direct influence on the internationalization vision and decisions of new ventures. Thus, the age of the INVs and BGs in the initial internationalization can be misleading. Because the age cannot fully capture the managerial experiences from the pre-venture time, it is also important to take prior experience into consideration for INV and BG study.

In addition, this study shows that environmental characteristics have a strong influence on both the initial speed of internationalization and intermittent changes of scope in continued internationalization. Different from some of the extant BG and INV literature, which emphasizes the dynamic and turbulent environment (Efrat and Shoham, 2011; Westhead et al., 2004) of the initial internationalization, this study shows that the munificence dimension of environment (Dess and Beard, 1984) in both industrial and task environment is an important contextual factor, influencing patterns in both initial and continued internationalization. The capacity for growth opportunity in the environmental munificence motivates small firms' decisions on further development in domestic markets, in regional (e.g. Nordic) markets, in MNEs' clusters or in true internationalization.

Furthermore, international knowledge and experiential knowledge (Johanson and Vahlne, 1977) and internationally-connected networks (Johanson and Vahlne, 2009; Coviello and Munro, 1997) are two important factors identified from the literature review which influence the pattern of internationalization. This study found that despite their importance, international knowledge and networks are not a premise for the initial inter- 
nationalization of small firms, especially for the "technology-push" type of new venture. Initial internationalization of technology-driven new ventures has a strong characteristic of Schumpeterian opportunity creation. Technology-push innovation motivates these firms to develop their international knowledge and build up their international networks rather quickly. On the other hand, the Krizenerian type of opportunity alertness (Kirzner, 1999) and Sarasvathy's type of effectuation (Sarasvathy, 2008) are more common in entrepreneurs with prior international knowledge and networks. These two elements are a strong facilitating factor for the internationalization of their small firms. Nevertheless, in the continued internationalization, experiential knowledge (Johanson and Wiedersheim-Paul, 1975) is still an important predictor for the changes of resource commitment in operation modes, which is a sub-dimension in scale of internationalization. In the continued internationalization, the development of an internationallyconnected network plays an important role to facilitate, bridge and support the expansion or contraction of the scope of internationalization.

Under the influence of the above-mentioned contextual factors, this study shows a mixed feature and dynamic changes in the evolving patterns of internationalization in three dimensions: speed, scope and scale. An interpretation of reasons and mechanisms underlying these changes is presented in the following section.

\subsubsection{Conditional preference on the perceived risk and perceived opportunity}

In last two decades of research on the internationalization of small firms, there are divergent opinions regarding the influence of firms' perceived risk versus opportunity on the sequence and tempo of the internationalization. The risk (uncertainty)-associated "psychic distance" concept has been marginalized in the U-network model (Johanson and Vahlne, 2009) and in recent international entrepreneurship studies (Jones et al., 2011), which focus more on the opportunities. Yet, this still shows the importance of, for example, the internationalization of family SMEs (Kontinen and Ojala, 2010).

By using the internationalization of small firms towards EMs as a context, this study 
uses several big EMs as examples to show the influence from high perceived risk (uncertainty) and high perceived opportunity at same time on the internationalization of small firms. The study reveals that in the EM entry context, "psychic distance" still largely influences the timing of small firms' EM entry. Timing of EM entry is subject to the interaction between small firms and their response to contextual factors from both the firms' internal and external environments. The preference of perceived risk regarding EMs has changed due to changes in the prospects in extant markets. The conditional preference on the perceived risk and perceived opportunity reflects changes in risk framing, which relate to the change mechanism in the internationalization process, as explained in the next section.

\subsubsection{Prospect-guided change mechanism in the interna- tionalization process}

This study further reveals that a change in the status quo prospect influences the preference for risk reduction versus opportunity focus during the internationalization of small firms. Two prospect view-based propositions (Proposition 4 and Proposition 5) are proposed from the study to explain situation-related transitions in the risk versus opportunity preference in the internationalization process. In addition, a prospectguided internationalization process model is constructed to reveal the mechanism behind dynamic features in motion patterns and changes in behavior patterns during the internationalization of small firms.

The study spots a new important element - "status quo prospect from extant market" and its related risk framing (Kahneman and Tversky, 1979; Tversky and Kahneman, 1992) on the risk versus opportunity perception under different contexts during internationalization. The proposed final process model explores a change mechanism, which explains the how and why of the observed dynamic and intermittent adjustments in the internationalization process of the small firms. 


\section{CONCLUDING DISCUSSIONS AND IMPLICATIONS}

\subsection{Theoretical contributions}

Internationalization has been recognized as one important aspect to improve the performance of SMEs in EU countries (European Commission, 2014). It has also attracted much attention in academia in recent decades. Extant literature and empirical evidence on the internationalization of small firms offer inconclusive results on the pattern of internationalization in this group (Kuivalainen et al., 2012). Bearing in mind the strength and limitations in extant research on this topic, this study uses a longitudinal approach to investigate the internationalization process of small firms under their EM entry context. The study contributes to the internationalization process study of small firms and the extant internationalization study in the following ways:

\section{Development of analytic frame and instrument}

In internationalization process study, the value of longitudinal design is recognized by researchers (Melin, 1992). However, due to the complexity in design and implementation of longitudinal process-based analysis (Pettigrew, 1997), there is very limited research applied to it. In the IE studies, it is very common to have a short-period focus on the internationalization pattern (Kuivalainen et al., 2012) and cross-sectional analysis and a partial focus on the speed dimension. In response to this insufficiency, this study uses RQ2 to help construct a process-based analytic framework and instrument. The analytic model built in Section 3.4 incorporates both perceived risk and perceived opportunity derived from the interaction of three levels of influence on the internationalization. This can map patterns of internationalization with three dimensions (speed, scope and scale). This contributes to the methodology of internationalization process study by developing an analytic model to visualize the evolution of motion pattern.

\section{Extend focus on the interaction}

In the extant internationalization literature, dominant theories to interpret the internationalization are generated either from the internal focus of the small firm and its TMT (Zahra, 2005), or from a strong external focus on the embedded networks of the firm (Johanson and Vahlne, 2009). This study takes a more balance view on the interaction between internal and external influence. Inspired by the contingency view of management, the study has a focus on the interactions in three levels (see Section 2.8) to probe 
the sources and triggers which might impact the patterns of the internationalization. Theoretical contributions are that the study identifies influence from the munificence dimension of environment on the pattern of internationalization in both the initial and continued periods. It adds body of knowledge in internationalization of small firms by showing an impact from the overlooked dimension of environment. In addition, interaction focus also helps further identify intermittent adaption during continued internationalization. This theoretical finding contribute a better understanding of the reason of changes in patterns of internationalization. Finally, interaction focus helps differentiate the sequence of influence from "means" and "end" for an identification of different behavior patterns. As a result, it adds knowledge by identifying different behavior patterns in the internationalization.

\section{Differentiated patterns}

Based on a synthesis of extant research on internationalization pattern studies, this study goes further in differentiating patterns of internationalization between the motion pattern and the behavior pattern. In addition, the study simultaneously takes three dimensions of motion pattern into consideration in the analysis. Further differentiation and categorization helps catch the evolution in features of the internationalization pattern. It contributes to theory development in the internationalization of small firms by enriching terminology and fine-tuning the theory related to the patterns of internationalization.

\section{Development of instant internationalization study}

One of the limitations of current instant internationalization studies (e.g. BG and INV) is their short-period focus. Most extant studies only focus on the initial period of BG and INV, and thus there is very little knowledge regarding what happens to BG and INV during longer periods (Trudgen and Freeman, 2014). 10 of 12 cases in this study belong to the BG and INV type of small firms. A longitudinal approach in the investigation of these firms explores the changes happening after the initial period of BG and INV. It shows that many BG and INV firms have shifted between exploration and consolidation periods after initial internationalization due to the intermittent adaption during internationalization. Thus, the study offers more empiric evidence and insights on the long-term international development of BG and INV. 


\section{A new input from behavioral economics}

This study takes a fresh angle to incorporate knowledge from behavioral economics. The study questions the latent assumption in the dominant internationalization process field by pointing out that context matters. Based on findings on intermittent adaption during internationalization of the small firms, this study further reveals the conditional preference during the internationalization. The adoption of the prospect theory in the study enables a better understanding of the mechanism underlying these dynamic changes in the patterns of the internationalization. Therefore, it enriches the state of the art of internationalization study by offering alternative insights and through exploring a potential explanation for untangled variance in the conditional preference on the risk versus opportunity perceptions.

\subsection{Managerial implications}

For SMEs from countries with very limited domestic markets (e.g. Sweden, Finland, New Zealand and so on), internationalization has been recognized as one of the important ways to further the growth of the firms. However, even with the large diffusion of ICT and the increasing globalization of markets, internationalization of SMEs, especially for small and micro firms, is still challenging due to the relatively large resource poverty of these small firms. The findings and conclusions drawn from this study have implications for entrepreneurs, managers and practitioners working with this issue.

\section{Toolbox for evaluation of resources}

Based on the synthesis of theory, this study developed several analytical and visualization tools (see Figure 2.4, Figure 3.2, and Table 6.4). These figures and table can be used as a toolbox to identify and evaluate mobilizable resources, both internal and external, for the small firms for internationalization. Readers should be aware that the proxies of perceived opportunities and perceived risk (uncertainty) can and should adapt to the small firm's real operating context. Development state, growth potential, competition and regulations of specific industrial segments in different international 
markets are more relevant to gauge potential opportunity and risk. The proxies used in this study were chosen for across-case comparison.

\section{Trade-off during internationalization}

Findings from this study show the important effect from the interplay of influence from the firms' industry and relations with stakeholders (e.g. distributors, public agencies, etc.) and the small firms' own resource constraints on the internationalization of the firm. There is no one-size-fits-all type of answer. How quick in tempo, how wide in scope or to what extent of scale the small firms can be involved in the internationalization depends on an adaptive match between the firms' interest, competence, and the environmental munificence of their industry and task environment. Since internationalization is a resource-demanding process, there will be a trade-off among the speed, scope and scale of engagements.

Due to resource and time limitations, small firms with a wide scope of international markets can hardly use high control modes of entry in every distant market. As a consequence, most small firms can only use the indirect mode of entry (e.g., use agents and distributors). There was very limited influence from the small firms on the performance and commitment of their overseas agents and distributors. Under this mode, the small firms largely depended on local distributors or agents' knowledge, competence and networks. Distributor or agent selection, training and evaluation becomes an important task for small firms. Small firms with large resource constraints need to develop a governance strategy and action plan to keep effective interaction with overseas intermediaries and to influence their commitment. This requires a trade-off between scope and resource commitment in scale. When a small firm covers a wide scope of international markets, it becomes difficult to keep sufficient communication and offer supportive service to all markets. One lesson from the empirical findings of this study is that firms with a large scope of internationalization do not have better overseas market performance compared to firms with moderate scope and better interaction of distributor networks.

Important function of network 


\section{CONCLUDING DISCUSSIONS AND IMPLICATIONS}

Small firms are embedded in different networks. These networks can be an important source of external resources for the small firms. First of all, being part of an international value chain of Swedish or Nordic MNEs is one of the common ways to reach international markets. Relationships with home country MNEs operating in intended host countries can reduce the influence from "psychic distance". This also applies in a reversed direction to establish business relationships with subsidiaries of EM MNEs in low-PD markets. In recent years, there have been some EM-based MNEs, such as Huawei, TATA, which have established in developed markets via M\&A. Connections with MNEs could help small firms gain recognition in their host countries. Furthermore, in addition to industrial networks, other loosely connected networks in the home country are an important external resource pool. For entrepreneurs who lack prior international experience and international networks, different business networks, professional networks, institutional networks and even personal networks are important sources with which to acquire necessary knowledge, exchange information about contacts in foreign markets, and share experience in order to reach intended foreign markets more effectively. For managers and entrepreneurs, besides trade shows, participating in different seminars and networking activities organized by trade-supportive projects and agencies can increase the chance of building up new connections and gaining new knowledge. For example, there is ongoing cooperation between big EMs (e.g., China and India) and Sweden in the clean technology and new energy segments. Institutional connections and networks could offer possibilities for small and micro firms to access some pilot projects and potential partners. As long as small firms can identify and mobilize the necessary resources (e.g., those with international knowledge and networks) from their different networks, it can help small firms' important decisions related to internationalization.

\section{Improve knowledge about foreign markets}

Competition in international markets often requires foreign small firms to be able to adapt their technology and service to local needs. Many manufacturing firms in this study reflect on the importance of continuous product development and improvement in technology performance in terms of stability and adaptability. In order to keep technology development, including products and services, moving in the right direction, small firms need to close the gap between markets and product development. Therefore, for continuing internationalization, small firms need to learn from the foreign markets 
and get better knowledge and feedback from international markets. When small firms only use indirect entry modes, this becomes difficult. Establishing close cooperation and open communication with intermediaries and end clients is an important way to improve knowledge acquisition from foreign local markets.

\section{Institutional influence}

For the SMEs' supportive agency, this study showed that there was institutional influence on the export activities of small firms. Small firms learned from other small firms with successful experience. They imitated other firms' actions and practices in their export activities. They also acted according to exceptions. However, the supportive agents also needed to take industrial traits and the firms' own preference into consideration in order to understand why some small firms were more responsive than others in reaching out for public support. In addition, many firms participating in this study reflected that the most needed support was for finding qualified intermediates and financial support in foreign market establishment. Most of the trade-supportive projects were not designed for these areas.

\subsection{Limitations and further work}

As does all research, this study has its limitations. The following are few limitations which might influence the application of the findings.

\section{Limitations}

Firstly, the study was based on the purposeful sampling of Swedish small and micro firms with EM entry experience. Although the study intended to have a balance of cases selected from different industries, 9 of the 12 final selected cases were from manufacturing.

Secondly, in order to be in focus, cases selected in this study covered outward internationalization. This means that the case firms needed to be engaged in the marketing 
activities of reaching the overseas clients. Inward internationalization was not in the scope. Therefore, even though some of the cases were involved in both inward (import) and outward (export) internationalization, inward internationalization was delimited from the analysis. Furthermore, most of the companies were either knowledge-intensive or technology-orientated firms working in B2B markets.

Thirdly, this longitudinal study focused on the influence from the perceived opportunity versus risk (uncertainty) on the patterns of internationalization. As mentioned earlier, the proxy of perceived opportunity is better to use in a market size at specific industrial segments. However, this proxy was very difficult to obtain. Thus, only one case, MC2, had this proxy at industry level as the second proxy of perceived opportunity.

\section{Further work}

This study focused on interactions between firms' internal and external influence. Based on the literature review, the study identified a few contextual factors internal to the firm and external to the firm's environment (see Figure 2.4). For example, environmental munificence is identified as an overlooked factor in the extant internationalization literature. However, this study could not differentiate the predicted power of those factors. In the further work, some theory testing could be done to test those contextual factors.

Furthermore, a new prospect-guided process model is proposed in this study. Since the model generated is mainly based on evidence from manufacturing sectors (only two service firms and one distributor are from other sectors), more empirical evidence from different industrial sectors is needed to validate the model.

Finally, this study touches upon the institutional influence of the internationalization of the small firms. In the EMs entry context, supportive programs conducted by public agencies at different government levels might be interested in conducting studies in this direction. 


\section{References}

Acedo, F. and Casillas, J. (2007). Age at entry in international markets of spanish smes: Entrepreneurial and institutional determinants. International Journal of Entrepreneurial Behaviour and Research, 13(3):130-150.

Acedo, F. and Galán, J. (2011). Export stimuli revisited: The influence of the characteristics of managerial decision makers on international behaviour. International Small Business Journal, 29(6):648-670.

Acedo, F. and Jones, M. (2007). Speed of internationalization and entrepreneurial cognition: Insights and a comparison between international new ventures, exporters and domestic firms. Journal of World Business, 42(3):236-252.

Agndal, H. and Chetty, S. (2007). The impact of relationships on changes in internationalisation strategies of smes. European Journal of Marketing, 41(11-12):1449-1474.

Agndal, H., Chetty, S., and Wilson, H. (2008). Social capital dynamics and foreign market entry. International Business Review, 17(6):663-675.

Agresti, A. (2007). An Introduction to Categorical Data Analysis. John Wiley Sons, Inc.,, New Jersey, second edition edition.

Alvesson, M. and Karreman, D. (2012). Qualitative Research and Theory Development: Mystery as Method. SAGE Publications Ltd.

Ambos, B. and Håkanson, L. (2014). The Concept of Distance in International Management Research. Journal of International Management, 20(1):1-7.

Andersen, O. (1993). On the internationalization process of firms: A critical analysis. Journal of International Business Studies, 24(2):209-231. 


\section{REFERENCES}

Andersson, S. (2004). Internationalization in different industrial contexts. Journal of Business Venturing, 19(6):851-875.

Andersson, S. (2011). International entrepreneurship, born globals and the theory of effectuation. Journal of Small Business and Enterprise Development, 18(3):627-643.

Andersson, S. and Evangelista, F. (2006). The entrepreneur in the Born Global firm in Australia and Sweden. Journal of Small Business and Enterprise Development, 13(4):642-659.

Andersson, S. and Florén, H. (2011). Differences in managerial behavior between small international and non-international firms. Journal of International Entrepreneurship, 9(3):233-258.

Andersson, S., Gabrielsson, J., and Wictor, I. (2004). International activities in small firms: examining factors influencing the internationalization and export growth of small firms. Canadian Journal of Administrative Sciences/Revue Canadienne des Sciences de l'Administration, 21(1):22-34.

Andersson, S. and Wictor, I. (2003). Innovative internationalisation in new firms: born globals - the Swedish case. Journal of International Entrepreneurship, 1(3):249-275.

Ardichvili, A., Cardozo, R., and Ray, S. (2003). A theory of entrepreneurial opportunity identification and development. Journal of Business Venturing, 18(1):105-123.

Aspelund, A. and Moen, Ø. (2003). Internationalization of small high-tech firms: The role of information technology. Journal of Euromarketing, 13(2-3):85-105.

Autio, E., Sapienza, H. J., and Almeida, J. G. (2000). Effects of age at entry, knowledge intensity, and imitability on international growth. Academy of Management Journal, 43(5):909-924.

Balkow, J. (2012). In the middle: on sourcing from China and the role of the intermediary. $\mathrm{PhD}$ dissertation, Jönköping University, Jönköping, Sweden.

Banalieva, E. and Sarathy, R. (2011). A contingency theory of internationalization: Performance for emerging market multinational enterprises. Management International Review, 51(5):593-634. 
Bell, J., Crick, D., and Young, S. (2004). Small firm internationalization and business strategy: An exploratory study of 'knowledge intensive' and 'traditional' manufacturing firms in the UK. International Small Business Journal, 22(1):23-56.

Bell, J., McNaughton, R., and Young, S. (2001). 'Born-again global' firms: An extension to the 'born global' phenomenon. Journal of International Management, 7(3):173189 .

Bell, J., McNaughton, R., Young, S., and Crick, D. (2003). Towards an integrative model of small firm internationalisation. Journal of International Entrepreneurship, $1(4): 339-362$.

Bilkey, W. J. and Tesar, G. (1977). The export behavior of smaller-sized Wisconsin manufacturing firms. Journal of International Business Studies, 8(1):93-98.

Blomstermo, A., Eriksson, K., Lindstrand, A., and Sharma, D. (2004). The perceived usefulness of network experiential knowledge in the internationalizing firm. Journal of International Management, 10(3):355-373.

Boter, H. and Holmquist, C. (1996). Industry characteristics and internationalization processes in small firms. Journal of Business Venturing, 11(6):471-487.

Brewer, P. (2007). Operationalizing psychic distance: A revised approach. Journal of International Marketing, 15(1):44-66.

Brock, J., Johnson, J., and Zhou, J. (2011). Does distance matter for internationallyoriented small firms? Industrial Marketing Management, 40(3):384-394.

Brouthers, K. D. and Nakos, G. (2004). SME entry mode choice and performance: A transaction cost perspective. Entrepreneurship Theory and Practice, 28(3):229-247.

Buckley, P. J. (1989). Foreign direct investment by small and medium sized enterprises: The theoretical background. Small Business Economics, 1(2):89-100.

Buckley, P. J. and Ghauri, P. N., editors (1999). The Internationalization of the Firm: A Reader. Cengage Learning EMEA, London, 2nd edition.

Calof, J. L. (1994). The relationship between firm size and export behavior revisited. Journal of International Business Studies, 25(2):367-387. 


\section{REFERENCES}

Calof, J. L. and Beamish, P. W. (1995). Adapting to foreign markets: Explaining internationalization. International Business Review, 4(2):115-131.

Canabal, A. and White III, G. O. (2008). Entry mode research: Past and future. International Business Review, 17(3):267-284.

Casillas, J. C. and Acedo, F. J. (2013). Speed in the internationalization process of the firm. International Journal of Management Reviews, 15(1):15-29.

Cassiman, B. and Golovko, E. (2011). Innovation and internationalization through exports. Journal of International Business Studies, 42(1):56-75.

Castrogiovanni, G. J. (1991). Environmental munificence: A theoretical assessment. Academy of Management Review, 16(3):542-565.

Cavusgil, S. T. (1984). Differences among exporting firms based on their degree of internationalization. Journal of Business Research, 12(2):195-208.

Cavusgil, S. T. (1997). Measuring the potential of emerging markets: An indexing approach. Business Horizons, 40(1):87-91.

Cavusgil, S. T., Kiyak, T., and Yeniyurt, S. (2004). Complementary approaches to preliminary foreign market opportunity assessment: country clustering and country ranking. Industrial Marketing Management, 33(7):607-617.

Cesinger, B., Danko, A., and Bouncken, R. (2012). Born globals: (almost) 20 years of research and still not 'grown up'? International Journal of Entrepreneurship and Small Business, 15(2):171-190.

Chandra, Y., Styles, C., and Wilkinson, I. (2009). The recognition of first time international entrepreneurial opportunities: Evidence from firms in knowledge-based industries. International Marketing Review, 26(1):30-61.

Chandra, Y., Styles, C., and Wilkinson, I. (2012). An opportunity-based view of rapid internationalization. Journal of International Marketing, 20(1):74-102.

Chetty, S. and Agndal, H. (2011). Social capital and its influence on changes in internationalization mode among small and medium-sized enterprises. Journal of International Marketing, 15(1):1-29. 
Chetty, S. and Blankenburg Holm, D. (2000). Internationalisation of small to mediumsized manufacturing firms: A network approach. International Business Review, $9(1): 77-93$.

Chetty, S. and Campbell-Hunt, C. (2004). A strategic approach to internationalization: A traditional versus a "born-global" approach. Journal of International Marketing, $12(1): 57-81$.

Child, P. J., Rodrigues, P. S. B., and Frynas, P. J. G. (2009). Psychic Distance, its Impact and Coping Modes. Management International Review, 49(2):199-224.

Coviello, N. E. and McAuley, A. (1999). Internationalisation and the smaller firm: A review of contemporary empirical research. Management International Review, 39(3):223-256.

Coviello, N. E., McDougall, P. P., and Oviatt, B. M. (2011). The emergence, advance and future of international entrepreneurship research - an introduction to the special forum. Journal of Business Venturing, 26(6):625-631.

Coviello, N. E. and Munro, H. (1997). Network relationships and the internationalisation process of small software firms. International Business Review, 6(4):361-386.

Covin, J. G. and Wales, W. J. (2012). The Measurement of Entrepreneurial Orientation. Entrepreneurship Theory and Practice, 36(4):677-702.

Creswell, J. W. (2008). Research Design: Qualitative, Quantitative, and Mixed Methods Approaches. SAGE Publications, Inc, 3rd edition.

Creswell, J. W. (2012). Educational Research: Planning, Conducting, and Evaluating Quantitative and Qualitative Research. Pearson, Boston, MA, 4 edition edition.

Crick, D. (2004). U.K. SMEs' decision to discontinue exporting: An exploratory investigation into practices within the clothing industry. Journal of Business Venturing, $19(4): 561-587$.

Crick, D. (2009). The internationalisation of born global and international new venture SMEs. International Marketing Review, 26(4):453-476.

Cyert, R. M. and March, J. G. (1963). A Behavioral Theory of the Firm. Prentice-Hall. 


\section{REFERENCES}

Dasí, T., Iborra, M., and Safón, V. (2015). Beyond path dependence: Explorative orientation, slack resources, and managerial intentionality to internationalize in SMEs. International Business Review, 24(1):77-88.

Davies, H., Leung, T. K. P., Luk, S. T. K., and Wong, Y.-h. (1995). The benefits of "Guanxi": the value of relationships in developing the chinese market. Industrial Marketing Management, 24(3):207-214.

Davis, G. F. and Powell, W. W. (1995). Organization-environment relations. In Handbook of Industrial and Organizational Psychology, volume 2. Nicholas Brealey Publishing, 2 sub edition.

Davis, K. A. (1992). Validity and reliability in qualitative research on second language acquisition and teaching. another researcher comments. TESOL Quarterly, 26(3):605-608.

Davis, M. S. (1971). That's interesting!: Towards a phenomenology of sociology and a sociology of phenomenology. Philosophy of the Social Sciences, 1(2):309-344.

De Clercq, D., Sapienza, H., and Crijns, H. (2005). The internationalization of small and medium-sized firms. Small Business Economics, 24(4):409-419.

Dess, G. G. and Beard, D. W. (1984). Dimensions of Organizational Task Environments. Administrative Science Quarterly, 29(1):52.

Dess, G. G. and Robinson, R. B. (1984). Measuring organizational performance in the absence of objective measures: The case of the privately-held firm and conglomerate business unit. Strategic Management Journal, 5(3):265-273.

Dill, W. R. (1958). Environment as an influence on managerial autonomy. Administrative Science Quarterly, 2(4):409-443.

Dow, D. (2000). A note on psychological distance and export market selection. Journal of International Marketing, 8(1):51-64.

Dow, D. and Karunaratna, A. (2006). Developing a multidimensional instrument to measure psychic distance stimuli. Journal of International Business Studies, 37(5):578-602. 
Drazin, R. and Van de Ven, A. H. (1985). Alternative Forms of Fit in Contingency Theory. Administrative Science Quarterly, 30(4):514-539.

Dubois, A. and Gadde, L.-E. (2002). Systematic combining: an abductive approach to case research. Journal of Business Research, 55(7):553-560.

Dunning, J. H. (2001). The eclectic (OLI) paradigm of international production: Past, present and future. International Journal of the Economics of Business, 8(2):173190.

Dyer, W. G. and Wilkins, A. L. (1991). Better stories, not better constructs, to generate better theory: A rejoinder to Eisenhardt. The Academy of Management Review, 16(3):613-619.

Eden, L. and Miller, S. R. (2004). Distance matters: Liability of foreignness, institutional distance and ownership strategy. Advances in International Management, $16: 187-221$.

Efrat, K. and Shoham, A. (2011). Environmental characteristics and technological capabilities' interaction in high-technology born global firms. European Journal of International Management, 5(3):271-284.

Eisenhardt, K. M. (1989). Building theories from case study research. Academy of Management Review, 14(4):532-550.

Eisenhardt, K. M. and Graebner, M. E. (2007). Theory building from cases: Opportunities and challenges. Academy of Management Journal, 50(1):25-32.

Ellis, P. (2008). Does psychic distance moderate the market size-entry sequence relationship? Journal of International Business Studies, 39(3):351-369.

Ellis, P. (2011). Social ties and international entrepreneurship: Opportunities and constraints affecting firm internationalization. Journal of International Business Studies, 42(1):99-127.

Eriksson, K., Johanson, J., Majkgård, A., and Sharma, D. (1997). Experiential knowledge and cost in the enternationalization process. Journal of International Business Studies, 28(2):337-360. 
European Commission (2005). The new SME definition - user guide and model declaration. Technical report.

European Commission (2014). SBA fact sheet 2014 - Sweden. Technical report.

Evans, J. and Mavondo, F. (2002). Psychic distance and organizational performance: An empirical examination of international retailing operations. Journal of International Business Studies, 33(3):515-532.

Evers, N. and O'Gorman, C. (2011). Improvised internationalization in new ventures: The role of prior knowledge and networks. Entrepreneurship and Regional Development, 23(7-8):549-574.

Felício, J. A., Caldeirinha, V. R., and Rodrigues, R. (2012). Global mindset and the internationalization of small firms: The importance of the characteristics of entrepreneurs. International Entrepreneurship and Management Journal, 8(4):467-485.

Fernhaber, S. A., McDougall, P. P., and Oviatt, B. M. (2007). Exploring the role of industry structure in new venture internationalization. Entrepreneurship Theory and Practice, 31(4):517-542.

Figueira-de Lemos, F., Johanson, J., and Vahlne, J.-E. (2011). Risk management in the internationalization process of the firm: A note on the Uppsala model. Journal of World Business, 46(2):143-153.

Fletcher, D. (2004). International entrepreneurship and the small business. Entrepreneurship and Regional Development, 16(4):289-305.

Flick, U. (2009). An Introduction to Qualitative Research. Sage Publications, 4th edition.

Ford, D. (2001). Understanding Business Marketing and Purchasing: An Interaction Approach. Cengage Learning EMEA, 3rd edition.

Freeman, S. and Cavusgil, S. T. (2007). Toward a typology of commitment states among managers of born-global firms: A study of accelerated internationalization. Journal of International Marketing, 15(4):1-40.

Freeman, S., Edwards, R., and Schroder, B. (2006). How smaller born-global firms use networks and alliances to overcome constraints to rapid internationalization. Journal of International Marketing, 14(3):33-63. 
Freeman, S., Giroud, A., Kalfadellis, P., and Ghauri, P. (2012). Psychic distance and environment: Impact on increased resource commitment. European Business Review, 24(4):351-373.

Freeman, S., Hutchings, K., Lazaris, M., and Zyngier, S. (2010). A model of rapid knowledge development: The smaller born-global firm. International Business Review, 19(1):70-84.

Freeman, S. and Sandwell, M. (2008). Professional service firms entering emerging markets: the role of network relationships. Journal of Services Marketing, 22(3):198212.

George, E., Chattopadhyay, P., Sitkin, S. B., and Barden, J. (2006). Cognitive underpinnings of institutional persistence and change: A framing perspective. Academy of Management Review, 31(2):347-365.

Ghemawat, P. (2001). Distance still matters. Harvard Business Review, 79(8):137-147.

globalEDGE (2015 (accessed March 3, 2015)). Market potential index (MPI) - 2014.

Golafshani, N. (2003). Understanding reliability and validity in qualitative research. The Qualitative Report, 8(4):597-607.

Guba, E. G. and Lincoln, Y. S. (1982). Epistemological and methodological bases of naturalistic inquiry. Educational Communication and Technology Journal, 30(4):233252.

Hagen, B., Zucchella, A., Cerchiello, P., and Giovanni, N. D. (2012). International strategy and performance - clustering strategic types of SMEs. International Business Review, 21(3):369 - 382 .

Håkanson, L. and Ambos, B. (2010). The antecedents of psychic distance. Journal of International Management, 16(3):195-210.

Håkansson, H. (1982). International marketing and purchasing of industrial goods: an interaction approach. Wiley, New York.

Halkidi, M., Batistakis, Y., and Vazirgiannis, M. (2001). On clustering validation techniques. Journal of Intelligent Information Systems, 17(2):107-145. 


\section{REFERENCES}

Hamilton, L. (2012). Statistics with STATA: Version 12. Cengage Learning EMEA, Boston, MA, 8th edition.

Harris, S. and Wheeler, C. (2005). Entrepreneurs' relationships for internationalization: Functions, origins and strategies. International Business Review, 14(2):187-207.

Hashai, N. (2011). Sequencing the expansion of geographic scope and foreign operations by "born global" firms. Journal of International Business Studies, 42(8):995-1015.

Hessels, J. and Kemna, M. (2008). Internationalization of European SMEs towards emerging markets. Scales Research Reports H200817, EIM Business and Policy Research.

Hilmersson, M. and Jansson, H. (2012). Reducing uncertainty in the emerging market entry process: On the relationship among international experiential knowledge, institutional distance, and uncertainty. Journal of International Marketing, 20(4):96-110.

Hurmerinta-Peltomäki, L. and Nummela, N. (2006). Mixed methods in international business research: A value-added perspective. Management International Review, 46(4):439-459.

Hutzschenreuter, T. and Horstkotte, J. (2013). Performance effects of international expansion processes: The moderating role of top management team experiences. International Business Review, 22(1):259-277.

Ivarsson, I. and Alvstam, C. G. (2013). Embedded internationalization: How smalland medium-sized Swedish companies use business-network relations with Western customers to establish own manufacturing in China. Asian Business $\mathcal{E}$ Management, 12(5):565-589.

Jansson, H. (2009). International Business Marketing in Emerging Country Markets: The Third Wave of Internationalization of Firms. Edward Elgar Publishing.

Javalgi, R. and Todd, P. (2011). Entrepreneurial orientation, management commitment, and human capital: The internationalization of smes in india. Journal of Business Research, 64(9):1004-1010.

Johanson, J. and Mattsson, L.-G. (1987). Interorganizational relations in industrial systems : a network approach compared with the transaction cost approach. Working Paper 1987:7, Uppsala University, Department of Business Studies. 
Johanson, J. and Mattsson, L.-G. (1988). Internationalization in industrial systems - a network approach. In Hood, N. and Vahlne, J.-E., editors, Strategies in global competition: selected papers from the Prince Bertil Symposium at the Institute of International Business, Stockholm School of Economics. Croom Helm Ltd, Stockholm.

Johanson, J. and Vahlne, J.-E. (1977). The internationalization process of the firm-a model of knowledge development and increasing foreign market commitments. Journal of International Business Studies, pages 23-32.

Johanson, J. and Vahlne, J.-E. (2009). The Uppsala internationalization process model revisited: From liability of foreignness to liability of outsidership. Journal of International Business Studies, 40(9):1411-1431.

Johanson, J. and Wiedersheim-Paul, F. (1975). The internationalization of the firm four Swedish cases. Journal of Management Studies, 12(3):305-323.

Jones, M. V. (1999). The internationalization of small high-technology firms. Journal of International Marketing, 7(4):15-41.

Jones, M. V. and Coviello, N. E. (2005). Internationalisation: Conceptualising an entrepreneurial process of behaviour in time. Journal of International Business Studies, $36(3): 284-303$.

Jones, M. V., Coviello, N. E., and Tang, Y. K. (2011). International entrepreneurship research (1989-2009): A domain ontology and thematic analysis. Journal of Business Venturing, 26(6):632-659.

Kahneman, D. and Tversky, A. (1979). Prospect theory: An analysis of decision under risk. Econometrica, 47(2):263.

Kale, S. and Arditi, D. (1998). Business Failures: Liabilities of Newness, Adolescence, and Smallness. Journal of Construction Engineering and Management, 124(6):458464.

Kalinic, I. and Forza, C. (2012). Rapid internationalization of traditional SMEs: Between gradualist models and born globals. International Business Review, 21(4):694707.

Kaplan, R. S. and Mikes, A. (2012). Managing risks: A new framework. Harvard Business Review, 90(6):48-60. 


\section{REFERENCES}

Keupp, M. M. and Gassmann, O. (2009). The past and the future of international entrepreneurship: A review and suggestions for developing the field. Journal of Management, 35(3):600 -633.

Khanna, T. and Palepu, K. G. (2010). Winning in Emerging Markets: A Road Map for Strategy and Execution. Harvard Business Press.

Khanna, T., Palepu, K. G., and Sinha, J. (2005). Strategies that fit emerging markets. Rivals from developing countries are invading your turf. How will you fight back?, page 4 .

Kirzner, I. M. (1978). Competition and entrepreneurship. University of Chicago Press, Chicago.

Kirzner, I. M. (1997). Entrepreneurial discovery and the competitive market process: An Austrian approach. Journal of Economic Literature, 35(1):60-85.

Kirzner, I. M. (1999). Creativity and/or alertness: A reconsideration of the Schumpeterian entrepreneur. The Review of Austrian Economics, 11(1-2):5-17.

Knight, G. and Kim, D. (2009). International business competence and the contemporary firm. Journal of International Business Studies, 40(2):255-273.

Knight, G. A. and Cavusgil, S. T. (1996). The born global firm: a challenge to traditional internationalization theory. Advances in International Marketing, 8:11-26.

Knight, G. A. and Cavusgil, S. T. (2004). Innovation, organizational capabilities, and the born-global firm. Journal of International Business Studies, 35(2):124-141.

Kogut, B. and Singh, H. (1988). The effect of national culture on the choice of entry mode. Journal of International Business Studies, 19(3):411-432.

Komulainen, H., Mainela, T., and Tähtinen, J. (2006). Social networks in the initiation of a high-tech firm's internationalisation. International Journal of Entrepreneurship and Innovation Management, 6(6):526-541.

Kontinen, T. and Ojala, A. (2010). Internationalization pathways of family SMEs: Psychic distance as a focal point. Journal of Small Business and Enterprise Development, 17(3):437-454. 
Kuivalainen, O., Sundqvist, S., Saarenketo, S., and McNaughton, R. (2012). Internationalization patterns of small and medium-sized enterprises. International Marketing Review, 29(5):448-465.

Kyvik, O., Saris, W., Bonet, E., and Felício, J. (2013). The internationalization of small firms: The relationship between the global mindset and firms' internationalization behavior. Journal of International Entrepreneurship, 11(2):172-195.

Langley, A. (1999). Strategies for theorizing from process data. The Academy of Management Review, 24(4):691-710.

Laufs, K. and Schwens, C. (2014). Foreign market entry mode choice of small and medium-sized enterprises: A systematic review and future research agenda. International Business Review, 23(6):1109-1126.

Leonidou, L. C. (2004). An analysis of the barriers hindering small business export development. Journal of Small Business Management, 42(3):279-302.

Levine, S. and White, P. E. (1961). Exchange as a conceptual framework for the study of interorganizational relationships. Administrative Science Quarterly, 5(4):583-601.

Li, W. and Hoyer-Ellefsen, R. (2008). Characteristics of emerging markets. SSRN Scholarly Paper ID 909890, Social Science Research Network, Rochester, NY.

Lichtman, M. (2012). Qualitative research in education: A user's guide. Sage.

Liesch, P., Welch, L., and Buckley, P. (2011). Risk and uncertainty in internationalisation and international entrepreneurship studies: Review and conceptual development. Management International Review, 51(6):851-873.

Lincoln, Y. S. and Guba, E. G. (1986). But is it rigorous? Trustworthiness and authenticity in naturalistic evaluation. New Directions for Program Evaluation, 1986(30):73-84.

Loane, S. (2005). The role of the internet in the internationalisation of small and medium sized companies. Journal of International Entrepreneurship, 3(4):263-277.

Long, J. S. (2014). Regression models for nominal and ordinal outcomes. In Best, H. and Wolf, C., editors, The SAGE Handbook of Regression Analysis and Causal Inference. SAGE Publications, Los Angeles, CA. 


\section{REFERENCES}

Lu, J. and Beamish, P. (2001). The internationalization and performance of SMEs. Strategic Management Journal, 22(6-7):565-586.

Luo, Y. (2011). Strategic responses to perceived corruption in an emerging market: Lessons from MNEs investing in China. Business 83 Society, 50(2):350 -387.

Madsen, T. (2013). Early and rapidly internationalizing ventures: Similarities and differences between classifications based on the original international new venture and born global literatures. Journal of International Entrepreneurship, 11(1):65-79.

Madsen, T. and Servais, P. (1997). The internationalization of born globals: An evolutionary process? International Business Review, 6(6):561-583.

Majocchi, A., Bacchiocchi, E., and Mayrhofer, U. (2005). Firm size, business experience and export intensity in SMEs: a longitudinal approach to complex relationships. International Business Review, 14(6):719-738.

Matanda, M. and Ndubisi, N. (2011). A comparison of interfirm relational capabilities in internationalising small-business enterprises (SBEs) and large firms in a developing country. International Journal of Entrepreneurship and Innovation Management, 13(3-4):296-313.

McAuley, A. (1999). Entrepreneurial instant exporters in the Scottish arts and crafts sector. Journal of International Marketing, 7(4):67-82.

McAuley, A. (2010). Looking back, going forward: reflecting on research into the SME internationalisation process. Journal of Research in Marketing and Entrepreneurship, $12(1): 21-41$.

McCullagh, P. (1980). Regression models for ordinal data. Journal of the Royal Statistical Society, Series B (Methodological), 42(2):109-142.

McDougall, P. P. and Oviatt, B. M. (2000). International entrepreneurship: The intersection of two research paths. The Academy of Management Journal, 43(5):902-906.

McDougall, P. P., Shane, S., and Oviatt, B. M. (1994). Explaining the formation of international new ventures: The limits of theories from international business research. Journal of Business Venturing, 9(6):469-487.

McFarland, D. A. (2012). Organizational analysis. [Lecture notes]. 
Melén, S. (2009). New insights on the internationalisation process of SMEs: a study of foreign market knowledge develpment. PhD dissertation, Economic Research Institute, Stockholm School of Economics, Stockholm, Sweden.

Melén, S. and Nordman, E. R. (2009). The internationalisation modes of Born Globals: A longitudinal study. European Management Journal, 27(4):243-254.

Melin, L. (1992). Internationalization as a strategy process. Strategic Management Journal, 13(S2):99-118.

Miles, M. B. and Huberman, A. M. (1994). Qualitative Data Analysis: An Expanded Sourcebook. SAGE Publications.

Miller, D. (1981). Toward a new contingency approach: The search for organizational gestalts. Journal of Management Studies, 18(1):1-26.

Mintzberg, H. and Waters, J. A. (1982). Tracking strategy in an entrepreneurial firm. The Academy of Management Journal, 25(3):465-499.

Mintzberg, H. and Waters, J. A. (1985). Of strategies, deliberate and emergent. Strategic Management Journal, 6(3):257-272.

Mishler, E. (1990). Validation in inquiry-guided research: The role of exemplars in narrative studies. Harvard educational review, 60(4):415-443.

Mittelstaedt, J., Harben, G., and Ward, W. (2003). How small is too small? firm size as a barrier to exporting from the united states. Journal of Small Business Management, 41(1):68-84.

Moen, Ø. (2002). The born globals a new generation of small European exporters. International Marketing Review, 19(2):156-175.

Moen, Ø. and Servais, P. (2002). Born global or gradual global? Examining the export behavior of small and medium-sized enterprises. Journal of International Marketing, 10(3):49-72.

Morgan, G. (2006). Images of organization. Sage Publications, Thousand Oaks, CA.

Morgan, G. and Smircich, L. (1980). The case for qualitative research. The Academy of Management Review, 5(4):491. 


\section{REFERENCES}

Mort, G. and Weerawardena, J. (2006). Networking capability and international entrepreneurship: How networks function in Australian born global firms. International Marketing Review, 23(5):549-572.

Nagelkerke, N. J. (1991). A note on a general definition of the coefficient of determination. Biometrika, 78(3):691-692.

Naldi, L. (2008). Growth through Internationalization : A Knowledge Perspective on SMEs. PhD dissertation, Jönköping International Business School, Jönköping, Sweden.

Nebus, J. and Chai, K. H. (2014). Putting the "psychic" back in psychic distance: Awareness, perceptions, and understanding as dimensions of psychic distance. Journal of International Management, 20(1):8-24.

Nielsen, S. (2010). Top management team internationalization and firm performance. Management International Review, 50(2):185-206.

Nordström, K. A. (1991). The internationalization process of the firm: searching for new patterns and explanations. $\mathrm{PhD}$ dissertation, Institute of International Business, Stockholm School of Economics, Stockholm, Sweden.

Norušis, M. (2011a). IBM SPSS Statistics 19 Advanced Statistical Procedures Companion. Addison Wesley, Upper Saddle River, New Jersey, 1 edition edition.

Norušis, M. (2011b). IBM SPSS Statistics 19 Statistical Procedures Companion. Addison Wesley, Upper Saddle River, New Jersey, 1 edition edition.

Ocasio, W. (1997). Towards an attention-based view of the firm. Strategic Management Journal, 18(Summer Special Issue):187-206.

Ojala, A. (2008). Entry in a psychically distant market:. finnish small and medium-sized software firms in japan. European Management Journal, 26(2):135-144.

Ojala, A. and Tyrväinen, P. (2008). Market entry decisions of US small and mediumsized software firms. Management Decision, 46(2):187-200.

Oviatt, B. M. and McDougall, P. P. (1994). Toward a theory of international new ventures. Journal of International Business Studies, 25(1):45-64. 
Oviatt, B. M. and McDougall, P. P. (1997). Challenges for internationalization process theory: The case of international new ventures. MIR: Management International Review, 37(Internationalization Processes - New Perspectives for a Classical Field of International Management):85-99.

Oviatt, B. M. and McDougall, P. P. (2005). Defining international entrepreneurship and modeling the speed of internationalization. Entrepreneurship Theory and Practice, 29(5):537-554.

Pangarkar, N. (2008). Internationalization and performance of small- and medium-sized enterprises. Journal of World Business, 43(4):475-485.

Papadopoulos, N. and Martín Martín, O. (2010). Toward a model of the relationship between internationalization and export performance. International Business Review, 19(4):388-406.

Patton, M. Q. (2002). Qualitative Research 8 Evaluation Methods. SAGE Publications, Thousand Oaks, CA, 3rd edition.

Pauwels, P. and Matthyssens, P. (1999). A strategy process perspective on export withdrawal. Journal of International Marketing, 7(3):10-37.

Peng, M. W., Wang, D. Y. L., and Jiang, Y. (2008). An institution-based view of international business strategy: a focus on emerging economies. Journal of International Business Studies, 39(5):920-936.

Penrose, E. (1995). The Theory of the Growth of the Firm. Oxford University Press Inc., NY.

Pentland, B. T. (1999). Building process theory with narrative: From description to explanation. Academy of Management Review, 24(4):711-724.

Pettigrew, A. M. (1997). What is a processual analysis? Scandinavian Journal of Management, 13(4):337-348.

Pfeffer, J. (1982). Organizations and organization theory. Pitman.

Pfeffer, J. and Salancik, G. R. (2003). The external control of organizations: a resource dependence perspective. Stanford Business Books, Stanford, CA. 


\section{REFERENCES}

Phillips, N., Tracey, P., and Karra, N. (2009). Rethinking institutional distance: strengthening the tie between new institutional theory and international management. Strategic Organization, 7(3):339-348.

Phillips, R., Freeman, R. E., and Wicks, A. C. (2003). What Stakeholder Theory Is Not. Business Ethics Quarterly, 13(4):479-502.

Pinho, J. and Martins, L. (2010). Exporting barriers: Insights from portuguese small- and medium-sized exporters and non-exporters. Journal of International Entrepreneurship, 8(3):254-272.

Pitelis, C. N. (2004). Edith penrose and the resource-based view of (international) business strategy. International Business Review, 13(4):523-532.

Rasmussen, E. S. and Madsen, T. K. (2002). The born global concept. In Paper for the EIBA conference.

Reid, S. D. (1983). Managerial and firm influences on export behavior. Journal of the Academy of Marketing Science, 11(3):323-332.

Rennie, M. W. (1993). Global Competitiveness: Born Global. The McKinsey Quarterly, $4: 45-52$.

Reynolds, P. and Miller, B. (1992). New firm gestation: Conception, birth, and implications for research. Journal of Business Venturing, 7(5):405 - 417.

Rialp, A. and Rialp, J. (2001). Conceptual frameworks on smes' internationalization: Past, present and future trends of research. Advances in International Marketing, 11:49-78.

Rialp, A., Rialp, J., and Knight, G. A. (2005). The phenomenon of early internationalizing firms: what do we know after a decade (1993-2003) of scientific inquiry? International Business Review, 14(2):147-166.

Rogers, E. M. (2003). Diffusion of Innovations, 5th Edition. Simon and Schuster, New York.

Roininen, S. and Ylinenpää, H. (2009). Schumpeterian versus Kirznerian entrepreneurship: A comparison of academic and nonacademic new venturing. Journal of Small Business and Enterprise Development, 16(3):504-520. 
Rothaermel, F. T. (2006). International Market Entry by U.S. Internet Firms: An Empirical Analysis of Country Risk, National Culture, and Market Size. Journal of Management, 32(1):56-82.

Ruokonen, M. (2007). Market orientation and product strategies in small internationalising software companies. Journal of High Technology Management Research, $18(2): 143-156$.

Ruzzier, M., Hisrich, R., and Antoncic, B. (2006). SME internationalization research: Past, present, and future. Journal of Small Business and Enterprise Development, $13(4): 476-497$.

Sakarya, S., Eckman, M., and Hyllegard, K. H. (2007). Market selection for international expansion: Assessing opportunities in emerging markets. International Marketing Review, 24(2):208-238.

Sallis, J. E. and Deo Sharma, D. (2009). Knowledge seeking in going abroad. Thunderbird International Business Review, 51(5):441-456.

Sandberg, S. (2012). Internationalization processes of small and medium-sized enterprises: Entering and taking off from emerging markets. $\mathrm{PhD}$ dissertation, Linnaeus University, Kalmar.

Sandulli, F., Fernández-Menéndez, J., Rodríguez-Duarte, A., and López-Sánchez, J. (2012). The productivity payoff of information technology in multimarket SMEs. Small Business Economics, 39(1):99-117.

Sarasvathy, S. D. (2001). What makes entrepreneurs entrepreneurial? Darden Business Publishing eLibrary, pages 1-9.

Sarasvathy, S. D. (2008). Effectuation: Elements of Entrepreneurial Expertise. Edward Elgar Publishing, Cheltenham, UK.

Schweizer, R. (2013). SMEs and networks: Overcoming the liability of outsidership. Journal of International Entrepreneurship, 11(1):80-103.

Schweizer, R., Vahlne, J.-E., and Johanson, J. (2010). Internationalization as an entrepreneurial process. Journal of International Entrepreneurship, 8(4):343-370. 
Scott, W. R. (2002). Organizations: Rational, Natural, and Open Systems. Prentice Hall, 5 edition.

Scott, W. R. and Davis, G. F. (2006). Organizations and Organizing: Rational, Natural and Open Systems Perspectives. Pearson, 1 edition.

Sharma, V. M. and Erramilli, M. K. (2004). Resource-Based Explanation of Entry Mode Choice. 12(1):1-18.

Sheng, S. Y. and Mullen, M. R. (2011). A hybrid model for export market opportunity analysis. International Marketing Review, 28(2):163-182.

Shih, M.-Y., Jheng, J.-W., and Lai, L.-F. (2010). A two-step method for clustering mixed categroical and numeric data. Tamkang Journal of Science and Engineering, 13(1):11-19.

Shuman, J. C. and Seeger, J. A. (1986). The theory and practice of strategic management in smaller rapid growth firms. American Journal of Small Business, 11(1):7-18.

Sinha, P., Wang, M., Scott-Kennel, J., and Gibb, J. (2015). Paradoxes of psychic distance and market entry by software INVs. European Business Review, 27(1):3459.

Sinkovics, R. R., Penz, E., and Ghauri, P. N. (2009). Enhancing the trustworthiness of qualitative research in international business. Management International Review, 48(6):689-714.

Slotte-Kock, S. and Coviello, N. (2010). Entrepreneurship research on network processes: A review and ways forward. Entrepreneurship Theory and Practice, 34(1):3157 .

Staw, B. M., Sandelands, L. E., and Dutton, J. E. (1981). Threat Rigidity Effects in Organizational Behavior: A Multilevel Analysis. Administrative Science Quarterly, 26(4):501.

Storey, D. J. and Greene, F. J. (2010). Small Business And Entrepreneurship. Pearson Education Ltd., Essex, UK.

Tillväxtverket (2014). Företagens villkor och verklighet 2014. Technical Report Info 0563, Tillväxtverket (The Swedish Agency for Economic and Regional Growth), Stockholm, Sweden. 
Trudgen, R. and Freeman, S. (2014). Measuring the Performance of Born-Global Firms Throughout Their Development Process: The Roles of Initial Market Selection and Internationalisation Speed. Management International Review, 54(4):551-579.

Tversky, A. and Kahneman, D. (1992). Advances in prospect theory: Cumulative representation of uncertainty. Journal of Risk and Uncertainty, 5(4):297-323.

Van de Ven, A. H. (2007). Engaged Scholarship: A Guide for organizationak and Social Research. Oxford University Press, Oxford.

Venkatraman, N. (1989). The Concept of Fit in Strategy Research: Toward Verbal and Statistical Correspondence. The Academy of Management Review, 14(3):423-444.

Vissak, T. (2003). The Internationalization of Foreign-Owned Enterprises in Estonia: An Extended Network Perspective. PhD dissertation, the University of Tartu, Tartu, Estonia.

Welch, C. and Paavilainen-Mäntymäki, E. (2014). Putting process (back) in: Research on the internationalization process of the firm. International Journal of Management Reviews, 16(1):2-23.

Welch, C. and Welch, L. (2009). Re-internationalisation: Exploration and conceptualisation. International Business Review, 18(6):567-577.

Welch, L. S. and Luostarinen, R. (1988). Internationalization: Evolution of a concept. Journal of General Management, 14(2):36-64.

Westhead, P., Wright, M., and Ucbasaran, D. (2001). The internationalization of new and small firms: A resource-based view. Journal of Business Venturing, 16(4):333358.

Westhead, P., Wright, M., and Ucbasaran, D. (2004). Internationalization of private firms: Environmental turbulence and organizational strategies and resources. Entrepreneurship and Regional Development, 16(6):501-522.

WTO (2012). World trade report 2012. Technical report, WTO.

Xin, K. R. and Pearce, J. L. (1996). Guanxi: Connections as substitutes for formal institutional support. The Academy of Management Journal, 39(6):1641-1658. 


\section{REFERENCES}

Yin, R. K. (2009). Case Study Research: Design and Methods. SAGE Publications, Inc, Thousand Oaks, CA, 4th edition.

Zaheer, S., Schomaker, M. S., and Nachum, L. (2012). Distance without direction: Restoring credibility to a much-loved construct. Journal of International Business Studies, 43(1):18-27.

Zahra, S. A. (2005). A theory of international new ventures: A decade of research. Journal of International Business Studies, 36(1):20-28.

Zahra, S. A. and Covin, J. G. (1993). Business strategy, technology policy and firm performance. Strategic Management Journal, 14(6):451-478.

Zahra, S. A. and Garvis, D. M. (2000). International corporate entrepreneurship and firm performance: The moderating effect of international environmental hostility. Journal of Business Venturing, 15(5-6):469-492.

Zhang, Y. (2012). Report on business opportunities in China for SMEs in the BENCH regions (Sweden). Technical report.

Zhou, L., Wu, W.-P., and Luo, X. (2007). Internationalization and the performance of born-global smes: The mediating role of social networks. Journal of International Business Studies, 38(4):673-690. 

Appendix A. Pre-study 


\section{A-1 Pre-study of the gap in China business involvement among Swedish SMEs in Östergötland}

This chapter presents a pre-study of the main study of this thesis. The chapter intends to probe elements discussed in the introduction chapter. Through establishing a tentative prediction model, the pre-study identifies and examines potential influential indicators, which might explain the gap of Swedish SMEs' involvement and preference in the EM (China business).

\section{$.1 \quad$ Introduction}

Knowledge on the internationalization of SMEs has grown in recent decades. Compared with large multinational companies, SMEs have limited human and financial resources. It is especially challenging for SMEs when they start to reach out to geographically, culturally and institutionally distant markets. In recent decades, researchers have offered insightful explanations about how SMEs can overcome these resource constraints (see Introduction chapter). However, existing research has not yet reached a consensus on the few common factors, such as the firm size (Calof, 1994) and the industrial sectors, which impact firms' actions and preference regarding internationalization. For instance, empirical studies on the internationalization of SMEs have a large variance in 


\section{A-1 PRE-STUDY OF THE GAP IN CHINA BUSINESS INVOLVEMENT AMONG SWEDISH SMES IN ÖSTERGÖTLAND}

the size of the SMEs, from no more than 250 employees (European definition) to 500 or even 1000 employees (US definition). Empirical studies on the relationship between firm size and its international business involvement, especially in the export field, often show some contradictory results (Majocchi et al., 2005). The influence from the size of firms on their preference in the international markets, especially those far distant markets, is still unclear.

Besides the employment dimension of size, annual turnover of SMEs is also used as one of two major criteria in their definition. The thresholds of these criteria have been adjusted a few times (European Commission, 2005). The current EU definition sets turnover of 2 million EUR, 10 million EUR, and 50 million EUR as three thresholds. Based on the best knowledge of the author, in large sample-based empirical studies on the internationalization of SMEs, the most current studies only use size, referring to the number of employees to define SMEs. Very few studies take annual turnover criteria into consideration. This might be attributed to the availability of the data. As a result, whether the indicator of financial resources has an influential role in indicating SMEs' involvement in distant international markets is still undetermined.

Internationalization has been closely associated with higher cost caused by the "liability of foreignness" (Liesch et al., 2011), especially when firms approach those emerging markets which have more or less incomplete market infrastructures (Khanna and Palepu, 2010) and some institutional constraints, such as changing policy, less transparency and corruption (Luo, 2011). Financial constraints of the SMEs often drive these firms to focus more on short and medium-term survival (Storey and Greene, 2010). This creates additional liability due to smallness, which makes small firms' internationalization even more challenging.

In addition, current research offers rather limited empirical evidence on the management performance (in financial terms) of the decision of internationalization in the emerging market context. It is still unclear regarding the role of efficiency in deploying assets in SMEs' decisions to do business with big emerging markets like China. Further, not only can the liability of foreignness and smallness cause problems; some young firms with limited managerial experience can be vulnerable to business failure as well (Kale 


\section{. A-1 PRE-STUDY OF THE GAP IN CHINA BUSINESS INVOLVEMENT AMONG SWEDISH SMES IN ÖSTERGÖTLAND}

and Arditi, 1998). Both management experience and performance might influence the internationalization decisions of small firms.

Finally, empirical data from the WTO showed a large difference between the export of goods and service. For example, based on data from the WTO Secretariat for merchandise and the WTO and the UNCTAD Secretariats for commercial services (WTO, 2012 ), Swedish export of goods was about 2.5 times the export of services in 2011. A few studies with focus on internationalization in the service sector have placed more attention on the ICT and professional service sectors. More empirical studies on the difference in internationalization among industries are needed (Freeman and Sandwell, 2008). Therefore, whether SMEs from different industrial sectors have a significant difference in the emerging market involvement is an interesting question to probe.

The aim of pre-study is to probe for factors which might likely influence the attitudes and actions of SMEs' China business involvement. The results of the pre-study are used as inputs for the subsequent case study. The pre-study also offers a sample pool for the case selection.

Accordingly, the purpose of the pre-study is to investigate Swedish SMEs from different industrial sectors regarding their different attitudes on emerging market (e.g. China) involvement. If there is a systematic difference, could factors discussed above (e.g., "smallness" of the firm in terms of size and recent annual turnover, the "nascence" of the firm in terms of age or the managerial efficiency of the firm in terms of deploying its assets) cause these differences? Therefore, the following specific research questions are addressed in the pre-study:

- Are the industrial sector groups of Swedish SMEs equally likely to have an interest in or be actively involved in business with China?

- If differences exist, how could these differences be explained by additional factors related to demographic features of Swedish SMEs and their financial performance? 


\section{.2 Conceptual model and operationalization}

This pre-study investigates factors that could have a strong impact on the primary decision of emerging market entry for small firms. As discussed in an earlier section, small firms often face large human and financial resource constraints when they are involved in international business (Buckley and Ghauri, 1999). In the emerging market entry context, the perceived additional institutional risk (Phillips et al., 2009) might even make small firms steer away from emerging markets. On the other hand, extant studies (Fernhaber et al., 2007; Andersson, 2004; Boter and Holmquist, 1996) show that the industry in which small firms operate also matters for the foreign market entry decision. Therefore, the pre-study proposes a conceptual model (see Figure 2), including two basic constructs, which influence small firms' primary decision on emerging market entry. The first construct is the firm's resource, while the second construct is the industrial category.

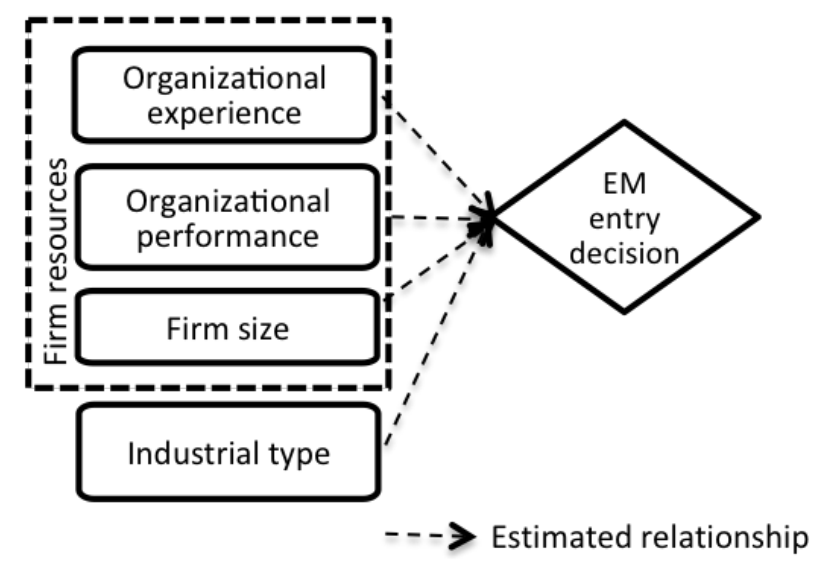

Figure 2: Conceptual framework of a primary decision of emerging market entry

The pre-study measures the firm's resources from three dimensions: organizational experience, organizational performance, and firm size. The study uses age of the firm as an indicator of organizational experience as a limited company, and uses return on the total asset (ROA) as an indicator of firms' organizational efficiency. ROA is one of key organizational performance indicators showing the efficacy of a firm in using its assets 
for profits (Dess and Robinson, 1984). ROA is a useful indicator in assessing firms in the same industry. Therefore, the study uses the second construct, industrial category, to investigate the inter-industry difference on firms' emerging market decision. The response variable is measured by firms' primary response on the China market entry.

\section{$.3 \quad$ Method}

Due to the nature of the research questions in the pre-study, quantitative research methods were adopted in the data collection and analysis. The main data was collected in the autumn of 2010 via a web questionnaire. The survey was a qualitative survey within the BENCH project framework (see Section 4.5.1). The intention of the survey was to get qualitative data regarding the current situation of China business involvement of Swedish SMEs in Östergötland at that time. Data from the survey responses was further complemented by the other indicators and information gathered from public databases for the analysis.

\section{.3 .1 Sample}

The data used in the pre-study was mainly from a survey in autumn 2010 on firms' China business involvement. The Chinese market was chosen as the emerging market of focus, as explained in the Methodology chapter. A sample of Swedish SMEs was chosen from the county of Östergötland, located in the southeastern part of Sweden. Based on data from Statistics Sweden ${ }^{41}$, from 2007 to 2010, the regional accounts of this county were at an average level compared with 21 other counties, excluding the top three counties in Sweden. Therefore, the pre-study assumed this county could represent common traits of other Swedish counties as well. The proportion of SME population in this county shares similar traits with other counties in Sweden.

Sampling criteria were mainly based on EU guidelines. The author of this thesis used two major sources to set up a sample framework for the survey. The main source was from a pubic database called Affärsdata, which includes all registered firms in Sweden.

\footnotetext{
${ }^{41}$ www.scb.se
} 


\section{A-1 PRE-STUDY OF THE GAP IN CHINA BUSINESS INVOLVEMENT AMONG SWEDISH SMES IN ÖSTERGÖTLAND}

From this source, around 2,000 SMEs with more than 6 and less than 250 employees were selected. Contact information was gathered from the internet, homepages of companies and so on. The second source was from a database of an anonymous survey on the internationalization theme conducted in the same county in 2008 by a local governmental organization. This source covered about 300 respondents, regardless of the size of companies. The names of the responding companies were anonymous. However, the emails of the respondents and survey responses were used as a part of database for the pre-study.

\section{.3 .2 Survey}

The survey used a web-based questionnaire. Potential respondents received the survey via an introduction email with a link to the survey. The survey questions were qualitative in nature. In addition to a few basic questions regarding the profile of the companies, the survey consisted of three level "Yes" or "No" questions with open questions attached to each level of responses. It is important to clarify that the survey was co-designed by a joint effort from BENCH project partners from three countries. Although the author of this thesis contributed to the design and was responsible for implementing the survey in Sweden, this pre-study only used one part of the answers from the survey, which were answers in two levels of "Yes" or "No" questions for analysis. Answers from open questions were not included in the analysis in this pre-study.

After testing the survey on three local SMEs, the survey was sent to 2,046 emails. Due to errors in some email addresses, in the end the survey reached 1,605 valid email addresses. Along with the email, a formal survey invitation letter addressed by all BENCH project partners in Sweden was attached to encourage managing directors or other top managers of the SMEs to answer the survey. After two rounds of following up with reminders, 293 respondents answered the questionnaires. The response rate was around $18 \%(293 / 1605=18.26 \%)$. The profile of the respondents was rechecked through the public database Retriever Business before further analysis. 280 valid responses remained after excluding duplication, firms without $\mathrm{F}$-taxation registration ${ }^{42}$ and firms with more than 250 employees or with no employees.

\footnotetext{
${ }^{42}$ In order to register for Ftaxation with the Swedish Tax Agency, an entrepreneur must be carrying on or intending to carry on business activity.
} 


\section{.3 .3 Analytic strategy}

The response variable of the China business involvement can be treated as three ordered categories (e.g., No; No but have interest; Yes). Therefore, the pattern of the gap in the China business involvement is most suitable for using the ordinal logistic regression analysis.

The prediction variable includes one categorical variable: the industrial sector with six categories and four continuous variables. The prediction variable covers demographic traits of SMEs such as age and size (number of employees), and two economic performance indicators: the last four years' (2007-2010) average turnover and return on the total assets (ROA).

Descriptive statistics and visualization of data were performed first in order to get an overview of the data. An additional two new categorical variables - size and turnover based on the SMEs EU threshold - were computed for visualization purposes. These two variables were categorized based on guidelines of the EU standard as seen in Table 1.

Table 1: Thresholds of SMEs

\begin{tabular}{|c|c|c|}
\hline & Size & Turnover \\
\hline Medium & $50-250$ & no more than Euro 50 million \\
\hline Small & $10-49$ & no more than Euro 10 million \\
\hline Micro & less than 10 & no more than Euro 2 million \\
\hline
\end{tabular}

The analysis used a backward approach to reach model parsimony. It started from a full contextual model, in which all predictors were estimated. Based on the results of the statistical tests in this model, insignificant predictors were dropped from the model afterwards. The new refined model included only the main effect of the remaining individual predictors. After examining the main effect of individual predictors, an interaction effect among remaining predictors was examined for searching for an adequate model. An interpretation of the meaning of the coefficient in the final selected model was given in the end. The analysis used IBM SPSS version 22. The whole analysis was repeated again in STATA version 13 to compare the results. 


\section{.3.4 Basic model}

Ordinal model: The ordinal model used in the analysis is represented by the ordered logit model, also known as the proportional odds model (McCullagh, 1980; Agresti, 2007). Probability that $\mathrm{Y}$ falls at or below $j$ equals $P(Y \leqslant j)=\pi_{1}+\ldots \pi_{j}, j=1 \ldots j$

$$
\operatorname{logit}[P(Y \leq j)]=\log \left[\frac{P(Y \leq j)}{1-P(Y \leq j)}\right], j=1, \ldots, J-1
$$

In this pre-study, $\mathrm{J}=3$. Therefore, the model uses both $\operatorname{logit}[P(Y \leq 1)]=\log \left[\frac{\pi_{1}}{\pi_{2}+\pi_{3}}\right]$ and $\operatorname{logit}[P(Y \leq 2)]=\log \left[\frac{\pi_{1}+\pi_{2}}{\pi_{3}}\right]$.

$\pi_{1}$ is the probability that respond variable $\mathrm{Y}=1$; the lowest ordered category.

\section{Define the events and response variable in the pre-study:}

In the pre-study, the response variable $\mathrm{Y}$ is the SMEs' responses from the survey on their experience and attitude of China business involvement. It is an ordinal variable reflecting three orders. Responses with no interesting in getting involved in any type of business with China are coded as score of $0(0=$ no). When respondents have no experience in doing business with China but have interesting in getting involved in business with China, it is coded as score of 1 ( $1=$ no but have interesting); When respondents have or had involved in China business, it is coded as score of 2 ( $2=$ Yes).

Therefore, in this study, odds at different levels could be expressed as the following:

Odds at the first level:

$$
\frac{P_{1}}{1-P_{1}}=\frac{\text { probability }(\text { Yscore }=0)}{\text { probability }(\text { Yscore }=1)+\text { probability }(\text { Yscore }=2)}
$$

Odds at the second level:

$$
\frac{P_{2}}{1-P_{2}}=\frac{\text { probability }(\text { Yscore }=0)+\text { probability }(\text { Yscore }=1)}{\text { probability }(\text { Yscore }=2)}
$$


The logit equations in the pre-study would be:

$$
\operatorname{logit}[P(\hat{Y} \leq j)]=\hat{\beta}_{0 j}+\hat{\beta}_{1} X_{1}+\hat{\beta}_{2} X_{2}+\ldots+\hat{\beta}_{i} X_{i}
$$

\section{Define the predictors $\mathrm{X}$ in the pre-study:}

Age of the SMEs: This independent variable represents the total number of years since firms had registered in F-taxation till the survey year 2010. The data source is from the public data base Retriever Business.

Size of the SMEs: This independent variable represents the number of employees in the SMEs. The data source is from the self reported information during survey. The number was compared with information registered in the Retriever Business. Although there are some variance, the self-reported number are more close to the real situation. Therefore, this study choose self reported employee numbers.

Annual turnover of the SMEs: This independent variable represents average four years (2007 to 2010) annual turnover of SMEs. When companies have less than four year history, the study uses the actual annual turnover. Data source of this variable are from the public data base Retriever Business.

Annual return on total assets (ROA) of the SMEs: This independent variable represents average four years (2007 to 2010) annual ROA of SMEs. When companies have less than four year history, the study uses the actual annual ROA. Data source of this variable are from the public data base Retriever Business.

Industrial sector of the SMEs: This nominal independent variable has 6 categories $^{43}$ : wholesale and retail coded as IndSector $=1$; Manufacturing coded as IndSector $=2$; Professional service (P-service) coded as IndSector $=3$; ICT coded as IndSector $=4$; Other general service (G-service) coded as IndSector $=5$; Construction coded as IndSector $=6$. The source of this variable are based on a combination of two sources. One is from firms' self reported main business field in the survey. This information is verified by their registration records from the public database Retriever Business.

\footnotetext{
${ }^{43}$ The industrial sector is also coded as 5 dummy variables to repeat same procedure in STATA 13 for verification.
} 


\section{.4 Results}

\section{.4.1 Sample descriptive}

Table 2 shows a summary of four numerical predictors and while Table 3 shows a summary of the categorical predictor in the first model. The valid cases of Age and Size of SMEs are 262, while other two numerical predictors (e.g., latest 4-year annual turnover and latest 4 year annual ROA) are 240 . The valid cases of categorical predictor (industrial sector) are 280.

Table 2: Sample Description of Four numerical Predictors

Descriptive Statistics of Four Numerical Variables (predictors)

\begin{tabular}{|l|r|r|r|r|r|r|}
\hline & $\mathrm{N}$ & Minimum & Maximum & \multicolumn{2}{|c|}{ Mean } & \multicolumn{1}{c|}{$\begin{array}{c}\text { Std. } \\
\text { Deviation }\end{array}$} \\
\cline { 2 - 7 } & Statistic & Statistic & Statistic & Statistic & Std. Error & \multicolumn{1}{c|}{ Statistic } \\
\hline AgeF (2010) & 262 & 0 & 18 & 11.69 & .328 & 5.312 \\
SizeFT & 262 & 1 & 250 & 23.48 & 2.395 & 38.763 \\
$07-10$ & 240 & .00 & 831027.00 & 46542.4274 & 6633.99636 & 102773.429 \\
aveturnover(t & & & & & & 71 \\
kr) & 240 & -162.50 & 72.62 & 7.1506 & 1.27773 & 19.79456 \\
07-10 & 239 & & & & & \\
aveROA(\%) & & & & & \\
Valid N & (listwise) & & & & & \\
\hline
\end{tabular}

\section{Observed gap among groups}

The Figure 3 shows observed gaps among different industrial groups, based on their involvement of China business. From Figure 3, one could see that there are a large gap between industrial sectors. Responses from construction sector has the least involvement $(0 \%)$ in the China business. Comparing to SMEs from other industrial sectors, wholesale and retail, and manufacturing have highest involvement (more than $50 \%$ in their sectors). Table 3 also shows proportions in detail regarding to the observed difference in China business involvement among different industries. Pearson chi-square test shows that there is a very strong evidence of a relationship between industrial sectors and firms' experience and attitude on China business involvement 


\section{A-1 PRE-STUDY OF THE GAP IN CHINA BUSINESS INVOLVEMENT AMONG SWEDISH SMES IN ÖSTERGÖTLAND}

Table 3: Description of the Response Variable related to the Categorical predictors

\begin{tabular}{|c|c|c|c|c|c|c|c|c|c|}
\hline & & & \multicolumn{6}{|c|}{ IndSector } & \multirow{2}{*}{ Total } \\
\hline & & & $\begin{array}{c}\text { Wholesale- } \\
\text { retailer }\end{array}$ & Manufactory & P-service & ICT & G-service & Construction & \\
\hline \multirow{12}{*}{$\begin{array}{l}\text { Ch business } \\
\text { involvement }\end{array}$} & \multirow{4}{*}{ No } & Count & & & 34 & 12 & 28 & 13 & 117 \\
\hline & & & $6.8 \%$ & $18.8 \%$ & $29.1 \%$ & $10.3 \%$ & $23.9 \%$ & $11.1 \%$ & $100.0 \%$ \\
\hline & & $\%$ within IndSector & $16.7 \%$ & $33.3 \%$ & $47.9 \%$ & $50.0 \%$ & $53.8 \%$ & $68.4 \%$ & $41.8 \%$ \\
\hline & & $\%$ of Total & $2.9 \%$ & $7.9 \%$ & $12.1 \%$ & $4.3 \%$ & $10.0 \%$ & $4.6 \%$ & $41.8 \%$ \\
\hline & \multirow{4}{*}{ No but Int } & Count & 15 & 11 & 20 & & 18 & 6 & 77 \\
\hline & & $\begin{array}{l}\text { \% within Ch business } \\
\text { involvement }\end{array}$ & $19.5 \%$ & $14.3 \%$ & $26.0 \%$ & $9.1 \%$ & $23.4 \%$ & $7.8 \%$ & $100.0 \%$ \\
\hline & & $\%$ within IndSector & $31.3 \%$ & $16.7 \%$ & $28.2 \%$ & $29.2 \%$ & $34.6 \%$ & $31.6 \%$ & $27.5 \%$ \\
\hline & & $\%$ of Total & $5.4 \%$ & $3.9 \%$ & $7.1 \%$ & $2.5 \%$ & $6.4 \%$ & $2.1 \%$ & $27.5 \%$ \\
\hline & \multirow{4}{*}{ Yes } & Count & 25 & 33 & 17 & 5 & $\overline{6}$ & 0 & 86 \\
\hline & & $\begin{array}{l}\% \text { within Ch business } \\
\text { involvement }\end{array}$ & $29.1 \%$ & $38.4 \%$ & $19.8 \%$ & $5.8 \%$ & $7.0 \%$ & $0.0 \%$ & $100.0 \%$ \\
\hline & & $\%$ within IndSector & $52.1 \%$ & $50.0 \%$ & $23.9 \%$ & $20.8 \%$ & $11.5 \%$ & $0.0 \%$ & $30.7 \%$ \\
\hline & & $\%$ of Total & $8.9 \%$ & $11.8 \%$ & $6.1 \%$ & $1.8 \%$ & $2.1 \%$ & $0.0 \%$ & $30.7 \%$ \\
\hline \multirow{2}{*}{ Total } & & Count & 48 & 66 & 71 & 24 & 52 & 19 & 280 \\
\hline & & $\%$ of Total & $17.1 \%$ & $23.6 \%$ & $25.4 \%$ & $8.6 \%$ & $18.6 \%$ & $6.8 \%$ & $100.0 \%$ \\
\hline
\end{tabular}

$\left(\chi^{2}=47.62, d f=10, p<.001\right)$. For a further interpretation of such relationship, it requires a full model evaluation.

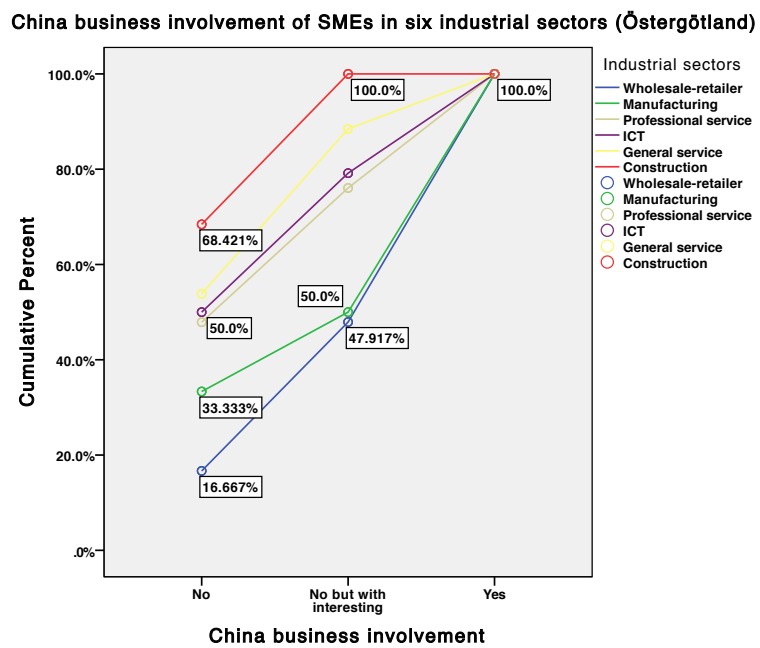

Note: Circles are thresholds of the three level responses within each industry

Figure 3: Gaps of China Business Involvement 


\section{.4 .2 Model comparisons}

The pre-study starts to construct the first prediction model including all of 5 predictors - Age of the SMEs (since the registration of F-taxation to the investigation time); Size of the SMEs (the number of employees); recent 4 years (2007-2010) average annual turnover of the SMEs; recent 4 years (2007-2010) average annual return on total assets (ROA) of the SMEs; Industrial sector of the SMEs (6 categories). Based on the results from the first model, the second model only includes statistical significant individual predictors on the response variable, which is the experience and attitude of SMEs on the China business involvement. The third model takes potential interaction effects into consideration.

A comparison of results from the three models shows in Table 4. Test of parallel lines indicates that all the three models satisfy the proportional-odds assumption $(p>.05)$. Model fitting information shows that there are very strong evidence of observed data being well fit the three models $(p<.001)$ (see Table 4$)$. Goodness of fit tests indicate that all of the three model are adequate $(p>.1)$ (Norušis, 2011a). From the model 1 , two of five predictors show statistically significant influence on the response variable. The model 2 includes the latest 4 years (2007-2010) average annual ROA and industrial sectors, which are two statistical significant predictors refined from model 1. Compared with the reference industrial sector (construction), there are very strong evidence of wholesale and retail $(p<.001)$, and manufacturing $(p<.001)$ sectors, which are more positive on China business involvement. There is a weak evidence for the third group, professional service $(p=.051)$ and the fourth group ICT $(p=.086)$, which have showed difference from construction sector. In the model 2 , there is a strong evidence $(p<.05)$ shows that 4 year average annual ROA is a good predictor on the China business involvement of firms. The model 3 includes possible interactions between the individual predictors in the model 2. However, the interaction terms do not show the statistic significance.

Pseudo R square was used to assess the overall goodness of fit regarding to tentative models (Long, 2014). Negelkerke's pseudo R square (Nagelkerke, 1991) is chosen because of its value in the full 0-1 range. Although pseudo $\mathrm{R}$ square could not be directly interpreted as R square in ordinary least squares (OLS) regression, it could mirror the 


\section{. A-1 PRE-STUDY OF THE GAP IN CHINA BUSINESS INVOLVEMENT AMONG SWEDISH SMES IN ÖSTERGÖTLAND}

R square for indicating to what extant the full model could improve prediction of outcome based on given data. Pseudo $\mathrm{R}$ square of the three models in Table 4 implies an improvement by each prediction model. The model 3 has a better improvement than the model 1 and the model 2. However, their difference is less than $3 \%$. The model 2 includes the minimum predictors with statistic significance among three models. Therefore, based on the parsimonious consideration, the model 2 is chosen as a preferred prediction model in this case.

Result in Table 4 shows that the model 2 is adequate for the prediction, based on goodness of fit $\left(\chi^{2}=470.52, d f=470, p>.1\right.$ ) (Hamilton, 2012). It could improve to $18.8 \%$ of correct predication in firms' preference and action in China business involvement. The parallel lines test for the proportional odds assumption in the model 2 yielded $p=.098$. It is higher than .05 and implies that slope coefficients in the model 2 are consistent cross different thresholds (Hamilton, 2012). Thus, the model 2 satisfies the proportional odds assumption and fits well with the observed data.

Table 4: Level of China business involvement by 3 prediction models

\begin{tabular}{|c|c|c|c|c|c|c|c|}
\hline & \multirow[b]{2}{*}{ Variable } & \multicolumn{2}{|l|}{ Model 1} & \multicolumn{2}{|l|}{ Model 2} & \multicolumn{2}{|l|}{ Model 3} \\
\hline & & $\mathrm{b}$ & $\exp (b)$ & b & $\exp (b)$ & $\mathrm{b}$ & $\exp (b)$ \\
\hline \multicolumn{8}{|c|}{ Constent (Ref group: Yes; ChAtt=2) } \\
\hline & No; ChAtt $=0$ & 1.225 & & 1.092 & & 1.551 & \\
\hline & No but have interesting; $\mathrm{ChAtt}=1$ & 2.485 & & 2.334 & & 2.821 & \\
\hline Registeration years & Age & .001 & & & & & \\
\hline Number of employee & SizeFT & .005 & & & & & \\
\hline \multirow[t]{2}{*}{ Eoconmy indicators } & Ave_turnover_tkr(07-10) & $6.437 \mathrm{E}-7$ & & & & & \\
\hline & Ave_ROA_\%(07-10) & $(-.015)^{* *}$ & 1.0151 & $(-.016)^{* *}$ & 1.016 & .021 & \\
\hline \multirow[t]{6}{*}{ Industrial Sectors } & 1. Wholesale-retailer & $2.586 * * *$ & 0.0753 & $2.572 * * *$ & 0.076 & $3.136 * *$ & 0.0435 \\
\hline & 2. Manufactory & $2.210^{* *}$ & 0.1097 & $2.349 * * *$ & 0.095 & $2.581 * *$ & 0.0757 \\
\hline & 3. Professional service & $1.223^{*}$ & 0.2943 & $1.242^{*}$ & 0.289 & $1.811^{*}$ & 0.1635 \\
\hline & 4. ICT & $1.283^{*}$ & 0.2772 & $1.258^{*}$ & 0.284 & 1.726 & \\
\hline & 5. General service & .836 & & .898 & & .837 & \\
\hline & 6. Construction (Ref group) & $0^{\mathrm{a}}$ & & $0^{\mathrm{a}}$ & & $0^{\mathrm{a}}$ & \\
\hline \multirow[t]{6}{*}{ Interaction } & 1. Wholesale-retailer*Ave_ROA_\%(07- & $-10)$ & & & & -.048 & \\
\hline & 2. Manufactory*Ave_ROA_\%(07-10) & & & & & -.014 & \\
\hline & 3. P-service*Ave_ROA_\%(07-10) & & & & & -.053 & \\
\hline & 4. ICT*Ave_ROA_\%(07-10) & & & & & -.046 & \\
\hline & 5. G-service*Ave_ROA_\%(07-10) & & & & & .016 & \\
\hline & 6. Construction (Ref group) & & & & & $0^{a}$ & \\
\hline Testing & Pseudo $\mathrm{R}^{\wedge} 2$ : Nagelkerke & .20 & & .188 & & .217 & \\
\hline Model fitting & Chi-Square & $46.505, \mathrm{df}$ & $p<.001$ & $43.751, \mathrm{df}$ & $p<.001$ & $51.068, \mathrm{~d}$ & $1, p<.001$ \\
\hline Goodness of fit & Pearson Chi-Square & Adequate & $59.19 ; p=.463)$ & Adequate & $70.52 ; p=.485)$ & Adequate & $59.26 ; p=.566)$ \\
\hline \multicolumn{2}{|c|}{ Parallel line assumption testing $(p>05)$} & $\chi^{\wedge} 2=14.2$ & $p=.114$ & $x^{\wedge} 2=10.69$ & $p=.098$ & $\chi^{\wedge} 2=17.8$ & $\mathrm{p}=.086$ \\
\hline
\end{tabular}




\section{$.4 .3 \quad$ Interpretation of results}

In the model 2, the magnitude of the effect of recent 4 years average annual ROA on the firms' China business involvement could be indicated by the estimated odds ratio $(O R=1.016)$. It means that increasing in one percent annual ROA, SMEs are less likely to get actively involved in China business, while the other variables in the model are held constant. When annual ROA increases in one unit, the odds of SMEs being positive in China business involvement versus the combined middle and being negative in China business involvement categories are 0.98 (1/1.016) times lower, given the other variables are held constant in the model.

Estimated OR of wholesale and retail sector is 0.076; OR of manufacturing sector is 0.095; OR of professional service is 0.289 ; and OR of ICT is 0.284 . They all less than 1 comparing to the reference group. The results indicate that comparing to the construction industry (the reference group), SMEs in the industrial sectors of Wholesale and retail, Manufacturing, Professional service and ICT are more likely have positive attitude and actions in China business involvement, while the other variables in the model are held constant. The sequence of magnitude of likelihood is that Wholesale - retail $>$ manufacturing $>I C T>$ professional - service. The odds for SMEs from the wholesale and retail sector to have positive attitude and actions in China business involvement versus the combined middle and low level are $13.16(1 / 0.076)$ times greater than for construction industry, given the other variables are held constant. The odds for SMEs from the manufacturing sector is about 10.53 (1/0.095) times greater than the odds for the construction sector. The odds for SMEs from ICT is about 3.52 $(1 / 0.284)$ times greater than odds for the construction sector. The odds for SMEs from the professional service sector is about $3.46(1 / 0.289)$ times greater than odds for the construction sector. There are very strong evidence $(p<.001)$ of such difference compared Wholesale and retail, and manufacturing sector to the reference group. There are weak evidence $(p<.1)$ of such difference compared ICT and professional service sector to the reference group. Difference in the gaps between general service and reference group are not statistically significant.

The result shows that not all the industrial sector group of Swedish SMEs in Östergötland region are equally likely to have interesting in China business involvement. Demo- 
graphic traits of SMEs such as size and age, and financial turnover could not explain the difference. However, recent managerial efficiency in deploying assets could.

\section{.5 Discussions and conclusions}

Extant literature on the internationalization of SMEs offers limited empirical evidence on the influence from some basic characteristics of SMEs, such as size and age, on firms' tendency and preference toward a large distant emerging market like China. Size of the SMEs could partial reflect the restriction of human resource can be deployed in the international market. Earlier studies on the export behavior often use it as one of the proxies of firm's resources. Age of the firm, on the other hand, could reflect how long operational experience a firm had as an organization. This pre-study uses the age as a proxy of the maturity of the firm. The pre-study intends to probe the potential influence of those basic traits of firm on their attitude and preference in China business involvement. In addition to these firm specific factors, the pre-study also intends to probe a potential influence from the firms' operation environment, such as industrial sector on the SMEs choice in the China business involvement.

\section{Firm size and emerging market involvement}

Compared to larger firms, smaller firms face resource scarcity in the management of time and financial constraint, when they are getting involved in the geographically dispersed international markets (Calof, 1994; Buckley and Ghauri, 1999). Is firm size an important prerequisite for SMEs' involvement in the international business with distant emerging markets? Previous studies offers inconsistent results (Calof, 1994). Some studies could not find that firm size has a significant influence on the international business involvement, especially for export, while others found a positive relationship (Calof, 1994). Few studies found that size matters only in a certain range, for instant, when firms are very small (Mittelstaedt et al., 2003). This pre-study considers the size in terms of both employment and annual turnover. The study could not find a significant relationship between size and firms' attitude in the China business involvement. It implicates that for the Swedish SMEs in the investigated region, firm size itself might not be a determinate barrier for SMEs to approach a big emerging market like China. 
However, small firms with a large financial and human resource scarcity, the limitation in the firm size will require small firms to find an effective solution or method in order to have a sufficient productive capacity for the emerging market involvement.

\section{Business experience and emerging market involvement}

The age of the firm reflects the organizational experience a firm has. Thus, it is often used as a proxy of the business experience (Majocchi et al., 2005). Early internationalization studies before 1990 often found that MNC in their mature period have a wider geographic coverage of international markets (Johanson and Vahlne, 1977; Dow, 2000). However, in recent decades, age seems not necessary to be one of important factors for even small firms to enter different international markets. INV and BGs studies often show that, regardless age, some firms started their internationalization within very short period after their establishment (Jones, 1999; Rialp et al., 2005). Study from Autio et al. (2000) even revealed a negative relationship between age of the firm and its international growth. The pre-study counts the taxation registration year of SMEs as their established year. It could not show a linkage between the age of the firm and its attitude and actions in the China business involvement. It is notable that many SMEs in the sample had many years history as an economic associations or other forms of entity before it converted to a limited company. It implies that the business experience of a firm might not simply reflect from the age of SMEs as a limited company. Accumulative learning experience from early history of the firm might also influence the choice of the firm once it converted to a limited company. A recent research from Chandra et al. (2012) also got a similar reflection on the influence from the previous experience on the internationalization of the firm as a current legal entity.

\section{Managerial efficiency and emerging market involvement}

Return on assets (ROA) is an important indicator to evaluate a firm's managerial efficiency in deploying its asset. The pre-study used the last four-year average ROA to avoid short-term fluctuation on the firm's performance. Getting involved in a large distant emerging market might require a small firms to use its assets and resource in a more effective way. Previous researches also used ROA to asses firms' performance 
related to its foreign markets development. The results from earlier studies are inconclusive on firms' international market involvement and its ROA. One of interesting findings from earlier studies shows that there is a point of diminishing returns on ROA, when firms aggressively engaged in the international markets under a higher level of environmental hostility (Zahra and Garvis, 2000). The interesting points from the results in the pre-study is that when there is an increase in the recent ROA of the responding firms, the likelihood on their China business involvement becomes less likely. One possible interpretation of the result is that when small firms have a better performance in deploying asset in the recent years, they might be not willing to take more risk to approach a distant large market like China. On the other hand, when the recent ROA is low, the risk perception of the firms might be dwindling. The small firms might turn to more likely to response the potential opportunities from the emerging market like China.

\section{Difference in the industrial sectors and emerging market involvement}

As a environmental factors of the firms, the industrial sectors, in which SMEs are operating shows a high relevance in the China business involvement in this study. Extant research on the internationalization of SMEs have recognized a substantial industry difference on the firms' propensity to the international market (Westhead et al., 2001). Much empirical evidence regarding rapid internationalization is often from the trading companies from/in the wholesale and retail sector, high-technology manufacturing sector, and ICT sector (Jones, 1999; Aspelund and Moen, 2003; Efrat and Shoham, 2011). However, in the BGs studies, there are also some evidence showing that fast internationalization is not industry specific factor (Jones et al., 2011). The prestudy shows a big gap and difference among SMEs in different industrial sectors on their preference in the China business involvement. Compared to firms from the professional service sector, firms from wholesale and retail sector and manufacturing sector are more than three times greater, in odds ratio, to have positive attitude in getting involved in China business. The result reflects a high level external environmental influence and industrial specific factors on the internationalization of small firms. For example, it could reason that Swedish firms in wholesale and retail sector are more likely involved in the inward internationalization, such as import or outsourcing. Because as a big 
emerging market and the "factory of the world", China might offer a higher perceived opportunities for the small Swedish firms in wholesale and retail sector.

\section{Inputs for the main study}

Through model-building, the pre-study identifies two important predictors, which differentiate the preference and attitude of Swedish SMEs in the Österötland region on the China business involvement. Recent ROA of the firm is identified as a firm specific factor, which negatively influences on the likelihood of China business involvement, while industrial sector as an important external factor, which influences the likelihood of China business involvement. Two predictors successfully improve a correct prediction to nearly $20 \%$ of outcome based on the observed data. The influence from a managerial efficiency indicator ROA on firms' preference in China market involvement is interesting. The direction of influence might reflect a dynamic relationship between risk versus opportunity perception on the China market related to the recent performance of the firm.

The pre-study shows that preference of emerging market involvement are influenced both the firm specific factor and its operational environment, in which a firm operates. Age of the firm could only reflects part of business experience. Previous experience and connections a firm had before its formal establishment as a limited company might also play an important role in the internationalization of the firm.

Nevertheless, despite the model's good fit with the observed data, there is still substantial room (about $80 \%$ ) to improve the fitted model with other potential explanatory elements. This unexplained part will be further investigated by the main study in this research. Results from the pre-study shows that there are multi-layer influence on firms' choice on the internationalization. Some indirectly observable influence requires a holistic method to inquiry and identify. 
A-2 Survey questionnaire 

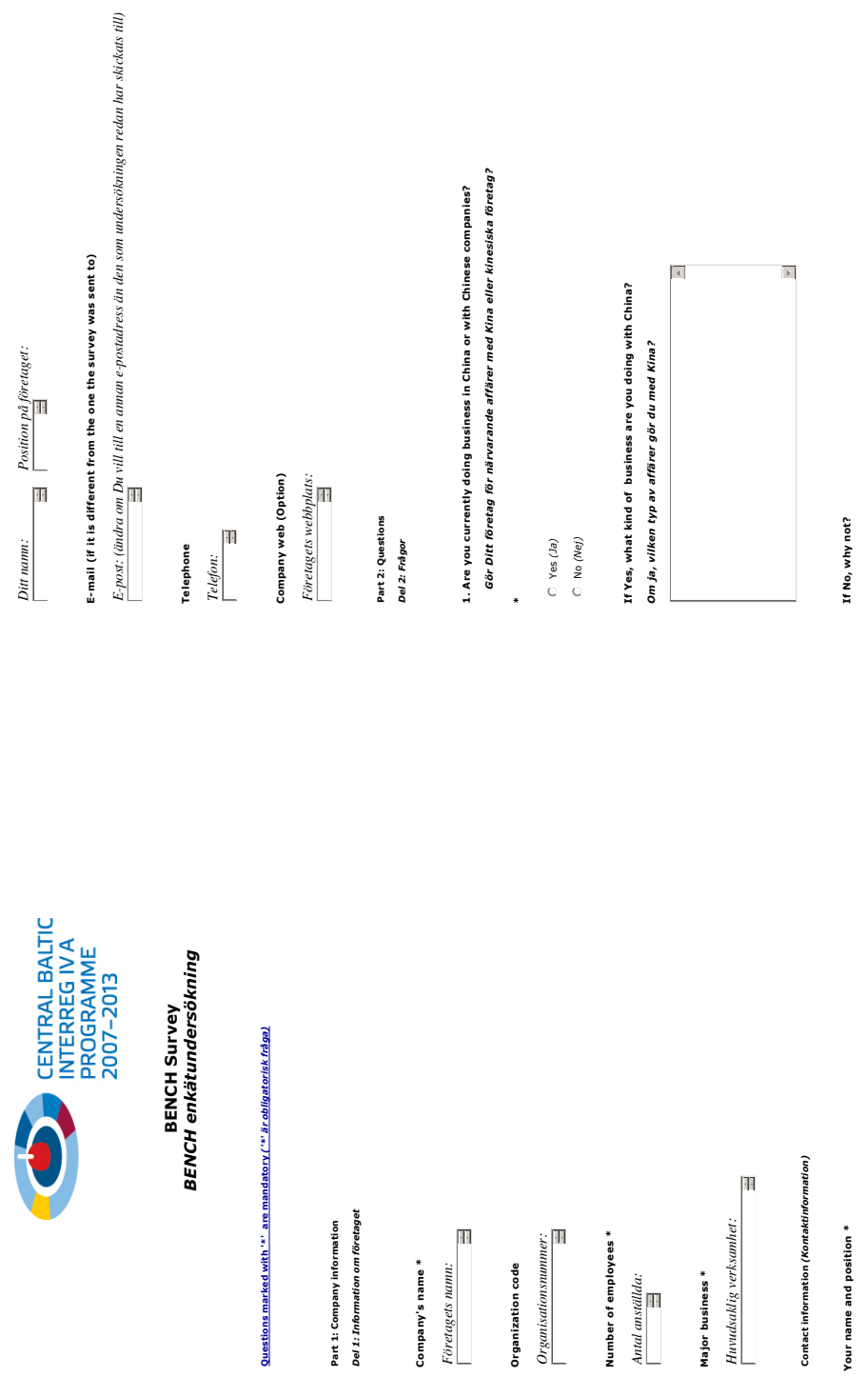

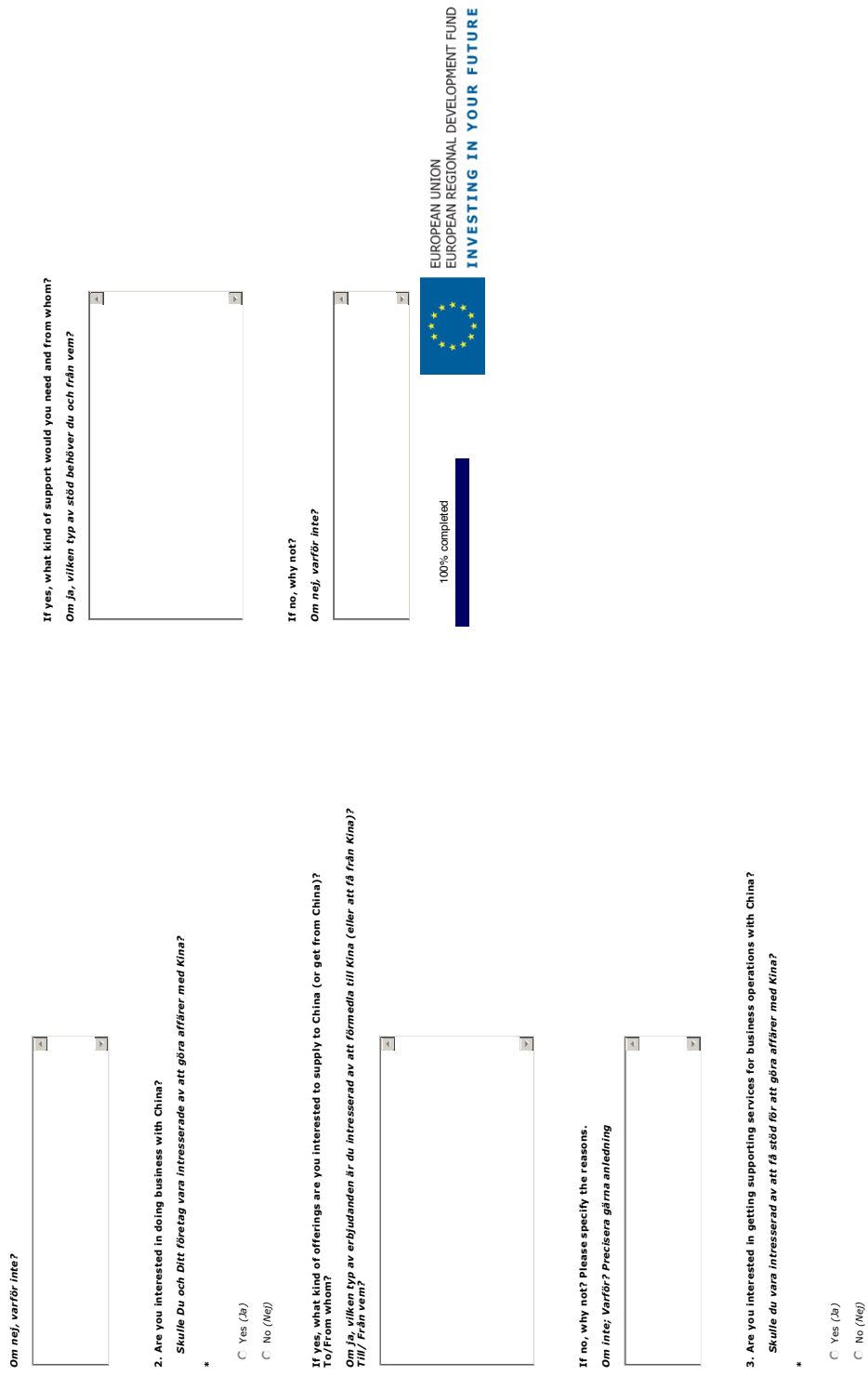


\section{Appendix B. Illustration of cases}

Appendix $B$ associated with this thesis have been removed for copyright reasons. For more details about these see:

http://urn.kb.se/resolve?urn=urn:nbn:se:liu:diva-121247 


\title{
Appendix C. Interview guidelines
}

\author{
Internal informants (case firms)
}

\section{Primary interview guide (for all cases)}

- Background of interviewee:

- Could you introduce yourself? (e.g., educational background, professional background, international background and venture experience)

- Your work history, role and responsibility in the firm?

- Background of the firm:

- When and how did the venture start? (e.g. business idea, financing and any prior form)

- What are the most critical events in the firm's history? (e.g. important orders, resources, crisis etc.)

- How is the current situation of the firm? (e.g. competition, important cooperation and inter-organizational relationship, main market(s) and key technology (competence) etc.)

- Internationalization of the firm:

- When, why, and how did the firm start in international business, and which foreign markets? (e.g. important persons/actors/agents, initiatives and operation modes in foreign markets)

- Recall the sequence of entry (e.g. when, why and how has the firm engaged in these markets?). 
- What were the most critical events during internationalization? (e.g. important orders, relationships, resources, problems etc.)

- How many foreign markets are the firm engaged in today, what are the operation modes in these foreign markets, and how is the performance in these markets? Has there been any change in the operation modes?

- Have you and your firm encountered/ perceived any challenges and opportunities in the internationalization process? Could you give some examples from your experience?

EM-related experience:

- What is your experience in EM market entry (e.g. when, why and how did the firm approach the EM (i.e. Chinese market)?)?

- What challenges and opportunities have you experienced in the entry process? How did you cope/respond?

- Who are your important actors/intermediaries, and what are their roles in your EM market development?

- Reflection and future

- Do you have any learning points from internationalization (i.e. important lessons and so on)?

- What is the future for your company? What will the company do in the next five years?

\section{Follow-up interview guide (only for Kina study stage)}

- What has changed in China market entry since the last interview? (e.g. important contacts, agents and activities, etc.)

- How do/will you organize sales and support service in China?

- Compared with other foreign market entries, was there any difference or special difficulty vs. facilitating factors in your Chinese market entry?

- Reflections and further plans for the Chinese market.

External informants (governmental agents, county officials in Kina study stage; researchers in EM extension study stage) 


\section{Interview guide}

- Background of interviewee

- Background of the organization

- Background of governmental cooperation with JS province in China (only for Kina study stage)

- When, why and with which Chinese counterparts did your organization start to cooperate and build relationship with JS?

- How was the initial period? (e.g. important actors on both sides and events as well as initial ideas and goals)

- When and why did the delegation start to take local SMEs to China? What kind of business-related activities were they involved in?

- How did you communicate with SMEs (channels) and were there any preparation activities for them?

- Were there any important learning points and experience from the relationship building process and the cooperation with the Chinese partner?

- How would you evaluate the current situation about cooperation between the two provinces? Any future plans?

- Relations and knowledge of investigated small firm(s) 


\section{Interview Protocol}

Interviewer: 1. Self-introduction

2. Introduction of study purpose and basic method

3. Communicate the use of interview material

4. Thanks

- $\quad$ To support notes-taking, this interview will be recorded, if the interviewee agree with it.

- $\quad$ The information of the interview will be hold on the basis of confidential consensus.

- $\quad$ The informant/interviewee could stop when she/he doesn't feel conformable to continue.

This interview is planed no longer than $2 h$ for each informant.

To interviewee: Do you have any questions before we begin?

Companies/ Organization

Interviewee name:

Title/ position/ main responsibility:

Interviewer: _Ya Z._( $\mathrm{Ph} . \mathrm{D}$ candidate in Industrial Marketing at LiU)

Time and place:

Discussed topics: International profile and internationalization experience of SMEs

Documents Obtained:

- Information from survey \& (external interviews)

- Information from official web of target company and news from web

- Information from Retrieve Business database

\section{Interview guidelines}

Post Interview Comments or Leads:

$\rightarrow$ If appropriate, ask for permission to follow up later 